Erster Beratungsgegenstand:

\title{
Verfassungstreue und Schutz der Verfassung
}

1. Bericht von Professor Dr. Erhard Denninger, Frankfurt/M.

Inhalt

Seite

I. Einleitung $\ldots \ldots \ldots \ldots \ldots$

II. Die Grundwerte-Diskussion . . . . . . . . . . . . 11

III. Unsicherheit über Grenzen und Methoden des Schutzes der Verfassung und der streitbaren Demokratie . . . . . . 14

IV. Das Leitbild des „streitbaren Demokraten“ und der "Wille zur Verfassung" .............. 20

V. Vorinstitutionelle Prinzipien der freiheitlichen demokratischen Grundordnung als Orientierung für streitbare Demokraten und Staatsgewalt: Freiheit von Angst, Vertrauen, Bereitschaft zum Engagement . . . . . . . . . 26 26

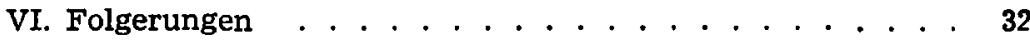

1. Beamtentreue ............... . . 32

2. Nachrichtendienstlicher Verfassungsschutz . . . . 35

3. Uberverfassungsgesetzlicher Notstand? . . . . . . 43 


\section{Einleitung}

1. Man liest von einer seit neun Jahren an Hauptschulen eines sozialliberal regierten Landes tätigen Lehrerin. In ihrem Deutschunterricht in der 10. Klasse wurde zusammen mit anderer Lyrik, u. a. von Matthias Claudius, auch ein Liebesgedicht von Peter Paul Zahn besprochen, der wegen versuchten Mordes an einem Polizisten zu 15 Jahren Freiheitsstrafe verurteilt wurde. Die Lehrerin wird wegen Zweifels an ihrer Verfassungstreue zur Anhörung vor die Schulbehörde geladen'.

2. Man liest von dem Lehramtsbewerber für das Lehramt an Volksschulen in einem nicht sozialliberal regierten Land, dessen Versuch, in den Vorbereitungsdienst aufgenommen zu werden, im Januar 1978 vor dem Verwaltungsgericht (Ansbach) scheitert². Die Richter bestätigen dem Kandidaten, einem

1 Fall der Lehrerin M. Eichstädt. Vgl. den Bericht „Entmündigte Lehrer" von J. Duhm-Heitzmann in: B:E, Heft 8/1978 S. $24 \mathrm{f}$. Die Lehrerin hatte außerdem, nach Absprache in der Lehrerkonferenz, im Wahlpflichtunterricht mehrere Wochen hindurch die Themen Ende der Weimarer Republik, Machtergreifung Hitlers, Einrichtung der Konzentrationslager, faschistische Geisteshaltung behandelt. Leitlektüre dabei: Eugen Kogons "Der SS-Staat". In das Klassenbuch wurden fast immer nur Kürzel wie „Faschismus" oder „Faschismus in Deutschland" eingetragen. In der Anhörung wurde der Beamtin eine überproportionale Beschäftigung mit dem Thema Faschismus vorgeworfen. (Man ist versucht, an dieser Stelle die verheerenden Ergebnisse der Untersuchungen über das Unwissen der meisten Schulabgänger gerade hinsichtlich der jüngsten deutschen Vergangenheit zu referieren; dies ist ein demokratie-relevanter Tatbestand). Das Gedicht von P. P. Zahn hat folgenden Wortlaut: „Februarsonne. / Die pritsche schräg vors fenster stellen / auf ihr liegen / das gesicht in der sonne/den kopf gleichmäßig drehen / manchmal streicht der wind über / die geschlossenen augen / ich stelle mir vor / es wären deine finger / sacht streicht der wind / und sacht / denke ich mir deine finger / denn stärker / könnte ich das nicht ertragen".

2 Fall des Lehramtsbewerbers $H$. H. Häberlein. Vgl. Urteil des VG Ansbach vom 10. 1. 1978 - AN $954-$ I/77. H. stammte aus einem christlichen EIternhaus, er selbst war im CVJM tätig. Später wurde er aktives Mitglied und Funktionär der „Deutschen Friedensgesellschaft - Vereinigte Kriegsdienstgegner (DFG-VK)", einer Sammelbewegung der Kriegsdienstgegner, in der auch Kommunisten Mitglieder sind, in der jedoch nach Auskunft des Verfassungsschutzberichtes 1977 des BMI Nichtkommunisten die weitaus größere Mehrheit haben, vgl. dort, Teil: Linksextremistische Bestrebungen, S. 41. In der Anhörung distanzierte sich der Bewerber ausdrücklich von der kommunistischen Zielsetzung einer Diktatur des Proletariats, ebenso, und zwar in Ubereinstimmung mit dem Programm seiner Organisation, von jeglicher Gewaltanwendung. Er bekannte sich eindeutig zur Beachtung der geltenden Gesetze. Seine Úberzeugung von der Notwendigkeit einer militärischen Ab- 
Kriegsdienstgegner aus christlich-pazifistischer Utberzeugung ausdrücklich, er sei zwar kein Verfassungsfeind, doch lasse er gegenüber der freiheitlichen demokratischen Grundordnung nur eine gleichgültig distanzierte Haltung erkennen; im Ernstfall werde er in der Situation eines Mannes sein, „der ratlos den Geschehnissen zusieht“, anstatt dem "Sturz der freiheitlichdemokratischen Grundordnung" durch eigenes aktives Verhalten entgegenzutreten. Ein solcher Mann könne nicht Beamter werden.

3. Man liest ferner ${ }^{3}$ von einer 19jährigen Münchner Abiturientin, die einem Anwerbungsversuch des Verfassungsschutzes widerstanden hat. Sie sollte für das Amt Spitzeldienste gegen Schülerorganisationen leisten. Ein Stadtrat soll erklärt haben, man müsse ihre Verfassungstreue schon deshalb anzweifeln, weil sie das Ansinnen des Verfassungsschutzes ausgeschlagen habe.

Man fragt sich angesichts solcher und zahlreicher ähnlicher Vorkommnisse: Leben wir wirklich, wie von offizieller Seite immer wieder versichert wird, im „,freiheitlichsten Staat der deutschen Geschichte" "? Oder haben nicht vielleicht eine Fülle von Einzelregelungen und die dazugehörige pflichteifrige Praxis die „Streitbarkeit" unserer Demokratie schon bis zu dem Punkt gebracht, an dem, mit den Worten der Dissenters zum Abhörgesetz-Urteil, die streitbare Demokratie sich gegen sich selbst zu kehren beginnt ${ }^{5}$ ? Und werden nicht mit der ständi-

rüstung werde aber, so bekundete er, nicht dadurch falsch, daB sie auch von Kommunisten geteilt werde.

Das Urteil, das möglicherweise in der höheren Instanz aufgehoben werden wird, ist ein Beleg für das schlimme Phänomen der „Kontaktschuld", das bis in den Bereich der Sprache, der Worte-Tabuisierung hineinreicht, vgl. das Beispiel bei Galtung und Preuß in: 3. Internationales Russell-Tribunal, Berlin 1978, S. $94 \mathrm{f}$.

3 Fall der Abiturientin Marianne Wei $\beta$, vgl. DER SPIEGEL, Nr. $31 / 1978$, S. $74 \mathrm{f}$.

4 Vgl. W. Maihofer, am 20. 11. 1976: „Wir leben im freiheitlichsten Staat der deutschen Geschichte", in: Innere Sicherheit, Nr. 36, 17. 12. 1976, S. 1; ferner derselbe im Deutschen Bundestag am 15. 11. 1974, BT-Prot. 7/8959 ff. abgedr. in Denninger (Hrsg.), Freiheitliche demokratische Grundordnung, Band II, 1977, S. 567: „Die freiheitlichste Verfassung in der deutschen Geschichte, unser Grundgesetz ..."

5 BVerfGE 30, 1 ff., 33 ff., 45: „Der Gesetzgeber, ..., hat daher bei Regelung der Gefahrenabwehr - etwa im Bereich der Verbrechensbekämpfung oder der im Wesen nicht anders gearteten Tätigkeit der Geheimdienste - die Rechtsgüter gegeneinander abzuwägen unter Berücksichtigung des Wertes, den das Grundgesetz den Individualrechten beimißt. Die "Staatsraison" ist kein unbedingt vorrangiger Wert. Verkennt der Gesetzgeber die Schranken, so kehrt die "streitbare Demokratie sich gegen sich selbst." Vgl. auch unten zu VI. 2. 
gen Berufung 1. auf die freiheitliche demokratische Grundordnung als eine unverrückbare Ordnung als „absolut" anerkannter Werte ${ }^{\beta}$ und 2. auf unantastbare sogenannte "Grundwerte", im Hintergrund eines zwar notwendigen, aber streng rechtsstaatlich und unpathetisch durchzuführenden Verfassungsschutzes Tendenzen sichtbar, die darauf abzielen, die ebenfalls oft berufene „Offenheit" ${ }^{\text {"7 }}$ der Verfassung allmählich einzuschlieBen, aus Freiheitsgebrauch wertverwirklichende Pflichterfüllung und an die Stelle pluraler Gemeinwohldiskussion den angeblich ideologiefreien technokratischen Nachvollzug von tatsächlichen oder nur deklarierten Sachzwängen treten zu lassen? Wo liegen für den säkularen, weltanschaulich neutralen Staat, der den ideologisch-kulturellen Pluralismus nicht nur obrigkeitsstaatlich-gönnerhaft, kantisch gesagt: paternalistisch toleriert ${ }^{\mathrm{B}}$, 9, sondern ihn vielmehr als ungeschriebene Voraussetzung seiner Existenz anerkennt, wo liegen für einen solchen Staat die prinzipiellen Schranken des Zugriffs auf das forum internum?

Dies scheinen mir die Kern- und Existenzfragen unserer Demokratie zu sein, ohne deren Beantwortung alle dogmatischen Einzelerörterungen über Grundrechtsverwirkung, Parteiverbot, Beamtentreue, Zweck und Grenzen des politischen Strafrechts,

${ }^{6}$ Seit BVerfGE 2, 1 ff., 12 f., und vor allem E 5, 85 ff., 139, st. Rspr.

7 Vgl. z. B. K. Hesse, Grundzüge des Verfassungsrechts, 9. Aufl. 1976 , S. $12 \mathrm{f}$. mit Bezug auf $R$. Bäumlin; A. Hollerbach, Ideologie und Verfassung, in W. Maihofer (Hrsg.), Ideologie und Recht, 1969, S. 57. Ferner $P$. Häberle in zahlreichen Arbeiten, zuletzt in Verfassungsinterpretation und Verfassungsgebung, ZfSchwR N. F. 97 (1978) S. 1 ff. m. v. N. Häberle akzentuiert Offenheit als und durch "Offentlichkeit". Im Hintergrund steht die Kategorie der "offenen Gesellschaft" im Sinne K. R. Poppers, Die offene Gesellschaft und ihre Feinde, I, 5. Aufl. 1977, S. 228 ff. G. Roellecke, Der Begriff des positiven Gesetzes und das Grundgesetz, 1969, versteht das Gesetz als offenes Verfahren. Gerade von diesem Ansatz aus erscheint seine Kritik in: Verfassungstreue und Schutz der Verfassung, DOV 1978 , S. $457 \mathrm{ff}$., $460 \mathrm{~N}$. 30 , an meiner Verteidigung der "Alternanzdemokratie“ (H. P. Schneider) gekünstelt, vgl. Verfassung und Gesetz, in: Frankfurter Hefte 3/1978, S. 32. Vgl. zum Thema auch meine Bemerkungen in $M$. Tohidipur (Hrsg.), Verfassung, Verfassungsgerichtsbarkeit, Politik, S. 176 ff. sowie demnächst Denninger, Staatsrecht 2, Kap. IV. 10.

${ }^{8}$ Kant, Uber den Gemeinspruch: ... II., Sämtl. Werke in sechs Bänden, Bd. 1, Leipzig 1912, S. 193; Rechtslehre II. Teil, § 49, in: Metaphysik der Sitten, Hamburg 1954, S. 140.

- Prägnant $K$. Schlaich, Neutralität als verfassungsrechtliches Prinzip, 1972, S. 254: "Toleranz ist heute Aufgabe Aller, nicht aber mehr eine Eigenschaft des Staates. Der Staat gewährt nicht eigentlich mehr Toleranz; er ist zum Hüter der Toleranz geworden.“ 
Aufgaben und Befugnisse der Ämter für Verfassungsschutz, über Datenschutz u. v. a. zusammenhanglos und arbiträr bleiben müssen.

\section{Die Grundwerte-Diskussion}

Die sog. Grundwerte-Diskussion der Jahre 1976/7710, die sich vor allem am Streit um die Reform des Abtreibungsstrafrechts und des Ehescheidungsrechtes entzündet hatte, war für die Suche nach dem gemeinsamen Fundament aller Demokraten, nach den unverzichtbaren „essentials“ der Verfassungsbasis jenseits des in Art. 79 Abs. 3 GG Gemeinten wenig hilfreich. Abgesehen von den zahlreichen, nur zum Teil auf die Unklarheit des Begriffs "Grundwert" zurückzuführenden Mißverständnissen ging es in der Debatte, wie richtig bemerkt wurde ${ }^{11}$, nicht eigentlich um eine Wertebestimmung, „sondern in erster Linie um eine Feindbestimmung". Der Kritik an den damals von Helmut Schmidt ${ }^{12}$ vertretenen Kulturkampfpositionen mit umgekehrtem Vorzeichen ging es um den Versuch, den "Staat", genauer: den demokratischen Gesetzgeber in dem Augenblick auf einen bestimmten soziokulturellen status quo festzuschreiben, in dem sich eine demokratisch repräsentierende Mehrheit im Parlament anschickte, bestimmte als unhaltbar empfundene

10 Vgl. G. Gorschenek (Hrsg.), Grundwerte in Staat und Gesellschaft, 1977; O. Kimminich (Hrsg.), Was sind Grundwerte?, 1977; W. Leisner (Hrsg.), Staatsethik, Bd. 9 der Reihe Gesellschaft-KircheWirtschaft, hrsg. von der Internationalen Stiftung Humanum, 1977; J. Isensee, Demokratischer Rechtsstaat und staatsfreie Ethik, in: Essener Gespräche zum Thema Staat und Kirche, Band 11, 1977, S. 92 ff., ferner die dort veröffentlichten Beiträge von W. Kluxen und K. Lehmann. J. Isensee, Verfassungsgarantie ethischer Grundwerte und gesellschaftlicher Konsens, in: NJW 1977, S. $545 \mathrm{ff}$. Vgl. neuerdings $E .-W$. Böckenförde, Der Staat als sittlicher Staat, Berlin 1978 , bes. S. $34 \mathrm{ff}$.

11 H. F. Lisken, Argernisse der Grundwertdebatte, Frankfurter Hefte 6/1978, S. 11.

${ }_{12} \mathrm{H}$. Schmidt, Ethos und Recht in Staat und Gesellschaft, in: Gorschenek, a. a. O., (N. 10) S. 13 ff. bes. S. 22, 26. Schmidts Thesen lassen sich so resümieren: a) der Staat des Grundgesetzes könne als Staat nicht Träger eines eigenen Ethos sein; nur was in der Gesellschaft an ethischen Grundhaltungen tatsächlich vorhanden sei, könne als Recht ausgeformt werden; b) der Staat habe zwar den Grundrechten Respekt und Geltung zu verschaffen, die Wahrung der Grundwerte sei jedoch Sache der Gesellschaft, jedes einzelnen Bürgers, jeder Gemeinschaft, nicht zuletzt der Kirchen. Man kann beide Sätze mühelos als vielleicht etwas pointierte Formulierungen des Prinzips der Nichtidentifikation (H. Krüger) auffassen. Die Aufregung, die sie dennoch vornehmlich in konservativen und kirchlichen Kreisen ausgelöst haben, wird erst aus dem im Text Ausgeführten erklärlich. 
Zustände zu reformieren. Das Ergebnis der "ständigen freien geistigen Auseinandersetzung" der politischen Kräfte, die ja doch gemäß der Formel des Bundesverfassungsgerichts „für die freiheitliche demokratische Staatsordnung schlechthin konstituierend" ist ${ }^{13}$, kann nach den Spielregeln der parlamentarischen Demokratie nur durch Mehrheitsentscheid ermittelt werden. Eben dies wird nun von den Kritikern für wichtige Sachbereiche geleugnet. Der Staat, wird gesagt, dürfe sich nicht einfach hinter den Schutzschild angeblicher oder wirklicher Mehrheitsmeinung zurückziehen ${ }^{14}$, er sei kein bloßer "Wert-Notar"15, auch „nicht das Instrument zur Durchsetzung der Interessen und Zwecke der jeweiligen Mehrheit" "16.

Auf diese Art und Weise, den Staat an seine Verantwortung für die Grundwerte zu erinnern, spielt man zunächst einmal nur behauptete Entscheidungen des Verfassungsgebers gegen den („einfachen“) Gesetzgeber aus, will man die demokratisch legitimierte Mehrheit auf einmal nicht mehr als repräsentativ für das Volk insgesamt gelten lassen. Wo wir aber - um die Worte Ulrich Scheuners zu gebrauchen - „Ablehnungen der Mehrheitsentscheidung, ..., begegnen, wird im Ergebnis nicht ein Weg zu einer herrschaftslosen Gemeinschaft gewiesen - sie kann es nur in einem utopischen Denken geben - und auch nicht eine Möglichkeit der politischen Einheit jenseits der Gegensätze eröffnet, sondern in der Regel wird die Herrschaft einer minoritären Gruppe durch illegitime Gleichsetzung ihrer Anschauung mit dem Gemeinwillen zu legitimieren gesucht."17 Wer also mit dem Vorwurf an den Gesetzgeber, dieser verlasse den durch die Verfassung umschriebenen, verbindenden Konsens über Grundwerte, zugleich das demokratische Mehrheitsprinzip angreift, der greift nicht allein dieses, sondern auch die es fundierenden Prinzipien des Pluralismus und der Repräsentation $^{18}$ und damit konstitutive Elemente des Basiskonsenses

13 BVerfGE 40, 287 ff., 294; st. Rspr.

14 A. v. Campenhausen, Grundwerte in Staat und Gesellschaft, in: Gorschenek, a. a. O. (N. 10), S. 207.

${ }_{15}$ H. Maier, Zur Diskussion über die Grundwerte, in: Gorschenek, a. a. O., S. 174 .

${ }_{16}$ Kommission I „Politik, Verfassung, Recht" des Zentralkomitees der deutschen Katholiken, in: Gorschenek, a. a. O., S. 146 ff., 148.

17 U. Scheuner, Das Mehrheitsprinzip in der Demokratie, Opladen 1973, S. 44. Zu den Grenzen der Anwendbarkeit des Mehrheitsprinzips ders. ebenda S. $48 \mathrm{ff}$.

18 Vgl. U. Scheuner, Konsens und Pluralismus als verfassungsrechtliches Problem, in: G. Jakobs, (Hrsg.), Rechtsgeltung und Konsens, Schriften zur Rechtstheorie Heft 49, 1976, S. $33 \mathrm{ff}$., "Grundkonsens". A. Podlech, Wertentscheidungen und Konsens, ebenda, S. 9 ff. insbesondere zur wichtigen Unterscheidung zwischen „Basis- 
an, der freiheitliche Demokratie überhaupt erst ermöglicht. Hier erst zeigt sich das Problem der Grundwerte in voller Schärfe: Der vielfach zu beobachtende Versuch ${ }^{10}$, die gegenständliche Reichweite des Mehrheitsprinzips durch eine Ausweitung des Bereichs des "Unabstimmbaren"20, des legislativ Unverfügbaren einzuschränken und durch Berufung auf Grundwerte eine normative Einheit zu postulieren, wo meinungs-, interesse- und willensmäßig offensichtlich keine Einheit existiert, bringt grundlegende Verfassungsprinzipien miteinander in Konflikt: die prozeduralen Prinzipien (also die das Verfahren des freien demokratischen politischen Prozesses regelnden) der Mehrheitsentscheidung ${ }^{21}$, der Pluralität, Alternativität und Kepräsentation stehen gegen die inhaltlichen gemeinsamer Wertüberzeugungen. Dabei geht es hier gerade nicht um ein Problem des Minderheitenschutzes, um den Schutz der Auffassungen der Minderheit als Minderheit, sondern um die Reichweite des Mehrheit und Minderheit umgreifenden inhaltlichen Basiskonsenses. Hier liegt das äußerst Besorgniserregende, das

konsens" und „Einzelkonsens". Ferner: E. Denninger, Staatsrecht 1, 1973 , S. 43, 53. Das BVerfGE 2, $1 \mathrm{ff}$., $12 \mathrm{f}$., begreift die drei Prinzipien (der Mehrheitsentscheidung, des Pluralismus und der Repräsentation) als wesentliche Elemente der „freiheitlichen demokratischen Grundordnung". Das gilt auch für das nicht ausdrücklich genannte Repräsentationsprinzip, das aber in den Grundsätzen der Gewaltenteilung, des Parteienpluralismus und des Rechts auf Opposition impliziert ist. Vgl. ferner G. Lautner, Die freiheitliche demokratische Grundordnung, Kronberg/Ts. 1978, bes. S. $38 \mathrm{ff}$.

10 Vgl. H. Kohl, Freiheit, Solidarität, Gerechtigkeit, in: Gorschenelk a. a. O., S. 52 ff., 57. Gegen die Pflicht des Politikers, „ein Maximum an Konsens über Grundwerte der Gesellschaft, die verfassungsrechtlich relevant sind, anzustreben", ist nichts einzuwenden, so lange die Konsensmaximierung über den offenen demokratischen Prozeß erfolgt. Zur Kritik des antagonistischen Dissensmodells einerseits, des idealistischen Konsensmodells der Verfassung andererseits vgl. meine Bemerkungen in Verfassung und Gesetz, jetzt auch in Denninger/Lüderssen, Polizei und Strafprozeß im demokratischen Rechtsstaat, 1978, S. 16 ff. Beide Extremmodelle der Verfassung führen zur Reformunfähigkeit der demokratischen $\mathrm{Ge}-$ sellschaft. Vorzüglich dazu: C. Graf v. Krockow, Konfliktfähigkeit: Grundbedingung der demokratischen Gesellschaft, in: Vorgänge 30 Heft 6/1977, S. 13 ff. Zutreffend auch $K$. Schlaich, Neutralität, a. a. O., S. $262 \mathrm{ff}$.: Nicht das weltanschauliche Minimum als solches ist anzustreben, sondern die „Fülle der Kultur“ der Bürger - aber in deren freier Wertewahl. „Nicht die Werte, sondern verbindlich gemachte Werthierarchien sind der Freiheit und Neutralität gefährlich" (264). Werte, wo immer und wem immer sie verkündet werden, tendieren aber $\mathrm{zu}$ absoluter Verbindlichkeit, vgl. JZ 1975, S. $545 \mathrm{ff}$.

20 BVerfGE 35, 79 ff., 151.

21 Zur Rechtfertigung des Mehrheitsprinzips vgl. immer noch: J. Locke, Über die Regierung, Buch VIII, Nr. $96 \mathrm{f}$. 
die Grundwerte-Diskussion jedenfalls als Problem klar zutage gebracht hat: Wenn über die „Wertgebundenheit" der Staatsorgane, vornehmlich des Gesetzgebers gestritten wird, und das ist insbesondere hinsichtlich der Grenzen der "streitbaren“, der "wehrhaften"22, d. h. „werthaften" Demokratie der Fall, dann geht es nicht mehr um die politisch-kämpferische Auseinandersetzung zur Ermittlung jeweiliger Gemeinwohlinhalte im Rahmen einer unangefochten akzeptierten Verfassung, sondern dann wird der grundlegende Verfassungskonsens selbst in Frage gestellt. Die Verfassung als normatives Gehäuse, als Grundstruktur des politischen Prozesses ${ }^{23}$ wird zum Kampfinstrument gegen den Gegner, den man außerhalb der Verfassung stellt; im Extremfall wird sie zum „Instrument der politisch-moralischen Ausbürgerung" 24 ; der politische Gegner wird zum Verfassungs- und damit zum Staatsfeind.

\section{Unsicherheit über Grenzen und Methoden des Schutzes der Verfassung und der streitbaren Demokratie}

Umstritten sind nicht allein die inhaltlichen Konkretisierungen der Grundwerte ${ }^{25}$ sowie das Ausmaß der Wertgebundenheit und Werteverantwortung des Staates, umstritten sind auch die normative Funktion und die Reichweite des „Prinzips der streitbaren Demokratie“ - besser: der „wehrhaften“ oder „abwehrbereiten" Demokratie ${ }^{26}$ — als dessen Schutzobjekt und

22 BVerfGE 39, 349.

23 Vgl. etwa $H$. Heller, Staatslehre, Leiden 1934, S. 259 ff., 269.

24 Auch Art. 18 GG erlaubt nur, den Demokratiegegner in bestimmtem AusmaB zu ,entpolitisieren“, nicht aber, ihn zu "entbürgerlichen", so zutreffend Dürig in Maunz/Dürig/Herzog/Scholz, Grundgesetz, Art. 18, Rdnr. 6. Das Zitat im Text: U. K. Preuß, Legalität - Loyalität - Legitimität, in: Leviathan $4 / 77, \mathrm{~S}$. $450 \mathrm{ff}$., 465. Wird die Verfassung in dieser Weise instrumentalisiert, so verkümmert die normale demokratische Integrations- und Innovationsfunktion des politischen Prozesses; Politik wird durch autoritativ verkündete Grundwertemetaphysik in Gestalt juristischer Entscheidungen ersetzt.

${ }^{25}$ Das Zentralkomitee der deutschen Katholiken nennt als solche Grundwerte: Liebe, Wahrheit, Schönheit, Freiheit, Frieden und Gerechtigkeit, vgl. a. a. O. (o. N. 16) S. 146. Bei den Parteien ist von „Freiheit, Gerechtigkeit, Solidarität“ oder auch, klassisch: von Freiheit, Gleichheit, Brüderlichkeit die Rede.

${ }_{26}$ R. Dreier, in Dreier/Schwegmann (Hrsg.), Probleme der Verfassungsinterpretation, 1976, S. 22; E. Bulla, Die Lehre von der streitbaren Demokratie, AöR 98 (1973), S. $340 \mathrm{ff}$; jüngst: G. Roellecke, Verfassungstreue und Schutz der Verfassung, DOV 1978, bes. S. $460 \mathrm{f}$; Hella Mandt, Demokratie und Toleranz, in: Festschrift Dolf Sternberger, 1977, S. 233; F. Fuchs/E. Jesse, Der Streit um die „streitbare Demokratie“, in: Aus Politik und Zeitgeschichte B 3/78, S. $17 \mathrm{ff}$; vor allem jetzt die Monographie von J. Lameyer, Streitbare Demo- 
Legitimationsgrund zugleich die freiheitliche demokratische Grundordnung erscheint. Da weist man einerseits auf die Doppelfunktion des Streitbarkeitsprinzips hin, welches Eingriffe in die Bürgerfreiheit sowohl legitimiere als auch limitiere; Doppelfunktion außerdem insofern, als die Wehrhaftigkeit nicht einseitig gegen den Bürger, sondern gleichermaßen gegen Angriffe auf die Verfassung von "oben" wie von "unten" gerichtet $\mathrm{sei}^{27}$. Art. 79 Abs. 3 (mit der Bindung der Legislative), Art. 98 Abs. 2 und 5 (mit seiner Adresse an die Organwalter der Dritten Gewalt) und Art. 1 Abs. 3 GG (mit der Bindung aller Arten von Staatsgewalt) dürfen hierfür genannt werden ${ }^{28}$. Bei dieser Betrachtungsweise wird dann beispielsweise Art. 18 sogar als „Verfestigung der Abwehrfunktion der Grundrechte

kratie, 1978, auch derselbe, Streitbare Demokratie contra Terrorismus, in ZRP 1978, S. 49 ff. Zum Grundsätzlichen vgl. C. J. Friedrich, Die Staatsräson im Verfassungsstaat, 1961, bes. S. $116 \mathrm{ff}$. Zu den Auswirkungen der Streitbarkeit im Privatrecht: J. W. Gerlach, Radikalenfrage und Privatrecht, Recht und Staat 482/483, 1978, m. zahlr. Beispielen. Über das Ausmaß der tatsächlichen Gefährdung der inneren Sicherheit unserer Republik und ihrer freiheitlichen demokratischen Grundordnung durch politische Gegner sowie über die Wirksamkeit der Elemente der Abwehrbereitschaft gehen selbst unter (strafrechtlichen) Experten die Meinungen weit auseinander. Vgl. einerseits G. Willms, Rückzug in die Zitadelle, in FAZ Nr. 202 v. 1. 9. 1977, der einen ständigen Abbau des Staatsschutzes beklagt und meint, daß heute "die Zeichen eher auf Förderung als auf Abwehr des Staatsfeindes" hinwiesen. (Vgl. auch denselben, Das Staatsschutzkonzept des Grundgesetzes und seine Bewährung, Karlsruhe 1974, sowie: Staatsschutz im Geiste der Verfassung, Frankfurt/Bonn 1962). S. andererseits $M$. Güde, Bekommen wir einen neuen Staat? in: Frankfurter Hefte $7 / 1978$, S. $15 \mathrm{ff}$., 17: „Eine ernstliche Umsturzgefahr durch einen inneren Feind hat seit Bestehen der Bundesrepublik nicht bestanden und besteht auch derzeit nicht. Im Widerspruch $\mathrm{zu}$ dieser Wirklichkeit verhält sich unsere Staatsschutzbürokratie so, als ob unser Staat aktuell vom gewaltsamen Umsturz bedroht sei." Derselbe, Die Verwirrung unseres Staatsschutzrechts, in: Zur Verfassung unserer Demokratie, Vier republikanische Reden, rororo aktuell 1978. Güdes Urteil über das Fehlen einer ernsthaften inneren Gefahr teilt der Verfassungsschutzexperte $H$. J. Horchem, Extremisten in einer selbstbewußten Demokratie, 1975, S. 126, ferner auch der Verfassungsschutzbericht des $B M I$ für 1976, s. Verfassungsschutz '76, Juli 1977, S. 7.

${ }^{27}$ So schon $U$. Scheuner, Der Verfassungsschutz im Bonr.er Grundgesetz, in: Festgabe E. Kaufmann, Stuttgart/Köln 1950, S. 313 ff., 321 für den Verfassungsschutz generell.

${ }^{28}$ Bulla, a. a. O., S. 351; zu Art. 79 Abs. 3 als Verfassungsschutznorm: G. Dürig, in Dürig/Evers, Zur verfassungsändernden Beschränkung des Post-, Telefon- und Fernmeldegeheimnisses, Bad Homburg v. d. H. u. a. 1969 , S. 12. 
gegenüber der Staatsgewalt“29, als „Aktivbürgerprivileg“30 ähnlich dem „Parteienprivileg“ des Art. 21 Abs. 2 begriffen, eine Auslegung, die freilich dem entstehungsgeschichtlich $\mathrm{zu}$ rekonstruierenden Sinn der Norm widerspricht ${ }^{31}$. Art. 18 normiert vielmehr eine Grundrechtsausübungsschranke, verbunden mit einer Eingriffsermächtigung, die aber gerade wegen der Schwere des möglichen Eingriffes nur in einem besonders freiheitsschonenden und -sichernden Verfahren realisiert werden darf. Auf der anderen Seite gewinnt man vielfach den Eindruck, das Streitbarkeitsprinzip solle zum Hauptprinzip der Verfassung und zum entscheidenden Geltungsgrund verfassungsgerechter Normschöpfung überhöht werden, besonders dort, wo es mit der Emphase des Primitivslogans „Keine Freiheit den Feinden der Freiheit!" auftritt"

Als das Bundesverfassungsgericht 1956 den von Karl Loewenstein (1937) und Karl Mannheim (1941) ${ }^{33}$ geprägten Terminus "streitbare Demokratie“ in sein Repertoire verfassungsrechtlicher Leitbegriffe aufnahm, war es sich dessen noch be-

${ }^{29}$ Hamann/Lenz, Grundgesetz, Kommentar, 3. Aufl. 1970, Art. 18 Anm. A 1, Bulla, a. a. O., S. 355.

30 Bulla, a. a. O.

s1 Vgl. JöR N. F. Bd. 1, 1951, S. 174. Der Abg. Dr. Dehler verteidigte die Monopolbefugnis des Bundesverfassungsgerichts, die Verwirkung festzustellen, gegen einen Streichungsantrag: „.. weil andernfalls die Tragweite dieser Bestimmung der Verwirkung der Grundrechte gar nicht abzusehen ist. Wer gegen irgendeines dieser Grundrechte verstößt, wäre praktisch vogelfrei. Jede Verwaltungsstelle könnte ihm die Grundrechte absprechen. Er müßte sich dann an das Gericht wenden und sehen, wie und wann er wieder zu seinem Recht kommt. Das gleiche könnte gegen eine Gruppe von Menschen geschehen. Jede Polizeibehörde könnte sagen: Du hast ein Grundrecht verletzt, jetzt hast du nicht das Recht der Meinungsfreiheit, du hast nicht das Recht der Versammlungsfreiheit, du hast dieses Recht verwirkt. Das wäre die Statuierung des Polizeistaates. Die Polizei könnte jeden vogelfrei machen..." Zur Deutung des Art. 18 als Schranke wie hier: W. Schmitt Glaeser, Mißbrauch und Verwirkung von Grundrechten im politischen Meinungskampf, 1968, S. $56 \mathrm{f}$. Unklar bleibt allerdings der Streit, ob Art. 18 einen „Negativstatus" sanktioniere: sowohl Hamann-Lenz (a.a.O., s. N. 29) wie Schmitt Glaeser gehen zutreffend davon aus, daß nur die in Art. 18 GG genannten Grundrechte verwirkt werden können; insoweit liegt also in der Sache keine Kontroverse vor.

${ }^{32}$ Z. B. K. A. Bettermann, Grenzen der Grundrechte, 1968, S. 12. Anders, vorsichtiger, richtiger BVerfGE 5, 138: „Keine unbedingte Freiheit für die Feinde der Freiheit“. Ferner: Maunz/Dürig/Herzog/ Scholz, GG, Art. 18 Rdnr. 4: "schlechter Slogan".

${ }^{33} K$. Loewenstein, Militant Democracy and Fundamental Rights, Am. Pol. Science Rev. XXXI (1937) S. $416 \mathrm{ff}$., $638 \mathrm{ff}$; derselbe, Verfassungslehre, 2. Aufl. 1969, S. $348 \mathrm{ff}$; $K$. Mannheim, Diagnose unserer Zeit, 1952, S. 6, 14. J. Lameyer, a. a. O., S. 13, N. 1, nennt Mannheim als Urheber des Begriffs. 
wußt, daß es dabei um den Versuch ging, ein "Grenzproblem" der freiheitlichen Demokratie zu lösen. Inzwischen ist die „Streitbarkeit" auch in Karlsruhe zu einer universell - und keineswegs nur an den "Grenzen" - einsetzbaren "Grundentscheidung des Grundgesetzes" ${ }^{44}$ avanciert, die - ebenso wie die "freiheitliche demokratische Grundordnung“s5 — als generelle Grundrechtsschranke interpretiert wird und auch in banalen Kollisionsfällen „das Ergebnis der Güterabwägung auf der Ebene des Verfassungsrechts vorzeichne(t $t)^{\text {"988 }}$. Das Licht der für die freiheitliche Demokratie schlechthin konstitutiven Bedeutung der Meinungsfreiheit etwa ${ }^{37}$ flackert in der streitbaren Atmosphäre nur noch spärlich unter dem Scheffel der allgemeinen Mißbrauchsabwehr ${ }^{38}$. Die Rangzuweisung als Verfassungsgrundentscheidung führt in der Tat dazu, daß das Grundgesetz insgesamt streitbarer wird als die Summe seiner streitbaren Elemente ${ }^{99}$. Es ist deshalb auch kein Ausrutscher, sondern nur folgerichtig, wenn in der obergerichtlichen Rechtsprechung diese Quelle der Legitimität ganz unverhüllt und unvermittelt gegen die als bloß „formal“ disqualifizierte Legalität ausgeschöpft wird. „Feinde dieser Grundordnung, auch wenn sie sich formal im Rahmen der Legalität bewegen", werden nicht toleriert ${ }^{40}$. Die folgende Entsprechung ist sachlich konsequent und politisch plausibel (trotzdem freilich inhaltlich nicht etwa zu billigen): So wie man mit einer aus "Grundwerten" - zu Recht oder zu unrecht - bezogenen Legitimitätsbehauptung sich über das demokratische Mehrheitsprinzip hinwegsetzen möchte, so dient die Berufung auf ein generalisiertes

${ }^{34}$ BVerfGE 28, 48; 30, 19 f.; Lameyer, a. a. O. (Nr. 26), S. 94 ff.

${ }^{35}$ So $H$. $H$. Klein, Zur Berufung von Mitgliedern der Verfassungsfeindlichkeit verdächtiger Parteien und Vereinigungen in das Beamtenverhältnis, in Festschrift E. R. Huber, 1973, S. $75 \mathrm{ff}$., S. $81 \mathrm{f}$. Zur Kritik vgl. die Replik von F. Müller, Nachschrift zur Radikalenfrage (1977) in: derselbe, Rechtsstaatliche Form und Demokratische Politik, 1977, S. $105 \mathrm{ff}$.

${ }^{36}$ BVerfGE 28, $36 \mathrm{ff}$., 48. Ist, wie das Gericht meint, das Ergebnis durch die "Grundentscheidungen" bereits vorgezeichnet, kann auch gar keine wirkliche, einzelfallausschöpfende "Güterabwägung“ mehr stattfinden. Der Hinweis auf sie wird zur façon de parler.

${ }^{37}$ BVerfGE 7, 198 ff., 208, st. Rspr.

s8 Vgl. Matth. 5, 15. Was wunder dann, daß das Licht schließlich in der Kaserne vor dem Anspruch der Kameraden, in Ruhe gelassen zu werden. also keine Meinung anhören zu müssen, ganz erlischt! So die Senatsmehrheit in BVerfGE 44, $197 \mathrm{ff}$., 204. Vgl. dazu aber die beiden dissenting votes der Richter Rottmann und Hirsch!

${ }^{30}$ So J. Lameyer in ZRP 1978, S. 50 (s. N. 26).

40 So OVG Lüneburg, DVBl. 1972, S. 961. Kritisch dazu: U. K. Preuß, Legalität und Pluralismus, 1973, S. 9 ff. und G. Frankenberg, Angst im Rechtsstaat, in KJ 1977, S. 353 ff., 366. 
Streitbarkeitsprinzip dazu, das rechtsstaatliche Legalitätsprinzip aus den Angeln zu heben. In diesem Zwischenreich einer der Legitimität für verlustig erklärten Legalität (,verfassungsfeindlich", aber nicht verboten) und einer nicht mehr legal, d.h. im einfachen Gesetz, sondern nur noch als Verfassungsgrundsatz formulierten Legitimität vegetieren dann die demokratietheoretisch wie rechtsstaatlich zwielichtigen Gestalten des "gesetzestreuen Verfassungsfeindes“ und des "legitimen Gesetzesmißbrauches"41.

Das Legalitätsprinzip und damit die rechtsstaatlich gesicherte Freiheit sind aber auch mit Sicherheit verloren, wenn, wie im Falle der Abhörentscheidung des Bundesverfassungsgerichts ${ }^{42}$ der rechtsstaatlich unzulässige Schluß von der Aufgabenübertragung auf die Zulässigkeit aller zu ihrer Durchführung geeigneten Mittel dazu führt, gravierende Eingriffsbefugnisse im Grundrechtsbereich aus den bundesstaatlichen Organisationsund Kompetenzverteilungsnormen (Art. 73 Nr. 10 und Art. 87 Abs. 1) herzuleiten. Die Entwicklung zu einer sorgfältigeren

41 Frankenberg (s. vor. N.) spricht hier von normativen Siamesischen Zwillingen, S. 367.

42 Vgl. BVerfGE 30, 1 ff., 20: „Es kann nicht der Sinn der Verfassung sein, zwar den verfassungsmäßigen obersten Organen im Staat eine Aufgabe zu stellen und für diesen $Z$ weck ein besonderes Amt vorzusehen, aber den verfassungsmäßigen Organen und dem Amt die Mittel vorzuenthalten, die zur Erfüllung ihres Verfassungsauftrages nötig sind." Dieser Satz wird mit Vorliebe von denjenigen zitiert, die etwa aus der Aufgabenumschreibung für den Verfassungsschutz, z. B. in \& 3 BVerfschG zugleich mehr oder weniger weitreichende Eingriffsbefugnisse herleiten wollen. $\mathrm{Zu}$ unrecht, denn genau besehen macht das BVerfG a. a. O. gar keine Aussage über das Wie der Aufgabenerfüllung. Keinesfalls entbindet der Satz des Gerichts von der Notwendigkeit der Beachtung des Gesetzesvorbehalts. Vgl. ferner Nr. 3.1. der Allg. Begründung zum Musterentwurf eines einheitlichen Polizeigesetzes, Stand Nov. 1977: die neuere Entwicklung des Polizeirechts führt zur eindeutigen Trennung von Aufgaben(normen) und Befugnissen bzw. -normen. In diesem Sinne auch: $H$. Borgs-Maciejewski, Parlament und Nachrichtendienste, in: Aus Politik und Zeitgeschichte B 6/77, S. $12 \mathrm{ff}$, 19. Unklar bleibt die Position $P$. Kirchhofs, Polizeiliche Eingriffsbefugnisse und private Nothilfe, NJW 1978, S. $969 \mathrm{ff} ., 970$ einerseits, 972 li. o. andererseits (im Zusammenhang mit der Spezialität und Subsidiarität polizeilicher Eingriffsnormen.). S. 970: Sondertatbestandliche Bindungen dürfen nicht durch Rückgriffe auf generalklauselartige Aufgabennorm unterlaufen werden (dem stimme ich zu); aber S. 972: Eine fehlende Befugnisnorm kann nicht zu einem Handlungsverbot für die Polizei führen, soweit die Generalklausel (Auftragsnorm) eine Handlungspflicht begründet - (auch im Bereich der Sondertatbestände?) Sollen Eingriffe aller Art also im Ergebnis doch allein vom Handlungsauftrag her gerechtfertigt werden können? S. dazu im Text VI. 3. und E.-W. Böckenförde, Der verdrängte Ausnahmezustand, NJW, 1978, S. $1881 \mathrm{ff}$. 
Scheidung von Aufgabennormen und Befugnisnormen im polizeilichen Bereich kann und darf nicht preisgegeben werden. Das ursprünglich ja nur zum Schutze des (partei)politischen Meinungskampfes und Willensbildungsprozesses für notwendig gehaltene Streitbarkeitsprinzip entwickelt sich allmählich zu einer Rundum-Waffe des Staatsschutzes. Ihren (vorläufigen) Höhepunkt erreicht dieser Prozeß in dem seriös gemeinten Vorschlag, auch Bereiche der inneren Sicherheit, und insbesondere des Antiterror-Strafrechts dem Regime der Streitbarkeit zu unterwerfen. Deshalb so heißt es, sollten sämtliche denkbaren Einzelmaßnahmen zur Bekämpfung des Terrorismus in einem Ausnahmegesetz zusammengefaßt werden ${ }^{43}$. Gegenüber einem verabsolutierten Sicherheits-Denken ist jedoch daran zu erinnern, 1. daß es totale Sicherheit ohne Risiko nicht geben kann ${ }^{44}$, nicht einmal um den Preis völliger Preisgabe der Freiheit und 2., daß die Verfassung dieses Staates nicht einfach seine Selbsterhaltung als pure Machtorganisation erlaubt und gebietet, sondern daß die „streitbare Demokratie“ ihren legitimierenden Grund darin findet, daß sie eine freiheitliche Demokratie bleibt ${ }^{45}$, und das heißt auch, daß sie das

43 A. v. Winterfeld, Terrorismus - ,Reform ' ohne Ende?, ZRP 1977, S. 265 ff., S. 269: „Erstmalig mit Erlaß des Kontaktsperregesetzes hat sich der Bundesgesetzgeber zum Bestehen einer Ausnahmesituation bekannt. ... Ein Ausnahmerecht, das der Abwehr schwerster Bedrohung des Gemeinschaftsfriedens dient, im übrigen die Integrität und Kontinuität der verfaßten Rechtsordnung wahrt, ist Ausdruck der "streitbaren" Demokratie des Grundgesetzes, Staatsnotwehr zur Rettung des Gemeinschaftsfriedens und Erhaltung des Rechtsstaates." Ausdrücklich zustimmend: $M$. Schröder, Staatsrecht an den Grenzen des Rechtsstaates, AöR 103 (1978), S. 121 ff., 138, N. 74. Gegen dieses Konzept überzeugend E.-W. Böckenförde, Der verdrängte Ausnahmezustand, NJW 1978, S. $1881 \mathrm{ff.,} \mathrm{1888:} \mathrm{„Wer}$ meint, Ausnahmelagen nur dadurch begegnen zu können oder zu dürfen, daß er sie gesetzlich normiert, schafft schließlich ein Recht der Normallage, das vom Ausnahmezustand her bestimmt ist." ,Liberty dies by inches"! Symptomatisch für die Tendenz zur "scheibchenweisen" Vernichtung rechtsstaatlicher Freiheit durch" immer neue scheinbar rechtsstaatliche, weil spezielle Befugnisnormen ist der jüngste Vorschlag von R. Riegel, Zur Frage der Auskunftspflicht nach Allgemeinem Polizeirecht, DƠV 1978, S. $501 \mathrm{ff}$. Riegel fordert die gesetzliche Verankerung eines allgemeinen Beobachtungs- und Befragungsrechtes der Polizei auch zur bloß vorbeugenden Straftatbekämpfung bezüglich bestimmter schwerer Delikte (z. B. nach $\S 129$ a StGB). Damit würde eine generelle Rechtsgrundlage für weitere Intensivierung der "BEFA" (der "beobachtenden Fahndung ") geschaffen, ein weiterer Schritt auf dem Weg zum perfekten Uberwachungsstaat getan.

44 C. J. Friedrich, a. a. O., (N. 26) S. $121 \mathrm{ff}$.

45 E. Denninger, Staatsrecht 1, 1973, S. 90. Vgl. auch $H$. Simon, Plädoyer für die rechts- und sozialstaatliche Demokratie, Frankfurter Hefte 2/1978 S. 5 ff., 13; BVerfGE 33, 85: „Nach dem Wert- 
Recht ihrer Normallage nicht vom Ausnahmezustand her bestimmen lassen darf.

\section{Das Leitbild des „streitbaren Demokraten“ und der „Wille zur Verfassung"}

Eine streitbare Demokratie erscheint nicht denkbar ohne "streitbare Demokraten". Dieses Thema bleibt, wie viele andere, gleichfalls dem status constituens ${ }^{46}$, dem „staatserzeugenden Rechtsstand" des Bürgers, zuzurechnende Fragen in der Literatur, sieht man von wenigen Ausnahmen, etwa Herbert Krüger ${ }^{47}$, ab, merkwürdig unterbelichtet, in der Rechtsprechung blaß und voller Ungereimtheiten. Dies überrascht denjenigen nicht, der die perspektivische Verengung der deutschen Staatsrechtswissenschaft auf bloße, zudem einseitig auf ein negatorisches Grundrechtsverständnis fixierte Rechtsstaatswissenschaft noch nicht endgültig überwunden sieht, der aber auch, insoweit im Gegensatz zu Ernst Forsthoff ${ }^{48}$, keinerlei Anlaß findet, vom „Ende des Staates“ zu sprechen. Außerdem hat man Mühe - um es durchaus zurückhaltend zu formulieren - aus der Judikatur des Bundesverfassungsgerichts kohärente Aussagen etwa aufgrund einer die Einzelentscheidungen durchgehend tragenden Demokratietheorie, zur inneren oder äußeren Haltung des Aktivbürgers zu den Grundentscheidungen der Verfassung herauszupräparieren. Anders etwa als die Menschen- und Bürgerrechtserklärung vom 26. 8. 1789, die die Ansprüche der Bürger immer zugleich auf die Erhaltung der Verfassung und das gemeine Wohl ausgerichtet wis-

system des Grundgesetzes dient eben der politische Staatsschutz nicht der Absicherung irgendeiner beliebigen, sondern ganz speziell derjenigen politischen Ordnung, für die Meinungs-, Presse- und Informationsfreiheit konstitutiv sind." (Minderheitsvotum).

46 Dazu meine Ausführungen schon 1968, jetzt in: Denninger/ Lüderssen, a. a. O. (N. 19,0). S. 102, $116 \mathrm{ff}$., und passim.

${ }_{47} H$. Krüger, Die Verfassung als Programm der Nationalen Repräsentation, in: Festschrift E. R. Huber, 1973, S. $95 \mathrm{ff}$., derselbe, Die Verfassung als Programm der Nationalen Integration, in: Festschrift F. Berber, 1973, S. 247 ff., derselbe, Verfassungsgebung im Hinblick auf die Auswärtige Lage, in: Festschrift W. Weber, 1974, S. $241 \mathrm{ff} ., 250$; derselbe, Der Wesensgehalt der Grundrechte, in Krïger/Seifert, Die Einschränkung der Grundrechte, Hannover 1976, S. 35 ff.

48 E. Forsthoff, Von der Staatsrechtswissenschaft zur Rechtsstaatswissenschaft, Studium generale 21 (1968) S. $692 \mathrm{ff}$., derselbe, Der Staat der Industriegesellschaft, 1971, S. 159, passim. Vgl. meine Einführung in: Denninger (Hrsg.), Freiheitliche demokratische Grundordnung, Band 1, 1977, S. $26 \mathrm{f}$. 
sen wollte ${ }^{49}$, anders als die Revolutionsverfassung von $1791^{30}$, welche von ihren Urhebern ausdrücklich nicht nur der Treue der Staatsorgane, sondern auch „der Wachsamkeit der Familienväter, den Ehefrauen und Müttern, der Liebe der jungen Bürger und dem Mute aller Franzosen" anvertraut wurde, und anders auch als beispielsweise die Hessische Verfassung vom 1. 12. $1946^{51}$, die ausdrücklich die Pflicht zum Widerstand gegen verfassungswidrig ausgeübte öffentliche Gewalt, ferner die Pflicht eines jeden normiert, „für den Bestand der Verfassung mit allen ihm zu Gebote stehenden Kräften einzutreten" - im Unterschied zu all diesem ist das Grundgesetz hier wenig ergiebig ${ }^{52}$. Die Kargheit des Grundgesetzes nötigt den Interpreten in die Dimension der ungeschriebenen Verfassungsvoraussetzungen, -erwartungen ${ }^{53}$, -aufträge und -ermächtigungen. Begriffsjuristischer Dogmatik und richterlicher, im Anspruchsdenken geschulter Zurückhaltung ist der Umgang mit derlei Kategorien ohnehin fremd. Das Bundesverfassungsgericht hat - mit Hinweis u. a. auf Art. 21 Abs. 2 GG - die Bundesrepublik als eine Demokratie bezeichnet, "die von ihren Bürgern eine Verteidigung der freiheitlichen Ordnung erwartet und einen Mißbrauch der Grundrechte zum Kampf gegen diese Ordnung nicht hinnimmt"54. Fünf Jahre später entnimmt derselbe (2.) Senat derselben Vorschrift aber die Freiheit des Bürgers, die „verfassungsmäßige Ordnung abzulehnen und sie politisch zu bekämpfen, solange er es innerhalb einer Partei, die nicht verboten ist, mit allgemein erlaubten Mitteln tut"s5. (= der „gesetzestreue Verfassungsfeind“, s. o.). Hier hätte man vom Gericht die Angabe des demokratietheoretisch gemeinsamen Nenners für beide Aussagen erwarten dürfen. Die Figur des „Vaterlandsverteidigers in Zivil "56 als streitbarer Bürger-

49 Vgl. Einleitungsformel der Déclaration vom 26. 8. 1789.

50 Verf. vom 3.9.1791, Titel VII, Art. 8 Abs. 4, in: G. Franz, Staatsverfassungen, 1964 , S. 370/71, zit. auch bei $H$. Krüger (o. N. 47 Festschrift W. Weber) S. 252.

51 Art. 147, 146 HessVerf. in einem besonderen Abschnitt XI: „Der Schutz der Verfassung“. Das hat Tradition, vgl. etwa Abschnitt VII der Paulskirchenverfassung vom 28. 3. 1849: „Die Gewähr der Verfassung".

52 Immerhin enthält die Präambel des GG die Aufforderung an das gesamte Deutsche Volk, die Einheit und Freiheit Deutschlands in freier Selbstbestimmung $\mathrm{zu}$ vollenden; auch Art. 6 Abs. 2 und Art. 14 Abs. 2 enthalten Hinweise auf spezielle Grundpflichtgehalte.

${ }^{53}$ Vgl. $H$. Krüger, Verfassungsvoraussetzungen und Verfassungserwartungen, in Festschrift U. Scheuner, 1973, S. $285 \mathrm{ff}$.

54 BVerfGE 28, 48 (1970).

55 BVerfGE 39, 359 (1975).

${ }^{58}$ H. Krüger, a. a. O., (N 47) Festschrift W. Weber, S. 250. 
Demokrat bleibt dem Gericht fremd, hingegen erscheint sie ihm um so strenger, genauer, pflichtenbeladener, „staatstragender" im Beamtenrock ${ }^{57}$.

Unklar bleibt sonach, welche Verteidigungsleistung mit welchen Mitteln unter welchen Voraussetzungen und zu welchem Ende erwartet wird. Eine in dem Sinne justiziable Rechtspflicht, daß an ihre Nichterfüllung in einem Individualverfahren negative Sanktionen geknüpft werden könnten, besteht nicht, vielmehr existiert nur eine "Verfassungserwartung“58. Dies wird indirekt durch die Einschränkung bestätigt, mit welcher der Hessische Gesetzgeber die ähnlich konturlose Verfassungstreuepflicht der Hessen-Verfassung, Art. 146 Abs. 150), konkretisiert hat, um sie, dem Verfassungsgebot entsprechend, justiziabel zu machen. Nämlich nur, wenn der Bürger durch eine strafbare Handlung seine Pflicht, für den Bestand der

57 Zur Kritik an der „Zwei-Sphären-Lehre“ des Bundesverfassungsgerichts (staatstragende Beamtenschaft - staatsirrelevante Bürgerschaft bzw. Parteientätigkeit) vgl. Denninger, Einführung zu Freiheitliche demokratische Grundordnung, Band 1, S. 23. Symptomatisch für das neo- (oder spät-?)wilhelminische Staatsverständnis in der Rechtsprechung auch die Ausführungen des BVerwG in E 47, 350. Gegen die „Sonderrolle eines besonders staatstragenden öffentlichen Dienstes gegenüber den in den vorstaatlichen, deshalb nicht so wichtigen Raum verwiesenen Parteien..." jetzt auch G. Jasper, die Krise der streitbaren Demokratie, DVBl. 1978, S. 725 ff., 732.

Unverkennbar ist die Tendenz der Rechtsprechung (des BGH), dem Beamtenrock bzw. der Richterrobe die Anwaltsrobe gleich zu achten, d. h. trotz des Wortlauts etwa des $\$ 7 \mathrm{Nr} .6 \mathrm{BRAO}$, „an den Rechtsanwalt die gleichen Anforderungen hinsichtlich der Verfassungstreue $z u$ stellen wie sie dem Richter abverlangt müssen“. (Vorlagebeschluß des BGH VRG 12/77). Dazu mit Recht kritisch: J. Schreiber, Politische Treuepflicht für Rechtsanwälte, Demokratie und Recht 1977, S. 79 ff. und F. Ostler (Präsident des Deutschen Anwaltvereins), Zum Erfordernis der Verfassungstreue des Rechtsanwalts, Bayer. VerwBl. 1978, S. $527 \mathrm{ff}$.

58 Eine Rechtspflicht kann u. U. trotz Sanktionslosigkeit oder erschwerter Durchsetzbarkeit einer Sanktion zu bejahen sein. Vgl. etwa $\S 6$ HessUnivG und die Ausführungen des BVerfG dazu im Beschluß E $47,327 \mathrm{ff}$., $366 \mathrm{ff}$. \$ 6 HUG ist mindestens teilweise, nämlich soweit sich die Informationsverpflichtung des Wissenschaftlers auf Gefahren für das „friedliche Zusammenleben der Menschen" bezieht, als eine unmittelbare Verfassungsschutzvorschrift anzusehen; vgl. den Bezug zu Art. 26 GG, der staats- und verfassungsschützenden Charakter hat. Die Handlungspflicht folgt in $\$ 6$ HUG aus einer Art Garantenstellung des speziell Sachkundigen. Im übrigen gilt das Prinzip, daß es, wie bei Art. 18 GG, bei der „Verfassungsverteidigung“ in der Regel bei Unterlassungsgeboten bleiben muß. Vgl. Maunz/Dürig/Herzog/Scholz, Grundgesetz, Art. 18, Rdnr. 61.

59 Art. 146 Abs. 1 HessVerf. lautet: „Es ist Pflicht eines jeden, für den Bestand der Verfassung mit allen ihm $\mathrm{zu}$ Gebote stehenden Kräften einzutreten.“ 
Verfassung einzutreten, verletzt hat, kann der Staatsgerichtshof, soweit zum Schutze der Verfassung erforderlich, „politische Folgen“ für den Angeklagten, i. e. Grundrechtsbeschränkungen, anordnen ${ }^{60}$. Außerdem wird die Verfassungsverteidigungspflicht von vormherein als durch die „individuelle und soziale Zumutbarkeit" begrenzt angesehen" ${ }^{61}$. Das Rollenbild, das man vom „streitbaren Demokraten" entwirft, schwankt begreiflicherweise - je nach dem zugrundegelegten Demokratieverständnis. Es reicht von der schroff gegen den Staat - qua Macht- und Sicherheitsapparat - gerichteten Forderung, die Bürger sollten sich zu „Vereinen für Verfassungsschutz" zusammenschließen ${ }^{62}$, über das Leitbild des zwar $€ n$ gagierten, aber rational argumentierenden, diskursfreudigen, kritischen, auch selbstkritischen Citoyen ${ }^{63}$, der durchaus als Alternative zu einem übermäßigen, die Freiheit letztlich erstickenden institutionellen Schutz gesehen wird ${ }^{64}$, über angepaßt-opportunistisches Mitläufertum bis hin zu jenem Grad an innerlich und äußerlich aktiver "Streitbarkeit", welchen das Bundesverfassungsgericht für den Beamten - in fragwürdigem Gegensatz zum Normalbürger - als Norm aufrichtet ${ }^{65}$.

$60 \S 33$ HessGStGH. Zweifelhaft ist der unbeschränkte Fortbestand dieses Verfahrens - und des zugrundeliegenden Art. 146 Abs. 2 HessVerf. - neben Art. 18 GG. Zinn/Stein/Reh, Verfassung des Landes Hessen, Kommentar, Art. 146 Nr. 8, gehen wegen Tatbestandsverschiedenheit zu Art. 18 von der Fortgeltung aus. Das ist bezüglich der beiden letzten Alternativen des Art. 146 Abs. 2 fraglich. Zutreffend anders im Ergebnis als Zinn/Stein, bezüglich Art. 17 HessVerf.: W. Schmitt Glaeser, a. a. O. (N. 31), S. 276.

${ }^{61} \mathrm{Vgl}$. Zinn/Stein, Kommentar zur Hess. Verf. Art. 146 Anm. 5. Der Widerstandspflicht nach Art. 147 soll dagegen unmittelbare rechtliche Verbindlichkeit überhaupt fehlen, a. a. O., Art. 147 Anm. 6.

${ }^{62}$ F. Duve, Anhang: Gründet Verfassungsschutzvereine! in W.-D. Narr, (Hrsg.), Wir Bürger als Sicherheitsrisiko, 1977, S. 325.

${ }^{63} J$. Lameyer, Streitbare Demokratie, 1978, S. 207.

${ }^{64}$ H. Simon, a. a. O. (o. N. 45) S. 12.

${ }_{65}$ BVerfGE $39,348 \mathrm{f}$. Das BVerwG, E 47, 330, 337, hatte schon den Satz aufgestellt, der Dienst des Beamten sei „immer Dienst an der freiheitlichen demokratischen Grundordnung als dem jeder Verfassungsänderung entzogenen Kernbereich des Grundgesetzes". Das BVerfG geht, a. a. O., wesentlich weiter: Der Beamte muß die ,geltende verfassungsrechtliche Ordnung, so wie sie in Kraft steht,“ bejahen, äußerlich und innerlich, und zwar nicht nur „kühl, innerlich distanziert". Der Rahmen für mögliche verfassungsloyale Kritik, die auch dem Beamten zustehen soll, verengt sich damit stark. Streng genommen hätten danach an der Enquete-Kommission Verfassungsreform Beamte entweder überhaupt nicht oder nur mit der ständigen Mentalreservation der Bejahung der geltenden Verfassungsrechtsordnung - und das hieße wohl: Verneinung einer revidierten - teilnehmen dürfen. 
Hermann Heller ${ }^{68}$, Dietrich Schindler ${ }^{67}$, Konrad Hesse ${ }^{68}$ und andere ${ }^{69}$ haben eindrucksvoll die Unentbehrlichkeit eines dauerhaften "Willens zur Verfassung", eines "gemeinsamen Staatswillens" dargelegt, ohne welchen gerade die freiheitliche Demokratie nicht zu existieren vermag. Dieser Wille zur Verfassung ist die notwendige komplementäre Kraft, die die tendenziell chaotischen und antagonistischen individuellen Freiheitsäußerungen so begrenzt und normativ „verfaßt", daß eine friedliche Koexistenz möglich wird. Aber dieser Wille zur Verfassung läßt sich nicht kommandieren, nicht durch Verwaltungsakt herstellen; er gehört zu denjenigen Voraussetzungen des säkularisierten Staates, die dieser, wie Böckenförde sagt $^{70}$, nicht selbst garantieren kann. Das Bundesverfassungsgericht hat beides, wenn auch zu einseitig staatsbezogen, gesehen, wenn es einmal das „Einverstandensein des Bürgers mit dem Staat", „die Chance zur Identifikation" ${ }^{\prime 31}$ als Existenzbe-

${ }^{66}$ H. Heller, a. a. O. (o. N. 23), S. 250, 269.

67 . Schindler, Verfassungsrecht und soziale Struktur, 2. Aufl. 1944, S. 141: „Die Demokratie kann nur bestehen, wenn die Differenzen auf dem Fundament gemeinsamer Uberzeugungen oder eines gemeinsamen Staatswillens ausgetragen werden können." S. 142: „Die Demokratie bedarf also nicht weniger als die Monarchie des Glaubens an feste politische Werte." Kritisch zur Fundierung auf Werte statt anderer: E. W. Böckenförde, Die Entstehung des Staates als Vorgang der Säkularisierung, in: Derselbe, Staat-GesellschaftFreiheit, 1976, S. 60. Schindler wendet sich, gegen Kelsen, gegen den von diesem behaupteten Zusammenhang von Demokratie und relativistischer Weltanschauung. Zu den hier vorkommenden Mißverständnissen vgl. u. zu N. 93 und im Text dort.

${ }^{68} \mathrm{~K}$. Hesse, Die normative Kraft der Verfassung (1959), jetzt in: M. Friedrich (Hrsg.), Verfassung, Darmstadt 1978, S. 77 ff., 86; Hesse, Grundzüge des Verfassungsrechts, 9. Aufl. 1976, S. 18.

${ }_{60}^{60}$ Etwa $D$. Grimm, Verfassungsfunktion und Grundgesetzreform, AöR 97 (1972), S. 489 ff., 503. Ausdruck solchen Willens zur Verfassung ist auch reflektierte Verfassungspolitik. Vgl. denselben, Gegenwartsprobleme der Verfassungspolitik und der Beitrag der Politikwissenschaft, in: PVS Sonderheft 9/1978, S. $272 \mathrm{ff}$. Das Thema des Willens zur Verfassung kehrt seit Platon wieder. Vgl. etwa auch J.-J. Rousseau, Considérations sur le gouvernement de Pologne, 1772, mit Betonung der edukatorischen Staatspflege. Vor allem: G. W. F. Hegel, Vorlesungen über die Philosophie der Geschichte, Theorie Werkausgabe, Band 12, S. $529 \mathrm{ff}$., 531. Hegel nennt drei Elemente und Mächte des lebendigen Staates: Die Gesetze, die Regierung und „die Gesinnung, welche das innere Wollen der Gesetre ist, nicht nur Sitte, sondern die Gesinnung, daß die Gesetze und die Verfassung das Feste seien und daß es die höchste Pflicht der Individuen sei, ihren besonderen Willen ihnen zu unterwerfen. "Nicht einmal bei Hegel ist Wille zur Verfassung identisch mit unbedingter Unterwerfung unter die Staatsgewalt.

${ }^{70}$ Böckenförde, a. a. O., (o. N. 67); jetzt auch in: Der Staat als sittlicher Staat (Reuchlin-Vortrag), 1978, (o. N. 10), S. $36 \mathrm{f}$.

71 BVerfGE 40, 237 ff., 251. 
dingung der Demokratie nennt, an anderer Stelle ${ }^{72}$ aber das Risiko unterstreicht, das in der Angewiesenheit dieses Staates auf die Aktivität und Urteilsfähigkeit seiner Bürger liegt.

Die Chance einer auch nur teilweisen Identifikation des Bürgers mit „seinem" Staat - mehr zu erwarten verstieße gegen das Prinzip der Freiheit - ergibt sich nur, wenn Zustimmung ebenso möglich ist wie Kritik und wenn staatlicherseits weder diese noch jene privilegiert oder diskriminiert wird ${ }^{73}$. Mit der angemessenen Äußerung, sodann auch Einschätzung und Aufnahme von Kritik hat man sich hierzulande, wo „die Versessenheit aufs Positive" immer wieder durchschlägt"74, schon immer schwer getan. So zeugt es von einer Verkennung des Wesentlichen demokratischer politischer Auseinandersetzungen, wenn etwa Hermann Lübbe ${ }^{75}$ neuerdings vor "Ideologiediskussionen, Grundwertdebatten, Menschenbildpräsentationen" als dissoziativen, desintegrierenden Veranstaltungen warnt. Während aber Lübbe für eine demokratisch möglichst unbehelligte Herrschaft der Technokraten plädiert, sieht sich Wilhelm Hennis ${ }^{76}$ heute „mehr und mehr mit einer Staatsappara-

72 BVerfGE 20, 56 ff., 103.

${ }^{73}$ In diesem Punkt verdient Zustimmung: $H$. Lübbe, Endstation Terror. Rückblick auf lange Märsche, in: $H$. Geißler (Hrsg.), Der Weg in die Gewalt, 1978, S. 96 ff., 107. Vgl. auch Lübbe, Endstation Terror, 1978.

${ }^{74}$ Th. W. Adorno in der ZEIT, Nr. 26/1969, S. 23: „Genügen mag der Hinweis darauf, daß sozialpsychologisch die Versessenheit aufs Positive ein Deckbild des unter dünner Hülle wirksamen Destruktionstriebs ist. Die am meisten vom Positiven reden, sind einig mit zerstörender Gewalt.“ $A$. meinte damals die Aktionisten der APO. Vgl. auch Denninger/Lüderssen, a. a. O. (o. N. 19), S. 158.

${ }_{75} H$. Lübbe, Warnung vor Ideologiediskussionen, in: Festschrift H. Schelsky, Opladen 1977, S. $156 \mathrm{ff}$., 158, wiederveröff. in Endstation Terror, (g. N. 73), S. 95 ff.

Keineswegs erbringen solche Debatten immer einen sachlichen Ertrag, dennoch sind sie im Felde des Politischen untrennbar mit der Erörterung von "Sachfragen" verbunden. Die Lïbbe'sche Parole von der „Pragmatik der Friedenssicherung durch Diskursvermeidung“, a. a. O., S. 161, gedeiht auf dem Boden eines kritikfeindlichen, nur scheinbar entpolitisierten, „den Prinzipien der Erfahrung und der Sachkunde erneut Geltung verschaffenden", kurz: eines autoritär-technokratischen Staatsverständnisses. In dieser Sicht stellen "die schwerwiegenden Probleme gegenwärtiger Politik in hochkomplexen, rasch sich wandelnden sozialen Systemen nicht Probleme eines Zieldefizits, sondern Steuerungsprobleme" dar (a. a. O., S. 163). Wer nach welchem Kompaß wohin steuern soll und was die Gesteuerten/Besteuerten dazu meinen, interessiert offenbar nicht näher.

${ }_{76} W$. Hennis, Vom gewaltenteilenden Rechtsstaat zum teleokratischen Programmstaat, in: Festschrift Dolf Sternberger, München 1977, S. 170 ff., 192, 191 Anm. 54. Es ist derselbe Hennis, der 1973 gegen Begriff und Politik der Demokratisierung als gegen eine „Re- 
tur konfrontiert, die immer aufdringlicher jene unsympathischen Züge des absolutistischen Polizeistaates annimmt, der zwar recht effizient, aber doch im Grunde bevormundend, unfreiheitlich, arrogant und überaus unfähig zur Selbstkritik gewesen ist.“ Wenn Hennis die hier dominant gewordene „Politik der teleokratischen Programmrealisierung“, das schier hemmungslose Sichaustoben der "Macher" angreift, wenn er von "der sturen Zielfixierung der Regierungen, dem nur noch ein "Instrumentarium“ zuliefernden Charakter der Gesetzgebung und der zum verlängerten Arm der, regierenden Gewalt' herabkommenden Justiz" spricht, so hat er offenbar eine völlig andere Vorstellung von demokratischer Bürgerkritik, von politisch notwendigen Mittel/Ziel-Diskussionen, kurzum: vom Verhältnis des ,Staates' zur ,Gesellschaft' als sein Kollege Lübbe. Die Verwirrung ist groß!

\section{Vorinstitutionelle Prinzipien der freiheitlichen demokrati- schen Grundordnung als Orientierung für streitbare Demo- kraten und Staatsgewalt: Freiheit von Angst, Vertrauen, Bereitschaft zum Engagement}

Es sollte keiner Erläuterung bedürfen, daß die skizzierten Differenzen nicht nur akademischen Streit bedeuten, sondern daß sie, vielfältig normativ und institutionell vermittelt, höchst praktische Auswirkungen zeitigen. Die Option für die eine oder die andere Lösung bestimmt und begrenzt einerseits den Aktionsradius für die politische Praxis kritischer streitbarer Demokraten, andererseits stellt sie die Weichen für das grundlegende (Selbst-)Verständnis des Berufsbeamtentums und seiner Rolle im Gemeinwesen - Stichworte: Neutralität? „Hüter der Staatlichkeit"? usw.; hiervon hängen wiederum die Anforderungen an die Beamtentreue $a b$ - und drittens fällt mit dieser Entscheidung über das Bürger-Staat-Grundverhältnis auch die alle Detailprobleme vorprägende Antwort auf die Frage der Ausbalancierung von individueller Freiheitssphäre und sie berührenden Staatsschutzmaßnahmen. Suchen wir in dem staatstheoretischen Dunkel nach einem verfassungsrechtlichen und nicht nur politikwissenschaftlichen Orientierungsmaßstab, so kann dieser kein anderer sein als die „freiheitliche demokratische Grundordnung" selbst, aber freilich nicht in der stereotypen Formalität, in der sie beamtenrechtliche Extre-

volte gegen die Natur" und eine "Preisgabe von Grundlagen der abendländischen politischen Kultur" zu Felde zog, vgl. Die mißverstandene Demokratie, Freiburg 1973, S. 51, 37. Dazu Denninger, in: Demokratisierung - Möglichkeiten und Grenzen, Ein Cappenberger Gespräch, 1976, S. 45 ff. 
misten-Bescheide und -Urteile schmückt, sondern in einer auf ihre demokratieverwirklichende Funktion hin problematisierten Fassung. Mit anderen Worten:

Wir fragen nach der von der geschriebenen Verfassung vorausgesetzten Grundverfassung des Bürgers, ohne welche die vom Bundesverfassungsgericht ${ }^{77}$ ja nicht abschließend katalogisierten institutionellen Elemente der freiheitlichen demolsratischen Grundordnung leerlaufen, ihren Zweck verfehlen (müssen). Umgekehrt sind aber gerade die Institutionen dieser Ordnung, etwa: Grundrechte, Gewaltenteilung, Pluralismus und Selbstbestimmungsprinzip so beschaffen, daß sie bei vernünftigem Einsatz jene weiteren Grundvoraussetzungen beim Bürger zu bewirken, mindestens zu fördern, zu festigen und zu erhalten vermögen ${ }^{78}$. Diese Wechselwirkung zwischen den institutionellen (d.h. derzeit: den die Definition der BVerfGE 2, $12 \mathrm{f}$. ausmachenden) und den sozusagen "vorinstitutionellen" Elementen der freiheitlichen demokratischen Grundordnung, ferner der instrumentale Charakter jener in bezug auf diese wird sofort einleuchten, wenn ich vorschlage, den definitorischen Katalog um die folgenden Elemente zu ergänzen: 1. Freiheit von Angst, 2. Vertrauen, 3. Bereitschaft zum Engagement.

Die umfassende Bedeutung dieser drei Grundelemente für die Konstitution sowohl des Rechtsstates als auch des politischen Prozesses der Demokratie und für deren reziproke Bedingtheit kann hier nur angedeutet werden. Am Anfang steht die Freiheit von Angst, - freedom from fear - jenes schon von Hobbes benannte 79 , genau 300 Jahre später von $F$. D. Roosevelt $t^{\text {so }}$ wiederentdeckte, weltweit verkündete Leitmotiv

77 BVerfGE 2, $1 \mathrm{ff}$., $12 \mathrm{f}$.

78 Es soll damit gerade jener Zustand vermieden werden, vor dem auch die Bundesrepublik keineswegs gefeit ist und den Montesquieu auf die Formel gebracht hatte: „Es kann geschehen, daß wohl die Verfassung frei ist, nicht aber der Bürger", De l' esprit des lois, Buch 12, Kap. 1. $M$. kennt auch den umgekehrten Fall; er dürfte heutzutage selten sein.

${ }_{7 \theta}$ Th. Hobbes, De Cive, 1642. Kap. I, $2.7 \mathrm{ff}$; Leviathan, 1651, Kap. 13.

${ }^{80}$ Als eine der Vier Freiheiten, die die Botschaft Roosevelts an den Kongreß am 6. 1. 1941 enthielt. Die Formel "frei von Furcht und Not" ging ein in die Atlantik-Charta Roosevelts und Churchills vom 14. 8. 1941 (Art. 6), später dann in die Präambel der Allgemeinen Erklärung der Menschenrechte vom 10. 12. 1948, in die Präambel der UN-Konventionen über wirtschaftliche, soziale und kulturelle Rechte bzw. über bürgerliche und politische Rechte vom 16. 12. 1966.

In der innerstaatlichen Diskussion hat die "Freiheit von Furcht" - anders als die "Freiheit von Not" — noch nicht die gehörige Aufmerksamkeit gefunden. Ausnahmen: Deutlich ist die für die Demokratie konstitutive Bedeutung gesehen bei $A$. Arndt, Der Rechtsstaat und sein polizeilicher Verfassungsschutz, NJW 1961, S. 898: 
nicht nur der Staatsgründung, sondern, zumal im Zeitalter totalitärer Systeme, auch der Staatsmachtbegrenzung. In diesem Sinne hat man neuerdings in unterschiedlichen Zusammenhängen auf die rechtliche Funktion der Freiheit von Angst hingewiesen: als Bestandteil des Rechts auf freie Entfaltung der Persönlichkeit gegenüber der heimlichen oder der sogar offenen Observierungspraxis der Verfassungsschutzämter ${ }^{81}$, ferner als Element der aktivbürgerlichen, demokratieverwirklichenden Grundrechtsbetätigung, als Freiheit von antizipierter ökonomischer Existenzangst (im Hinblick auf karriereschädliche politische Aktivitäten) ${ }^{82}$. Aus diesem, aber nicht nur aus diesem Grund sind Ausforschungen durch Verfassungsschutzagenten an Schulen und - abgesehen von konkreten Gefahrenfällen - auch an Hochschulen rechtlich ein Ding der Unmöglichkeit ${ }^{83}$.

Freiheit von Angst gehört aber nicht nur zur Atemluft lebendiger Demokratie; sie ist ein Grundbaustein rechtsstaatlicher Freiheit und umgekehrt erfüllen rechtsstaatliche Institutionen ihren Sinn dann, wenn sie zur Befreiung von Angst beitragen. Niemand hat dies eindrucksvoller bedacht als Montesquieu. Politische, besser staatsbürgerliche Freiheit bestehe in der Sicherheit des Einzelnen, oder mindestens in der Uberzeugung von der eigenen Sicherheit; die Freiheit des Bürgers beruhe deshalb entscheidend auf der Güte der Strafgesetze ${ }^{84}$. Nota

„Denn um Demokratie von der Wurzel her wachsen zu lassen, ist für den Jedermann, der ein „Einzelner“ ist, Freiheit von Furcht das erste Erfordernis." Vgl. auch Dürig (1964) in Maunz/Dürig/Herzog/ Scholz, GG, Art. 18 Rdnr. 8. Jetzt: VG Kassel, NJW 1977, S. 692 m. Anm. von J. Scherer, NJW 1978, S. $237 \mathrm{f}$. auch zum Einschüchterungseffekt, "chilling effect" mit Nachw. der US-Rspr. Auch W. Schmidt, Die bedrohte Entscheidungsfreiheit, JZ 1974, $241 \mathrm{ff}$., 248 o.

${ }_{81}$ J. Salzwedel, Möglichkeiten und Grenzen einer rechtsstaatlichen Kontrolle des Verfassungsschutzes, Festschrift Hans Peters, Berlin 1967, S. $756 \mathrm{ff}$., 761, m. Hinw. auf Maunz, Deutsches Staatsrecht $\S 14$ III, 21. Aufl. 1977, S. 124 „Freisein von Furcht".

${ }_{82}$ Vgl. J. Lameyer, Streitbare Demokratie, S. 159. Eindrucksvoll F. Neumann schon 1953: Zum Begriff der politischen Freiheit, jetzt in: Demokratischer und autoritärer Staat, 1967, S. $100 \mathrm{ff}$., $128 \mathrm{f}$. zum Problem der gesellschaftlichen Ächtung bei Entlassung wegen vermuteter Illoyalität. Vgl. auch denselben, Angst und Politik, a. a. O., S. $261 \mathrm{ff}$.

${ }_{83}$ Für den Schulbereich gilt verstärkt das in BVerfGE 39, $356 \mathrm{f}$. Gesagte. Gegen „Verfassungsschnüffelei" an Schulen auch $A$. Dregger, laut dpa vom 20. 8., FAZ 21. 8. 1978, sowie die Fraktionsvorsitzenden der F.D.P., FR vom 11. 9. 1978; vgl. auch BMI Baum am 27. 9. 1978 vor dem Innenausschuß des Deutschen Bundestages. Eine Überwachung der Schulen führe zu einem nicht wieder gut zu machendem Vertrauenseinbruch. Vgl. ,Woche im Bundestag' 8. Jg. Nr. 17/1978, S. 5.

${ }_{84}$ Montesquieu, a. a. O. (o. N. 78), Buch 12, Kap. 2. 
bene: Montesquieu hat nicht die „Innere Sicherheit" im Auge, wie die Konferenz der Innenminister den Begriff versteht, nämlich als möglichst effektiven Schutz der Rechtsgüter der Allgemeinheit, als hohe Verbrechensaufklärungsquote und drakonische Strafdrohungen, nein, der Franzose denkt an Garantien des due process, an Tatbestandsbestimmtheit, rechtsstaatliche Beweisführung und Verteidigung, Schutz gegen falsche Anschuldigungen, an richterliches Gehör $u$. ä. Man lese seine Kritiken an der Strafpraxis aufgrund des uferlosen crimen laesae majestatis, man setze stattdessen den „Mißbrauch zum Kampf gegen die freiheitliche demokratische Grundordnung", und es wird deutlich, wo hier und heute die Probleme liegen. Dies gilt für seine Warnungen vor der Verwendung von Indiskretionen $^{85}$, dies gilt insbesondere für die Kritik an Verurteilungen aufgrund bloßen Verdachts und, ebenso schlimm, wegen bloßer Gesinnungen. Es war eine böse Tyrannei des Dionysios, einen gewissen Marsyas hinrichten zu lassen, bloß weil dieser geträumt hatte, er würde den Herrscher umbringen. Gesetze haben, so Montesquieu, dafür zu sorgen, daß nur äußere Handlungen mit Strafe belegt werden ${ }^{86}$. Grund hierfür ist die Sicherheit, die Freiheit von Furcht, die aus der Berechenbarkeit und der durch eigenes Verhalten möglichen Steuerung der Rechtsfolgen entspringt. Dies gilt prinzipiell nicht allein für Strafgesetze. Diese Bedingungen der Freiheit von Angst entfallen, wenn die Gesetze dem Bürger nicht mehr nur meßbares, jedenfalls beobachtbares, damit beweisbares äußeres Verhalten abverlangen, sondern Gewissensproben, Utberzeugungen, Gesinnungen. Die Gesellschaft polarisiert sich dann in die Tugendhaften, die in der rechten Gesinnung sind, und in jene, die es nicht sind, in „Freunde“ oder „Feinde der Freiheit". „Die Gesinnung aber kann nur von der Gesinnung erkannt und beurteilt werden. Es herrscht somit der Verdacht; ... Es herrschen

85 Derselbe, a. a. O., Buch 12, Kap. 12.

${ }_{86}$ Derselbe, a. a. O., Buch 12, Kap. 11. Gegen das délit d'opinion jüngst dezidiert: $M$. Güde, Die Verwirrung unseres Staatsschutzrechts, in: Güde/Raiser/Simon/v. Weizsäcker, Zur Verfassung unserer Demokratie, 1978, S. $10 \mathrm{ff}$. Vgl. auch $H$. Steinberger, Konzeption und Grenzen freiheitlicher Demokratie, 1974, mit Blick auf das amerikanische Antisubversionsrecht: "Auch wer die freiheitliche Demokratie als eine an inhaltlichen Wertelementen orientierte Lebensform staatlicher Gesellschaft und als legitimerweise schützenswertes Rechtsgut anerkennt, kann sich gleichwohl entschließen, subversiven Bestrebungen erst an der Schwelle der formalen, insbesondere gewalttätigen Verletzung der Rechtsordnung entgegenzutreten - und er wird unter den Voraussetzungen einer demokratisch gefestigten Gesellschaft in der Regel gut beraten sein, $\mathrm{Ab}-$ wehrmaßnahmen erst an diese Schwelle anzusetzen." 
jetzt die Tugend und der Schrecken; denn die subjektive Tur gend, die bloß von der Gesinnung aus regiert, bringt die fürchterlichste Tyrannei mit sich" ${ }^{\text {"87}}$. Diese Revolutionskritik Hegels trifft jegliche Art von Jakobinismus; ex negativo läßt sie die Fundamente des rechtsstaatlichen Legalitätssystems um so leuchtender hervorscheinen. An die Stelle der Tugend tritt der Gesetzesgehorsam, an die Stelle von Verdacht, Mißtrauen und Schrecken treten Bestimmtheit, Vertrauen, Sicherheit. Das Grundmuster der Bürger-Staat-Beziehung muß deshalb von wechselseitigem Vertrauen geprägt sein. Dem favor legis entspricht der favor civis, eine Vermutung für die Verfassungstreue des Bürgers. Dieser vertraut seinerseits darauf, daß der doppelte Gewaltverzicht (auf Faust- oder Selbsthilferecht und auf Revolution), den er mit der Anerkennung des staatlichen Rechtsschutz- und Gesetzgebungsmonopols geleistet hat, durch die Herrschaft im Recht auch in doppelter Hinsicht wettgemacht wird: durch den Schutz erworbener Rechte und ausgeübter Grundrechte einerseits, durch die Offenhaltung der Innovationschance, $d . h$. der legalen Änderungsmöglichkeit der Verteilungsregeln andererseits ${ }^{88}$.

Das rechtsstaatliche Legalitätssystem kann seine Funktion der Friedenswahrung durch Rechtsgüterschutz und normativ geleiteten sozialen Wandel auf Dauer nur erfüllen, wenn es von der Bereitschaft eines großen Teiles der Bürger getragen wird, sich im permanenten Prozeß der Staatshervorbringung und der "Gemeinwohl"-Bestimmung ${ }^{80}$ zu engagieren und sei es nur in der bescheidenen Rolle des vernünftig überlegenden freien Wählers. Dieser so ungemein wichtige Ausdruck einer realisierbaren politischen Autonomie ${ }^{90}$ hat ebenso wie jedes intensivere demokratische Engagement zur elementaren Voraussetzung, daß die erst aufgrund politischer Auseinanderset-

${ }^{87}$ Hegel, Werke, a. a. O. (o. N. 69), S. $532 \mathrm{f}$.

88 Vgl. vor allem $U$. K. Preuß, in Leviathan, a. a. O., (o. N. 24), S. 463: Zumutbarkeit des Gesetzesgehorsams, „weil und solange das Gesetz eine revidierbare soziale Ordnungsform ist und letzte Fragen nicht letztverbindlich entscheidet."

${ }_{80} \mathrm{Vgl}$. W. Schmidt, Organisierte Einwirkungen auf die Verwaltung, VVDStRL Heft 33, 1975, S. 183 ff., 194 ff. Ferner W. Maihofer in der BT-Debatte vom 15. 11. 1974, a. a. O. (o. N. 4), S. 567: „Die freiheitlichste Verfassung in der deutschen Geschichte, unser Grundgesetz, ist auf das aktive politische Engagement unserer Bürger begründet." Es rächt sich, wenn man diese Einsicht zur Phrase verkommen läßt.

${ }^{80}$ Man soll hier ruhig auch von einer ungeschriebenen BürgerGrundpflicht sprechen. Nichts ist törichter, als die Bedeutung des allgemeinen aktiven und passiven Wahlrechts $\mathrm{zu}$ verkleinern oder herabzusetzen. Aber es ist schwierig, der ungeduldigen Jugend dies deutlich zu machen. 
zung zu findenden Lösungen und zu treffenden Entscheidungen nicht bereits durch staatlich vorfixierte Werte-Canones vorweggenommen sind. Der Staat, in dem sich nicht nur der Beamte $^{91}$, sondern in erster Linie der Bürger zu Hause fühlen soll, muß diesem die Chance lassen, sich aktiv und kooperativ in diesem "Hause“ einzurichten. Bereitschaft zu demokratischem Engagement erweist sich sowohl als Bedingung als auch als Bedingtes einer Verfassung offener Kritikmöglichkeit, pluralen Ideen- und Interessenwettbewerbes, politischer Toleranz und, nicht zuletzt, der Revidierbarkeit staatlicher Entscheidungen. In bestimmte Bezirke der Persönlichkeitsentfaltung darf der Staat überhaupt nicht eintreten; das Dekretieren letzter Wahrheiten und existenzieller Sinngebung ist ihm ebenso verwehrt wie einer politischen Partei die Durchsetzung eines mit dem Anspruch auf den Besitz absoluter Wahrheit auftretenden Programmes. Die freiheitliche Demokratie muß streitbar sein gerade um der Erhaltung dieser pluralistischen Offenheit willen; gerade die streitbare Demokratie ist die eigentlich "relativistische", die eben diesen relativistischen Pluralismus absolut verteidigt. Hierin liegt die konsequente Fortführung des alten, von Kelsen ${ }^{92}$ entwickelten und oft mißverstandenen Zusammenhanges von philosophischem Relativismus und demokratischem Prinzip ${ }^{93}$, den ich in der verfeinerten Fassung durch den Popper-Schüler und -kritiker H.F. Spinner aufgreifen möchte: Während erkenntnistheoretischer Monismus mit seiner Orientierung an Rechtfertigung bzw. Verifizierung in der poli-

91 BVerfGE 39, 349.

$92 \mathrm{H}$. Kelsen, Vom Wesen und Wert der Demokratie, Neudruck 1963 der 2. Aufl. 1929, S. 98 ff. Auch mein Staatsrecht 1, S. 54. Ahnlich G. Radbruch, Vorwort zur Rechtsphilosophie.

${ }_{83}$ Zum Verhältnis von pluralistischer Demokratie und weltanschaulichem Relativismus vgl. U. Scheuner, a. a. O. (o. N. 18), S. 50, und $P$. Badura, Verfassung und Verfassungsgesetz, in Festschrift U. Scheuner, 1973 , S. $19 \mathrm{ff}$., $30 \mathrm{f}$. einerseits, H. Krüger, a. a. O., in Festschrift W. Weber (o. N. 47), S. 248 andererseits. Zutreffend stellt Krüger fest, daß ein gewisser Relativismus mit "Streitbarkeit" sehr wohl vereinbar ist. Andererseits ist Pluralismus nur dann praktisch realisierbar, wenn alle Gruppen ihre Existenzansprüche auf die wechselseitige Koexistenz hin relativieren. Vgl. ferner W. Scheel, Ansprache vor dem 16. Weltkongreß für Philosophie, Presse- $u$. Informationsamt der Bundesregierung, Bulletin Nr. 90, 1978, S. $85 \mathrm{ff}$., bes. 847: „In einer Demokratie ist jeder Gedanke demokratisch bis auf den einen: daß nicht jeder Gedanke demokratisch sei. Und diesen Gedanken findet man, das ist kein Zufall, immer nur bei denen, die den Staat zu einem Instrument ihrer Wahrheit machen wollen. Und das ist just der Absolutheitsanspruch, demgegenüber die Demokratie mißtrauisch ist."

Den Hinweis auf diese Stelle verdanke ich Herrn Kollegen Tomuschat. 
tischen Praxis zu autoritären Einstellungen führt, „enthält das fallibilistisch-pluralistische Erkenntnis- und Handlungsmodell den Keim einer humanitären Ethik sowie einer Philosophie der Demokratie" ${ }^{\text {"94. }}$.

\section{Folgerungen}

Wir haben versucht, die Freiheit von Angst, das Vertrauen und die Bereitschaft zum Engagement als aufeinander aufbauende Elemente nicht einer politischen Soziopsychologie im allgemeinen, sondern speziell der sozialpsychologischen Fundierung einer freiheitlichen Demokratie aufzuzeigen. In diesem Sinne kann man, normativ gewendet, von vorinstitutionellen Elementen der freiheitlichen demokratischen Grundordnung sprechen. Versuchen wir nun, die Bedeutung dieser Elemente als Kriterien für die Beurteilung dogmatischer Einzelfragen im Bereich des Verfassungsschutzes abzuklären.

\section{Beamtentreue}

Für Beamtenbewerber wie für bereits ernannte Beamte spricht eine Ausgangsvermutung zugunsten ihrer Verfassungsloyalität ${ }^{95}$. Für Angehörige beider Gruppen gilt insoweit nichts anderes als für jeden anderen Staatsbürger auch. Ohne eine solche Vermutung ließe sich die beamtengesetzliche Gewähr-

${ }^{94}$ H. F. Spinner, Pluralismus als Erkenntnismodell, 1974, S. $104 \mathrm{f}$. Im Rahmen einer Evolutionstheorie ließe sich außerdem zeigen, daß das pluralistisch-falliblistische Modell gegenüber ideologisch monistischen Formen die spätere, differenziertere und insofern höhere politische Lebensform darstellt. So gesehen ist es auch zutreffend, monistisch-totalitäre Systeme als Ausdruck kollektiver Regression im strengen Sinne zu begreifen.

${ }_{95}$ Hiervon geht auch der Deutsche Bundestag in seiner EntschlieBung vom 24. 10. 1975 aus. Vgl. P. Frisch, Extremistenbeschluß, 4. Aufl. Leverkusen 1977, S. 145 (dort Wortlaut); ebenso die „Grundsätze der Bundesregierung für die Prüfung der Verfassungstreue vom 19. Mai 1976“, Pressemitteilung Nr. 195/76 des Presse- und Informationsamtes der Bundesregierung, im Wortlaut bei Frisch, a. a. O., S. $147 \mathrm{f}$. Ebenso die Verfahrensregelung des Landes Bremen vom 14. 3. 1977, Amtsblatt der Freien Hansestadt Bremen S. 87, vgl. Frisch a. a. O., S. 169; Maihofer in der Debatte vom 15. 11. 1974, a. a. O. (o. N. 4) S. 575 f.; ferner: H. Koschnick, Verfahrenspraxis der öffentlichen Hand bei der Beurteilung von Bewerbern für die Einstellung in den öffentlichen Dienst, ... Erster Zwischenbericht 1978, Typoskr. S. 7: "Ich gehe davon aus, daß zunächst bei jedem Bewerber in einer freiheitlichen Demokratie unterstellt werden darf, er sei ein verfassungstreuer Staatsbürger, der sich aktiv für die Verwirklichung des Grundgesetzes einsetzt. Alles andere wäre ein Rückfall in die Zeit des Obrigkeitsstaates.“ 
bieteklausel ${ }^{96}$ rechtsstaatlich, d.h. willkürfrei gar nicht handhaben, denn wie sollte ein junger Beamtenbewerber, ein politisch unbeschriebenes Blatt, sonst den Beweis über ein zukünftiges Verhalten überhaupt führen können? Auch den Fortbestand der verfassungstreuen Gesinnung beim ernannten Beamten muß diese Vermutung sichern, die allein ihn davon entbindet, andernfalls täglich, stündlich, immerfort Bekenntnisse im Sinne des $\S 35$ BRRG ablegen zu müssen. Zum Probierstein für den Rang der Loyalitätsvermutung wird die Fra$\mathrm{ge}^{\text {97}}$, ob die einfache Mitgliedschaft in einer von einer (oder mehreren) Einstellungsbehörde(n) für verfassungswidrig gehaltenen Partei oder in einer sonstigen Gruppe - ohne daß ein entsprechendes Verbot durch das Bundesverfassungsgericht bzw. die nach § 3 VereinsG zuständige Behörde vorläge - nicht nur im Einzelfall ausräumbare Zweifel an der Treue, sondern, wie gesagt wurde, bereits eine "erdrückende Vermutung "88 für

${ }^{96} \S 4$ Abs. 1 Nr. 2 BRRG und die entsprechenden Regelungen der Bundes- und Landesbeamtengesetze. Auf eine bürgerfeindliche Umkehrung der Vermutungslage läuft die Argumentation der Bezirksregierung von Schwaben im Falle der Lehrerin C. LichtwarckAschoff hinaus. Danach "kann die vom Bundesverfassungsgericht getroffene Feststellung, wonach insbesondere auch die Zeit des Vorbereitungsdienstes geeignet ist, sich ein zuverlässiges Bild von einem Bewerber zu machen, nur dann zum Tragen kommen, wenn der Bewerber völlig unvoreingenommen und ohne Kenntnis darüber, da $B$ aufgrund seiner bisherigen politischen Aktivitäten Zweifel an seiner Verfassungstreue im Raume stehen könnten, seinen Vorbereitungsdienst abgeleistet hat." Vgl. FR vom 20. 9. 1978, DER SPIEGEL Nr. 39/1978, S. $126 \mathrm{f}$. Dies ist ein Beispiel für die Herrschaft des Verdachts (Hegel, vgl. o.): Die Möglichkeit der Verdachtsentkräftung wird durch die bloße Mitteilung des Verdachts abgeschnitten.

${ }^{07}$ K. Stern, Zur Verfassungstreue der Beamten, 1974, S. 56: hier liegt der entscheidende Dissens um den Kern der Auseinandersetzung. Vgl. dazu G. Jasper, a. a. O. (o. N. 57), S. 726: Radikalenerlaß als Ersatz für das politisch nicht gewollte Parteiverbot. Das Schrifttum zur Verfassungstreuepflicht der Beamten hat im übrigen inzwischen einen solchen Umfang angenommen, daß hier auf ausführliche bibliographische Hinweise verzichtet werden muß. Zahlreiche Nachweise finden sich bei: $R$. Dreier, Verfassung und Ideologie, Gedächtnisschrift F. Klein, München 1977, S. 86 ff., sowie bei B. Schlink, Zwischen Identifikation und Distanz, Der Staat 1976, S. $335 \mathrm{ff}$. Auf diese beiden wichtigen Arbeiten sei besonders aufmerksam gemacht. Informativ zur Geschichte des Problems: H.-W. Laubinger, Die Treuepflicht des Beamten im Wandel der Zeiten, in: Festschrift C. H. Ule, Köln u. a. 1977, S. 89 ff.

Kritisch zur Gewährbieteformel jüngst: E. Küchenhoff/H.-J. Schimke, Ein Verstoß gegen Neutralität und Toleranz, in Frankfurter Rundschau vom 30. 9. 1978, Nr. 217 S. 14.

${ }^{88} \mathrm{~K}$. Carstens in der BT-Debatte am 15. 11. 1974, abgedruckt in Freiheitliche demokratische Grundordnung Band II (o. N. 4), S. 580. 
mangelnde Verfassungstreue begründet. Nicht zuletzt an dieser Differenz ist 1974 der Versuch einer gesetzgeberischen Entschärfung des Extremistenproblems gescheitert. Mit Sicherheit kann man hier im Hinblick auf ein parteipolitisch wohlgefälliges Beamtencorps nicht einfach unter Berufung auf Art. 79 Abs. 3 i. V.m. Art. 20 GG, auf den Rang also der sozialen Rechtsstaatlichkeit, einen Vorrang des Staates und folglich des für seine Erhaltung notwendigen öffentlichen Dienstes im Verhältnis zur Funktion der politischen Parteien herleiten ${ }^{99}$. Denn Rechtsstaat ist nicht gleich Staat und Staat ist nicht gleich Beamtentum; Art. 79 Abs. 3 i. V.m. Art. 20, zumal Abs. 1, garantiert also nicht „primär Staatlichkeit“ im Gegensatz zum politischen Parteileben, vielmehr wird eine rechts- und sozialstaatliche Demokratie garantiert und zwar als parteienplurale. Eine den Prinzipien der Angstfreiheit und der vertrauensvollen Bereitschaft zum demokratischen Engagement gerecht werdende Problemlösung wird hier nicht mit pauschalen Verurteilungen im Sinne des auch hierzulande unzulässigen „guilt by association"100, sondern nur mit einer sorgfältigen Einzelfallprüfung arbeiten dürfen ${ }^{101}$. Können Art um Umfang der Identifikation eines Mitgliedes mit dem Programm seiner Partei nur individuell ermittelt werden, dann ist es methodisch fragwürdig und sachlich unzulässig, aus dem Wortlaut einer Parteisatzung eine „besondere Inpflichtnahme“ jedes einzelnen Mitgliedes und hieraus wieder eine volle Identifizierung mit dem Programm zu folgern ${ }^{102}$. Und wenn obergerichtliche Recht-

${ }^{99}$ So aber K. Stern, a. a. O. (o. N. 97), S. 35.

100 Dazu vgl. H. Steinberger, a. a. O. (o. N. 86), S. $377 \mathrm{ff}$.

101 Die Schwierigkeiten der Prüfung im Einzelfall und die Gefahren des Ausuferns der Uberwachungspraxis rechtfertigen nicht von extremen Fällen klar verfassungsfeindlicher Gruppen abgesehen - die schematische Anknüpfung der beamtenrechtlichen „Nichteignung" an die bloße Zugehörigkeit zu einem Kollektiv - auch nicht mit der von W. Schmidt, Das Parteienprivileg zwischen Legalität und Opportunität, DOV 1978, S. 468 ff. versuchten Begründung. Aus diesem Grunde führen auch die von $K$. Stern, $M$. Kriele, $A z-$ zola/Lautner u. a. diskutierten, unterschiedliche Vorschläge zur Trennung von Verfassungswidrigkeitsfeststellung und Parteiverbot - Anderung der $\$ \S 43,46$ BVerfGG — nicht zu einer dem Prinzip der individuellen Eignungsprognose gerecht werdenden Lösung. Vgl. die Nachweise bei Schmidt, a. a. O., S. 473 f. Anm. 34, ferner bei $K$. Stern, Grundrechtsverwirkung und Parteiverbot, in Festgabe für das Bundesverfassungsgericht, 1976, Band I, S. 194 ff., 223.

102 So z. B. OVG Rheinland-Pfalz, U. v. 29. 8. 1973, ZBR 1973, S. 338 ff., 344, VGH Baden-Württemberg, U. v. 29. 6. 1976, IV 911/74 S. 15. Kritisch zu solchen Identifizierungsvermutungen auch $J$. Isensee, Der Beamte zwischen Parteifreiheit und Verfassungstreue, JuS 1973, S. $265 \mathrm{ff} ., 270$ mit zutr. Hinweis auf die disziplinarrechtlich zu beachtende rechtsstaatliche Unschuldsvermutung. Eine In- 
sprechung sich zwar bei einem NPD-Mitglied eine innere Distanznahme von verfassungsfeindlichen Zielen der Partei auch ohne Parteiaustritt vorstellen kann, hingegen bei einem DKP-Mitglied nur die volle Identifizierung, dann vermag so feine Unterscheidungskunst bei einem, der auf die Welt kam, als die erste Republik im braunen Strudel versank, nur noch Trauer und Sorge zu bewirken ${ }^{103}$.

\section{Verfassungsschutz}

Wir müssen uns auf die Skizze weniger Problemschwerpunkte beschränken, welche den nachrichtendienstlichen Verfassungsschutz i. e. S. betreffen ${ }^{104}$. Der Bundesnachrichtendienst

pflichtnahme der Mitglieder findet satzungsrechtlich übrigens auch bei den demokratischen Parteien statt. $\$ 5$ des Organisationsstatuts der SPD vom 12. 4. 1973 verpflichtet das Mitglied u. a., „die Ziele der Sozialdemokratischen Partei zu unterstützen“.

103 VGH Baden-Württemberg, U. v. 14. 2. 1978, DOV 1978, S. 522 ff. Dazu G. Jasper, a. a. O. (o. N. 57), S. 731 u. 732 o.

104 Rechtsgrundlagen: Art. 73 Nr. 10, 87 Abs. 1 S. 2 GG; Gesetz über die Zusammenarbeit des Bundes und der Länder in Angelegenheiten des Verfassungsschutzes v. 27. 9. 1950 i. d. F. vom 7. 8. 1972; Gesetz über die parlamentarische Kontrolle nachrichtendienstlicher Tätigkeit des Bundes v. 11. 4. 1978, ferner entsprechende Landesgesetze. Nicht veröffentlicht sind die sog. „Zusammenarbeitsrichtlinien“: „Richtlinien für die Zusammenarbeit der Verfassungsschutzbehörden, des Bundesnachrichtendienstes (BND), des Militärischen Abschirmdienstes (MAD), der Polizei und der Strafverfolgungsbehörden in Staatsschutzangelegenheiten" vom 18. 8. 1970 i.d. F. v. 23. 7. $1973-$ OS $2-601531$ VS - NfD. Aus der Literatur sind hervorzuheben: C. Arndt, Gesetzliche Neuregelungen auf dem Gebiete der Nachrichtendienste, DVBl. 1978, S. 385 ff.; $H$. BorgsMaciejewski, Parlament und Nachrichtendienste, in: Aus Politik und Zeitgeschichte B 6/77, S. $12 \mathrm{ff}$; J. A. Brückner/H. Th. Schmitt, Verfassungsschutz und innere Sicherheit, Wuppertal 1977; Bundesminister des Innern, betrifft: Verfassungsschutz, jährliche Berichte, zuletzt für 1977. Derselbe (Hrsg.), Verfassungsschutz, Beiträge aus Wissenschaft und Praxis, Köln u. a. 1966; S. Cobler, Die Gefahr geht von den Menschen aus, 2. Aufl. Berlin 1978; H.-U. Evers, Privatsphäre und Ämter für Verfassungsschutz, 1960; derselbe, in: Bonner Kommentar zum Grundgesetz, Art. $73 \mathrm{Nr}$. 10, Zweitbearbeitung 1974; Polizei-Institut Hiltrup, Zusammenwirken von Polizei und Verfassungsschutz, insbesondere bei politischen Unruhen und in politischen Spannungszeiten, Seminar vom 8. bis 12. 3. 1971 mit Referaten von Brasse, Evers, Smoydzin, Häring, Hiltrup 1971; J. Rottmann, Verfassungsschutz im Rechtsstaat, AöR 88 (1963), S. $227 \mathrm{ff}$; J. Salzwedel, Möglichkeiten und Grenzen einer rechtsstaatlichen Kontrolle des Verfassungsschutzes, in Gedächtnisschrift H. Peters, Berlin 1967, S. 756 ff.; W. Schatzschneider, Die Ermittlungstätigkeit der Ämter für Verfassungsschutz und Grundrechte, Frankfurter jur. Diss. 1978 (dort weitere Bibliographie); H.-P. Schneider, Der Verfassungsschutz - Grundordnungshüter, Sicherheitsdienst oder Geheimpolizei? in: W.-D. Narr (Hrsg.), Wir Bürger 
(BND) und das Amt für Sicherheit der Bundeswehr (Militärischer Abschirmdienst, MAD), die für die Auslandsaufklärung bzw. für die Spionageabwehr und die innere Sicherheit bei der Bundeswehr zuständig sind, bei dem Bundeskanzleramt bzw. bei dem Bundesminister der Verteidigung ressortieren und beide weithin ohne gesetzliche Grundlage arbeiten ${ }^{105}$, bleiben außer Betracht. Die Konzentration auf die Ämter für Verfassungsschutz rechtfertigt sich nicht nur wegen der aktuellen Bedeutung ihrer Mitwirkung bei den Einstellungen in den öffentlichen Dienst, sondern weil sie von der Struktur ihrer Aufgabenstellung und ihrer Arbeitsweise her gewissermaßen in schärfstem Gegensatz ${ }^{10 B} \mathrm{zu}$ den oben entwickelten vorinstitutionellen Elementen freiheitlicher Demokratie geraten und weil sie dennoch - als notwendige Instrumente des Staatsschutzes und als ein Stück verfaßte Hoheitsgewalt im Sinne der Art. 1 Abs. 1, 3; 20 Abs. 2, unverbrüchlich in den rechtsstaatlichen Rahmen der Verfassung integriert werden müssen. Mit moralischen Kategorien, etwa, daß der Einsatz von V-Leuten „anstößig" und „letztlich eines Rechtsstaates unwürdig“ $\operatorname{sei}^{107}$, ist hier nichts $\mathrm{zu}$ gewinnen. Es ist ein Kennzeichen des administrativen Verfassungsschutzes, zu dem neben dem allgemeinpolizeilichen, dem vereins-, versammlungs-, ausländerpolizeilichen und dem pädagogischen ${ }^{108}$ auch der nachrichtendienstliche Verfassungsschutz gehört, daß er seine Aufgaben vielfach nur auf der Basis von Generalklauseln erfüllt; was hier an Abstrichen am Ideal perfekter Legalität hingenommen

als Sicherheitsrisiko, 1977, S. $93 \mathrm{ff}$; derselbe, Rechtsschutz und Verfassungsschutz NJW 1978, S. $1610 \mathrm{ff}$. $H$. J. Schwagerl, Zu den Ãnderungen im Verfassungsschutzrecht, $\mathrm{DOV}$ 1974, S. 109 ff.; $H$. $J$. Schwagerl/R. Walther, Der Schutz der Verfassung, 1968.

${ }_{105} \mathrm{Zu}$ den Rechtsgrundlagen des BND und des MAG vgl. K. Stern, Das Staatsrecht der Bundesrepublik Deutschland, Band I, 1977, S. 186. Eine gesetzliche Regelung fordert (u. a.) Evers, Bonner Kommentar, a. a. O., Rdnr. 69, vgl. auch $\S 1$ G 10 vom 13. 8. 1968.

100 Vgl. H. Schrübbers, Organisation und Aufgabe des Verfassungsschutzes in der Bundesrepublik Deutschland, in: Verfassungsschutz, 1966 (o. N. 104), S. 69: ein geheimer Nachrichtendienst ist in einer Demokratie in Gefahr, als "Fremdkörper" angesehen zu werden. Eindrucksvoll auch $A$. Arndt, a. a. O. (o. N. 80): für den belauschten Bürger liegt "sein Staat ... nicht mehr verläßlich im Hellen."

107 Rottmann, a. a. O. (o. N. 104), S. 237.

108 Zum pädagogischen Verfassungsschutz gehört die "Staatspflege", vgl. H. Krüger, Allgemeine Staatslehre, H. Ritter" v. Lex, Die Voraussetzungen eines wirksamen Staatsschutzes ... DOV 1960, 218 ff., 285 f.; Evers, Bonner Komm. a. a. O. (N. 104), Rdnr. 43. Schwagerl, Informativer Verfassungsschutz 1976/77 in Hessen (Typoskr.) bevorzugt diese Bezeichnung gegenüber der als "positiver" oder pädagogischer Verfassungsschutz. 
werden muß, kann zum Teil durch strikte Kompetenzaufteilungen und wirksame Interorgankontrollen kompensiert werden ${ }^{109}$. Eben diese Sicherungen werden aber beim nachrichtendienstlichen Verfassungsschutz wegen der ihm eigentümlichen Heimlichkeit in gefährlicher Weise geschwächt. Probleme und Gefahren, wie sie seit der Abhöraffäre der sechziger Jahre bis zu den jüngsten Amtshilfeexzessen zwischen BGS und Verfassungsschutz - Stichwörter: Listen linker Literatur und Organisationen, „Schwarze Bände“, Funktionärskartei110 — immer wieder sichtbar geworden sind, lassen sich weder durch eine gutgemeinte „Parlamentarische Kontrollkommission“, wie sie das Gesetz vom 11. 4. 1978 vorsieht, noch durch eine übrigens mit Warnungszeichen versehene Entscheidung des Europäischen Gerichtshofes für Menschenrechte ${ }^{111}$ über die Vereinbarkeit des Abhörgesetzes 1968 mit der Menschenrechts-Konvention ${ }^{112}$ bannen.

Die Unsicherheiten beim Einbau der Ämter für Verfassungsschutz in das rechtsstaatliche Verwaltungsgefüge beginnen bei der Frage, ob und in welchem Sinne sie als "Polizei" anzusehen seien - trotz des Wortlauts des $\S 3$ Abs. 3 S. 1 BVerfschG, der dem Bundesamt „polizeiliche Befugnisse" ausdrücklich abspricht ${ }^{113}$. Einerseits wird ihre Tätigkeit materiell als polizei-

109 Vgl. als ein Beispiel die Rechtsprechung des BVerfG in den Beschwerdeverfahren gegen Ausweisungsverfügungen gegen Araber, BVerfGE 34, $211 \mathrm{ff}$., 35, $382 \mathrm{ff}$.

${ }_{110}$ „Uberwachungspraktiken alarmieren Baum“, Frankfurter Rundschau Nr. 142 v. 5. 7. 1978.

${ }_{111}$ Entscheidung des Europäischen Gerichtshofes für Menschenrechte vom 6. 9. 1978 (Klass-Urteil), vgl. ErGRZ 1978, S. 357.

112 Konvention zum Schutze der Menschenrechte und Grundfreiheiten vom 4. 11. 1950, zu Gesetz vom 7. 8. 1952. Gesetz zu Art. 10 Grundgesetz vom 13. 8. 1968.

${ }_{113}$ Die Trennung von Polizei(aufgaben) und Verfassungsschutz(aufgaben) war seinerzeit durch die Alliierten vorgegeben worden. Vgl. den „Polizeibrief“ der drei Militärgouverneure an den Parlamentarischen Rat vom 14. 4. 1949: ... „2. Der Bundesregierung wird ... gestattet, eine Stelle zur Sammlung und Verbreitung von Auskünften über umstürzlerische, gegen die Bundesregierung gerichtete Tätigkeiten einzurichten. Diese Stelle soll keine Polizeibefugnisse haben." Vgl. dazu W. Schatzschneider, a. a. O. (o. N. 104) S. 13, Nr. 38 und die dortigen Nachweise. Auf den Polizeibrief wird in dem Genehmigungsschreiben der Militärgouverneure zum Grundgesetz vom 12. 5. 1949 unter Ziff. 3 ausdrückllich Bezug genommen. Vgl. den vollständigen Text bei J. Seifert, Grundgesetz und Restauration, 3. Aufl. Neuwied/Darmstadt, 1977, S. 198. Vgl. jetzt $\S 3$ Abs. 3 BVerfschG, der dem Bundesamt für Verfassungsschutz nicht nur polizeiliche Befugnisse oder Kontrollbefugnisse versagt, sondern auch eine organisatorische "Angliederung" an eine polizeiliche Dienststelle verbietet. Dies ist auch für die Modalitäten des Informationsaustauschs von Bedeutung. 
liche qualifiziert, um sie damit den Bindungen polizeirechtlicher Grundsätze unterwerfen zu können ${ }^{14}$, andererseits sollen trotz der Qualifikation als Polizei diese Rechtsgrundsätze gerade nicht oder nur modifiziert Anwendung finden ${ }^{115}$. Einerseits wird von der Aufgaben- und Befugnisumschreibung her auf die fehlende Qualität als Polizei geschlossen ${ }^{116}$, andererseits soll umgekehrt die Qualifizierung als Nichtpolizei den Schluß auf einen bestimmten Aufgabenumfang tragen ${ }^{117}$. Der Streit ist in der Sache wenig fruchtbar, denn für die Entscheidung der drängendsten Probleme gibt er nichts her, nichts nämlich für die Frage nach der Reichweite der nachrichtendienstlichen Generalklausel des $\S 3$ Abs. 3 S. 2 BVerfschG und ebensowenig für die schwierige Problematik der Wahrung der gesetzlich und verfassungsrechtlich geforderten organisatorischen Trennung von Polizei, Strafverfolgungsbehörden unid Verfassungsschutzbehörden auf der einen Seite, und der Ermöglichung einer aufgabengerechten, also auch elektronischen Zusammenarbeit der verschiedenen Zweige des Staats- und Verfassungsschutzes auf der anderen. Die Geltung der allgemeinen Grundsätze des Polizeirechts, insbesondere des Ubermaßverbotes und der willkürfreien Ermessensausübung ist ohnehin von Verfassung wegen, also unabhängig von der systematischen Einordnung der nachrichtendienstlichen Funktionen, zu beachten. Für jede einzelne Phase der Tätigkeit des nachrichtendienstlichen Verfassungsschutzes - für das "Sammeln" = Beschaffen, das Speichern, das interne Auswerten und das Weitergeben von Informationen - sind der Charakter als Grundrechtseingriff, die Rechtsgrundlagen und ihre Tragweite

114 Salzwedel, a. a. O. (o. N. 104), S. 772. Dies entspricht offenbar auch dem Selbstverständnis des Amtes für Verfassungsschutz, wie es sich in den Dienstvorschriften niederschlägt: "Verfassungsschutz ist Spezialpolizei“, so Smoydzin, Vizepräsident des Bundesamtes (damals) in: Polizei-Institut Hiltrup, Zusammenwirken usw. (o. N. 104) S. $98 \mathrm{ff}$., 105. Den weiteren Ausführungen des Referenten über die Eingriffisbefugnisse der Verfassungsschutzbehörden (S. $110 \mathrm{f}$. a. a. O.) kann nur mit erheblichen Einschränkungen zugestimmt werden.

${ }_{115} H$. Schäfer, Verfassungsschutz im demokratischen Rechtsstaat, in: Bundesminister des Innern (Hrsg.), a. a. O. (o. N. 104), S. 46 f., $48 \mathrm{ff}$. Schäfer schlägt vor, einen eigenen verfassungsschutzrechtlichen Störerbegriff zu entwickeln.

${ }_{116}$ So K. Stern, a.a.O. (o. N. 105), S. 188. Stern zitiert u.a. Borgs-Maciejewski, a. a. O. (N. 104) für die Gegenmeinung. Dieser bezeichnet es aber, a. a. O., S. 19, als sehr zweifelhaft, ob der Verfassungsschutz polizeilichen Charakter trage, und bringt im Folgenden eine Reihe von Gegenargumenten.

$117 \mathrm{~J}$. Welp, Nachrichtendienstliche und strafprozessuale Eingriffe in das Post- und Fernmeldegeheimnis, DOV 1970, S. 267 ff., 269 o. re. 
gesondert zu bestimmen, wobei insbesondere in Fällen der Amtshilfe die Grundsätze des Persönlichkeitsschutzes bei der Datenverarbeitung $\mathrm{zu}$ beachten sind ${ }^{118}$. Der mir verbliebene Zeitraum erlaubt nur knappste Andeutungen: a) Bei der $B e-$ schaffung von Informationen vermag die unspezifische Ermächtigung zum Einsatz „nachrichtendienstlicher Mittel“119 dem Verhältnismäßigkeitsprinzip entsprechende Beeinträchtigungen der Privatsphäre zu rechtfertigen, soweit diese nur nach Art. 2 Abs. 1 GG geschützt ist, nicht hingegen Eingriffe in Bereiche qualifizierten Schutzes wie nach Art. 10 und Art. 13 GG oder auch nach $\S \S 201$ ff. StGB ${ }^{120}$. Besonderer Prüfung bedarf in jedem Falle, ob eine Maßnahme nicht schon den absolut geschützten Kernbereich des Persönlichkeitsrechtes verletzt, der den Schutz nach Art. 1 Abs. 1 genießt. Auch hier vermag das Kriterium der Freiheit von Angst wirksam zu werden ${ }^{121}$; es fordert Bezirke absoluten Schutzes, in welchen der Bürger sich

118 Zur Einführung in die Problematik: H. Auernhammer, Bundesdatenschutzgesetz, Taschenkommentar, 1977; Damann/Karhausen/Müller/Steinmüller, Datenbanken und Datenschutz, 1974; Gola/ Hümmerich/Kerstan, Datenschutzrecht, Teil 1 1977; H. Krauch (Hrsg.), Erfassungsschutz, 1975; O. Mallmann, Zielfunktionen des Datenschutzes, 1977; G. Rüpke, Der verfassungsrechtliche Schutz. der Privatheit, 1976; U. Seidel, Datenbanken und Persönlichkeitsrecht, 1972; Simitis/Dammann/Mallmann/Reh, Kommentar zum Bundesdatenschutzgesetz, 1978 (zur Forts.); W. Steinmüller (Hrsg.), Informationsrecht und Informationspolitik, 1976.

110 „Eine inhaltliche Präzisierung des Begriffes ,nachrichtendienstliche "Mittel' erwies sich als untunlich", stellt der Schriftliche Bericht des Innenausschusses bei der Novellierung des BVerfschG vom 7. 8. 1972 lakonisch fest, zu BT-Drucks. VI/3533, S. 5.

${ }^{120}$ Zum Diskussionsstand jetzt eingehend: $W$. Schatzschneider, a. a. O. (o. N. 104), S. 216 ff. betr. die qualifizierten Informationseingriffe. Informativ auch: $R$. Rupprecht, Vertraulichkeit des Wortes und seine heimliche Aufnahme, DVBl. 1974, S. 579 ff. Zutreffend hebt $R$. hervor, S. 582, Verhältnismäßigkeitsprinzip und Güterabwägungsprinzip seien zwar Leitregeln mit Verfassungsrang, aber nicht „Rechtsgrund staatlichen Handelns", d. h. es wird eine rechtsstaatliche einwandfreie spezielle Eingriffsermächtigung gefordert. Vgl. weiter die sorgfältige Analyse von $D$. de Lazzer/D. Rohlf, Der ,Lauschangriff', JZ 1977, S. $207 \mathrm{ff}$,, bes. 210 f. Vorbildlich die Klarstellung in $\S 4$ Abs. $1 \mathrm{~S}$. 2 des Gesetzes über den Verfassungsschutz im Lande Niedersachsen vom 12. 7. 1976, GVBl. Nr. 22, S. 181 f.: „Bei der Anwendung nachrichtendienstlicher Mittel ist die Verfassungsschutzbehörde an die allgemeinen Rechtsvorschriften gebunden". Die Vorschrift wurde erst während der Beratungen in den Entwurf aufgenommen. Vgl. auch $H$. P. Schneider, in Narr (Hrsg.), a. a. O. (o. N. 104), S. 119 f. Zur Rechtslage in den USA: C. O. Steger, Der Schutz des gesprochenen Wortes in der Verfassung der Vereinigten Staaten von Amerika, Frankfurt/M./Bern, 1975.

121 Nochmals ist hier auf $A$. Arndt, a. a. O. (o. N. 80) zu verweisen, S. 898 . 
unbelauscht und unbeobachtet wissen darf ${ }^{122}$, und solche, in denen er nur unter streng umschriebenen Voraussetzungen mit unerwünschter staatlicher Kommunikationsteilhabe rechnen muß.

b) Für die Speicherung personenbezogener Informationen gilt keineswegs die Maxime „Mögen sie Dossiers anlegen, soviel sie wollen" ${ }^{123}$. Wie $\S \S 4$ und 14 BDSG $^{124}$ zeigen und das VG Hannover ${ }^{125}$ unlängst erkannt hat, stellt die schlichte Existenz und Aufbewahrung z. B. eines ehrverletzenden oder unrichtigen Vermerks eine Verletzung der personalen Eigensphäre dar. Ein Datenlöschungsanspruch ist dann gegeben. Der Grundsatz des elementaren wechselseitigen Vertrauens im Verhältnis Bürger - Staat bedeutet hier, daß auch der Verfassungsschutz nicht zu einer Institution des systematischen generellen Mißtrauens werden darf, die jeden Bürger immer und überall zunächst als potentiellen Verfassungsfeind ansieht. Insoweit gilt für die Beschaffung wie für die Speicherung von personenbezogenen Informationen nichts prinzipiell anderes als für die Behandlung erkennungsdienstlicher Unterlagen durch die Kriminalpolizei ${ }^{126}$.

c) Schließlich bedürfen die leitenden Gesichtspunkte für die Weitergabe von Informationen (die Datenübermittlung) an Dienststellen außerhalb des Bereichs des nachrichtendienstlichen Verfassungsschutzes der Klärung. Eine siebenstellige Zahl von Amtshilfeersuchen an die Ämter für Verfassungsschutz bei der Einstellungspraxis des öffentlichen Dienstes macht die enorme praktische Bedeutung des Problems deutlich. Auszugehen ist von Art. 35 GG i. V.m. $\S \S 4$ ff. VwVfG, § 10 BDSG und den einschlägigen Aufgabenzuweisungsnormen der

122 BVerfGE 27, 1 ff., 6 „Recht auf Einsamkeit“ m. N.; 34, $238 \mathrm{ff}$, 245 m. N., st. Rspr.

${ }^{123}$ So Rottmann, a. a. O. (o. N. 104), S. 242, der sich aber selbst auf S. 239 sehr viel differenzierter äußert: „Richtig ist sicher, daß diese Dossiers-Sammlungen, wenn sie nicht behutsam benutzt werden, eine Atmosphäre des Mißtrauens in der Gemeinschaft hervorzurufen vermögen, die mit der freiheitlich-demokratischen Grundordnung nicht vereinbar ist."

124 \& 4 BDSG: Ansprüche auf Auskunft, Berichtigung, Sperrung oder Löschung; § 14 BDSG: Berichtigung, Sperrung und Löschung ggfs. von Amts wegen.

125 VG Hannover, Urteil vom 2. 3. 1978, VI A 198/76, bes. S. 6.

${ }^{126}$ Vgl. BVerwGE 26, S. $169 \mathrm{ff}$., $170 \mathrm{f}$. Was dort über die Grenzen erkennungsdienstlicher Registrierung gesagt wird, müßte auch zu einer sinnvollen Begrenzung der Datenspeicherung im Rahmen der sog. Befa, (= beobachtenden Fahndung) durch das BKA führen. $\mathrm{Zu}$ den Auswirkungen der jetzigen Praxis vgl. die Beispiele bei P. Koch/ R. Oltmanns, SOS - Freiheit in Deutschland, Stern-Buch, 1978, S. $63 \mathrm{ff}$. 
Verfassungsschutzgesetze. Danach sollte dreierlei außer Streit sein: Erstens, daß keineswegs etwa aus dem Gedanken der Einheit der Staatsgewalt auf einen schrankenlos zulässigen Informationsfluß zwischen allen staatlichen Stellen geschlossen werden darf ${ }^{127}$. Vielmehr stellt grundsätzlich jeder „Akt der personenbezogenen Informationsweitergabe durch den Staat einen Eingriff in die Freiheit des Betroffenen" dar, der einer formellgesetzlichen Ermächtigung bedarf ${ }^{128}$. Zweitens ist, wie $\S 5$ Abs. 2 Nr. 1 VwVfG ${ }^{129}$ unterstreicht, die Datenübermittlung nur zulässig, wenn sie in die Kompetenz der übermittelnden Behörde fällt ${ }^{130}$. Eine fehlende Sachkompetenz kann nicht durch Berufung auf Art. $35 \mathrm{GG}$ ersetzt werden ${ }^{131}$. Und drittens ist

${ }_{127}$ Dies betont zutreffend $H$. $P$. Schneider, a. a. O. (N. 104), NJW 1978, S. 1602. Schwächer: $H$. U. Evers, Die rechtlichen Grenzen der Nachrichtensammlung durch die Ämter für Verfassungsschutz, in BMI, Verfassungsschutz, S. $93 \mathrm{ff} ., 98 \mathrm{f}$. Abw. Rottmann, a. a. O. (N. 104) S. $235 \mathrm{f}$. bez. Informationen an die Verfassungsschutzbehörden. $\mathrm{Zu}$ undifferenziert auch Wand in BVerfGE 39, 390: „Es wäre ... angesichts der Einheit der Staatsgewalt geradezu widersinnig, den Staat an der Verwertung von Material zu hindern, das sich legitimerweise in seinen Händen befindet und das er sich zum Schutze der freiheitlichen demokratischen Grundordnung, ..., beschafft hat." Mit dem "Argument" aus der "Einheit der Staatsgewalt" könnte man auf diese Weise die gesamte Kompetenzordnung aus den Angeln heben. Zutreffend hingegen Roll, Wissenschaftlicher Dienst des Deutschen Bundestages, Fachbereich III, 201 (12), Nr. 145/78 vom 4. 8. 1978, Möglichkeiten und Grenzen einer Amtshilfe für das Bundesamt für Verfassungsschutz, S. 6: „Daraus ergibt sich, daß das Bundesamt für Verfassungsschutz nur dann berechtigte Amtshilfe-Ersuchen stellen kann, wenn die begehrte Amtshandlung in einem unmittelbaren Sinnzusammenhang mit der eigenen, in $\S 3$ Abs. 1 und 2 Verfassungsschutzgesetz näher umschriebenen Kompetenz steht." Entsprechendes muß auch für den Output aus dem Bundesamt an andere Behörden gelten, vgl. u. zu N. 133.

${ }^{128}$ E. Schwan, Datenschutz, Vorbehalt des Gesetzes und Freiheitsgrundrechte, Verwaltungsarchiv 66 (1975), S. 120 ff., 135 f. m. w. N.; vgl. auch Schatzschneider, a. a. O. (N. 104), S. $151 \mathrm{ff}$., Borgs-Maciejewski, a. a. O. (N. 104), S. 17 m. N.

${ }^{129}$ Die Amtshilfevorschriften des VwVfG sind auch im Bereich der nachrichtendienstlichen Amtshilfe - Eingabe wie Ausgabe anwendbar, vgl. \& 1 VwVfG. So zutr. auch Roll, a. a. O. (N. 127), S. 2.

${ }_{130}$ H. P. Schneider, a. a. O. (N. 127); H. Meyer, in Meyer/Borgs, VwVfG § 5 Rdnr. 8; Klappstein in Knack, VwVfG, \& 5 Anm. 5.2.1.

${ }^{131}$ Dies verkennt das OVG Berlin, IV. Senat, NJW 1978, S. 1648, wenn es sagt: „Wann die Prüfung der Verfassungstreue eines Beamtenbewerbers verfassungsrechtlich legitim ist, ergibt sich auch aus der Verfassung selbst, nämlich aus Art. 35 I GG, die Grundlage für die Einschaltung der Staatsschutzbehörden bei der Durchführung dieser Prüfung." Dieser Satz ist in mehrfacher Hinsicht falsch und ungenau. Zutreffend hingegen der Hessische Datenschutzbeauftragte in seiner Stellungnahme vom 9. 2. 1978 in dem Verfassungsbeschwerdeverfahren Hans Roth -1 BvR 231/77, S. 10: „Die Amtshilfeverpflichtung ist jedoch keine absolute, sondern unterliegt den 
auch eine Weitergabe von Informationen, die formal in den Aufgabenbereich der Verfassungsschutzbehörde fällt, nicht allein deshalb schon in jedem Falle auch materiell-rechtlich zulässig. Für diese, wie für jede andere, Grundrechte berührende Verwaltungstätigkeit gilt die Orientierung an rechtsstaatlichen Grundsätzen, insbesondere an dem der Verhältnismäßigkeit ${ }^{132}$. Bei konsequenter Anwendung dieser Grundsätze sollten krasse Divergenzen in der Rechtsprechung, sogar ein und desselben Gerichts, wie jüngste Entscheidungen des OVG Berlin belegen $^{133}$, vermeidbar sein. Nachahmung verdient der Versuch des 2. Senats des Berliner Gerichts, durch genaue Interpretation des gesetzlichen Auftrages der Verfassungsschutzbehörden die generelle Mitwirkung bei Einstellungsverfahren außerhalb des sicherheitsempfindlichen Bereiches gehört nach Bundesrecht und den meisten Landesgesetzen ${ }^{134}$ nicht $\mathrm{zu}$ ihm - und durch Anwendung des Toleranzprinzips ${ }^{135}$, alle jene Informationen von der "Auswertung", also auch von der Weitergabe auf Anfrage auszuschließen, deren Gehalt unter der vom KPD-Urteil des Bundesverfassungsgerichts vorgezeichneten Schwelle der aktiv-aggressiven Grundordnungsbekämpfung im Sinne des Art. 18 und 21 GG bleibt ${ }^{136}$.

Einschränkungen, die sich aus der Rechtsordnung, insbesondere aus bereichsspezifischen Gesetzen ergeben, wie sich auch aus $\S \S 4$ bis 7 VwVfG und $\S 5 \mathrm{HVwVfG}$ ergibt.“

${ }_{132}$ So auch BVerfGE 39, 357. Ferner: Schwagerl, a. a. O. (o. N. 104), S. 113: ... „erhebliche Zurückhaltung bei den Verfassungsschutzbehörden geboten". Die Weitergabe von Personendaten muß zur Abwehr einer drohenden Gefahr für die freiheitliche demokratische Grundordnung unerläßlich erscheinen."

${ }^{133}$ OVG Berlin, U. des IV. Senats vom 24. 2. 1978, NJW 1978, S. 1648 und U. des II. Senats vom 18. 4. 1978, NJW 1978, S. 1644.

134 Die Mitwirkung des Landesamtes für Verfassungsschutz „bei der Überprüfung von Personen, die sich um Einstellung in den öffentlichen Dienst bewerben" ist vorgesehen in den Landesgesetzen von Bayern, Bremen und Rheinland-Pfalz. Schleswig-Holstein sieht eine Beratung vor.

${ }^{135}$ Das Toleranzprinzip ist die Konsequenz der Anerkennung der Prinzipien grundsätzlichen Vertrauens und der Bereitschaft, ja der Notwendigkeit zu demokratischem Engagement. Vgl. BVerfGE 5, $85 \mathrm{ff}$., $138 \mathrm{f}$., 13, 49, st. Rspr. Das Toleranzprinzip als „Ordnungsfaktor" (OVG Berlin a.a. O.) findet seine Grenze dort, wo es, im Einzelfall, auf prinzipielle Intoleranz stößt.

136 Vgl. BVerfGE 5, 141 sowie die Rspr. zu Art. 18. Die Zusammenarbeitsrichtlinien (o. N. 104) spezifizieren unter $\S 1$ Abs. 2 a) die gesetzliche Aufgabenbeschreibung als Informationssammlung und -auswertung über ,verfassungsfeindliche Bestrebungen (z.B. Verstöße gegen Art. 9 Abs. 2, 18, 21 Abs. 2 GG). Das OVG Berlin, II. Senat, a. a. O. (o. N. 133), engt die Weitergabebefugnis auf Tatsachen ein, "die den Schluß einer verfassungsfeindlichen, die demokratischen Freiheiten zielstrebig untergrabenden Hetze oder eines 
Das hölzerne Eisen der legal-illegitimen Verfassungsfeindschaft würde dadurch in seiner praktischen Bedeutung erheblich zusammenschmelzen. Dieser verfassungsschutzrechtliche Ansatz ist von der beamtenrechtlichen Seite her dadurch zu ergänzen, daß der vorhin skizzierte favor civis, der zu einer, übrigens auch vom Bundestag bekräftigten ${ }^{137}$ und mit dem Extremistenbeschlu $B$ des Bundesverfassungsgerichts voll verträglichen ${ }^{138}$ Vermutung für die Verfassungsloyalität des Bewerbers führt, ernstgenommen wird. D. h., daß in allen Fällen, in denen der lebenszeitlichen Verbeamtung ein Vorbereitungsoder Probedienst voran geht, das Vertrauensprinzip in Verbindung mit dem Grundsatz der Freiheit von Angst die routinemäßige sog. „Karteianfrage“ bei den Ämtern für Verfassungsschutz verbietet, sofern nicht im Einzelfall konkrete Verdachtsmomente auftauchen. Die Vorbereitungs- oder Probephase bietet ausreichende Möglichkeiten, das Eindringen wirklicher Verfassungsfeinde in die Beamtenschaft abzuwehren.

\section{Uberverfassungsgesetzlicher Notstand?}

„Schutz der Verfassung“ bedeutet mehr als nur Verteidigung einer abstrakten Normenordnung, bedeutet, wie auch die For-

tätlichen Angriffs zuverlässig tragen. Die Mitgliedschaft in einer nicht verbotenen Partei, die Teilnahme an einer erlaubten Demonstration, die Unterzeichnung einer nach Form und Inhalt nicht zu beanstandenden Resolution oder Petition und andere von der Verfassung und vom geltenden Recht gewährleistete politische Willensbekundungen oder Betätigungen reichen hierfür nicht aus. Für die Weiterleitung derartiger Informationen fehlt dem Bekl. nicht nur der formelle Gesetzesauftrag, sondern auch die materielle Berechtigung." Schwenkte die Praxis der beamtenrechtlichen Treueprüfung auf diese Linie ein, so wäre das sog. Radikalenproblem wohl bald kein Problem mehr.

137 Entschließung des Deutschen Bundestages vom 24. 10. 1978, Ziff. 1. Aufgenommen in die Grundsätze der Bundesregierung für die Prüfung der Verfassungstreue vom 19. 5. 1976, wiedergegeben bei Frisch, a. a. O. (o. N. 95).

${ }_{138} \mathrm{Ihr}$ entsprechen die Ausführungen in BVerfGE 39, $356 \mathrm{f}$. S. 355 führt das Gericht zwar aus, daß Treuepflicht und Prüfung des Bewerbers auf seine Treuegewährbietung für jedes Beamtenverhältnis gelten. Nirgends aber ist gesagt, daß etwa die Prüfung in allen Fällen nur durch Anfrage bei den Verfassungsschutzbehörden erfolgen könne und müsse. Vielmehr gelten hierfür, soweit Beamte auf Widerruf und Probe in Betracht kommen, die Ausführungen auf S. 356, die deshalb auch für diesen Personenkreis "tragende Gründe" und nicht nur - so aber Richter Wand, a. a. O., S. 390 - obiter dicta sind. Sie stimmen mit den Erwägungen auf S. 352 überein: eben weil sich der Staat von Widerrufs- und Probebeamten leichter als von Beamten auf Lebenszeit und nicht nur im förmlichen Disziplinarverfahren trennen kann, vgl. § 23 BRRG, ist es gerechtfertigt, die Modalitäten der Treueprüfung bei jenen anders und einfacher zu gestalten. 
mel "Bestand und Sicherheit des Bundes oder eines Landes" zeigt, den Schutz realer Rechtsgüter bis hin zur territorialen Integrität. Außergewöhnlich intensive oder massenhafte Angriffe auf diese Rechtsgüter führen, wie sich aus den Art. 35 Abs. 2, 87 a Abs. 4, 91 und 115 a ff. GG ergibt, zu einer Konzentration und Zentralisation der staatlichen Kräfte, meistens mit Vorrangkompetenz der Exekutive. Einzelheiten wären unter dem Titel „Recht des Ausnahmezustandes“ zu erörtern, jedenfalls verläßt man damit den Rahmen der rechtsstaatlichen Verfassung nicht. Diese Grenze überschreitet man jedoch, wenn man sich, wie der Bundesminister des Innern im Abhörfall Traube hilfsweise ${ }^{140}$ oder wie andere staatliche Stellen bei der Kontaktsperre vor Erla $\beta$ des Kontaktsperregesetzes und im Abhörfall im Stammheimer Gefängnis auf einen „übergesetzlichen Notstand" - richtig dann: „überverfassungsgesetzlichen Notstand" - beruft, der staatliche Notmaßnahmen bei sonst fehlender einfachgesetzlicher oder verfassungsrechtlicher Handlungsermächtigung rechtfertigen soll ${ }^{141}$. Es führt von der damit wieder akut gewordenen klaren, klassischen ${ }^{142}$ Frage nach der Existenz eines vor- oder überverfassungsrechtlichen (nicht nur: überverfassungsgesetzlichen!) ungeschriebenen Staatsnotrechtes ab ins Seitendickicht strafrechtlicher Rechtswidrigkeitstheoreme, wenn man in diesem Zusammenhang auf $\S 34$ StGB als Rechtfertigungsgrund rekurriert. Sollte

139 Vgl. Art. 73 Nr. 10 GG, $\$ 3$ Abs. 1 Nr. 1 BVerfschG. Art. 91 Abs. 1 GG: „Bestand oder die freiheitliche demokratische Grundordnung" ... Vgl. auch die Legaldefinition in $\$ 92$ StGB.

${ }_{140}$ W. Maihofer, BMI, am 1. 3. 1977 vor dem Innenausschuß des Deutschen Bundestages: ... „Selbst wenn die Verfassung diese Einschränkung durch die Gemeingefahr-Abwägung wie den Gemeinwohl-Vorbehalt nicht vorgesehen hätte, würde sich die Eingriffsmöglichkeit aus dem Gesichtspunkt des „übergesetzlichen Notstandes ergeben haben, um die Abwehr der hier gegenwärtigen unabsehbaren Gefahren zu rechtfertigen." Zit. nach Brückner/Schmitt, a. a. O. (N. 104), S. 87.

${ }_{141}$ Zutr. A. Arndt, a. a. O. (o. N. 80), S. 900. Vgl. ferner J. Seifert, Die Abhör-Affäre 1977 und der Überverfassungsgesetzliche Notstand. Eine Dokumentation zum Versuch, Unrecht zu Recht zu machen, KJ 1977, S. $105 \mathrm{ff}$. mit vielen Lit.nachweisen, auf die verwiesen wird. A. Roßnagel, Der alltägliche Notstand, KJ 1977, S. $257 \mathrm{ff}$; W. Holtfort, Bleibt immer noch freiheitlicher Rechtsstaat genug? in: Vorgänge $30,6 / 77$, S. 7 ff.; $M$. Schröder, Staatsrecht an den Grenzen des Rechtsstaats, AöR 103 (1978), S. $121 \mathrm{ff}$; E. $-W$. Böckenförde, Der verdrängte Ausnahmezustand, NJW 1978, S. $1881 \mathrm{ff}$.

142 Das Bild der für einen Augenblick durch einen Schleier verhüllten Freiheit, das C. Schmitt, Verfassungsrechtliche Aufsätze, 1958, S. 261, benützt, stammt von Montesquieu, a. a. O. Buch 12, Kap. 19; vgl. auch Seifert, a. a. O., 120, N. 94. 
diese Vorschrift direkt oder analog angewendet werden, so gilt, wie vor allem Amelung und Kirchhof überzeugend dargelegt haben ${ }^{143}$, daß strafrechtliche, dem Einzelnen zugute kommende Rechtfertigungsgründe niemals staats- oder verwaltungsrechtliche Handlungskompetenzen für Hoheitsträger zu begründen vermögen. Sollte die Vorschrift aber als Ausdruck eines überpositiven allgemeinen Rechtsgedankens der Güterabwägung ins Feld geführt werden ${ }^{144}$, so wäre das nur eine überflüssige Verkleidung des Problems. Also: Kann es in der Rechtsordnung des durch das Grundgesetz verfaßten Staates eine Norm geben, die jenseits aller geschriebenen und gewohnheitsrechtlichen Rechtssätze, jenseits des normierten Ausnahmezustandes, staatliches Handeln ,aus der dem Staat wesensimmanenten Obliegenheit der Selbsterhaltung "145 auch bei klarer Verletzung geltenden Verfassungsrechts erlaubt? Gilt der Satz „Not kennt kein Gebot!“ für die Amtsträger im Verfassungsstaat? Auf die Gefahr hin, von der einschlägigen, dem Ernst der Frage freilich nicht ganz angemessenen Polemik in der Staatstheorie ebenfalls einer "Art von Hurrapatriotismus der Freiheit"146 geziehen $z u$ werden, möchte ich die Frage verneinen. Dabei möchte ich mich nicht nur in die rechtsstaatsbewußte Tradition großer Vorbilder wie Georg Jellinek ${ }^{147}$, Richard Thoma ${ }^{148}$, Hans Kelsen ${ }^{149}$ und Adolf Arndt ${ }^{150}$ einrei-

${ }^{143}$ K. Amelung, Erweitern allgemeine Rechtfertigungsgründe, insbesondere $\S 34$ StGB, hoheitliche Eingriffsbefugnisse des Staates? NJW 1977, S. $833 \mathrm{ff}$. Derselbe, Nochmals: § 34 StGB als öffentlichrechtliche Eingriffsnorm? NJW 1978, S. 623. P. Kirchhof, Polizeiliche Eingriffsbefugnisse und private Nothilfe, NJW 1978, S. $969 \mathrm{ff}$. Gegen Amelung, aber nicht überzeugend: $R$. Lange, Terrorismus kein Notstandsfall? NJW 1978, S. 784 ff. Kritisch zu Lange auch Böckenförde, a. a. O., S. 1883 , N. 21 , dort w. N.

144 So offenbar Schröder, a. a. O., S. 138.

145 E. R. Huber, Zur Lehre vom Verfassungsnotstand in der Staatstheorie der Weimarer Zeit, in: Festschrift W. Weber, 1974, S. 31 ff., 35.

${ }^{146}$ H. Krüger, Rechtsstaat - Sozialstaat - Staat oder: Rechtsstaat + Sozialstaat ergeben noch keinen Staat, 1975, S. 10.

147 G. Jellinek, Allgemeine Staatslehre, 6. Neudruck der 3. Aufl. 1959 , S. 359.

${ }_{148}$ R. Thoma, Der Vorbehalt der Legislative und das Prinzip der Gesetzmäßigkeit von Verwaltung und Rechtsprechung, in: Anschütz/ Thoma (Hrsg.), Handbuch des Deutschen Staatsrechts, II. Band, 1932, S. 232: „Ein Staatsnotrecht über das verfassungsrechtlich regulierte hinaus kann es im geordneten republikanischen Verfassungsstaat nicht geben, so wie es auch schon im Kaiserreich und selbst in den konstitutionellen Monarchien (deren Struktur immerhin Zweifel erlaubte) nicht gegolten hat." Mit N. in Anm. 29.

$148 \mathrm{H}$. Kelsen, Allgemeine Staatslehre, 1925: "Man spricht von einem Staatsnotrecht und argumentiert etwa in der Weise: der Staat muß eben leben, und wenn dies auf rechtmäßigem Wege unmöglich 
hen, sondern zum Abschluß noch einmal auf den wechselseitigen Bedingungszusammenhang von freiheitssicherndem Rechtsstaat und staatshervorbringender freiheitlicher Demokratie hinweisen, wie er in der Dreiheit: Freiheit von Angst, Vertrauen und Bereitschaft zum Engagement begründet ist. Die rechtsstaatliche Republik oder der demokratische Verfassungsstaat trägt seine Legalität nicht als ein Akzidens, das er in der Stunde der Gefahr, die, innerhalb der Verfassung, durchaus die Stunde der Exekutive sein mag, wie ein beengendes Kleid abzustreifen vermöchte, um darunter als mächtige „Staatlichkeit an sich" zum Vorschein zu kommen. Unter der Geltung des Grundgesetzes ist Staatsgewalt immer und nur verfaßte Staatlichkeit. Dieser Staat verlöre seine Identität, gäbe er diese Verfaßtheit - und sei es auch nur eine Sekunde lang - preis. Was übrig bliebe, wäre nicht Staatsgewalt, schon gar nicht „eigentliche Staatlichkeit", sondern allenfalls Gewalt schlechthin, ohne rechtliche Verbindlichkeit, der verfassungstreue Bürger u. U. Widerstand leisten dürften, Art. 20 Abs. 4 GG. Daß der demokratische Verfassungsstaat ein solches Auseinandertreten von rechtsstaatlicher Legalität und einer schieren „Staatlichkeit", die sich vielleicht auf eine Grundwerte-bezogene Legitimität stützt, nicht kennt und auch nicht kennen kann, hat niemand klarer dargelegt als, vor eben dieser Vereinigung im Jahre 1924, Carl Schmitt ${ }^{151}$. Die scheinbare Schwäche der

ist, sind die höchsten Organe des Staates und vor allem das höchste Organ, der Monarch, verpflichtet alles zu tun, um den Staat zu erhalten. Dabei handelt es sich natürlich nur um ein politisch-naturrechtliches Räsonnement, das sich - wie gewöhnlich - als positives Recht zu geben versucht."

150 A. Arndt, z. B. a. a. O. (o. N. 80), S. 899: „Ein Verfassungsstaat hat keine andere "Raison" als seine Verfassung ... Der ärgste Angriff auf die Rechtlichkeit des Staates ist die wieder und wieder aufflackernde Angst, es könne doch höchst-politische Aufgaben geben, die sich einer rechtlichen Normierung entzögen. Mit der letzten Gewißheit, daß es keinen Primat der Politik vor dem Recht geben kann, steht und fällt der Rechtsstaat."

E.-W. Böckenförde, a. a. O. (o. N. 141), S. 1883: „Eine solche offene Generalermächtigung verstößt gegen die Grundstruktur einer rechtsstaatlichen Verfassung". Vgl. auch das Folgende dort.

151 Vgl. C. Schmitt, Die Diktatur des Reichspräsidenten nach Artikel 48 der Weimarer Verfassung, Anhang zu: derselbe, Die Diktatur, 2. Aufl. 1928, S. 213 ff., 236, 238. Schmitt betont den prinzipiellen Unterschied zwischen der Stellung eines souveränen Fürsten und derjenigen eines republikanischen Präsidenten. In der Monarchie ist "neben der ordentlichen, verfassungsmäßig geteilten Gewalt noch eine außerordentliche, durch die verfassungsmäßige Regelung, niemals restlos zu erfassende staatliche Gewalt latent vorhanden." Eben dies ist in einem (demokratischen) Verfassungsstaat nicht der 
rechtsstaatlichen res publica, daß sie nicht über ihren eigenen Schatten: die Legalität aller Staatsgewalt, springen kann, ohne ihre Identität zu verlieren, möge sich als ihre eigentliche Stärke erweisen: Sie befreit von der Angst vor dem Leviathan als vor einer unmeßbaren Ubermacht, die sich anderenfalls stets mit dem Schein des Rechts (kraft der staatsnotrechtlichen "Legalitätsreserve") zu umgeben vermöchte; sie stärkt das Vertrauen des Bürgers in die Rechtmäßigkeit des Handelns der Organwalter, indem sie deren Gesetzes- und Verfassungstreue zur absoluten Handlungsmaxime setzt, ohne "flexible" situative Abstriche und Lockerungen ${ }^{152}$, und sie stimuliert die Wachsamkeit und Bereitschaft der Bürger ${ }^{153}$, die Staatsgewalt von Rechts wegen zur Abwehr auch äußerster Bedrohungen instand zu setzen. Solange in diesem Sinne Staatsschutz immer zugleich Verfassungsschutz ist und umgekehrt, solange ist die

Fall: „Mit einer rechtsstaatlichen Verfassung ist eine souveräne Diktatur eben unvereinbar. Eine republikanische Verfassung, welche sie vorbehalten wollte, wäre als Ganzes ein Provisorium und Precarium in der Hand eines souveränen Diktators“, ... S. 238. Vgl. auch den Kontext dort.

152 Unklar ist die Fragestellung bei Schröder, a. a. O. (N. 141), S. 127, „ob nicht je nach Art der Ausnahmelage die für die Normallage geltenden strikten rechtlichen Bindungen der staatlichen Organe zurückgenommen werden müssen, wenn der Schutz der Verfassung und der Rechtsordnung nur durch eine Lockerung solcher Bindungen erreicht werden kann." Eine je nach Schwierigkeit der Lage immer wieder praktizierte Durchbrechung des Gesetzmäßigkeitsprinzips kann damit ja wohl im Ernst nicht gemeint sein es wäre das Ende des Rechtsstaates. Ist aber an Freiheitsbeschneidungen im Wege gesetzgeberischer Salamitaktik gedacht, so schlägt hiergegen die von Böckenförde (a. a. O., o. N. 43) exemplarisch formulierte Kritik durch.

153 Hier liegt das Arbeitsfeld des „positiven“ oder „informativen“ Verfassungsschutzes, der edukatorischen "Staatspflege“, vgl. o. N. 108.

154 Das schließt eine Kluft zwischen "staatstragender" Beamtenschaft und "gewöhnlichen“, in den "Niederungen“ der (Partei)politik befangenen Bürgern im Sinne der von uns kritisierten Zwei-Sphären Theorie, o. N. 57, aus. Trotz der von Hennis, vgl. o. zu N. 76, nicht ohne Anknüpfungsmomente in der Realität beschworenen Vision des autoritären Verwaltungsstaates möchte ich bezweifeln, daß W. Webers düstere Staatsbild-Beschreibung aus dem Jahre 1967 heute die Bewußtseinslage des Durchschnittsbürgers trifft. „Es ist das Bild vom politischen Gemeinwesen als einem potentiell unverständigen, anmaßenden und bösartigen Wesen, das ständig auf dem Sprunge ist, dem Individuum mit Belästigungen und Ungerechtigkeiten zu Leibe zu gehen" usw. Vgl. W. Weber, Der deutsche Bürger und sein Staat, in: Spannungen und Kräfte im westdeutschen Verfassungssystem, 3. Aufl. 1970, S. 339. Staatsvergötzung auf der einen, Staatsverhetzung auf der anderen Seite - wir Deutschen 
Verfassungstreue aller Bürger ${ }^{154}$ — wie der Schwabe Justinus Kerner schon vor 150 Jahren gesungen hat ${ }^{155}$ - der kostbarste, beste und dauerhafteste Schutz der Verfassung.

von 1978 haben Grund und Chancen, diesen selbstzerstörerischen Teufelskreis endlich zu verlassen!

155 Justinus Kerner, Sämtliche Werke in acht Bänden, Hrsg. v. W. Heichen, 3. Band, Berlin o. J., S. 196 f.: Der reichste Fürst: . . "Eberhard, der mit dem Barte, / Württembergs geliebter Herr, / Sprach: Mein Land hat kleine Städte, / Trägt nicht Berge silberschwer; / / Doch ein Kleinod hält's verborgen: - / Daß in Wäldern, noch so groß, / Ich mein Haupt kann kühnlich legen / Jedem Unterthan in SchoB. / / Und es rief der Herr von Sachsen, / Der von Bayern, der vom Rhein: Graf im Bart: Ihr seid der reichste, / Euer Land trägt Edelstein!" Es gilt, solche patriarchalisch-monarchische Untertänigkeit in demokratisches Bürgerbewußtsein zu verwandeln. 
Leitsätze des Berichterstatters über:

\section{Verfassungstreue und Schutz der Verfassung}

$Z u$ I. 1. Angesichts einer zunehmenden Tendenz, rechtliche Sanktionen an Tatbestände aus dem Innenbereich, an Gesinnungen, Absichten und Wertungen zu knüpfen, stellt sich die Frage nach den prinzipiellen Schranken des staatlichen $\mathrm{Zu}$ griffs auf das forum internum.

Zu II. 2. Der in der sog. Grundwerte-Diskussion, aber auch sonst zu beobachtende Versuch, die gegenständliche Reichweite des Mehrheits-Prinzips durch eine Ausweitung des Bereichs des "Unabstimmbaren", des legislativ Unverfügbaren einzuschränken, bringt grundlegende Verfassungsprinzipien miteinander in Konflikt: die prozeduralen Prinzipien der Mehrheitsentscheidung, der Pluralität, Alternativität und Repräsentation stehen gegen die inhaltlichen gemeinsamer Wertüberzeugungen.

Zu III. 3. Die inhaltlichen Konkretisierungen der Grundwerte, das Ausmaß der Wertgebundenheit und Werteverantwortung des Staates, ferner die normative Funktion und Reichweite des „Prinzips der streitbaren Demokratie“ sind umstritten.

4. So wie man mit einer aus "Grundwerten“, $z u$ Recht oder $z u$ Unrecht, bezogenen Legitimitätsbehauptung sich über das demokratische Mehrheitsprinzip hinwegzusetzen versucht, so dient die Berufung auf ein generalisiertes Streitbarkeitsprinzip dazu, das rechtsstaatliche Legalitätsprinzip aus den Angeln zu heben. Beides verdient Kritik.

5. Das ursprünglich nur zum Schutz des (partei)politischen Meinungskampfes und Willensbildungsprozesses für notwendig gehaltene Streitbarkeitsprinzip entwickelt sich allmählich zu einer Rundum-Waffe des Staatsschutzes.

6. Gegenüber einem verabsolutierten Sicherheits-Denken ist daran zu erinnern, 1. daß es totale Sicherheit ohne Risiko nicht geben kann und 2. daß die streitbare Demokratie ihren legitimierenden Grund darin findet, daß sie eine freiheitliche Demokratie bleibt. 
Zu IV. 7. Die in der Rechtsprechung vom Bürger erwartete Verteidigungsleistung für die Demokratie bleibt unbestimmt. Es handelt sich nur um eine „Verfassungserwartung“, nicht um eine individuell justiziable, sanktionierbare Rechtspficht.

8. Unentbehrlich ist ein dauerhafter "Wille zur Verfassung“, der sich jedoch nicht herbeikommandieren läßt.

Zu V. 9. Zur Klärung der Grenzen der streitbaren Demokratie wie auch der grundsätzlichen Position des Berufsbeamtentums innerhalb des demokratischen Gemeinwesens ist nach der von der geschriebenen Verfassung vorausgesetzten Grundverfassung des Bürgers $z u$ fragen.

10. In diesem Sinne wird vorgeschlagen, den Katalog der Elemente der freiheitlichen demokratischen Grundordnung um drei „vorinstitutionelle" Elemente zu ergänzen: 1 . Freiheit von Angst, 2. Vertrauen, 3. Bereitschaft zum demokratischen Engagement. Diese Elemente bauen aufeinander auf.

11. Freiheit von Angst setzt voraus, daß die Gesetze dem Bürger möglichst weitgehend nur meßbares, jedenfalls beobachtbares, damit beweisbares äußeres Verhalten abverlangen, nicht aber Gewissensproben, Uberzeugungen und Gesinnungen.

12. Das Grundmuster der Bürger-Staat-Beziehung muß von wechselseitigem Vertrauen geprägt sein. Dem favor legis entspricht der favor civis, eine Vermutung für die Verfassungstreue des Bürgers.

13. Bereitschaft $z u$ demokratischem Engagement ist sowohl Bedingung als auch Bedingtes einer Verfassung offener Kritikmöglichkeit, pluralen Ideen- und Interessenwettbewerbes, politischer Toleranz und der Revidierbarkeit staatlicher Entscheidungen.

Zu VI. 14. Eine den Prinzipien der Angstfreiheit und der vertrauensvollen Bereitschaft zum demokratischen Engagement gerecht werdende Lösung des Problems der Fernhaltung extremistischer Bewerber vom öffentlichen Dienst kann nur mit sorgfältigen Einzelfallprüfungen arbeiten.

15. Die Unklarheit über die Stellung der Ämter für Verfassungsschutz im Verwaltungsgefüge offenbart sich im Streit um die Frage, ob diese Äter als "Polizei" (im materiellen Sinne) anzusehen seien. Der Streit ist für die Lösung der drängendsten Einzelfragen unfruchtbar. 
16. Allgemeine Prinzipien des Polizeirechts wie das Ubermaßverbot und der Grundsatz willkürfreier Ermessensausïbung gelten schon kraft Verfassungsrechts auch für den nachrichtendienstlichen Verfassungsschutz.

17. Für jede einzelne Phase der Tätigkeit des nachrichtendienstlichen Verfassungsschutzes, für das Beschaffen, das Speichern, das (interne) Auswerten und das Weitergeben von Informationen, sind der Charakter als Grundrechtseingriff, die Rechtsgrundlagen und ihre Tragweite gesondert zu bestimmen, wobei insbesondere in Fällen der Amtshilfe die Grundsätze des Persönlichkeitsschutzes bei der Datenverarbeitung zu beachten sind.

18. Der Grundsatz des elementaren wechselseitigen Vertrauens im Verhältnis Bürger - Staat gebietet, daß der Verfassungsschutz nicht zu einer Institution des systematischen generellen Mißtrauens werden darf, die jeden Bürger zunächst einmal als potentiellen Verfassungsfeind ansieht.

19. Nicht jede Kritik an bestehenden verfassungsrechtlichen Verhältnissen erfüllt schon den Tatbestand der verfassungsfeindlichen Bestrebung im Sinne der Gesetze über die Verfassungsschutzämter. Deshalb sind solche Informationen von der Weitergabe auszuschließen, deren Gehalt unter der vom Bundesverfassungsgericht vorgezeichneten Schwelle aktiv-aggressiver Grundordnungsbekämpfung im Sinne der Art. 18 und 21 GG bleibt.

20. Der favor civis ist ernst zu nehmen. Er führt dazu, daß in allen Fällen der Beamteneinstellung außerhalb des sicherheitsempfindlichen Bereiches, in denen der Verbeamtung auf Lebenszeit ein Vorbereitungs- oder Probedienst vorangeht, eine Anfrage an das Amt für Verfassungsschutz nur noch erfolgen soll, wenn im Einzelfall Verdachtsmomente auftauchen.

21. Ein überverfassungsgesetzlicher Notstand, der die Berufung auf ein überverfassungsrechtliches ungeschriebenes Staatsnotrecht erlaubte, ist aus rechtslogischen und rechtsstaatstheoretischen Gründen abzulehnen. Unter der Geltung des Grundgesetzes ist Staatsgewalt immer nur verfaßte Staatlichkeit. Der demokratische Verfassungsstaat kennt rechtens ein Auseinandertreten von Legalität und "schierer" oder nur auf Argumente der Legitimität gestützter Staatlichkeit nicht.

22. Der beste und dauerhafteste Schutz der Verfassung ist die Verfassungstreue aller Bürger. 

2. Mitbericht von Professor Dr. Hans Hugo Klein, Göttingen*) Verfassungstreue und Schutz der Verfassung Inhalt

Seite

I. Der Gegenstand des Verfassungsschutzes . . . . . . . . 55

1. Zum Begriff der freiheitlichen demokratischen Grundordnung ................... 55

2. Die Staatlichkeit der Bundesrepublik Deutschland als weiteres Schutzgut ............... 61

3. Die "streitbare Demokratie" des Grundgesetzes . . . . 63

4. Die Rechtsstellung des Verfassungsfeindes . . . . . . 71

II. Die Pflicht des Staates zum Schutz der Verfassung . . . 72

1. Grundsatz . . . . . . . . . . . . . . . 72

2. Parteiverbot . . . . . . . . . . . . 73

3. Verbot von Vereinigungen und Ersatzorganisationen . 78

III. Verfassungstreue und Bürgerpflicht . . . . . . . . . . . 80

1. Keine allgemeine Verfassungstreupflicht . . . . . . . 80

2. Die allgemeine Mißbrauchsschranke aktiver Verfassungsfeindlichkeit . . . . . . . . . . . . . 81

3. Die Verfassungstreupflicht der Beamten . . . . . . . 83

IV. Der administrative Verfassungsschutz . . . . . . . . . . 90

1. Parlamentarische Kontrolle . . . . . . . . . . . . . 90

2. Rechtsgrundlagen .. . . . . . . . . . . . . . 92

V. Verfassungsschutz und innerer Notstand . . . . . . . . . 99

VI. Verfassungsschutz und Verfassungspflege . . . . . . . . 104

* Herrn Wiss. Assistenten Assessor Dierk-Peter Steffan habe ich fur seine wertvolle Unterstützung bei der Vorbereitung dieses Referates herzlich zu danken. 
"Gefahren für die Constitution" können "theils von oben, theils von unten, d.h.... von der Regierung oder von den Regierten herkommen" und "in inneren Verhältnissen oder in äußeren Einwirkungen ihren Grund haben". Diese Feststellung Carl von Rottecks ${ }^{1}$ bezeichnet die Reichweite unserer Thematik auch heute noch in zutreffender Weise ${ }^{2}$, obzwar die uns bekannten Strategien der Systemüberwindungs an Raffinement die zu Zeiten des großen Liberalen üblich gewesenen weit übertreffen ${ }^{4}$.

Aus dem Spektrum der möglichen Gefahrenlagen und denkbaren Vorkehrungen kann ich nur eine kleine Auswahl behandeln. Der äußere Notstand bleibt beiseite. Die Garantien des Grundgesetzes gegen Verletzungen des Verfassungsrechts durch staatliche Organe sind zu großer Vollkommenheit entwickelt und funktionieren - im allgemeinen ${ }^{5}$ - verläßlich. Ebenso sind - von wenigen Ausnahmen abgesehen ${ }^{6}$ - Span-

1 v. Aretin/v. Rotteck, Staatsrecht der constitutionellen Monarchie, 2. Aufl., 3. Bd. 1840, S. 4.

2 Vgl. etwa U. Scheuner, Der Verfassungsschutz im Bonner Grundgesetz in: Um Recht und Gerechtigkeit, Festgabe für E. Kaufmann, 1950 , S. 313 ff., 321.

s H. Schelsky, Die Strategie der "Systemüberwindung“. Der lange Marsch durch die Institutionen in: Systemüberwindung, Demokratisierung, Gewaltenteilung. Grundsatzkonflikte der Bundesrepublik, 2. Aufl. 1973, S. $19 \mathrm{ff}$. Schelsky (a. a. O., S. 23) beschreibt sie als die Perversion der die Institutionen von Gesellschaft und Staat tragenden moralischen und politischen Grundwerte und -reaktionen $\mathrm{zu}$ Kampfmitteln und als den Versuch, so die Stabilität dieser Institutionen mit Hilfe ihrer eigenen Wertüberzeugungen aus den Angeln $\mathrm{zu}$ heben.

${ }_{4} \mathrm{Zu}$ den durch die Logik unseres sozialen Systems bedingten, inzwischen vielfach realisierten Gefahrenmomenten vgl. E. Forsthoff, Die Bundesrepublik Deutschland - Eine Realanalyse (1960) und Verfassung und Verfassungswirklichkeit der Bundesrepublik (1968) in: ders., Rechtsstaat im Wandel, Verfassungsrechtliche $\mathrm{Ab}-$ handlungen 1954-1973, 2. Aufl. 1976, S. 1 ff., $25 \mathrm{ff}$.

5 Einzelne Mängel wie beispielsweise die lange Dauer der Verfahren vermögen an diesem Gesamteindruck nichts zu ändern.

${ }^{\circ}$ Hier ist an die Diskussion um die Rolle des Bundesrates zu erinnern, die infolge der die Jahre nach 1969 kennzeichnenden, auch die Verfassungsebene tangierenden politischen Spannungen geführt worden ist, sowie an die gelegentlich festzustellende Weigerung, grundsätzliche Entscheidungen des BVerfG, deren Rechtskraft und Bindungswirkung sich formal auf das Recht eines anderen Landes erstrecken, zu beachten. So weigerte sich die Freie Hansestadt Bremen jahrelang, ihre verfassungswidrige Universitätsstruktur dem Hochschulurteil des BVerfG (BVerfGE 35, $79 \mathrm{ff}$.) entsprechend zu korrigieren. Es bedurfte eines weiteren Normenkontrollverfahrens vor dem BremStGH (Urteil vom 6. 6. 1977, DOV 1977, S. 595 ff.) um Bremen zu veranlassen, wenigstens die gröbsten und offenkundigsten Widersprüche zu beseitigen, allerdings auch mit einem Höchstmaß an Raffinesse Regelungen auszutüfteln, die die Konsequenzen 
nungen im föderativen Bereich nicht zu verzeichnen. Das Kapitel Verfassungsstörungen bedarf seiner Vielschichtigkeit wegen gesonderter Behandlung?. Das Feld der Untersuchung ist damit auf die Frage nach dem Gegenstand des Verfassungsschutzes und die Behandlung einiger seiner Insrumente eingeengt.

\section{Der Gegenstand des Verfassungsschutzes}

\section{Zum Begriff der freiheitlichen demokratischen Grundord- nung}

Wo das Grundgesetz vom Schutz der Verfassung spricht nennt es als dessen Gegenstand regelmäßig die freiheitliche demokratische Grundordnung sowie den Bestand und die Si-

der verfassungsgerichtlichen Urteile wie des Hochschulrahmengesetzes zu umgehen trachten. - Auch die Freie und Hansestadt Hamburg bedurfte einer verfassungsgerichtlichen Anmahnung (BVerfGE 43, 242 ff.), ehe sie sich bequemte, dem Hochschulurteil des Gerichts Folge zu geben. Auch die von Land zu Land divergierende Praxis bei der Einstellung von Extremisten in den öffentlichen Dienst gehört hierher. Sie nimmt besonders ernste Formen an, wenn ein Land die in einem anderen Land ergangene höchstrichterliche Entscheidung, die die Nichteinstellung eines bestimmten Bewerbers wegen mangelnder Gewähr der Verfassungstreue rechtskräftig gutheißt, nicht respektiert. Vgl. den Fall der Juristin Charlotte NieB, die trotz rechtskräftiger Ablehnung ihrer Bewerbung für den bayerischen Staatsdienst durch den BayVGH im Staatsdienst des Landes Nordrhein-Westfalen beschäftigt wird; s. FAZ vom 23. 2. 1978 , S. 1 .

7 Die klassischen Themen dieses Bereichs sind im Bericht der Enquete-Kommission Verfassungsreform des Deutschen Bundestages behandelt, BT-Drucks. 7/5924, 3. Kapitel, S. 32 ff. Probleme neuerer Art und größerer Aktualität sind etwa: die ständig abnehmende Transparenz staatlicher Entscheidungsprozesse (dazu E. Forsthoff, Der Staat der Industriegesellschaft, 1971, S. $82 \mathrm{f}$.; vgl. auch ders., Die Bundesrepublik Deutschland [Fn. 4], S. 8); die wachsende Verbandsmacht; der Immobilismus des Parteiensystems. E. Forsthoff hat bekanntlich den Ausfall des Systems der Umverteilung als den eigentlichen Ernstfall, den Ausnahmefall also, des Sozialstaates bezeichnet - z. B. die Bundesrepublik Deutschland (Fn. 4), S. 13; Das politische Problem der Autorität in: Rechtsstaat im Wandel (Fn. 4), S. 14 ff., 21. Es ist daran zu erinnern, daB dieser Ernstfall noch immer nicht eingetreten ist - trotz eines seit Jahren schrumpfenden wirtschaftlichen Wachstums und anhaltender relativ hoher Arbeitslosigkeit. Allerdings knirscht es vernehmlich im Gebälk des Systems: die Defizite in der Sozialversicherung wachsen, ihr Ausgleich durch weitere Anhebungen der Abgaben ist angesichts des hohen Niveaus derselben ebenso begrenzt wie die Möglichkeiten einer Steigerung der Bruttoeinkommen im bisher gewohnten Umfang im Hinblick auf den Arbeitsmarkt, das internationale Lohnniveau und die Kostenbelastung der Unternehmen.

${ }^{8}$ Vgl. vor allem die Legaldefinition in Art. $73 \mathrm{Nr} .10 \mathrm{~b}$ GG. 
cherheit des Bundes oder eines Landes ${ }^{9}$. Unter Hinweis auf die einschlägige Literatur und Rechtsprechung ${ }^{10}$ verzichte ich auf eine detaillierte Analyse des Begriffs der freiheitlichen demokratischen Grundordnung. Jedoch ist die Streitfrage zu behandeln, ob der Begriff der freiheitlichen demokratischen Grundordnung mit dem Gegenstand der Unantastbarkeitsgarantie des Art. 79 Abs. 3 GG identisch ist ${ }^{11}$.

- Vgl. H. U. Evers, BK, Art. 73 Nr. $10 \mathrm{RN} \mathrm{39.} \mathrm{-} \mathrm{Art.} 9$ II GG spricht von der verfassungsmäßigen Ordnung - der Begriff deckt sich richtiger Ansicht nach (vgl. K. Stern, Das Staatsrecht der Bundesrepublik Deutschland, Bd. I, 1977, S. 184, 415) mit dem der freiheitlichen demokratischen Grundordnung; der Schutz des Bestandes und der Sicherheit von Bund und Ländern ist durch die Erwähnung der Strafgesetze (Hoch- und Landesverrat) bzw. des Verstoßes gegen sie als eines weiteren Verbotsgrundes einbezogen. Vgl. ferner Art. 10 II, 11 II, 18 GG; Art. 20 IV GG spricht von "dieser Ordnung" und meint damit die in Art. 20 I - III definierte Ordnung sie ist wiederum identisch mit der freiheitlichen demokratischen Grundordnung (dazu etwa $R$. Herzog in: Maunz/Dürig/Herzog/ Scholz, Das Grundgesetz, Art. 20 RN 223, 227, 232); Art. 21 II, 28 IV, $73 \mathrm{Nr} .10 \mathrm{~b}, 87$ a IV, 91 I, 98 II GG. Die im einzelnen unterschiedliche Formulierung ist nicht $\mathrm{zu}$ übersehen. So wird etwa in Art. 18 GG nur von der freiheitlichen demokratischen Grundordnung gesprochen, in Art. 10 II und $73 \mathrm{Nr} .10 \mathrm{~b}$ GG werden freiheitliche demokratische Grundordnung und Bestand bzw. Sicherheit des Bundes oder eines Landes nebeneinander erwähnt, ähnlich Art. 11 II, 21 II, 87 a IV u. 91 I GG, allerdings ohne Erwähnung der Sicherheit. Die Unterschiede erklären sich $\mathrm{z}$. T. sicherlich aus der verschiedenen Entstehungszeit der genannten Vorschriften und dürften insoweit ohne Bedeutung sein. Ob die Nichterwähnung des Bestandes des Staates in Art. 18 GG den Anwendungsbereich dieser Bestimmung etwa im Vergleich zu Art. 21 II GG einschränkt, mag hier dahinstehen. Hingewiesen sei jedoch auf Herzog a. a. O., RN 232, der in bezug auf Art. 20 IV GG zu Recht auf den "(als selbstverständlich mitgeschriebenen) Grundsatz des GG“ aufmerksam macht, „daß die Bundesrepublik Deutschland als Staat besteht", anarchistische wie separatistische Bestrebungen (für die letzteren dürfte das freilich nicht immer zutreffen) aber auf Verfassungsänderungen auf anderem Wege als dem des Art. 79 GG hinauslaufen, damit das demokratische Prinzip in Art. 20 I GG tangieren und den Tatbestand des Art. 20 IV GG erfüllen. S. auch - im gleichen Sinne - J. Isensee, Das legalisierte Widerstandsrecht, S. $17 \mathrm{f}$.

10 Vgl. insbes. BVerfGE 2, 1 ff., $12 \mathrm{f}$; 5 , $85 \mathrm{ff}$., 140, sowie Dürig in: Maunz/Dürig/Herzog/Scholz, Art. 18 RN 52. Im Vergleich zu § 88 II StGB a. F., an den sich das BVerfG in seinen Parteiverbotsurteilen erkennbar anlehnte, formuliert $\S 92$ II StGB n. F. den Grundsatz der parlamentarischen Verantwortlichkeit der Regierung präziser -- „die Ablösbarkeit der Regierung und ihre Verantwortlichkeit gegenüber der Volksvertretung" -, womit nach Stern, a. a. O., S. 420, klargestellt ist, daß z. B. die Forderung nach Einführung eines Präsidialsystems erlaubt ist.

11 Zwar scheint mir, als sei diese Frage für die Praxis von eher geringer Bedeutung, weil einerseits weder prinzipiell gegen den Sozialstaat oder die Republik gerichtete Bestrebungen erkennbar 
Dieser vor allem von Schmitt-Glaeser ${ }^{12}$ befürwortete Bezug liefert zunächst den konkreten Nachweis dessen, was das Grundgesetz selbst der Veränderung schlechthin entzogen wissen will. Jeder Versuch, in die Garantiezone des Art. 79 Abs. 3 GG einzugreifen, wird, mit Isensee ${ }^{13} \mathrm{zu}$ reden, von der Verfassung selbst in die Illegalität gedrängt. Es ist nur logisch ${ }^{14}, \mathrm{da} ß$ der selbst für den verfassungsändernden Gesetzgeber, also „von oben“, unangreifbare Verfassungskern zugleich den Gegenstand des Schutzes bildet, den das Grundgesetz gegen Angriffe auf die Verfassung „von unten“ gewährt. Art. 79 Abs. 3 GG wird so zur zentralen Norm des Verfassungsschutzes ${ }^{15}$. Dadurch wird zugleich, was Skeptiker ${ }^{16}$ gerne betonen, deutlich, daß das Grundgesetz beiden Richtungen, aus denen die freiheitliche demokratische Grundordnung bedroht werden kann, gleichviel Aufmerksamkeit zugewendet hat. In der Tat: die Grundintention der Verfassung zielt, wie Denninger ${ }^{17}$ sagt, ,auf die Freiheit des Bürgers und ihren Schutz, und zwar in doppelter Hinsicht: auf die Freiheit des privaten... Individuums, mithin des ,bourgeois', wie auch... auf die politische Autonomie, auf die Selbstbestimmung des demokratischen, citoyen'“. Um dieser doppelten Zielsetzung willen möchte sie sowohl den citoyen als einzelnen und in der Verbindung mit anderen einzelnen als auch seine demokratische Repräsentanz der Möglichkeit be-

oder in der Wirklichkeit, in der wir leben, auch nur denkbar sind und andererseits Kräfte, die das föderalistische Prinzip grundsätzlich infrage stellen, dieses nur als ein Hindernis, das ihren auf die Beseitigung anderer Verfassungsgrundsätze gerichteten Zielen im Wege steht, zu eliminieren trachten. Für die verfassungsrechtliche Theorie jedoch liegen die Dinge anders.

${ }_{12}$ MiBbrauch und Verwirkung von Grundrechten im politischen Meinungskampf, 1968, S. $46 \mathrm{ff}$.

13 A. a. O., S. 15.

14 So auch G. Roellecke, Verfassungstreue und Schutz der Verfassung, DOUV 1978, S. 457 ff., 460.

15 BVerfGE 30, $1 \mathrm{ff}$., 46 (Sondervotum), im AnschluB an Dürig in Dürig/Evers, Zur verfassungsändernden Beschränkung des Post-, Telefon- und Fernmeldegeheimnisses, 1969, S. 12.

${ }_{16}$ Geradezu apokalyptische Visionen beschwört J. Lameyer, Streitbare Demokratie, 1978, S. 205, für den von ihm befürchteten Fall, daß das BVerfG die Richtung grundgesetzlicher Streitbarkeit einseitig, d.h. unter Schonung freiheitsbeschränkender Aktivitäten des Staates und verschärfter Repression bürgerlicher Freiheiten, definiert. Absurd und deshalb ernsthafter Erörterung nicht bedürftig auch die Thesen von W.-D. Narr und U.-K. Preu $\beta$, über die F. Fuchs/J. Jesse, "Der Streit um die streitbare Demokratie“ in: Aus Politik und Zeitgeschichte, Beilage zur Wochenzeitung "Das Parlament", B 3/78, S. $22 \mathrm{f}$., berichten.

17 Einführung des Herausgebers in: Freiheitliche demokratische Grundordnung I, 1976, S. $18 \mathrm{f}$. 
raubt sehen, sich jene Freiheit - als private wie als politische - selbst zu nehmen ${ }^{18,}{ }^{19}$.

Die Anbindung des Begriffs der freiheitlichen demokratischen Grundordnung an die Unantastbarkeitsgarantie des Art. 79 Abs. 3 GG macht ferner deutlich, daß es bestimmte, mit normativer, nämlich sogar den verfassungsändernden Gesetzgeber und eben deshalb jedermann bindender Kraft ausgestattete Rechtsgrundsätze sind, deren Unangreifbarkeit die Verfassung gewährleisten will ${ }^{20}$. Sind es aber Rechtsnormen,

${ }^{18}$ Es ist daher unstreitig, daß auch und gerade die freiheitsgewährleistenden Elemente des Grundgesetzes, also namentlich der Menschenwürdegehalt der Grundrechte, ein „integraler Bestandteil" (BVerfGE 30, 1 ff., 45, Sondervotum) der freiheitlichen demokratischen Grundordnung sind. Vgl. auch BVerfGE 25, 44 ff., 55 f., zu Art. 5 I: „konstitutionelles Element des Schutzguts".

19 Zum Problem der Legitimation der freiheitlichen demokratischen Ordnung vgl. ergänzend $G$. Roellecke, DOV 1978, S. 459: Anerkennung der Möglichkeit staatlichen Unrechts - sie liegt in der Gewährleistung individuellen Freiheitsschutzes gegen die Staatsgewalt beschlossen.

20 Das BVerfG (vgl. beispielsweise BVerfGE 2, 1 ff., 12: „Grundwerte", „dauernde Grundwerte“, „wertgebundene Ordnung“; 5, 85 ff., 139: Das Grundgesetz habe auf den Schutz eines „eigenen Wertsystems" nicht verzichtet; gewisse Grundprinzipien seien als „absolute Werte“ anerkannt. Später wird der Wertcharakter bekanntlich vor allem den Grundrechten zugesprochen. S. auch die kritische Bemerkung bei Badura, Verfassung, Staat und Gesellschaft in: Bundesverfassungsgericht und Grundgesetz in: BVerfG und GG, Bd. II, hrsg. von Chr. Starck, 1976, S. 5) hat mit seiner in der Literatur vielfach aufgegriffenen Wertterminologie zur Klarstellung dieses Sachverhalts nicht beigetragen und manches Mißverständnis auch seiner eigenen Rechtsprechung damit erleichtert. C. Schmitt, Die Tyrannei der Werte in: Säkularisation und Utopie, Ebracher Studien, 1967, S. 37 ff.; E. Forsthoff, Die Umbildung des Verfassungsgesetzes in: Rechtsstaat im Wandel (Fn. 4), S. $130 \mathrm{ff}$., und E. Denninger, Freiheitsordnung-Wertordnung-Pflichtordnung, $\mathrm{JZ}$ 1975, S. $545 \mathrm{ff}$., haben in bemerkenswerter Übereinstimmung an dieser Terminologie Kritik geübt. Hier sei nur daran erinnert, daß der Wert vom Bürger nicht wie der Rechtssatz nur Beachtung, sondern vielmehr Identifizierung und Realisierung verlangt, ihn also in einem sehr viel intensiveren Grade in Pflicht nimmt, als dies durch eine freiheitsgewährleistende Rechtsnorm geschieht. Das aber ist von der die Freiheit des Individuums in den Mittelpunkt stellenden Verfassung der Bundesrepublik Deutschland nicht gewollt, jedenfalls nicht, soweit es sich um den Bürger handelt, der kein Staatsorgan ist.

U.-K. Preuß, „Freiheitliche demokratische Grundordnung“ als Superlegalität; Demokratische Substanz und politische Verkehrsformen in: Denninger (Hrsg.), Freiheitliche demokratische Grundordnung I, S. $445 \mathrm{ff}$., 451, beschreibt die Gefahr, die es abzuwehren gilt, in der Tendenz richtig, wenn er - diesen Sachverhalt fälschlich als gegeben unterstellend - sagt: „Existentielle Entscheidungen enthalten Wertfestlegungen, die dem juristisch normierten Verhalten vorgelagert sind und es von einer gesellschaftlichen Beziehung 
die den Inhalt der freiheitlichen demokratischen Grundordnung bilden, so erweisen sich ohne weiteres Befürchtungen als unbegründet, die „Basisideologie der FDGO“ tendiere dazu, sich „zur staatstragenden ,religion civile $\mathrm{zu}^{\mathrm{u}}$ verfestigen“21. Die grundrechtliche Verbürgung der individuellen, insbesondere der Freiheit des Gewissens, zwingt den Staat des Grundgesetzes zu weltanschaulicher Neutralität; damit wird ,allen Formen einer verordneten religion civile eine Absage erteilt"22.

Jene Rechtsnormen, die den unantastbaren Kern der Verfassung bilden und im Falle ihrer Beeinträchtigung den Verfassungsschutz auf den Plan rufen, sind freilich durch die Besonderheit gekennzeichnet, daß sie Rahmen- bzw. Grundsatzcharakter haben. Bei ihnen gibt es also "Toleranzbereiche“23, innerhalb deren sich durchaus unterschiedliche gesetzliche Realisierungen vorstellen und mithin auch rechtmäßig diskutieren und anstreben lassen. Der Umfang der Toleranzbereiche ist allerdings nicht leicht zu bestimmen und bleibt es auch dann, wenn man mit der $\mathrm{Kritik}^{24}$ die dem verfassungsändernden $\mathrm{Ge}$ setzgeber aus Art. 79 Abs. 3 GG erwachsenden Bindungen in

zu einem Akt der Wertverwirklichung machen. Nicht der Zusammenhang des Verhaltens der einzelnen Subjekte zueinander begründet demnach den Begriff der Verfassung, sondern die Wertentscheidung für bestimmte Normen, deren Verwirklichung das Verhalten der Subjekte zu dienen hat". Das BVerfG hat freilich mit der von Preuß u. a. (vgl. z. B. E. Bulla, Die Lehre von der streitbaren Demokratie, AöR 98 (1973), S. 340 ff., 356 f.) kritisierten Entscheidung BVerfGE 28, $36 \mathrm{ff}$., (vgl. auch BVerfGE 28, $51 \mathrm{ff}$. u. $56 \mathrm{ff}$.) Handhaben für überzogene Befürchtungen geliefert. Statt das zutreffende Ergebnis all dieser Entscheidungen mit der sich aus Art. 17 a und 87 a I 1 GG ergebenden gesteigerten Treuepflicht der Soldaten zu begründen, hat es sich zu dem problematischen Satz verstiegen, die Demokratie der Bundesrepublik Deutschland erwarte von ihren Bürgern (sic!) eine Verteidigung (!) der freiheitlichen Ordnung (a. a. O., S. 48). Dazu auch später unter III 1.

${ }_{21}$ E. Denninger, Staatsrecht 1, 1973, S. 87.

${ }^{22} P$. Badura, Verfassung, Staat und Gesellschaft in der Sicht des BVerfG in: BVerfG und GG II, S. 1 ff., 6 f.; vgl. auch E. W. Böckenförde, Der Staat als sittlicher Staat, 1978, S. $24 \mathrm{f}$. Positiv scheint der Begriff der religion civile in unserem Zusammenhang aufgenommen bei Stern, Staatsrecht I, S. 418, der denn auch zu der in dieser Formulierung nicht ganz unbedenklichen Folgerung gelangt: "Im Verhältnis zur freiheitlichen demokratischen Grundordnung darf es lkeine Distanz, sondern nur Identifikation geben" (Hervorhebung im Original).

${ }^{23}$ G. Dürig in: Maunz/Dürig/Herzog/Scholz, a. a. O., Art. 18 RN 56.

24 Vor allem $P$. Häberle, Die Abhörentscheidung des BVerfG vom 15. 12. 1970 , JZ 1971, 145 ff., 149 f.; vgl. auch Stern, Staatsrecht I, S. $141 \mathrm{f}$., $656 \mathrm{ff}$., der ebenfalls dem Sondervotum (BVerfGE $30,33 \mathrm{ff}$.) zustimmt. Weitere Literaturhinweise bei C. Arndt, Gesetzliche Neuregelungen auf dem Gebiete der Nachrichtendienste, DVBl. 1978, S. 385 ff., 387 Fn. 29. 
einem strikteren Sinne interpretiert, als dies im Urteil des $B V e r f G$ vom 15. Dezember $1970^{25}$ geschehen ist, wenn man also nicht etwa erst die „prinzipielle Preisgabe“ der geschützten elementaren Verfassungsgrundsätze für unerlaubt und ihre systemimmanente Modifikation noch für zulässig hält. Bei der Eingrenzung des der Verfassungsänderung verbleibenden Spielraums hilft auch das gelegentlich bemühte Regel-Ausnahme-Schema ${ }^{26}$ nicht weiter, da, wie Stern ${ }^{27}$ zutreffend bemerkt, eine grundsätzlich restriktive Auslegung der Bindung des pouvoir constitué noch nichts zu der Frage besagt, ob auch alle in Art. 79 Abs. 3 GG für unantastbar erklärten Grundsätze in sich restriktiv auszulegen sind.

Die damit in bezug auf den Begriff der freiheitlichen demokratischen Grundordnung verbleibende Unklarkeit ist, weil sie aus dem Grundsatzcharakter der seinen Inhalt ausmachenden Normen folgt, ebenso notwendig wie, so paradox dies auch erscheinen mag, der Freiheit dienlich. Denn sie hat zur Folge, daß der Rahmen der zur Disposition stehenden Alternativen weit gespannt ist und auf eine Veränderung der verfassungsmäßigen Ordnung gerichtete Bestrebungen erst dann dem Verdikt der Illegalität verfallen, wenn sie deren Wesensgehalt zu beeinträchtigen trachten ${ }^{28,}{ }^{29}$.

Der dem einzelnen verbleibende Freiheitsraum ist um so größer, als der für jedermann unantastbare Kern der Verfas-

25 BVerfGE 30, $1 \mathrm{ff}$, $24 \mathrm{f}$.

26 Vor allem BVerfGE 30, 25; kritisch das Sondervotum das. S. 38 f., und Häberle a. a. O., S. 150 mit Fn. 76.

27 A. a. O., S. $136 \mathrm{f}$.

${ }_{28}$ Wobei der weitere Vorbehalt zu machen ist, daß sie den Intensitätsgrad der Aggressivität erreichen müssen.

29 Schlechterdings abwegig erscheinen daher Denningers (Freiheitliche demokratische Grundordnung I, Vorwort des Herausgebers, S. 7 ff.) Klagen über den „proteushaften Charakter“ des Begriffs der freiheitlichen demokratischen Grundordnung - angesichts der weitgehenden Einigkeit über seinen Inhalt kann keine Rede davon sein, daß die „Interpretations- und Verfügungsherrschaft über die ,fdGO'Formel" weitgehend der Exekutive überantwortet und dieser damit „nahezu kontrollfreie politische Machtmittel zur Ausschaltung oppositioneller Meinungsbildung an die Hand" gegeben seien. Was der Exekutive in dem von Denninger wohl gemeinten, wenngleich in ganz unzulässiger Weise verallgemeinerten Zusammenhang (der Einstellung von Extremisten in den öffentlichen Dienst) überantwortet ist, ist die ihr regelmäBig zustehende vorläufige (!), weil gerichtlicher Utberprüfung unterworfene, Subsumtion eines konkreten Sachverhalts unter einen unbestimmten Rechts-(Verfassungs-)begriff. Alles andere ist pure Hysterie, so insbesondere die Sorge, die Bundesrepublik stehe in der Gefahr des allmählichen Übergangs in einen selbstherrlich autoritären Vervaltungsstaat (a.a.O., S. 9; noch absurder das., Einführung des Hrsg., S. 26 f.). 
sung im wesentlichen aus bestimmten Verfahrensregeln und der Ausübung öffentlicher Gewalt um der Menschenwürde willen gezogenen elementaren Schranken besteht ${ }^{30}$. In ihrer Summe unterscheiden sie die vom Grundgesetz garantierte offene Ordnung von Staat und Gesellschaft von geschlossenen Systemen beliebiger ideologischer Provenienz ${ }^{31,32}$.

\section{Die Staatlichkeit der Bundesrepublik Deutschland als wei- teres Schutzgut}

Schutzgut der Verfassung sind neben der freiheitlichen demokratischen Grundordnung der Bestand und die Sicherheit ${ }^{33}$

so J. Isensee, Demokratischer Rechtsstaat und staatsfreie Ethik, Essener Gespräche zum Thema Staat und Kirche 11 (1977), S. $92 \mathrm{ff}$., 102: „Die Schutzgüter sind wesentlich Freiheitsrechte und freiheitssichernde Verfahren".

${ }^{31}$ Mit Recht weist $M$. Hättich, Radikale Demokratie in: Der Weg in die Gewalt, hrsg. von H. Geißler, 1978, S. $190 \mathrm{ff} ., 195,197$, darauf hin, daß die heutige Demokratiekritik, indem sie unsere Demokratie in disqualifizierender Absicht als Formaldemokratie bezeichnet, vielfach mit einem geschlossenen Demokratiekonzept arbeitet, in dem viele kontroverse Entscheidungsinhalte vorweg beantwortet sind. Darin wie in der Inanspruchnahme der Erkenntnis der Wahrheit für die eigene politische Vorstellung offenbare sich eine Verkennung des Wesens der Demokratie als eines Systems von Verfahren, um unter den Bedingungen von Dissens und Konflikt zu Entscheidungen z.u kommen.

${ }^{32}$ Es verdient nicht Kritik - vgl. etwa G. B. (Gerhard Böhme) in: Denninger (Hrsg.), Freiheitliche demokratische Grundordnung I, S. $69 \mathrm{f}$. - , sondern ist folgerichtiger Ausdruck dessen, was das Grundgesetz positiv als unangreifbar festlegt, wenn das BVerfG (E 2, $1 \mathrm{ff}$., 12 f.; 5, 85 ff., 140) die freiheitliche demokratische Grundordnung als eine Ordnung beschreibt, die jegliche Gewalt- und Willkürherrschaft ausschließt, und wenn es dementsprechend totalitäre Bestrebungen nationalsozialistischer wie kommunistischer Art für unvereinbar mit dieser Ordnung hält.

K. D. Bracher, Terrorismus und Totalitarismus in: Der Weg in die Gewalt (Fn. 31), S. $201 \mathrm{ff}$, hat einmal mehr klar und zutreffend hervorgehoben, daß der Totalitarismus von rechts wie von links die grundlegende, das Handeln der Verfassungsväter bestimmende Erfahrung nach 1945 war, auf die sich das Selbstverständnis der Bundesrepublik Deutschland gründet. Eine antifaschistische Orientierung, wie sie auch in der DDR anzutreffen war, habe nicht genügt. Die in jüngerer Zeit in der Bundesrepublik erfolgte Verdrängung des antitotalitären durch das antifaschistische Verständnis der Demokratie ermögliche einen Abbau der "wehrhaften Demokratie", insofern sie sie gegen die marxistisch-kommunistische Variante dé Totalitarismus wehrlos mache und damit deren Gegner automatisch unter Faschismusverdacht stelle, was in die verhängnisvolle Frontstellung der dreißiger Jahre „Faschismus oder Kommunismus" zurückführe, die zu überwinden der Sinn des GG war. Im Ergebnis ebenso Denninger, Verfassung und Gesetz, Frankfurter Hefte 1978, Heft 3, S. 27 ff., 32.

${ }^{33}$ Dazu zutreffende Darlegungen bei $H$. U. Evers, BK, Art. 73 Nr. 10 RN 39. 
des Bundes und der Länder. Mit „Bestand“ ist unstreitig die territoriale Integrität und die politische Handlungsfreiheit im außenpolitischen Bereich gemeint. Darüber hinaus aber sollte es, wie immer die Tatbestandsmerkmale der verschiedenen Verfassungsschutznormen voneinander abgegrenzt werden ${ }^{34}$, keinem Zweifel unterliegen, daß der Schutz der Verfassung auch der Staatlichkeit der Bundesrepublik Deutschland als solcher gilt ${ }^{35}$. Damit wird nicht einem Vorrang der Staats- vor der Verfassungsraison das Wort geredet. A. Arndts ${ }^{36}$ Wort, der Verfassungsstaat habe keine andere Raison als seine Verfassung, behält seine Gültigkeit, ist allerdings um die (schon früher getroffene) ${ }^{37}$ Feststellung zu ergänzen, daß es der Zweck der Verfassung ist, den Staat in Form, und nicht, ihn umzubringen. Die Staatsraison ist selbst ein integrales Element des Verfassungsrechts, wobei es sich eben um die Raison nicht eines beliebigen, sondern eines in bestimmter Weise verfaßten Staates handelt ${ }^{38}$. Die Begründung liegt auf der Hand: ohne eine funktionierende Staatlichkeit bleibt die freiheitliche demokratische Grundordnung ein leerer $\mathrm{Wahn}^{30}$.

34 So vertritt Th. Maunz in Maunz/Dürig/Herzog/Scholz, Art. 21 RN 118, mit guten Gründen die Auffassung, im Rahmen des Art. 21 II GG werde der innerstaatliche Bestand des Staates nicht durch das zweite, sondern durch das erste Tatbestandsmerkmal abgedeckt.

${ }^{35}$ Art. 24 GG bleibt von dieser Feststellung naturgemäß unberührt.

${ }^{36}$ Der Rechtsstaat und sein polizeilicher Verfassungsschutz, NJW 1961, S. 897 ff., 899. Sehr dezidiert auch J. Salzwedel, Möglichkeiten und Grenzen einer rechtsstaatlichen Kontrolle des Verfassungsschutzes in: Gedächtnisschrift für H. Peters, 1967, S. 756 ff., 769: "Verfassungsschutz durch Verfassungsbruch ist ein Unding" - die Frage bleibt: was ist Verfassungsbruch?

${ }^{37}$ H. H. Klein, Bundesverfassungsgericht und Staatsraison, 1968, S. 33.

${ }_{38}$ BVerfGE 20, $162 \mathrm{ff}$., 178, bringt dies dadurch zum Ausdruck, daß es zu dem Bestand der Bundesrepublik Deutschland, den es zu schützen gelte, nicht nur ihr organisatorisches Gefüge, sondern auch ihre freiheitliche demokratische Grundordnung rechnet. Erinnert sei im übrigen an die sehr zurückhaltende, relativierende Formulierung im Sondervotum zu BVerfGE 30, $1 \mathrm{ff}$., 45: „Die ,Staatsraison" ist kein unbedingt (sic!) vorrangiger Wert". Diese Formulierung deckt nicht eine Auffassung, die die selbständige verfassungsrechtliche Relevanz der Staatsraison schlechthin negiert. Zum Problem s. auch $M$. Schröder, Staatsrecht an den Grenzen des Rechtsstaats, AöR 103 (1978), S. $128 \mathrm{f}$, $129 \mathrm{f}$.

${ }^{30}$ Auch im Verteidigungsfall gilt die Verteidigung nicht nur der Verfassung, sondern auch dem Staat. Für Bedrohungen, die dem Staat von innen her erwachsen, kann nichts anderes gelten. Mit Recht bezeichnet Schmitt Glaeser, a. a. O. (Fn. 12), S. 38, es als nicht ernstlich umstritten, daß der Staat als solcher ein Recht auf Schutz seiner Existenz hat. A. M. allerdings Bulla, AöR 98 (1973), S. 359. 


\section{Die „streitbare Demokratie“ des Grundgesetzes}

Die „kopernikanische Wendung“40, die das Grundgesetz im Verhältnis zur Weimarer Reichsverfassung vollzogen hat, wird im allgemeinen als die Preisgabe der relativen zugunsten der werthaften Demokratie beschrieben. Sieht man von der nicht unproblematischen 2'erminologie ${ }^{41} \mathrm{ab}$, triftt die Beschreibung das Entscheidende: Das Grundgesetz hat den Versuch unternommen, die ihm zugrundeliegende Staatsidee in die Form bestimmter Rechtsgrundsätze mit normativem Charakter zu gießen und diese der politischen Disposition zu entziehen. Es hat die Legalität an die durch diese Grundsätze definierte Legitimität gebunden, stellt sie außerhalb der Kontroverse und trifft zugleich Vorsorge, daß Versuchen, sie in die Kontroverse einzubeziehen, mit staatlichen, äußerstenfalls aber auch mit privaten (Widerstandsrecht!) Mitteln entgegengetreten werden kann. Die Hegung der politischen Freiheit beschränkt sich nicht auf die Unterbindung bestimmter Methoden, insbesondere der Gewalt, bei der Verfolgung politischer Ziele ${ }^{42}$. Denn — und das ist das wesentliche - es gibt nach dem Grundgesetz politische $\mathrm{Ziele}$, in erster Linie die Beseitigung der freiheitlichen demokratischen Grundordnung, also der Bedingungen individueller (privater wie politischer) Freiheit, die nicht, jedenfalls nicht in kämpferischer Form ${ }^{43}$, erstrebt werden dürfen ${ }^{44}$.

Dabei ist es, um das im Text Gesagte $\mathrm{zu}$ wiederholen, selbstverständlich, daß der (Verfassungs-)Staat dieses Recht nur mit dem Ziel geltendmachen und durchsetzen darf, die Voraussetzungen für die Wahrung der ihm gegebenen freiheitlichen demokratischen Grundordnung, d.h. insbesondere die Funktionstüchtigkeit seiner Organe zu erhalten und ihre Fähigkeit, die verfassungsmäßige Ordnung zu schützen. Von daher sind jedenfalls im Ergebnis auch diejenigen Entscheidungen des BVerfG zu rechtfertigen, von denen Lameyer, a. a. O. (Fn. 16) befürchtet, in ihnen sei das Gericht der Gefahr erlegen, den staat mit der Verfassung zu identifizieren. Unzweifelhaft ist jedenfalls der Staat (im Unterschied zum Bürger!) gehalten, sich mit seiner Verfassung zu identifizieren, wenn deren Schutz, der ja in erster Linie durch den Staat erfolgen muB, nicht eine leere Forderung bleiben soll. Dazu auch $F$. K. Fromme, Wiedereinsetzung des Staates, FAZ v. 2.11.1977, und die verfehlte Kritik Denningers, Verfassung und Gesetz (Fn. 32) S. 37 f. mit S. 40 (Fn. 33).

40 Stern, Staatsrecht I, S. $416,468$.

41 Vgl. oben Fn. 20.

42 Das Schwanken von Gesetzgebung und verfassungsgerichtlicher Rechtsprechung in den USA vor diesem vom GG vollzogenen Schritt schildert anschaulich $H$. Steinberger in seiner großen Monographie über „Konzeption und Grenzen freiheitlicher Demokratie“, 1974.

43 Die hiermit gemachte Einschränkung, die der einhelligen Auslegung der neben der Grundnorm des Art. 79 III GG wichtigsten 
Das Grundgesetz hat, historischer Erfahrung folgend, die Lehre aus der Erkenntnis gezogen, daß die Verwirklichung freiheitswidriger Entwürfe nicht aus der Idee der Freiheit legitimiert werden kann, aut welchem Wege auch immer - mit friedlichen Mitteln oder gewaltsam - sie betrieben wird ${ }^{45}$.

Verfassungsschutznormen entspricht (Art. 9 II, 18, 21 II GG), ist allerdings von äußerster Wichtigkeit. Sie stellt klar, daß auch die freiheitliche demokratische Grundordnung und, zumal im Hinblick auf das Verfassungsziel der Wiederherstellung der staatlichen Einheit Deutschlands, der Bestand der Bundesrepublik frei diskutiert und beurteilt werden dürfen. Lediglich die aktiv kämpferische, aggressive Haltung gegenüber den Schutzgütern der Verfassung ist illegalisiert bzw. (im Fall der politischen Partei) illegalisierbar. So mit Recht Schmitt Glaeser, a. a. O. (Fn. 12), S. 54 f.; s. a. BVerfGE 5, 85 ff., 141 ff.; 33, 52 ff., 68. Die Schwierigkeit der Unterscheidung von (zulässiger) expression und (unzulässiger) action ist freilich nicht zu leugnen; dazu Steinberger, a. a. O., S. $585 \mathrm{ff}$., der zu dem Ergebnis kommt, was Aktion sei, müsse „funktional im Hinblick auf den politischen ProzeB in der konkreten Situation einer demokratischen Gesellschaft bestimmt werden" (S. 589) - eine etwas sybillinische Formulierung!

44 Denninger, JZ 1975, 549, fragt nach der Einordnung des Grundgesetzes zwischen den Polen einer sich als "Ensemble von Kompetenzen und Verfahrensregelungen“ und einer sich als "Aktionsprogramm“, als "Grundplan eines Gesellschaftssystems" verstehenden Verfassung und meini, man gerate bei der Standortbestimmung in Verlegenheit. Ich hege diese Empfindung nicht. Das GG ist - im Gegensatz etwa zu der von Denninger zitierten Verfassung der DDR - eindeutig dem ersten Typus zuzurechnen, mit der einzigen Maßgabe, daß es seinen Grundcharakter als "Ensemble von Kompetenzen (einschließlich der als negative Kompetenzen zu verstehenden Grundrechte) und Verfahrensregelungen" selbst nicht zur Disposition zu stellen erlaubt. Daran ändert sich auch dann nichts, wenn man die Verfassungsinterpretation des BVerfG oder auch die Wirklichkeit unseres Verfassungslebens in den Blick nimmt. In letzterem Betracht besorgniserregend ist allerdings die häufiger $\mathrm{zu}$ beobachtende Neigung gewisser politischer Kräfte, ihre Problemlösungsvorstellungen mit dem demokratischen oder anderen Verfassungsprinzipien zu identifizieren und die Gegner dieser Vorstellungen damit automatisch als Verfassungsfeinde abzustempeln; vor allem die Verfechter der sog. Demokratisierung stehen in der gefährlichen Versuchung einer solchen Verfahrensweise; dazu Hättich, a. a. O. (Fn. 31), S. $195 \mathrm{f}$.

45 Steinberger, a. a. O., S. 261 f., 267, 595 ff. Diese Einsicht liegt inzwischen auch dem internationalen Recht zugrunde: vgl. Art. 5 I IPbürgR und IPwirtR. Zum Legitimationsproblem vgl. auch $R$. Dreier, Verfassung und Ideologie in: Gedächtnisschrift für F. Klein. 1977, S. $86 \mathrm{ff}$., 98, der den Versuchen, die streitbare Demokratie des Grundgesetzes in dem Sinne restriktiv zu interpretieren, daß sie nur die Bekämpfung von Methoden, nicht auch von Zielen gestatte, entgegenhält, ihnen stehe, ,zumindest der Wortlaut des Art. 21 II entgegen“. Dazu BVerfGE 5, 85 ff., 134. 
Diese Lehre lautet: die Realisierung solcher Entwürfe ist zu verhindern ${ }^{46}$.

Es entspricht nicht der Logik des grundgesetzlichen Selbstverständnisses $\mathrm{zu}$ glauben, die konkreten Freiheitsrechte eines jeden könnten am wirkungsvollsten dadurch verteidigt werden, daß man ihm ein Maximum an Bindungslosigkeit garantiert. Zwar ist die Freiheit im Rechtsstaat immer und ausschließlich die Freiheit von heteronomen Verbindlichkeiten ${ }^{47}$. Dennoch kann sie ohne ein gewisses $\mathrm{Maß}$ solcher Verbindlichkeiten nicht gedacht werden. Dazu rechnen die Existenzbedingungen des demokratischen und sozialen Rechtsstaats. Er ist der Garant und deshalb die notwendige Voraussetzung einer Freiheit, die sich als „Freiheit von der Kompetenz Dritter, ihr einen verbindlichen Inhalt vorzuschreiben "48, versteht. Um deswillen ist, um den gängigen Begriff aufzunehmen, die Verfassung des Grundgesetzes die einer streitbaren Demokratie, die sich die unbegrenzte Toleranz anderer Verfassungen gegenüber jedweden politischen Zielsetzungen nicht $\mathrm{zu}$ eigen gemacht hat.

Damit entgeht das Grundgesetz natürlich nicht dem praktischen Problem, das darin besteht, daß bei dem Versuch, die Freiheit zu bewahren, die Freiheit selbst in Gefahr geraten kann, zerstört zu werden ${ }^{49}$. Tatsache ist indes, daß das Grundgesetz sich von dieser Sorge weniger bewegt zeigt als manche seiner Interpreten und andere freiheitliche Verfassungen ${ }^{50}$. Im Vergleich zu ihnen hat es die Grenzlinie zu dem, was es abzuwehren gilt, vorverlegt und im gleichen $\mathrm{Maße}$ die politische Freiheit beschränkt. Nicht erst die Revolution, sondern schon die auf die Herbeiführung der Revolution gerichtete geistige,

${ }^{46}$ Gewiß mag man skeptisch bleiben, ob, wie $K$. Hesse, Grundzüge des Verfassungsrechts der Bundesrepublik Deutschland, 10. Aufl. 1977, \& 20 (S. 273) - dag. Stern, Staatsrecht I, S. 163 f. - sich ausdrückt, die Substanz der freiheitlichen Demokratie durch eine Verkürzung von Freiheit gesichert werden kann. Es ist jedoch festzuhalten, daß damit zwar Zweifel an der Richtigkeit der Demokratiekonzeption des Grundgesetzes ausgedrückt werden, nicht aber diese Konzeption als solche in Frage gestellt werden kann.

47 Vgl. H. Lübbe, Freiheit und Verbindlichkeit in: Theorie und Entscheidung, 1971, S. 134 ff., $136 \mathrm{f}$.

48 Lübbe, a. a. O.

${ }^{49} \mathrm{Zu}$ diesem Dilemma schon BVerfGE 5, $85 \mathrm{ff}$., $134 \mathrm{ff}$.

50 Das vom Sondervotum der Richter Rupp-von Brünneck und Simon, BVerfGE 33, 86, zitierte Wort Gladstones: "It is liberty alone, which fits men for liberty" wirkt angesichts der Erfahrungen mit dem möglichen Mißbrauch der Freiheit zum Zwecke ihrer Zerstörung aus heutiger Sicht wenig realitätsnah, wenngleich die dahinter stehende Mahnung, jeđe Freiheitsbeschränkung sorgfältigst auf ihre Notwendigkeit zu überprüfen, gewiß ständige Beachtung verdient. 
propagandistische und vor allem organisatorische Aktivität wird grundsätzlich mit dem Verdikt der Verfassungswidrigkeit belegt ${ }^{51}$. Zwar bleibt das liberale Marktmodell der Demokratie auch in der streitbaren Demokratie des Grundgesetzes prinzipiell erhalten ${ }^{52}$, der suizidalen Lethargie gegenüber formell-legalen Formen der Liquidierung demokratischer Verfassungsstrukturen ${ }^{53}$ ist jedoch abgeschworen ${ }^{54}$.

Die vom Grundgesetz zum Schutz der Verfassung getroffenen Vorkehrungen sind, sieht man von den hier nicht zu behandelnden Sondervorschriften für die Fälle des äußeren und - weniger eindeutig - des inneren Notstandes ab, in ihrem zeitlichen Geltungsbereich nicht beschränkt. Sie sind - in überkommenen rechtsstaatlichen Kategorien gesprochen - Bestandteil des Normal- und nicht des Ausnahmezustandes ${ }^{55}$. Sie

51 Vgl. O. Kirchheimer, Wandlungen in der Struktur des Staatsschutzes, ZPol. 1964, S. 126 ff., 142, der zu Recht auch auf die Taktik moderner Revolutionäre verweist, ihre Kundschaft mit einer radikal verzerrten Vision der Wirklichkeit zu versorgen, um auf der Grundlage der Diffamierung des Bestehenden dessen Zerstörung voranzutreiben (S. 143). Dazu kommen weiterhin etwa die Strategie der Unterwanderung sowie die der Veränderung des Bewußtseins, insbesondere mit dem Ziel einer Verunsicherung der Bevölkerung, der Imputation von Mißtrauen in die Handlungsfähigkeit des Staates, z. B. durch örtlich begrenzte Gewaltanwendung („Demonsration") oder die Schaffung rechtsfreier Räume (Hochschulen). Will der Staatsschutz nicht a priori kapitulieren, muß er seine Vorkehrungen so treffen, daß er den Methoden seiner Gegner wirksam zu begegnen vermag, was selbstverständlich nicht heißt, daß er seinerseits in die Illegalität abgleiten dürfte.

${ }_{32} H$. Mandt, Grenzen politischer Toleranz in der offenen Gesellschaft in: Aus Politik und Zeitgeschichte, Beilage zur Wochenzeitung "Das Parlament", B 3/78, S. 3 ff., 11. Mit Recht bemerkt BVerfGE 40, 287 ff., 291: „Unbeschadet dessen, daß sich die Bundesrepublik Deutschland als streitbare Demokratie versteht und kraft ihrer Verfassung auch verstehen muß ..., bleibt sie doch primär auf die freie, selbstbestimmte (Art. 1 I GG) Integration aller politischen Meinungen und Kräfte im Rahmen und durch die Grundwerte der Verfassung angelegt". Vgl. auch BVerfGE 5, 85 ff., $197 \mathrm{ff}$.

53 So $K$. Loewenstein nach Mandt, a. a. O., S. 4.

54 Das - etwa im Vergleich zu Weimar - eigentlich Neue am GG ist seine Kampfansage auch gegen gewaltfreie ideologische Angriffe auf die freiheitliche Demokratie. G. Willms, Das Staatsschutzkonzept des Grundgesetzes und seine Bewährung, 1974, S. 27, beklagt zu Recht, daß dieser Gedanke in der politischen Wirklichkeit heute keine Stätte mehr habe, ja daß an seine Stelle sogar eine verbreitete Toleranz gegenüber der Gewalt gegen Sachen und Personen getreten sei. Die jüngste Entwicklung des Terrorismus hat bislang wohl nur eine recht oberflächliche Revision dieser Ende der 60er Jahre aufgekommenen Einstellung bewirkt.

55 Insoweit stimme ich mit $B$. Schlink, Zwischen Identifikation und Distanz, Der Staat 15 (1976), S. 335 ff., 346 f., überein. 
beschreiben - mit permanentem Geltungsanspruch - Schranken sowohl staatlichen als auch individuellen Handelns ${ }^{56}$.

Strittig ist, ob der Begriff der streitbaren Demokratie „lediglich eine Sammelbezeichnung für die Staatsschutzvorschriften des Grundgesetzes ist oder darüber hinaus ein Verfassungsprinzip bezeichnet, welches eigenständige Bedeutung entfaltet" ${ }^{157}$. Die Alternative ist so indessen $\mathrm{zu}$ scharf formuliert ${ }^{58}$ und verdeckt damit das eigentliche Problem. Einerseits kann es sich nicht darum handeln, einen zunächst nur deskriptiv gemeinten Begriff zur selbständigen Rechtsquelle zu erheben ${ }^{59}$. Andererseits muß dem Ring von Schutzvorkehrungen, den das Grundgesetz um den in Art. 79 Abs. 3 definierten Verfassungskern errichtet hat, eine die Verfassung insgesamt prägende Grundentscheidung entnommen werden, die nicht ohne Einfluß bleiben kann auf die Auslegung der einzelnen Verfassungsnor-

${ }^{56}$ Die Folge davon ist, daß das Grundgesetz auf den Ausnahmezustand als Mittel innerer Befriedung - jedenfalls bisher - weitgehend verzichtete; so zutreffend $R$. Wassermann, Sicherung oder Aushöhlung des Rechtsstaats? in: ders. (Hrsg.), Terrorismus contra Rechtsstaat, 1976, S. 125 ff., 134. Die Reaktion des Grundgesetzes auf die mit den - wirklichen oder nur angenommenen - Unzulänglichkeiten der Weimarer Reichsverfassung gemachten Erfahrungen ist ja durchaus ambivalent: Auf der einen Seite hat es die Wehrhaftigkeit der Demokratie gestärkt, auf der anderen Seite enthält es eine dem Art. 48 WRV entsprechende Bestimmung nicht. Dahinter steht die Absicht, eine revolutionäre Lage, zu deren Bewältigung es diktatorischer Befugnisse bedurfte, gar nicht erst entstehen zu lassen. Dafür ist naturgemäß ein Preis zu zahlen. Er besteht, um es in einem Paradoxon auszudrücken, in der teilweisen Vorverlagerung des Ausnahmezustandes in den Normalzustand. Zuzustimmen ist G. Roellecke, DOUV 1978, S. 457 ff., 458, wenn er Revolution als Wechsel der Legitimationsprinzipien eines Gemeinwesens definiert und darauf hinweist, daß Revolutionen nicht mit dem Aufbau neuer, sondern mit der Zerstörung der geltenden Legitimationsprinzipien beginnen (S. 459). Ihr zu wehren ist Aufgabe des Verfassungsschutzes.

57 R. Dreier, a. a. O. (Fn. 45), S. 95. Vgl. ferner u. a.: Bulla, AöR 98 (1973), S. 352, 355; Hesse, Grundzüge, \$ 20 (S. 273); Lameyer, a. a. O. (Fn. 16), der seine ganze Untersuchung dieser Frage widmet, vgl. bes. S. 48, $77 \mathrm{ff}$,, 86 ff. (Literaturbericht), 133; $A$. Sattler, Die Entscheidung für die streitbare Demokratie (unveröffl. Manuskript).

${ }_{58}$ Auch Dreier, a. a. O., scheint dieser Meinung zu sein, wenn er ausführt, daß gegen die von ihm für die zweitgenannte Auffassung in Anspruch genommene Rechtsprechung des BVerfG (Nachweis S. $95 \mathrm{Fn} .39$ ) insoweit nichts einzuwenden sei, als der Hinweis auf das Verfassungsprinzip der streitbaren Demokratie die ratio legis der einschlägigen Grundgesetzbestimmungen zum Ausdruck bringen solle.

${ }_{50}$ Zur Bedenklichkeit dieses Verfahrens s. H. Krïger, Der Verfassungsgrundsatz in: Festschrift für E. Forsthoff zum 70 . Geburtstag, 2. Aufl. 1974, S. 187 ff. 
men einschließlich der Grundrechte ${ }^{60}$. Nur eine solche Auffassung entspricht dem Interpretationsprinzip der Einheit der Verfassung ${ }^{61}$, das allerdings auch dazu zwingt, das zwischen einzelnen Normen und Prinzipien der Verfassung mitunter bestehende Spannungsverhältnis zu „praktischer Konkordanz"62 zu bringen ${ }^{63,64,65}$.

${ }^{60}$ Diese Feststellung steht nicht im Widerspruch zu der Tatsache, daß der Menschenwürdegehalt der Grundrechte selbst ein, wenn nicht gar der wesentliche Bestandteil des Schutzguts freiheitliche demokratische Grundordnung ist, nachdem sich die Verfassung einmal dazu entschlossen hat, auch auf dem Gebiet der politischen Betätigung (wie von jeher selbstverständlich auf dem Feld privaten Handelns) zum Schutz der Freiheit gewisse Verkürzungen der Freiheit vorzunehmen.

${ }_{61}$ Vgl. statt vieler Stern, Staatsrecht I, S. $107 \mathrm{ff}$., m. Nachw. insb. auch aus der Rechtsprechung des BVerfG; ferner noch $P$. Badura, a. a. O. (Fn. 20), S. 2 ff., und G. Roellecke, Prinzipien der Verfassungsinterpretation in der Rechtsprechung des BVerfG in: BVerfG und GG II, S. 22 ff., 33.

${ }^{62}$ Hesse, Grundzüge, $\S 2$ III 2 c (S. 28 f.).

63 Dieser Aufgabe wird ein Verfahren nicht gerecht, welches die Lösung grundsätzlich stets in einer Richtung sucht, geht es doch darum, allen jeweils miteinander konkurrierenden Verfassungsrechtsgütern zu optimaler Wirksamkeit zu verhelfen (Hesse, a. a. O.). S. auch $D$. Göldner, Integration und Pluralismus im demokratischen Rechtsstaat, 1978, S. 80. - Einseitig ist es z. B., wenn Bulla, AöR 98 (1973), S. 351, aus dem Umstand, daß die Streitbarkeit der freiheitlichen Demokratie „allenfalls“ (?) durch die im GG ausdrücklich normierten Verfassungsschutzbestimmungen festgelegt wird, folgert: „Nur soweit diese Verfassungsnormen eine streitbare Tendenz enthalten, kann überhaupt von einer streitbaren Demokratie gesprochen werden". Damit wird verdrängt, daß - eben im Zeichen der Einheit der Verfassung - Verfassungsnormen aufeinander "ausstrahlen" und eben nicht bloß isoliert voneinander betrachtet werden können. Wie Bulla auch Schlink, a. a. O. (Fn. 55), S. 361. S. dagegen BVerfGE 2, $380 \mathrm{ff} ., 403$. - Aus diesem Grunde ist die Maxime „in dubio pro libertate“ (vgl. bes. P. Schneider, In dubio pro libertate in: Festschrift zum 100jährigen Bestehen des Deutschen Juristentages II, 1960, S. 263 ff.; W. Maihofer, Rechtsstaat in der Bewährung in: Bitburger Gespräche, Jahrbuch 1974-1976, S. $147 \mathrm{ff}$., 150) kein geeignetes Mittel zur Lösung der hier anstehenden Probleme. Abl. etwa Hesse, Grundzüge, a. a. O., S. 29; J. Schwabe, Probleme der Grundrechtsdogmatik, 1977, S. 62 ff.; Stern, Staatsrecht I, S. 109 f., jeweils $\mathrm{m}$. w. Nachw. Insbesondere der Konflikt zwischen Freiheit und Sicherheit (dazu Maihofer, a. a. O.), in dessen Zusammenhang auch das Spannungsverhältnis zwischen Freiheit und Verfassungsschutz gehört, ist einer Auflösung nach der Maxime „in dubio pro libertate" nicht zugänglich, weil Sicherheit selbst ein Element von Freiheit ist. Eine Automatik dergestalt, daß, was der Seite der Sicherheit hinzugefügt wird, der Seite der Freiheit abgeht (so $R$. Wassermann, a, a, O. (Fn. 56), S. 133), gibt es nicht. Das Verhältnis von Freiheit und Sicherheit ist in der Struktur demjenigen von Freiheit und Gleichheit vergleichbar: ein Zuwenig an Sicherheit und Gleichheit ist der Freiheit ebenso abträglich wie ein 
Zuviel. Aber glatte Formeln, die es erlaubten, ein für allemal zu bestimmen, was zuwenig ist und was zuviel, stehen nicht zur Verfügung. Immerhin mag die von Dürig in: Maunz/Dürig/ Herzog/ Scholz, Art. 3 I RN 135, konstatierte „Präponderanz der Freiheit" im Verhältnis zur Gleichheit und seine Hervorhebung von deren dienender Funktion auch für die nähere Bestimmung des Verhältnisses von Freiheit und Sicherheit bzw. Verfassungsschutz als Richtschnur in Betracht $z u$ ziehen sein, da außer Zweifel steht, daß die Verfassungsschutznormen der Erhaltung der Freiheit zu dienen bestimmt sind. Dieser Gesichtspunkt ist bei der jeweils in concreto erforderlichen verhältnismäßigen Zuordnung beider Rechtsgüter $\mathrm{zu}$ berücksichtigen. -

Unrichtig ist es auch, die Verfassungsschutznormen zu Ausnahmevorschriften $\mathrm{zu}$ erklären und daraus die Notwendigkeit einer streng restriktiven Interpretation abzuleiten: so z. B. Bulla, AöR 98 (1973), S. 355 - zutreffende, obgleich komplizierte Formulierung (des Verhältnismäßigkeitsprinzips) dag. auf S. 351: „Daraus folgt, daß Eingriffe in die Freiheitssphäre des einzelnen zum Schutz der freiheitlichen demokratischen Grundordnung nicht allein an der Notwendigkeit, jene $\mathrm{zu}$ verteidigen, vielmehr auch an deren Sicherungsfunktion für den einzelnen zu messen sind “ -; für einen Ausnahmecharakter von Art. 21 II GG auch VG Neustadt, ZBR 1973, $147 \mathrm{ff}$., 149: die Vorschrift sei nicht als Anwendungsfall eines allgemeinen Rechtsgedankens streitbarer Demokratie zu begreifen. S. ferner Schlink, a. a. O. (Fn. 55), S. 346. Allerdings gilt auch umgekehrt, daß das „Spannungsverhältnis zwischen den Erfordernissen des politischen Staatsschutzes und den politischen Freiheitsrechten ... nicht von vornherein und allgemein zum Nachteil der Grundfreiheiten gelöst werden darf" (BVerfGE 33, 52 ff., 85 (Sondervotum), unter Bezugnahme auf das Spiegel-Urteil, BVerfGE 20, $162 \mathrm{ff}$., $177 \mathrm{f}$.).

64 Ein Bruch mit dem rechtsstaatlichen Verteilungsprinzip wird durch die hier vertretene Meinung entg. Schlink, a.a.O. (Fn. 55), S. 361 , nicht vollzogen, noch auch durch die früher von mir daraus gezogenen Folgerungen; vgl. H. H. Klein, Zur Berufung von Mitgliedern der Verfassungsfeindlichkeit verdächtiger Parteien und Vereinigungen in das Beamtenverhältnis in: Festschrift für E. R. Huber, 1973, S. 75 ff. Das Prinzip (grundlegend C. Schmitt, Verfassungslehre, 4. Aufl. 1965, S. 126) besagt, daß die Freiheitssphäre des einzelnen als etwas vor dem Staat Gegebenes vorausgesetzt wird, und daß die Freiheit des einzelnen prinzipiell unbegrenzt ist, während die Befugnis des Staates zu Eingriffen in diese Sphäre prinzipiell begrenzt ist. Daran ändert sich nichts, wenn man - als eine unter anderen verfassungsunmittelbaren Schranken der Grundrechte - anerkennt, daß das GG durch sein in zahlreichen Normen dokumentiertes "Bekenninis“ zu einer (nach oben und unten gleichermaßen) streitbaren Demokratie den Gebrauch der Freiheit zum Zwecke ihrer Zerstörung rechtlich mißbilligt. Das rechtsstaatliche Verteilungsprinzip begründet keine Rechtsvermutung zugunsten der Freiheit und gegen die Eingriffsbefugnis des Staates; darin liegt der Unterschied zu einem Auslegungsprinzip wie in dubio pro libertate. Es besagt vielmehr, daß der staatliche Eingriff in Freiheit und Eigentum einer gesetzlichen Grundlage bedarf, die sich ihrerseits an der Verfassung legitimieren muß. Ebensowenig durchschlagend sind - jedenfalls gegenüber der hier vertretenen Auffassung Schlinks logische Bedenken gegen den „Induktionsschluß von der Streitbarkeit einzelner Vorschriften auf die Streitbarkeit der ganzen Verfassung“. Abgesehen davon, daß ein solcher Schluß hier gar 
nicht gezogen, sondern nur das Auslegungsprinzip der Einheit der Verfassung zur Anwendung gebracht wird, muß die Frage aufgeworfen werden, ob Schlink seine Bedenken auch aufrecht erhält, wenn es darum geht, aus der Summe einschlägiger Vorschriften den Schluß zu ziehen, daß das Grundgesetz eine rechtsstaatliche Verfassung ist, und aus dem Rechtsstaatsprinzip, von dem sich auf dieser Grundlage sagen ließe (vgl. dazu Stern, Staatsrecht I, S. 613 f.), es sei zunächst auch nicht mehr als eine Sammelbezeichnung, Konsequenzen abzuleiten, die keinen ausdrücklichen Niederschlag in der Verfassung gefunden haben (z. B. das Prinzip des Vertrauensschutzes, das grundsätzliche Verbot der Rückwirkung belastender Gesetze oder das Prinzip des möglichst lückenlosen Rechtsschutzes; s. BVerfGE $30,1 \mathrm{ff}$., 25). I. ü. sei daran erinnert, daß das BVerfG seinerzeit auf besonders scharfe Kritik mit der These gestoßen ist, nicht das Rechtsstaatsprinzip als solches, sondern nur bestimmte Grundsätze desselben seien Gegenstand der Ewigkeitsgarantie des Art. 79 III GG, BVerfGE 30, 1 ff., 24 f.; dazu Sondervotum, ebenda, S. $40 \mathrm{ff}$; Häberle, JZ 1971, S. $152 \mathrm{f}$.

${ }^{65}$ Der Hinweis, die hier empfohlene - und in anderen Zusammenhängen allgemein akzeptierte - Interpretationsmethode berge gewisse Unsicherheiten und die Gefahr der Subjektivität in sich, ist zwar nicht unberechtigt, jedoch in Ermangelung einer annehmbaren Alternative ohne überzeugende Kraft (dazu Schwabe, a. a. O. [Fn. 63], S. 319 ff.). In der rechtsstaatlichen Verfassungsordnung der Bundesrepublik Deutschland ist auch der Proze $\beta$ der Rechtsfindung und Rechtsanwendung ein grundsätzlich öffentlicher und offener Prozeß, der Fehlentwicklungen nicht ausschließt, aber auch ihre Korrektur erlaubt. In ihm werden sich auf die Dauer nur solche Meinungen behaupten können, die sich nicht als die Opfer der „Ideologieanfälligkeit“ bestimmter Begriffe, sondern als das Resultat rational nachvollziehbarer Denkprozesse darstellen, die, wie es juristischer Interpretationskunst entspricht, vom Text des Grundgesetzes ihren Ausgang nehmen.

"Ideologieanfälligkeit" ist ein beliebter Vorwurf gegen den Begriff der streitbaren Demokratie (vgl. z. B. Lameyer, a. a. O. [Fn. 16], S. 136), der in der Absicht vorgebracht zu werden pflegt, die Streitbarkeit des GGes zu minimieren oder gar die Rückkehr zu einem der WRV adäquaten Verfassungsverständnis zu propagieren, nach dem alles (mit Ausnahme natürlich „faschistischer" Bestrebungen!) erlaubt ist, sofern dabei nur - bis zum point of no return! - die Spielregeln eingehalten werden. - Irrelevant für die Deutung des positiven Verfassungsrechts und damit auch für die Frage der extensiven oder restriktiven Auslegung des Streitbarkeitsprinzips sind die von Dreier, a. a. O. (Fn. 45), S. $98 \mathrm{f}$., geäußerten Zweifel an der wissenschafts- und moraltheoretischen Begründbarkeit der materialwertgebundenen Demokratie (wobei erneut die Skepsis zum Ausdruck zu bringen ist, ob mit der einer solchen Theorie eigenen Begrifflichkeit der Charakter des GGes zutreffend erfaßt werden kann). Denn selbst wenn diese Zweifel begründet wären, vermöchte dies an der vom Verfassungsgeber getroffenen Entscheidung für die Streitbarkeit und deren Rang im Vergleich zu anderen Grundentscheidungen nichts zu ändern. Erblickt man in der freiheitlichen demokratischen Grundordnung nicht eine Ansammlung absoluter Werte, sondern ein unantastbares „Ensemble von Kompetenzen und Verfahrensregelungen" (vgl. Fn. 44), dann erledigt sich auch der Vorhalt Dreiers, a. a. O., S. 99, historischer Erfahrung zufolge sei es allemal weniger die Schwäche des "Wertrelativismus" als viel- 


\section{Die Rechtsstellung des Verfassungsfeindes}

Dem Verfassungsfeind ${ }^{66}$ wird der Schutz der Verfassung nicht verweigert. Zwar genießt der Feind der Freiheit keine unbedingte (!) Freiheit ${ }^{67}$, aber diese Feststellung besagt nicht mehr, als daß die um des Schutzes der Verfassung willen von der Rechtsordnung errichteten Schranken der Freiheit in den jeweils vorgesehenen administrativen oder gerichtlichen Verfahren zu aktualisieren sind. Selbst derjenige, der das eine oder andere seiner Grundrechte nach einem Spruch des BVerfG verwirkt hat, wird nicht „entbürgerlicht", sondern nur (partiell) „entpolitisiert"68. Er wird nicht out of law gestellt, wie Wernicke ${ }^{69}$ bekanntlich gemeint hat. Die Folge der Grundrechtsverwirkung ist vielmehr nur, daß sich der Betroffene auf die durch den Spruch des BVerfG aberkannten Grundrechte

mehr die Ideologieanfälligkeit des „Wertabsolutismus“ gewesen, die den Totalitarismus hervorgebracht oder doch begünstigt habe. Auch hier zeigt sich, daß die Wertterminologie auf argumentative Abwege führt.

${ }^{66}$ Die Bedenken gegen diesen Begriff - vgl. statt vieler Dreier, a. a. O. (Fn. 45), S. 110 f. - vermag ich mir nicht zu eigen zu machen. Zwar ist er wie viele andere Begriffe emotionaler Aufladung zugänglich - die Verfassungslehre und -rechtsprechung waren solcher Versuchung jedoch bislang nicht erkennbar ausgesetzt. Verfassungsfeind ist derjenige, der mit rücksichtsloser Aggressivität gegen die freiheitliche demokratische Grundordnung zu Felde zieht oder den Bestand bzw. die Sicherheit des Bundes oder eines Landes (vgl. Art. 73 Nr. 10 b GG) in ernste Gefahr bringt. Der Begriff, der gewiß nicht zum Zwecke leichtfertiger Etikettierung bestimmter Personen, Organisationen oder Bestrebungen vorschnelle Verwendung finden sollte, ist dort, wo er nach gewissenhafter Prüfung oder gar aufgrund unanfechtbarer richterlicher Entscheidung am Platze ist, geeignet, das Bewußtsein für die Gefährdetheit unserer Verfassung zu schärfen und die zu ihrem Schutz erforderliche Wachsamkeit auf den Plan zu rufen. Ein Monopol des BVerfG, bestimmte politische Ziele oder Organisationen als verfassungsfeindlich zu qualifizieren, gibt es nicht. Niemand ist gehindert, sich darüber Gedanken zu machen und sie auch auszusprechen, Gerichte und Behörden sind nach Maßgabe ihrer gesetzlich fixierten Zuständigkeit auch befugt, daran rechtsverbindliche Folgen zu knüpfen. Das BVerfG (E 13, $123 \mathrm{ff}$.) hat bekanntlich keinen Anstand daran genommen, daß eine Partei im Verfassungsschutzbericht der Bundesregierung oder in der parlamentarischen Äußerung eines Ministers als verfassungsfeindlich qualifiziert wird. Ebenso fällt es in die Kompetenz öffentlicher Dienstherren, darüber zu befinden, ob ein Bewerber die Eignungsvoraussetzung des \& 4 I Nr, 2 BRRG erfüllt, was (insoweit wohl unstreitig) die Prüfung einschließt, ob er verfassungsfeindliche Bestrebungen verfolgt. Zum Begriff des Verfassungsfeindes s. auch Roellecke, DÖV 1978, S. $463 \mathrm{f}$.

${ }_{67} \mathrm{~S}$. BVerfGE 5,85 ff., 138.

${ }_{68}$ Dürig in Maunz/Dürig/Herzog/Scholz, Art. 18 GG, RN 11.

${ }^{69}$ BK Art. 18 II Erl. 2 d. 
nicht mehr berufen kann ${ }^{70}$. Der im Vollbesitz seiner Grundrechte befindliche Verfassungsfeind hingegen steht jedem anderen Bürger rechtlich gleich, der die seinen subjektiven Rechten gezogenen Schranken übertritt: er hat mit den an Gesetz und Recht gebundenen Reaktionen der staatlichen Gewalt zu rechnen ${ }^{71}$.

\section{Die Pflicht des Staates zum Schutz der Verfassung}

\section{Grundsatz}

Die Entscheidung des Grundgesetzes für die wehrhafte Demokratie ist kein freibleibendes Angebot, dessen sich zu bedienen im Belieben des Staates stünde. Wenn es richtig ist, daß sich der Staat der Bundesrepublik Deutschland mit jenen Inhalten, die seine freiheitliche demokratische Grundordnung ausmachen, identifiziert ${ }^{72}$ und insoweit seine Neutralität aufgegeben $^{73}$ hat, dann folgt daraus, daß die staatlichen Organe gehalten sind, diese Ordnung zu verteidigen. Die Pflicht, die freiheitliche demolkratische Grundordnung zu wahren und Gefahren für den Bestand und die Sicherheit des Bundes und der Länder abzuwehren, ist eine grundlegende Verpflichtung aller staatlichen Einrichtungen und Amtsträger ${ }^{74}, 75$.

${ }^{70}$ Dürig, a. a. O., RN 63, 78 f.; vgl. $\$ 39$ I 4 BVerfGG. Zu den Verwirkungsfolgen s. auch Schmitt Glaeser, a. a. O. (Fn. 12), S. $160 \mathrm{ff}$.

${ }^{71}$ Der Umstand, daß auch der Verfassungsfeind den Schutz der Rechtsordnung genießt, verhindert den Ausbruch des Bürgerkriegs - vgl. R. Altmann, Macht die Verfassung den Staat? Carl Schmitt wird neunzig, FAZ vom 8. 7. 1978, Beilage „Bilder und Zeiten“.

72 Hesse, Grundzüge, $\S 5$ II 4 a (S. 66).

73 Stern, Staatsrecht I, S. 425.

${ }^{74}$ So spricht beispielsweise BVerfGE 40, $287 \mathrm{ff} .$, 292, ganz selbstverständlich von dem Auftrag der mit dem Recht zum Verbotsantrag nach Art. 21 II GG, $\S 45$ BVerfGG ausgestatteten Verfassungsorgane, „die freiheitliche demokratische Grundordnung zu wahren und zu verteidigen". BVerfGE 39, 334 ff., 349, führt unter Hinweis auf Art. 1 GG aus, daß die Verfassung dem Staat aufgibt, die zentralen Grundwerte, für die sie sich entschieden hat, zu sichern und zu gewährleisten. Die Beamtengesetze haben daraus die richtige Konsequenz gezogen, daß der einzelne Amtswalter sich zur freiheitlichen demokratischen Grundordnung nicht nur $\mathrm{zu}$ bekennen, sondern auch für sie einzutreten hat; vgl. z. B. § 35 I 2 BRRG, 52 II BBG. S. ferner BVerfGE 8, 122 ff. (LS. 6); 13, 54 ff., 76.

75 Die die Streitbarkeit des GGes konstituierenden Normen der Verfassung sind i.S. W. Bagehots nicht ein dignified, sondern ein efficient part of the constitution; dazu Herb. Krüger, Allg. Staatslehre, 1966, S. 215; s. a. H. Mandt, a. a. O. (Fn. 52), S. 14, mit Hinweisen auf Versuche, das Prinzip der streitbaren Demokratie i. d. S. um- bzw. abzuwerten. 


\section{Parteiverbot}

Der Grundsatz präjudiziert nicht die Antwort auf die Frage, ob und unter welchen Voraussetzungen von den in der Verfassung bereitgehaltenen Instrumenten des Verfassungsschutzes Gebrauch zu machen ist. Sie muß sich an der jeweils in Betracht kommenden Norm orientieren. So steht beispielsweise nahezu außer Streit, da $\beta$ die Antragstellung nach Art. 21 Abs. 2 GG im Ermessen der antragsberechtigten Stellen steht ${ }^{78}$. Aber es wäre falsch zu meinen, dieses Ermessen sei unbegrenzt oder der Antrag dürfe nur gestellt werden, wenn der Antragsteller von der hochgradigen Gefährlichkeit der Partei überzeugt ist ${ }^{77}$. An der Inkorporation in das Verfassungsgefüge, die den Parteien durch Art. 21 GG zuteil geworden ist, können „politisch sinnvoll nur diejenigen unter ihnen teilnehmen, die auf dem Boden der freiheitlichen demokratischen Grundordnung stehen "78. Das BVerfG bezeichnet es als "eine notwendige Folge“ der „verfassungsrechtlichen Garantie der Parteien ..., daß verfassungswidrige Parteien von der politischen Willensbildung des Volkes ausgeschlossen sein müssen “79. Kommt die zur

76 BVerfGE 5, 85 ff., 113, 129 f.; 40, 287 ff., 291 f.; Stern, Staatsrecht I, S. 173; ders., Verfahrensrechtliche Probleme der Grundrechtsverwirkung und des Parteiverbots in: BVerfG und GG, 1976, 1. Bd., S. 194 ff., 201 m. w. Nachw. (Fn. 25); a. M. insb. K.-H. Seifert, Die politischen Parteien im Recht der Bundesrepublik Deutschland, 1975 , S. 490 f. m. Nachw. (Fn. 184), der für eine grundsätzliche Verpflichtung zur Antragstellung „,bei nur engem Ermessensspielraum“ plädiert. $\mathrm{Zu}$ Problematik und Folgen des Opportunitätsprinzips W. Schmidt, Das Parteienprivileg zwischen Legalität und Opportunität, DOV 1978, S. $468 \mathrm{ff}$.

77 S. B. Höver, Das Parteiverbot und seine rechtlichen Folgen, 1975 , S. $140 ; F$. Stollberg, Die verfassungsrechtlichen Grundlagen des Parteiverbots, 1976, S. 88.

78 BVerfGE 2, 1 ff.; 73; 5, 85 ff., 134.

70 BVerfGE 5, $85 \mathrm{ff}$., 134 (Hervorhebung von mir). - E. Forsthoff, Bemerkungen zur Situation der Verwaltung in: Standorte im Zeitstrom, Festschrift f. A. Gehlen, 1974, S. 41 ff., 49, bemerkt zu Recht, wenn die Zugehörigkeit zu einer Partei nicht mit dem Odium der Verfassungsfeindlichkeit belegt werden dürfe (BVerfGE 12, $296 \mathrm{ff}$ ), müsse dem Nachweis der verfassungsfeindlichen Zielsetzung und Betätigung i. S. des Art. 21 GG das Verbotsverfahren auf dem Fuße folgen. Anderenfalls ergäbe sich die absurde Konsequenz, daß der verfassungsfeindlichen Betätigung ein verfassungsrechtlich geschützter Freiraum zugestanden und damit der Sinn des Art. 21 in sein genaues Gegenteil verkehrt würde. Ein schlagkräftiges Beispiel dafür liefert BVerfGE 47, $198 \mathrm{ff}$., $227 \mathrm{ff}$., wo in folgerichtiger Anwendung des Parteienprivilegs die öffentlich-rechtlichen Rundfunkanstalten für verpflichtet gehalten werden, auch solche Wahlkampfsendungen politischer Parteien auszustrahlen, die einen verfassungsfeindlichen Inhalt haben, sofern sie nicht allgemein Strafgesetze verletzen. S. a. - das Parteienprivileg einschränkend - 
Antragstellung berechtigte Stelle zu dem Ergebnis, daß eine Partei verfassungswidrig ist, ist sie deshalb mindestens berechtigt, den Verbotsantrag zu stellen. Im übrigen ist es, wie das BVerfG $^{80}$ sagt, legitim, wenn "zunächst" (!) der Versuch gemacht wird, eine verfassungswidrige Partei durch eine mit politischen Argumenten geführte Auseinandersetzung in die Schranken zu weisen und dadurch ein Verbotsverfahren überflüssig zu machen. Wenn allerdings der Kampf der Partei gegen die freiheitliche demokratische Ordnung oder den Bestand der Bundesrepublik Deutschland evident ${ }^{81}$ und die Erfolglosigkeit der politischen Auseinandersetzung erwiesen ist, schrumpft der Ermessensspielraum der antragsberechtigten Verfassungsorgane auf Null ${ }^{82}$. Ermessensfehlerhaft und damit rechts- bzw. verfassungswidrig ist es jedenfalls, wenn Verfassungsorgane den Einsatz der ihnen durch Art. 21 Abs. 2 GG an die Hand gegebenen Waffe aus grundsätzlichen Erwägungen ablehnen ${ }^{83}$ - denn damit setzen sie sich in Widerspruch zur Verfassungsschutzkonzeption des Grundgesetzes - oder sich gegenüber einer auswärtigen Macht verpflichten, von ihr ge-

BVerfGE 47, 130 ff.; BVerfGE 47, 198 ff., 230 ff. Dazu W. Schmidt, a. a. O. (Fn. 76).

80 BVerfGE 40, 287 ff., 292.

81 Auf die Evidenz stellt bes. H. Heckelmann, Das Ermessen staatlicher Organe bei der Stellung von Verbotsanträgen nach Art. 21 II GG ( 843 BVerfGG), 1976, S. 195 f., ab.

${ }_{82}$ Vgl. K. Doehring, Das Staatsrecht der Bundesrepublik Deutschland unter besonderer Berücksichtigung der Rechtsvergleichung und des Völkerrechts, 1976, S. 135, der sehr zu Recht betont, daß es sich bei der Antragstellung nicht um eine Rechts-, sondern um eine Kompetenzausübung und damit um eine Pflichterfüllung handelt. Ebenso ders., Sozialstaat, Rechtsstaat und freiheitlich-demokratische Grundordnung, Die Politische Meinung, Sonderheft, 1978, S. 26 f. Das häufig zu hörende, von Politikern freilich allzuoft nur zum Zwecke der Vertuschung ihrer Handlungs- und Entscheidungsschwäche verwendete Argument, die Uberwachung einer verbotenen, in den Untergrund gedrängten Organisation sei wesentlich schwieriger als die einer im Schutz der Legalität operierenden, ist nicht nur wenig überzeugend, sondern jedenfalls dann auch verfassungsrechtlich bedenklich, wenn es zum Vorwand genommen wird, das Instrument des Parteiverbots aus dem Waffenarsenal des Verfassungsschutzes zu verbannen.

${ }^{83}$ An der Zweckmäßigkeit (!) eines Partei- bzw. Organisationsverbots zu zweifeln, ist angezeigt, wenn die betroffene Organisation die Unzufriedenheit nicht nur unerheblicher Bevölkerungsteile über tatsächlich bestehende Mißstände zum Ausdruck bringt und in politische Aktion umsetzt. Ein wirksamer Verfassungsschutz muß dann primär die Ursachen dieser Unzufriedenheit bekämpfen. Ein evtI. Verbot kann in solchem Zusammenhang nur die Bedeutung einer flankierenden Maßnahme haben, die für sich genommen zur Wirkungslosigkeit verurteilt bliebe. 
genüber einer bestimmten Partei keinen Gebrauch zu machen ${ }^{84}$.

Die Tatsache, daß sich diese rechtlichen Erwägungen insbesondere seit dem Wiedereintritt der seinerzeit verbotenen KPD in das Verfassungsleben als gänzlich wirkungslos erwiesen haben, hat zu Uberlegungen geführt, wie „das Staatsschutzkonzept des Grundgesetzes aus (s)einem seit langem fortschreiten-

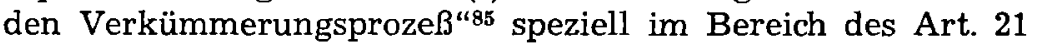
GG gelöst werden könne.

So hat Willms $s^{86}$ vorgeschlagen, die Feststellungen der Verfassungswidrigkeit einer Partei nicht länger mehr mit ihrer Auflösung zu verbinden ( $\$ 46$ Abs. 3 S. 1 BVerfGG), diese vielmehr (dem Ermessen) der Exekutive anheimzustellen. Bernstein/Zweigert ${ }^{87}$ bevorzugen das sog. Quarantänemodell, d. h.: Folge des Verdikts der Verfassungswidrigkeit soll wiederum nicht die Auflösung, sondern der Ausschluß von der Teilnahme an Wahlen und Abstimmungen sein. Ferner wird eine Befristung des Parteiverbots erwogen ${ }^{88,}{ }^{89}$. Im Zusammenhang mit der Frage der Beschäftigung von Mitgliedern verfassungsfeindlicher Organisationen im öffentlichen Dienst und im Bemühen um die Rechtsstaatlichkeit des Verfahrens befürworten u. a. Stern ${ }^{90}$ und Kriele ${ }^{91}$ die Einführung eines administrativen Verfahrens, in dem - entsprechend den Anforderungen des Beamtenrechts negativ! - festgestellt werden soll, daß die Partei oder Vereinigung nicht für die freiheitliche demokratische Grundordnung eintritt; gegen diese Feststellung soll von der betroffenen Organisation das BVerwG (in erster und letzter

84 Allerdings fragt $H$. Maurer, Das Verbot politischer Parteien, AöR 96 (1971), S. 203 ff., 226 (Fn. 74), mit Recht, was geschehen könne, wenn die antragsberechtigten Organe ihrer Rechtspflicht zur Antragstellung nicht nachkommen, und antwortet, da eine Klage beim BVerfG mangels einer Rechtsverletzung nicht in Betracht komme, bleibe nur die politische Einflußnahme, äußerstenfalls das Widerstandsrecht des Art. 20 IV GG.

${ }_{85}$ G. Willms, Muß es gleich das Parteiverbot sein? FAZ vom 10. 5. 1977.

86 A. a. O.

97 Die Rehabilitierung einer aufgelösten politischen Partei, 1972.

88 G. Willms, Zur Problematik des Parteiverbots, JZ 1973, S. 455 f., der auch für eine widerrufliche Suspendierung des Parteiverbots durch das BVerfG eintritt.

${ }_{89} R$. Dolzer, Die staatstheoretische und staatsrechtliche Stellung des BVerfG, 1972, S. $120 \mathrm{f}$., möchte ebenfalls der Exekutive das Verbot überlassen, dessen nachträgliche Uberprüfung durch das BVerfG sich auf die Feststellung eines etwaigen Ermessensfehlgebrauchs zu beschränken habe.

Q0 Zur Verfassungstreue der Beamten, 1974, S. $53 \mathrm{ff}$.

91 Feststellung der Verfassungsfeindlichkeit von Parteien ohne Verbot, ZRP 1975, S. 201 ff.; ders., Replik, ZRP 1976, S. 58 f.; ebenso F. Fuchs/E. Jesse, a. a. O. (Fn. 16), S. $29 \mathrm{f}$. 
Instanz) angerufen werden können. Das Verfahren nach Art. 21 Abs. 2 GG bliebe davon formaliter unberührt.

Gegen alle diese Vorschläge sprechen verfassungsrechtliche und verfassungspolitische Bedenken.

In verfassungsrechtlicher Hinsicht hat W. Henke ${ }^{92}$ dargelegt, warum das BVerfG ${ }^{93}$ mit guten Gründen die Auflösung als die mindestens „normale, typische und adäquate Folge der Feststellung der Verfassungswidrigkeit" der Partei betrachtet ${ }^{94}$. Um nur die m. E. wichtigsten Gründe hier anzuführen: Das Parteienprivileg besteht, soweit es sich um verfassungsfeindliche Organisationen handelt, vor allem ${ }^{95}$ in der verfassungsgerichtlichen Zuständigkeit für die Feststellung der Verfassungswidrigkeit ${ }^{96}$; dafür, daß die Partei hinsichtlich der Verbotsfolge anders als andere Vereinigungen $\mathrm{zu}$ behandeln wäre, gibt Art. 21 GG nichts her. Weiterhin hat das BVerfG ${ }^{97}$ es als eine zwingende Folge nicht etwa der Auflösung der Partei, sondern der Feststellung ihrer Verfassungswidrigkeit angesehen, daß parlamentarische Mandatsträger ihr Mandat verlieren - eine gesetzliche Ermächtigung für den Ausspruch dieser Rechtsfolge hielt es nicht für nötig. Daraus folgt zumindest, da $\beta$ eine Partei, deren Verfassungswidrigkeit festgestellt ist, sich an Wahlen nicht mehr beteiligen kann - ein Wahlerfolg wäre ihr von Verfassungs wegen verwehrt.

Die Befristung (oder widerrufliche Suspendierung) von Parteiverboten - in der Absicht, der Partei Zeit zu geben, auf ihre verfassungsfeindlichen Bestrebungen $\mathrm{zu}$ verzichten - ist überflüssig: die Partei kann in diesem Fall jederzeit neu gegründet werden.

Die Einführung eines administrativen Feststellungsverfahrens nach den Vorschlägen Sterns und Krieles dürfte mit dem

92 Verteidigung der Demokratie durch Parteiverbot oder Parteiquarantäne, JZ 1973, S. 293 ff., 295 f.

${ }_{93}$ BVerfGE 5, 85 ff., 391. S. auch das Zitat zu Fn. 79 und die Argumentation in BVerfGE 2, 1 ff., $72 \mathrm{ff}$.

${ }_{84}$ Allerdings meint BVerfGE 2, 1 ff., 74, auch, zur Auflösung einer Partei hätte es der in $\S 46$ III BVerfGG enthaltenen ausdrücklichen gesetzlichen Ermächtigung bedurft. Der Hinweis könnte sich allerdings auch auf die Auflösung durch das BVerfG selbst beziehen: danach wäre eine Regelung denkbar, die die Auflösung zwar der Exekutive überließe, sie aber nicht in deren Ermessen stellte.

${ }^{95}$ Nicht ausschließlich: die Deutung des Parteienprivilegs durch das $B V e r f G$ bringt es mit sich, da $B$ parteikonnexe verfassungsfeindliche Betätigung, soweit sie sich ,allgemein erlaubter Mittel“ bedient, bis zum Verbotsausspruch als legal zu gelten hat; dazu $H$. $H$. Irlein in: Festschrift für E. R. Huber, S. 86, und W. Schmidt, DOVV 1978 , S. $470 \mathrm{f}$.

${ }^{86}$ Henke, JZ 1973, S. 296; Stern, Staatsrecht I, S. 177.

${ }^{97}$ BVerfGE 2, 1 ff.; 72 ff. 
in Art. 21 Abs. 2 GG statuierten Entscheidungsmonopol des BVerfG kaum zu vereinbaren sein; denn dieses schließt es aus, die Verfassungswidrigkeit einer Partei ihr gegenüber anders als aufgrund eines Spruchs des BVerfG unmittelbar geltend zu machen ${ }^{88}$. Eben das geschieht jedoch (wie sich aus der Anfechtbarkeit der Feststellung durch die betroffene Partei ergibt), und zwar unbeschadet der Tatsache, daß nicht positiv die Verfassungsfeindlichkeit der Partei, sondern nur negativ deren mangelndes Eintreten für die Verfassung festgestellt werden soll. Art. 21 Abs. 2 GG erlaubt es nicht, außer verfassungsfeindlichen auch noch verfassungsneutrale Parteien mit einem rechtlichen Unwerturteil zu versehen: in der politischen Auseinandersetzung, für die das Grundgesetz den Parteien Chancengleichheit gewährleistet, wäre auch eine solche Partei evident rechtlich benachteiligt ${ }^{90}$. Verfassungsrechtlich bedenklich wäre es auch, aus einem etwaigen Unterbleiben der Feststellung durch den zuständigen Bundesminister des Innern die Folgerung zu ziehen, die öffentlichen Dienstherren seien insoweit gezwungen, Verfassungsfeinde einzustellen ${ }^{100}$. Zöge man diesen Schluß jedoch nicht, verlöre die Regelung jeden Sinn.

Unter verfassungspolitischen Gesichtspunkten gilt es vor allem zu bedenken, ob die Vorschläge geeignet sind, die Effektivität des Verfassungsschutzes zu erhöhen. Das ist nachhaltig $z u$ bezweifeln. Insbesondere wäre es pure Illusion zu glauben, wer zu schwach ist, Verbotsanträge zu stellen, wäre eher willens, die Feststellung der Verfassungswidrigkeit einer Partei zu beantragen bzw. eine solche Feststellung selbst zu treffen oder ein Verbot auszusprechen. Im Bereich der Vereinigungen, wo die Exekutive schon heute alle Vollmachten besitzt, ist sie ebenfalls seit langem untätig geblieben. Die Existenz von Parteien minderen Rechts, wie sie Willms ${ }^{101}$ vorschwebt, wäre

$98 \mathrm{Zu}$ Kriele vgl. auch W. Wiese, Eine Erwiderung, ZRP 1976, S. 54 ff.

${ }_{99}$ Hinzu kommt, daß zwar aus der Zugehörigkeit zu einer verfassungsfeindlichen, nicht aber aus der Mitgliedschaft in einer bloß verfassungsindifferenten Partei der (im Einzelfall widerlegbare) Schluß auf mangelnde Eignung für den öffentlichen Dienst gezogen werden darf.

100 BVerfGE 46, $43 \mathrm{ff}$., 55, bezeichnet das Verbot, Verfassungsfeinde in den staatlichen Vorbereitungsdienst aufzunehmen, ausdrücklich als "zwingendes Verfassungsrecht"!

101 A. a. O. (Fn. 85). - Willms denkt an die Erleichterung der politischen Kontrolle „einschließlich der Versagung öffentlicher Kundgebungen und Umzüge“, an die Nichterstattung von Wahlkampfkosten, sowie an die Verweigerung der steuerlichen Abzugsfähigkeit von Spenden, von Sendezeiten im Rundfunk und Uberlassung im Eigentum der öffentlichen Hand stehender Versammlungslokale. 
von Utbel: sie könnten ihr schlechtes Abschneiden bei Wahlen auf die permanente Beeinträchtigung ihrer Chancengleichheit zurückführen und ihre Behinderung zum Gegenstand einer Vielzahl von gerichtlichen Verfahren machen - die daraus sich ergebenden Schwierigkeiten wären ein ständiges politisches Ärgernis ${ }^{102}$. Wie übrigens, wenn die Exekutive sich erst längere Zeit nach der Feststellung der Verfassungswidrigkeit einer Partei zu deren Verbot entschlösse? Könnte die Partei nicht - mit welcher Rechtsfolge? - geltend machen, sie habe sich inzwischen geändert? Gegen das von Stern und Kriele empfohlene Feststellungsverfahren spricht, daß es sein Hauptziel, die Vermeidung der Einzelfallprüfung und der mit ihr verbundenen Nachforschungen, nicht erreicht ${ }^{103}$, da nach der P.echtsprechung des BVerfG ${ }^{104}$ die Zugehörigkeit zu einer verfassungsfeindlichen Organisation nur als "ein Stück des Verhaltens" gewertet werden darf, aufgrund dessen die Eignung eines Bewerbers für den öffentlichen Dienst verneint werden kann.

\section{Verbot von Vereinigungen und Ersatzorganisationen}

Insbesondere das Wiedererstehen der durch das BVerfG verbotenen KPD in Gestalt der DKP - und in deren Gefolge das Aufleben einer Vielzahl von der DKP teils angegliederten, teils ablehnend gegenüberstehenden linksextremistischen, an den Rändern die Terrorszene berührenden Organisationen hat der Frage, ob das Verbot verfassungsfeindlicher Vereinigungen und von Ersatzorganisationen verbotener politischer Parteien im Ermessen der zuständigen Behörden liegt (Opportunitätsprinzip) oder bei Vorliegen der tatbestandlichen Voraussetzungen ausgesprochen werden muß (Legalitätsprinzip), zu neuer Aktualität verholfen. Die Meinungen darüber sind ge-

${ }^{102} \mathrm{Zu}$ den Vorschlägen von Bernstein/Zweigert bemerkte Willms, JZ 1973, S. 454: „Eine solche Partei, die keine Partei mehr wäre, aber doch wieder eine sein möchte, könnte nur zu einer Quelle beständiger Unruhe und unfruchtbarer Konflikte werden“. Das gilt ebensosehr gegenüber seinen eigenen Vorschlägen.

103 So auch Wiese, a. a. O., S. 58.

104 BVerfGE 39, 334 ff., 359; s. dazu das Sondervotum des Richters Wand, das., S. 389 f. M. E. ist das BVerfG nicht so zu verstehen, daß die Mitgliedschaft des Bewerbers in einer Organisation mit verfassungsfeindlicher Zielsetzung allein in keinem Falle genügt, die Eignungsvoraussetzung des $\S 4$ BRRG zu verneinen. Es sind jedoch Umstände denkbar, die im Einzelfall die durch die Mitgliedschaft begründete Indizierung mangelnder Verfassungstreue widerlegen. 
teilt $^{105}$. Die einschlägigen gesetzlichen Vorschriften sind nicht eindeutig ${ }^{106}$. Die Argumente des Für und Wider sind ausgetauscht. So kann hier nur erneut bekräftigt werden:

Die Feststellung der Verfassungswidrigkeit einer Partei und die zwingend daran geknüpfte Rechtsfolge a) ihrer Auflösung, b) des Verbots, eine Ersatzorganisation zu bilden, wären sinnund wirkungslos, wenn die Exekutive zwar das Auflösungsgebot zu vollstrecken hätte, es ihr jedoch freistünde, dem Wirken sogleich oder später gegründeter Ersatzorganisationen untätig zuzusehen $^{107}$. „Wenn Worte etwas bedeuten“108, „sind“ verfas-

105 In bezug auf Ersatzorganisationen verbotener politischer Parteien (gleiches muß gelten, wenn es sich um Ersatzorganisationen verbotener Vereinigungen handelt) haben sich gegen eine Ermessensfreiheit ausgesprochen: BVerfGE 6, $300 \mathrm{ff} ., 308 \mathrm{f}$; dem Sinne nach auch Hess. VGH, OVGE 7, S. 81 ff., $83 \mathrm{f}$; F. Klein in: Maunz/ Schmidt-Bleibtreu/Klein/Ulsamer, BVerfGG, § $46 \mathrm{RN} 40 ; K . H$. Seifert, a. a. O. (Fn. 76), S. 515; Wiese, ZRP 1976, S. 56; Willms, Das Staatsschutzkonzept des Grundgesetzes, S. 23; ders., Die Sicherheit dieser Republik in: Die Politische Meinung, 1975, S. 21 ff., 28; ders., JZ 1973, S. 455; a. M. W. Henke, Das Recht der politischen Parteien, 2. Aufl. 1972, S. 260, 265; ders., JZ 1973, S. 293 ff., 294 Fn. 9; ders., Das Verbot von Ersatzorganisationen verfassungswidriger Parteien, DƠV 1974, S. $793,797$.

In bezug auf Vereinigungen gegen Ermessensfreiheit: $K$. Doehring, Staatsrecht (Fn. 82), S. $308 \mathrm{f}$; E. Forsthoff, Festschrift für Gehlen, S. 49 f.; G. Schnorr, Offentliches Vereinsrecht, 1965, S. 109 ff., 133 f., 166; a. M. BVerfGE 2, 1 ff., 78; Bernstein/Zweigert, a. a. O. (Fn. 87), S. 13; C.-F. Gastroph, Die politischen Vereinigungen, Inhalt und Grenzen der Vereinigungsfreiheit des Art. 9 des Grundgesetzes im politischen Bereich in der Verfassungsstruktur der Bundesrepublik Deutschland, Diss. München 1969, S. 137 (anders S. 253 These 30); Maunz in: Maunz/Dürig/Herzog/Scholz, Art. 9 Nr. 75; v. Münch, GG-Kommentar I, 1975, Art. 9, RN 32; B. Reichert u. a., Handbuch des Vereins- und Verbandsrechts, 2. Aufl. 19, S. $566 \mathrm{RN}$ 1375; Henke, DƠV 1974, S. 791; W. Spiller, Das Vereinsverbot nach geltendem Verfassungsrecht, Diss. Würzburg, 1967, S. 88 ff.; Wiese, ZRP 1976, S. 57; Willms, JZ 1973, S. $455 \mathrm{f}$.

${ }_{106}$ Vgl. \$§ 46 III BVerfGG, 33 PartG, 3 ff. VereinsG. Stern, Grundrechtsverwirkung und Parteiverbot in: BVerfG und GG I, S. 221, bemerkt zutreffend: „Das geltende Recht läßt in diesem Bereich Úbersichtlichkeit vermissen".

${ }_{107}$ Das Gesetz verbietet es, Ersatzorganisationen zu bilden ( $\S 33$ I PartG, 8 I VereinsG). Die Vollstreckung des Verbots ist keineswegs in das Ermessen der Exekutive gestellt: $\S 8$ II VereinsG stellt mit der Verweisung auf $\S 3$ VereinsG lediglich klar, daß dem Vollzug aus anzuerkennenden Gründen der Rechtssicherheit (dazu grundlegend BVerwGE 4, $188 \mathrm{ff}$.) ein die Eigenschaft als Ersatzorganisation feststellender Verwaltungsakt vorauszugehen hat. Auch § 3 I VereinsG beschränkt sich in bezug auf nach Art. 9 II GG verbotene Vereine darauf, eine solche Verfügung deklaratorischen Charakters zu fordern.

${ }_{108}$ Forsthoff, Festschrift für Gehlen, S. 50. 
sungsfeindliche Vereinigungen und Ersatzorganisationen kraft (Verfassungs-)Gesetzes "verboten“ (Art. 9 Abs. 2 GG) ${ }^{109}$. Was aber verboten ist, darf - von ausdrücklich zugelassenen Ausnahmen abgesehen ${ }^{110}$ - nicht geduldet werden, wenn anders die normative Kraft der Rechtsordnung und damit diese selbst nicht zum Gespött werden soll111!

Nach alledem ist die Praxis des Verfassungs- und Rechtsungehorsams, die seit der mit der Geburtshilfe der damaligen Bundesregierung vollzogenen „Wiederzulassung" der KPD in diesem Bereich geübt wird, ein permanentes Skandalon unseres Rechtsstaates, dessen verhängnisvolle Auswirkungen auf das allgemeine Rechtsbewußtsein heute offen zutage liegen.

\section{Verfassungstreue und Bürgerpflicht}

\section{Keine allgemeine Verfassungstreuepflicht}

Eine rechtliche Verpflichtung des Bürgers zu aktiv bewiesener Verfassungstreue besteht im demokratischen Rechtsstaat nicht. Mit der verfassungsrechtlich gemeinten Aussage, die Demokratie des Grundgesetzes erwarte von ihren Bürgern eine Verteidigung der freiheitlichen Ordnung, hat das BVerfG ${ }^{\mathbf{1 1 2}}$

109 Soweit es sich um Ersatzorganisationen verbotener Parteien handelt, die selbst Parteicharakter haben: mit Ausnahme der zur Zeit des Verbots schon bestehenden ( $\$ 33$ II PartG).

110 Eine solche ist grundsätzlich im Bereich des Polizeirechts gegeben; daraus folgt aber nicht, daB das Opportunitätsprinzip in allen Bereichen des Rechts gilt, die im weiteren Sinne dem Polizeirecht zuzurechnen sind.

${ }^{111}$ Schlicht zur Farce degradiert wurde das Staatsschutzrecht durch die Übernahme des Feststellungsprinzips aus dem Vereinsin das Strafrecht durch das 8. Strafrechtsänderungsgesetz von 1968. Seither ist die Betätigung in einer Ersatzorganisation nur strafbar, wenn deren Eigenschaft als Ersatzorganisation zuvor in dem dafür vorgeschriebenen Verfahren unanfechtbar festgestellt wurde ( $\$$ 84, 85 StGB). Die Zuwiderhandlung gegen ein Partei- oder Vereinigungsverbot ist bei einigermaßen geschicktem Vorgehen nunmehr so gut wie risikolos. Vgl. dazu $H$. Krauth u. a., Das neue Staatsschutzstrafrecht in der Praxis in: 25 Jahre Bundesgerichtshof, 1975, S. $227 \mathrm{ff}$; Lüttger, Das Staatsschutzstrafrecht gestern und heute, JR 1969, S. 121 ff., 128; G. Willms, JZ 1973, S. 456; ders., Die politische Meinung 1975, S. $27 \mathrm{ff}$. Alles in allem handelt es sich hierbei freilich nur um ein besonders sinnfälliges Beispiel für die seit den 60 er Jahren konsequent durchgeführte Kastration unseres politischen Strafrechts.

112 BVerfGE 28, $36 \mathrm{ff}$., 48. Der insoweit $\mathrm{zu}$ beanstandende Satz steht im Kontext der Erörterung des Umfangs der in § 10 VI SG normierten Zurückhaltungspflicht der Soldaten bei A̛ußerungen innerhalb und außerhalb des Dienstes. Bezogen auf die Dienstpflichten der Soldaten wie anderer Angehöriger des öffentlichen Dienstes bleibt er berechtigt. Kritisch zu der Entscheidung des BVerfG K. Ipsen/J. Ipsen, BK, Art. 17 a GG, RN $56 \mathrm{ff}$. 
die Anforderungen an Bürgersinn und Bürgertreue überdehnt ${ }^{113}$.

Die Entwicklung „eines sittlichen Berufs des Staatsbürgers als sinngebender Voraussetzung seiner ganzen öffentlichen Rechtsstellung"114 gehört, was ihre Bedeutung nicht mindert, in das Kapitel "Staatsethik"; sie ist nicht Aufgabe des Verfassungsrechts. Die rechtliche Inpflichtnahme der Gesinnung des Bürgers ist unvereinbar mit der ihm garantierten geistigen Freiheit und im übrigen - jedenfalls in dieser Allgemeinheit - von der Rechtsordnung auch nicht zu leisten. Das Grundgesetz kennt keine Grundpflicht zur Verfassungstreue ${ }^{15}$. Es statuiert nur ein Bürgerrecht116 zur Verteidigung der freiheitlichen demokratischen Grundordnung.

\section{Die allgemeine Mißbrauchsschranke aktiver Verfassungs- feindlichkeit}

Hingegen ist es richtig, wenn das BVerfG im Anschluß an die soeben beanstandete Formulierung fortfährt, das Grundgesetz nehme einen Mißbrauch der Grundrechte zum Kampf gegen die freiheitliche Ordnung nicht hin. Damit wird nur die zutreffende Schlußfolgerung aus der dem Grundgesetz zugrundeliegenden Einsicht gezogen, daß das Recht zur Zerstörung der Freiheit nicht aus der verfassungsrechtlichen Garantie der Freiheit legitimiert werden kann ${ }^{117}$.

Zur Begründung dieser weit überwiegend geteilten Meinung muß hier aus Zeitgründen auf an anderer Stelle Gesagtes Bezug genommen werden ${ }^{118}$. Jedoch sei ausdrücklich bemerkt, daß mit der hier vertretenen Auffassung zugleich gegen eine Aus-

113 Gleiches gilt für Art. 146 I Hess. Verf. Dazu s. Schmitt Glaeser, a. a. O. (Fn. 12), S. 127 Fn. 233, 282.

${ }_{114} R$. Smend, Bürger und Bourgeois im deutschen Staatsrecht, in: Staatsrechtliche Abhandlungen, 2. Aufl. 1968, S. $309 \mathrm{ff}$., 320.

115 Vgl. zum Problem $H$. $H$. Klein, Uber Grundpflichten, Der Staat 14 (1975), S. $153 \mathrm{ff}$.

${ }_{116}$ Isensee, Das legalisierte Widerstandsrecht, S. 82; Herzog in: Maunz/Dürig/Herzog/Scholz, Art. 20, RN 214, 274.

117 S. O. I 3 zu Fn. 45.

118 H. H. Klein, Festschrift f. E. R. Huber, S. 81 f.; H.-U. Gallwas, Der Mißbrauch von Grundrechten, 1967, S. 91 ff.; Schmitt Glaeser, a. a. O. (Fn. 12), S. $128 \mathrm{f}$. m. w. Nachw., 132, 251 - nicht zu folgen vermag ich allerdings Schmitt Glaesers Ansicht (a. a. O., S. 145), der Mißbrauch der Grundrechte zum Kampf gegen die freiheitliche demokratische Grundordnung i.S. des Art. 18 GG müsse ein in seiner Gesamttendenz gewaltloser sein; es ist nur schwer zu begreifen, warum gewalttätigen Verfassungsfeinden die in Art. 18 GG genannten Grundrechte nicht solIten aberkannt werden können. Vgl. auch die Nachw. bei $H$. Copić, Grundgesetz und politisches Strafrecht neuer Art, 1967, S. 37 Fn. 76. 
legung des Art. 18 GG Position bezogen wird, wie sie vor Jahren von Copic ${ }^{\mathbf{1 1 9}}$ vorgetragen und jüngst von $S$ chlink ${ }^{\mathbf{1 2 0}}$ wieder aufgegriffen worden ist. Danach soll Art. 18 GG eine Sperrwirkung dergestalt entfalten, daß das BVerfG nicht nur für die Verhängung der Sanktion, sondern auch für die Feststellung des Grundrechtsmißbrauchs in der spezifischen Erscheinungsform des Kampfes gegen die freiheitliche demokratische Grundordnung ausschließlich zuständig ist. Art. $18 \mathrm{GG}$ wird hier also - wie übrigens auch Art. 9 Abs. 2 GG - in Parallele zu Art. 21 Abs. 2 GG konstruiert: aus dem Parteienprivileg wird ein Privileg für Verfassungsfeinde schlechthin - für Copić ist „eine verfassungsfeindlichen Zielsetzungen dienende Grundrechtsbetätigung im Rahmen der allgemeinen Rechtsordnung ...Rechtsverwirklichung politischer Grundrechte... und folglich rechtmäßiges Tun"121. Schmitt-Glaeser ${ }^{122}$ hat dieser Auslegung zu Recht vorgehalten, weiter könne man die Pervertierung einer Verfassungsschutzbestimmung sicher nicht treiben ${ }^{123}$. Richtiger Ansicht nach ${ }^{124}$ entfaltet Art. 18 GG Sperrwirkung nur bei Identität von Tatbestand un d Sanktion ${ }^{125}$.

Die sozialstaatliche Bändigung grundgesetzlich gewährleisteter Freiheit ist ein als selbstverständlich anerkanntes verfassungsrechtliches Postulat ${ }^{126}$. Wie das Prinzip der Sozialstaatlichkeit zieht auch die Entscheidung des Grundgesetzes für die freiheitliche Demokratie die Grenze zwischen Grundrechtsgebrauch und Grundrechtsmißbrauch ${ }^{127}$.

119 A. a. O., S. 98 f., 101.

120 A. a. O. (Fn. 55), S. 356.

121 A. a. O., S. $98 \mathrm{f}$.

122 A. a. O., S. 257; zu Copić s. auch Steinberger, Konzeption und Grenzen freiheitlicher Demokratie, S. 393 Fn. 409.

${ }_{123}$ Vgl. auch Dürig in: Maunz/Dürig/Herzog/Scholz, Art. 18 RN 69, und U. Matz, Extremisten im öffentlichen Dienst, DOV 1978, S. 464 ff., 467.

124 Dürig, a. a. O., RN 94.

125 So auch BVerfGE 25, $88 \mathrm{ff}$., $92 \mathrm{f}$.

126 BVerfGE 5, 85 ff., 206; 8, 274 ff., 329; 21, $87 \mathrm{ff} ., 91 ; 21,245 \mathrm{ff}$, 251. - Zu Art. 14 GG: BVerfGE 25, 112 ff., 117; 37, 132 ff., 140; 38, 348 ff., 370 .

127 Gegen die Auffassung, jede Form des Kampfes gegen die freiheitliche demokratische Grundordnung sei grundrechtsmißbräuchlich und also rechtswidrig, verschlägt der Einwand nichts, Art. 5 III Satz 2 GG werde dadurch überflüssig; so aber Copić, a. a. O., S. 38. Er verkennt den Bedeutungsgehalt dieser Vorschrift, die die Verfassungsuntreue nicht nur in der Verhaltensform des Kampfes gegen die freiheitliche demokratische Grundordnung, sondern generell dem Schutzbereich des Grundrechts der Lehrfreiheit entzieht (so richtig R. Scholz in: Maunz/Herzog/Dürig/Scholz, Art. 5 III RN 202) und damit die allgemeine $\mathrm{Mi} ß$ brauchsschranke verschärft.

Verfehlt ist auch die Behauptung, die Charakterisierung aktiv 


\section{Die Verfassungstreuepflicht der Beamten}

So unzweideutig das BVerfG ${ }^{128}$ die in den Beamtengesetzen niedergelegte Pflicht der Beamten zur Verfassungstreue als "zwingendes Verfassungsrecht"129 gekennzeichnet hat, so wenig läßt sich bedauerlicherweise in bezug auf dieses leidige Problem von einer Befriedung der Lage sprechen ${ }^{130}$. Ich kann zu den strittig gebliebenen Fragen nur thesenartig Stellung nehmen ${ }^{131}$ :

- Die Kritik wendet sich mit besonderem Nachdruck gegen die Forderung, der Beamte habe sich auch gesinnungsmäßig - seiner inneren Haltung nach - mit dem Staat und seiner Verfassung $\mathrm{zu}$ identifizieren ${ }^{132}$. Ihr ist in erster Linie ent-

kämpferischer Verfassungsfeindlichkeit als durch die Grundrechte nicht gedecktes, rechtswidriges Handeln, stelle die Betroffenen rechtlos, da insbesondere die Exekutive dagegen vorgehen dürfe, ohne noch einer Rechtsgrundlage zu bedürfen (so aber Schlink, a. a. O. (Fn. 55), S. 362 f.). Richtig ist demgegenüber, daß bezüglich der Folgen des Grundrechtsmißbrauchs im Anschluß an Gallwas (a.a. O. [Fn. 118], S. 99 f.) zwischen mehreren möglichen Reaktionen des Staates unterschieden werden muß: Begnügt er sich mit der bloßen Verhinderung oder Unterbindung des Grundrechtsmißbrauchs weist er den Grundrechtsträger lediglich in die Schranken seines Rechts zurück; das allgemeine Polizeirecht setzt hier Maßstab und Grenze. - Im polizeirechtlichen Schrifttum steht es übrigens außer Streit, daß der Staat und seine Einrichtungen einschließlich seiner verfassungsmäßigen Ordnung als Polizeigüter zu betrachten sind, deren Beeinträchtigung polizeiliche Reaktionen auslöst - vgl. statt vieler: V. Götz, Allgemeines Polizei- und Ordnungsrecht, 4. Aufl. 1977, S. $38 \mathrm{f}$; Drews/Wacke/Vogel/Martens, Gefahrenabwehr, 8. Aufl., 2. Bd., 1977, S. $118 \mathrm{f}$. Was aber polizeiwidrig ist, ist richtiger Ansicht nach auch rechtswidrig! - Jede darüber hinausgehende Sanktion hingegen bedarf als ein die Unterbindung des fehlsamen Rechtsgebrauchs überschreitender Eingriff in Freiheit oder Eigentum des Betroffenen einer zusätzlichen gesetzlichen Grundlage.

${ }^{128}$ BVerfGE 39, 334 ff. S. auch BVerwGE $47,330 \mathrm{ff}$.

129 BVerfGE 46, 43 ff., 55.

130 Ich sehe dabei von jenen Attacken ab, die in (mehr oder minder durchsichtiger) politischer Absicht gegen die verfassungsgerichtlichen Entscheidungen geritten werden und dazu dienen sollen, den Widerstand gegen die Unterwanderung des Staates durch Verfassungsfeinde erlahmen zu lassen.

131 Ein Verzeichnis der - allerdings nicht durchweg negativen Stellungnahmen zum Extremistenproblem in der Zeit seit 1974 bei Dreier, Gedächtnisschrift für F. Klein, Fn. 130. Ergänzend ist insbesondere auf Dreiers eigenen Beitrag und die Arbeiten von Schlink und Roellecke, DÖV 1978, S. $457 \mathrm{ff}$., hinzuweisen. S. auch Kriele, Wider die alte Schwarmgeisterei, Die ZEIT vom 21. 4. 1978; Matz, DÖV 1978, S. 464 ff.; W. Schmidt, ebenda, S. $468 \mathrm{ff}$.

132 BVerfGE 39, $334 \mathrm{ff}$. (LS 2), $348 \mathrm{f}$. - Vgl. etwa Dreier, a. a. O., S. 90; Böckenförde, Der Staat als sittlicher Staat (Fn. 22), S. 26 ff. 
gegenzuhalten: Gegenstand des geforderten Bekenntnisses ist der demokratische und soziale Rechtsstaat des Grundgesetzes ${ }^{135}$. Das macht jeden Vergleich mit der Rechtslage zur Zeit des Nationalsozialismus hinfällig ${ }^{134}$. Bestehen bleibt freilich die auch im Beamtenrecht nicht ohne Auswirkungen bleibende Tatsache, daß das Grundgesetz den Versuch unternommen hat, die Wehrhaftigkeit des von ihm verfaßten Staates gegen zerstörerische Bestrebungen im Vergleich zur Weimarer Demokratie zu stärken. Von seinen Beamten darf dieser Staat daher mehr erwarten als distanzierte Indifferenz. Wenn er sich auch und gerade in Krisenzeiten auf seine Organwalter soll verlassen und seiner Pflicht zur Verteidigung der freiheitlichen Ordnung ${ }^{135}$ soll genügen können, dann reicht es eben nicht aus, wenn die Beamten in allen Lagen zu korrekter Anwendung der Gesetze bereit sind ${ }^{138}$, und zwar schon deshalb nicht, weil die Aufgabe der Beamten keineswegs nur in der Anwendung von Gesetzen besteht $^{197}$. Der Staat muß davon ausgehen können, daß seine Bediensteten auch aus eigenem Antrieb und nicht nur dort, wo sie - $u$. U. innerlich widerstrebend - dem Befehl des Gesetzes oder den Anordnungen ihres Vorgesetzten Folge leisten, das zur Erhaltung des demokratischen Rechtsstaates Notwendige tun ${ }^{138}$.

133 S. O. I 1.

134 Er wird von Böckenförde, a. a. O., im Hinblick auf äußere Ähnlichkeiten im Wortlaut der damals und heute geltenden Beamtengesetze gezogen.

135 Vgl. oben II 1.

136 So Denninger, Einführung in: Freiheitliche demokratische Grundordnung I, S. 24; vgl. auch Dreier, a. a. O. (Fn. 45), der auf Gesetzes- und Verfassungstreue, jedoch „weniger auf die ,Gesinnung' abgestellt" wissen möchte - wo liegt der Unterschied?

${ }_{137}$ Richtigerweise sieht es etwa Schlink, a. a. O. (Fn. 55), S. 350, nicht als Verstoß gegen Art. 3 III GG an, einen Bewerber für den öffentlichen Dienst mit der Begründung abzuweisen, seine Weltanschauung verpflichte ihn, Gesetze und Amtspflichten nur dann als verbindlich zu betrachten, wenn sie mit seinem Interesse oder Gewissen vereinbar sind. Warum anderes gelten soll, wenn ein Bewerber nicht dem von Schlink beispielhaft zitierten „naiven Anarchismus" oder "ethischen Rigorismus" huldigt, sondern sich einer höchst realitätsnahen, mit zerstörerischer Energie geladenen - kommunistischen oder faschistischen - Ideologie verschworen hat, ist nicht zu begreifen.

${ }^{138}$ BVerfGE 39, $334 \mathrm{ff}$., wird verschiedentlich entgegengehalten, das Gericht habe sich damit in Widerspruch $\mathrm{zu}$ seiner früheren Rechtsprechung zur Frage des Fortbestehens der vor dem 8. Mai 1945 begründeten Beamtenverhältnisse gesetzt, vgl. BVerfGE 3, $58 \mathrm{ff}$, $85 \mathrm{ff} . ; 6,132 \mathrm{ff} ., 152 \mathrm{f}$. So insbes. Dreier, a. a. O. (Fn. 45), S. 90, und Denninger, a. a. O. (Fn. 136), S. 12. Der Vorhalt ist nicht berechtigt. Das BVerfG hat seine damalige Auffassung gerade damit be- 
- Gesetz und Verfassung gestatten es nicht, das Maß der zu fordernden Verfassungstreue unterschiedlich zu bemessen je nach der Art des Beamtenverhältnisses oder der dienstlichen Obliegenheiten ${ }^{139}$. Lediglich für den Vorbereitungsdienst - soweit die darin vermittelte Ausbildung auch der Vorbereitung auf einen außerhalb des Staatsdienstes auszuübenden Beruf dient - erfährt der Grundsatz für Bewerber, die einen solchen Beruf anstreben, eine gewisse Einschränkung: die Schwelle der Verfassungstreuepflicht liegt niedriger, nur verfassungsfeindliche Betätigung ist unstatthaft ${ }^{140}$.

- Den Behörden des Verfassungsschutzes vorliegende Erkenntnisse über einen Bewerber sind von der Einstellungsbehörde für die Beurteilung seiner Eignung unter dem Gesichtspunkt der Verfassungstreue grundsätzlich ${ }^{141}$ heranzuziehen. Das gilt auch, wenn es sich um die Ubernahme in

gründet, daß der Nationalsozialismus mit der Vorstellung, der Staat habe parteipolitisch neutral zu sein und den in ihm sich bewegenden und bekämpfenden politischen und gesellschaftlichen Mächten gleiche Chancen zur Mitwirkung bei der politischen Willensbildung einzuräumen, brechen wollte und gebrochen hat (BVerfGE 3, 85). Die Forderung, der Beamte habe für die freiheitliche Ordnung des Grundgesetzes einzutreten und für den demokratischen und sozialen Rechtsstaat Partei zu ergreifen (BVerfGE 34, $348 \mathrm{f}$ ), mit dem Gesinnungsterror des nationalsozialistischen Regimes auch nur zu vergleichen, ist ein starkes Stück! Richtig ist nur, daß das Grundgesetz nicht $z u$ jener uferlosen Toleranz zurückgekehrt ist, die in den Augen seiner Väter den Untergang der ersten deutschen Demokratie mitverursacht hat, und daß es sich deshalb auch zu einer im Vergleich zur Weimarer Republik (vgl. zur damaligen Praxis $H$. $H$. Klein, Festschr. für E. R. Huber, S. 90 ff.) weitergehenden Inpflichtnahme der Diener des von ihm verfaßten Staates entschlossen hat.

${ }_{139}$ BVerfGE 39, 334 ff., 355; BVerfGE 47, $330 \mathrm{ff} ., 340 ; \mathrm{s}$. auch W. Schmitt Glaeser, Was noch geschehen muß. Sicherung und Sicherheit der Grundrechte in: Die Politische Meinung, 1977, Heft 175, S. $5 \mathrm{ff}$., $13 \mathrm{ff}$, in berechtigt scharfer Auseinandersetzung mit einer verantwortungslosen Äußerung des Bundeskanzlers H. Schmidt im "Spiegel“ Nr. 43/1976, S. 42, er vermöge nicht einzusehen, warum ein Lokomotivführer der Deutschen Bundesbahn nicht Kommunist sein darf.

${ }_{140}$ BVerfGE 39, 334 ff., 374; BVerfGE 46, 48 ff., 52: die Verfassung schließe es aus, "daß der Staat seine Hand dazu leiht, diejenigen auszubilden, die auf die Zerstörung der Verfassungsordnung ausgehen"; vgl. den ausführlichen Bericht von $F$. K. Fromme, Noch keine Reform des staatlichen Vorbereitungsdienstes, FAZ vom 12. 4. 78 , S. $10 \mathrm{ff}$.

${ }_{141}$ Einschränkungen, wie sie z. B. der Beschluß des nds. Landesministeriums vom 10. 7. 1972 i. d. F. v. 3. 5./21. 6. $77 \mathrm{Nds}$. MBl. Nr. 34/ 1977 , S. 884 ff., unter Nr. 2.3. vorsieht, sind nicht nur zulässig, sondern zweckmäßig. 
den Vorbereitungsdienst handelt. Das BVerfG ${ }^{142}$ hat sich zu dieser Frage überaus mißverständlich geäußert. Thm ist zuzustimmen, wenn es dazu neigt, auf jugendliche Aktivitäten gerichtete Ermittlungen der Staatsschutzbehörden und die Speicherung ihrer Ergebnisse für Zwecke der Einstellungsbehörden ${ }^{143}$ für einen Verstoß gegen Rechtsstaats- und Verhältnismäßigkeitsprinzip zu halten. Dem Gericht kann jedoch nicht gefolgt werden, wenn es der Auffassung gewesen sein sollte, in anderem Zusammenhang angefallene Erkenntnisse seien nicht verwertungsfähig ${ }^{144}$.

- Die Eignung der Bewerber für den öffentlichen Dienst ist unvoreingenommen aufgrund des vorhandenen Tatsachenmaterials zu prüfen. Eine Vermutung spricht weder für noch gegen ihre Verfassungstreue ${ }^{145}$, sowenig das Vorliegen anderer Eignungsvoraussetzungen, die Gesundheit etwa, vermutet wird. Für sämtliche Eignungsvoraussetzungen im Sinne des Beamtenrechts gilt ohne Unterschied: sie müssen „zur Uberzeugung der Einstellungsbehörde feststehen. Ein non liquet geht zu Lasten des Bewerbers"148.

142 BVerfGE 39, 334 ff., 356 f, zu Recht kritisch zu dieser Passage des Urteils das Sondervotum des Richters Wand, a. a. O., S. $390 \mathrm{f}$.

143 Hervorhebung im Urteil!

144 Die unguten Folgen der vom Gericht befürworteten schwerpunktmäßigen Verlagerung der Prüfung der Verfassungstreue in die Probe- und Vorbereitungszeit werden von Wand, a. a. O., zutreffend dargelegt und von Dreier, a. a. O. (Fn. 45), S. 107 f., verharmlost.

${ }_{145} \mathrm{Abw}$. die gegen die Stimmen der CDU/CSU-Fraktion verabschiedete Resolution des Deutschen Bundestages vom 20. 10. 1975 (Prot. 7/13600 und BT-Drucks. 7/4183 S. 5); ebenso $K$. Lange, „Radikale“ im öffentlichen Dienst, NJW 1976, S. 1809 ff., 1816; Dreier, a. a. O. (Fn. 45), S. 108 f., 111, dessen Behauptung, die Praxis vor 1972 sei von einer solchen Loyalitätsvermutung ausgegangen, nicht belegt und auch nicht belegbar ist; Beschluß des Senats der Freien Hansestadt Bremen betr. Verfahren bei Feststellung des Erfordernisses der Verfassungstreue von Bewerbern für den öffentlichen Dienst vom 14. 3. 77, Nr. 2.1, Amtsbl. 1977, S. 87.

$140 \mathrm{~K}$. Stern, Verwaltungsprozessuale Probleme in der öffentlichrechtlichen Arbeit, 3. Aufl. 1976, S. 147; s. a. ders., Staatsrecht I, $\mathrm{S} .282 \mathrm{~m}$. w. Nachw. auch für die Gegenmeinung; ferner $H$. $H$. Klein, Festschr. für E. R. Huber, S. 90; zutr. der in Fn. 141 erwähnte Beschluß des nds. Landesministeriums unter Nr. 2.5: „Können die bestehenden Verdachtsgründe nicht ausgeräumt werden, darf der Bewerber nicht in den öffentlichen Dienst eingestellt werden". Die höchstrichterliche Rechtsprechung in dieser Frage ist seltsam unklar und widersprüchlich, steht im Ergebnis aber wohl mit der hier vertretenen Auffassung im Einklang: vgl. BVerwGE 47, 330 ff., Leitsatz 3, S. 337 ff., BVerfGE 39, 334 ff., 352 f. - zutr. Kritik bei Stern an o. a. Fundstellen. 
- Für die Beurteilung der Eignung des Bewerbers ist die Zugehörigkeit zu einer verfassungsfeindlichen Organisation ein relevanter Umstand ${ }^{147}$. Dementsprechend muß die Frage danach erlaubt $\operatorname{sein}^{148}$ - unbeschadet der Tatsache, daß grundsätzlich eine Verpflichtung des Beamtenbewerbers zur Offenbarung von Parteimitgliedschaften nicht besteht $t^{149}$. Verweigert der Bewerber die Antwort auf diese Frage, kann und wird in aller Regel dieses Verhalten den Zweifel an seiner Verfassungstreue nähren ${ }^{150}$.

- Das BVerfG ${ }^{151}$ hat hervorgehoben, daß das Urteil der Einstellungsbehörde über die Eignung des Bewerbers „nur den Einzelfall im Auge (hat) und sich... jeweils auf eine von Fall zu Fall wechselnde Vielzahl von Elementen und deren Bewertung" gründet. Es verrät eine merkwürdige Logik, wenn mancher, der sich zunächst engagiert dagegen gewandt hatte, die Zugehörigkeit $\mathrm{zu}$ einer verfassungsfeindlichen Organisation als einen unwiderlegbaren Zweifel an der Eignung begründenden Umstand anzusehen, nunmehr gegen diese im Interesse der Einzelfallgerechtigkeit $\mathrm{zu}$ begrüßende Rechtsprechung mit dem Vorwurf zu Felde zieht, sie führe $z u$ "Gesinnungsschnüffelei"152.

147 Die Zugehörigkeit $\mathrm{zu}$ einer verfassungsfeindlichen Organisation ist nach BVerfGE 39, 334 ff., 353, 359, ein Element für die Beurteilung der Verfassungstreue des Bewerbers, ein Stück des dafür erheblichen Verhaltens. Das Gericht hält es für verfassungsrechtlich bedenklich, „wenn ein Gesetz allgemein zwingend vorschreibt, daß einzelne konkrete Verhaltensweisen", also auch diese, die Gewähr der Verfassungstreue ausschließen (a. a. O., S. 354 f.). Der Akzent liegt auf „zwingend“. Im Einzelfall kann dieser oder ein anderer einzelner Umstand durchaus Zweifel an der Verfassungstreue rechtfertigen; vgl. das insoweit klarstellende Sondervotum des Richters Wand, a. a.O., S. $389 \mathrm{f}$. Es muß nur die Möglichkeit offenbleiben, sich im Einzelfall ein abweichendes Urteil - i.S. einer Bejahung der Gewähr - zu bilden.

148 So schon H. H. Klein, Festschr. für Huber, S. 89 f.

149 Dreier, a. a. O. (Fn. 45), S. $108 \mathrm{~m}$. Nachw. - allerdings ohne klare Aussage im hier entscheidenden Punkt.

150 Anders LAG Bremen, NJW 1978, S. $910 \mathrm{f}$.

151 BVerfGE 39, 334 ff., 353.

152 Es bleibt daran zu erinnern, daß staatsschutzbehördliche Ermittlungen gegen Einzelpersonen für Zwecke der Einstellungsbehörden - gewissermaßen vorsorglich - grundsätzlich nicht erfolgen dürfen (BVerfGE 39, 334 ff., $356 \mathrm{f}$.); eine Ausnahme ist dann anzunehmen, wenn es konkrete Anhaltspunkte für eine verfassungsfeindliche Einstellung des Bewerbers gibt, die ja belegbar ("gerichtsverwertbar") sein müssen, wenn sie zur Begründung einer Ablehnung herangezogen werden sollen. Im übrigen aber kann keineswegs der Satz gelten: „Zielobjekte des Verfassungsschutzes haben Organisationen zu sein und nicht einzelne Personen" - so das ArbG Hamburg in einem Urteil vom 11. 10. 1976, zit. nach Fromme, 
- Eine normative Regelung des bei der Prüfung der Verfassungstreue eines Bewerbers einzuhaltenden Verfahrens etwa nach dem Vorbild der im Jahre 1977 in Niedersachsen durch einen Beschluß der Landesregierung getroffenen ${ }^{153}$ vermöchte jedenfalls dort zur Versachlichung des Meinungsstreits und zum Abbau unbegründeter Besorgnisse einen Beitrag zu leisten, wo solche Besorgnisse nicht absichtsvoll und wider besseres Wissen geäußert werden und die Bereitschaft zur Sachlichkeit noch besteht ${ }^{154}$.

- Die allgemeine beamtenrechtliche Treupflicht gilt ohne jede Einschränkung auch für beamtete Wissenschaftler. Die Frei-

a. a. O. (Fn. 146), der dazu nicht ohne sarkastischen Unterton bemerkt, es sei nicht leicht verständlich, wie der Verfassungsschutz Organisationen beobachten und dabei von den Personen absehen könne, deren Verhalten die Eigenart der Organisation prägt.

${ }^{153}$ S. o. Fn. 141. Der Beschluß regelt im einzelnen die Einholung von Auskünften beim Minister des Innern und deren Umfang; er sieht für den Fall, daß wegen bestehender Zweifel an der Verfassungstreue des Bewerbers dessen Ablehnung erwogen wird, die Eröffnung und Erörterung der Verdachtsmomente mit dem Bewerber vor. Dafür ist durch einen weiteren Beschluß des Landesministeriums vom 3. 5./21. 6. 1977 (MinBl. Nr. 34/1977, S. 886) eine Anhörkommission gebildet worden, der vier ständige Mitglieder und ein Mitglied desjenigen Ressorts angehören, dessen Geschäftsbereich von der Bewerbung betroffen ist. Gegen die Entscheidung der Kommission kann von der obersten Dienstbehörde, vom Minister des Innern und vom Ministerpräsidenten das Landesministerium angerufen werden. Dem anzuhörenden Bewerber ist es gestattet, einen Rechtsanwalt mitzubringen, dessen Tätigkeit sich auf die Beratung und Beobachtung des Verfahrens zu beschränken hat. Das Verfahren ist in einem weiteren Beschluß des Landesministeriums vom gleichen Datum (gleiche Fundstelle) geregelt.

154 Ein Gebot der Sachlichkeit ist es beispielsweise darauf hinzuweisen, daß die etwa von Lange, NJW 1976, S. 1809, in perhorreszierender Absicht mitgeteilte Zahl von zwischen August 1972 und März 1976 durchgeführten 496700 Uberprüfungsverfahren (C.-Chr. Kaiser spricht in einem Artikel in "Die ZEIT“ vom 5. 5. 1978 gar von einer Million) keineswegs darüber Auskunft gibt, in welchem Umfang das Vorleben von Bewerbern bis in die letzten Schlupfwinkel ihrer Persönlichkeitsstruktur durchforscht worden ist, wie wohl suggeriert werden soll. In Wirklichkeit handelt es sich um die Zahl der Bewerber für den öffentlichen Dienst innerhalb dieser Zeitspanne, deren Eignung routinemäßig und pflichtgemäß geprüft und deren weit überwiegender Teil positiv im Sinne der Bejahung der Verfassungstreue abgeschlossen werden konnte, weil keine anderslautenden Erkenntnisse vorlagen. Wo es solche gab, wurden - freilich mit unterschiedlichem Eifer und wohl auch mit unterschiedlichem Geschick! - weitere Nachforschungen angestellt. Wer sich dagegen wendet, muß in Kauf nehmen, da $\beta$ die Einstellungsbehörde auftauchenden Zweifeln an der Verfassungstreue eines Bewerbers nicht nachgeht, sondern ohne weiteres die Bewerbung ablehnt. 
heit der Wissenschaft und ihrer Lehre schafft - jedenfalls in dieser Hinsicht - keinerlei Privileg. Das deutlich zu machen, ist der Sinn der Treueklausel in Art. 5 Abs. 3 S. 2 $\mathrm{GG}^{155}$. Wissenschaftlich-rationale Kritik der Verfassung einschließlich ihrer Grundlagen ist damit nicht inhibiert ${ }^{156}$. Objektiv verfassungswidrige Wissenschaft ist ein Widerspruch in sich ${ }^{157}$. Dessen ungeachtet aber gilt: auch die Freiheit der Wissenschaft (wie der Kunst) unterliegt jenen Schranken, die sich aus dem Grundgesetz selbst ergeben ${ }^{158}$. Daraus ergibt sich das - der zuvor entwickelten allgemeinen Mißbrauchsschranke entsprechende - Verbot, das Grundrecht zum Kampf gegen die freiheitliche demokratische Grundordnung $\mathrm{zu}$ mißbrauchen ${ }^{158}$. Ferner folgt: Auch dem beamteten wissenschaftlichen Lehrer bleibt Verfassungskritik nicht verwehrt; das entbindet ihn jedoch nicht von der Pflicht, in voller Loyalität zur freiheitlichen demokratischen Grundordnung im Sinne des Grundgesetzes zu stehen und sich für ihre Geltung einzusetzen. Ein sich daraus etwa ergebender Gewissenskonflikt ist lösbar nur durch das Ausscheiden aus dem Dienst des Staates, dessen verfassungsrechtliche Grundlagen der Beamte verneint ${ }^{100}$.

155 BVerfGE 39, 334 ff., 346 f., hält neben Art. 33 IV auch Art. 5 III 2 GG für eine der Vorschriften, in denen das GG auf die traditionelle Treupflicht des Beamten als einen hergebrachten Grundsatz des Berufsbeamtentums Bezug nimmt. Vgl. zum Problem Scholz in: Maunz/Dürig/Herzog/Scholz, Art. 5 III RN 203.

156 Scholz, a. a. O., RN 199. Ebenso schon die bekannte Äußerung C. Schmids im Hauptausschuß des Parlamentarischen Rates. JöR N. F. 1, S. 92. Nicht anders ist das BVerfG zu verstehen (E $5,85 \mathrm{ff}$, 146), wenn es sagt, daß Wissenschaft, sofern sie die Erarbeitung und Darstellung von Erkenntnissen ist, niemals gegen die freiheitliche demokratische Grundordnung verstoßen kann.

${ }^{157}$ Insoweit richtig von Oertzen, Rede in der 84. Plenarsitzung des 8. Nds. Landtags am 17. 2. 1978, Prot. S. 8199.

158 BVerfGE 30, 173 ff., 193 ff. (Mephisto).

150 Das wird bei $v$. Oertzen, a. a. O., zwar nicht verkannt, die Einsicht in die Möglichkeit solcher Grenzüberschreitung bleibt jedoch folgenlos, wenn $v$. Oertzen (S. 8201) für die Wissenschaft selbst das ausschließliche Recht beansprucht, Grenzfälle zu beurteilen; denn staatliche, insbesondere beamtenrechtliche Sanktionen sind dann allenfalls mit der Ausnahme des Art. 18 GG - ausgeschlossen. Wie hier dagegen Scholz, a. a. O., RN 58 (zur Kunstfreiheit), 185 (zur Wissenschaftsfreiheit), $93 \mathrm{~m}$. w. Nachw. (zur Abgrenzung zwischen wissenschaftlicher Theorie und politischer Aktion).

${ }_{180}$ E. Friesenhahn, Staatsrechtslehrer und Verfassung in: RechtStaat-Wirtschaft, 3. Bd. 1950 , S. 64 , schreibt: „Kommt er (der Wissenschaftler) in seinem Forschen aus wissenschaftlicher Uberzeugung zur Verneinung der Grundlagen der bestehenden staatlichen Ordnung, so darf er nicht erwarten, daß dieser Staat ihn in seinem Lehramt beläßt". 


\section{Der administrative Verfassungsschutz}

\section{Parlamentarische Kontrolle}

Die Einrichtungen des administrativen Verfassungsschutzes $^{161}$ sind durch das Bekanntwerden einer Reihe bislang nicht restlos aufgeklärter Vorgänge, aber auch durch die gezielte Agitation gewisser Kreise in jüngster Zeit allzu häufig Gegenstand der öffentlichen Erörterung gewesen. Auch die Rechtswissenschaft hat sich ihrer nach längerem Schweigen ${ }^{162}$ wieder anzunehmen begonnen ${ }^{163}$. Die Reaktion des Bundesgesetzgebers beschränkt sich vorerst auf den Erlaß des Gesetzes über die parlamentarische Kontrolle nachrichtendienstlicher Tätigkeit des Bundes ${ }^{164}$.

Das Gesetz überträgt die Kontrolle der Bundesregierung hinsichtlich der Tätigkeit des Bundesamtes für Verfassungsschutz, des MAD und des BND der Parlamentarischen Kontrollkommission (PK). Ob das mit dem Gesetz verfolgte Ziel, die Intensivierung der parlamentarischen Kontrolle der genannten Dienste ${ }^{165}$, erreichbar ist, steht dahin. Zwar hat nach $\S 3$ Abs. 1 des Gesetzes die PK einen Anspruch darauf, von der Bundes-

161 Gemeint sind die Verfassungsschutzbehörden des Bundes und der Länder, der Bundesnachrichtendienst (BND) und der Militärische Abschirmdienst der Bundeswehr (MAD).

162 An die grundlegenden Beiträge von H.-U. Evers, Privatsphäre und Ämter für Verfassungsschutz, 1960, J. Salzwedel, Gedächtnisschrift für Peters, 1967, S. 756 ff., sowie an den Besprechungsaufsatz von A. Arndt, NJW 1961, S. $897 \mathrm{ff}$., sei erinnert. Vgl. ferner: Bundesministerium des Innern (Hrsg.), Verfassungsschutz. Beiträge aus Wissenschaft und Praxis, 1966. Weitere Literaturangaben bei Stern, Staatsrecht I, S. $147 \mathrm{f}$.

${ }_{163} H$. Borgs-Maciejewski, Parlament und Nachrichtendienste, Aus Politik und Zeitgeschichte, Beilage zur Wochenzeitung "Das Parlament", B 6/77, S. 12 ff.; D. Hömig, Zur parlamentarischen Kontrolle der Nachrichtendienste, das., B 42/77, S. 15 ff., mit einer Erwiderung von Borgs-Maciejewski, Die Nachrichtendienste im Spannungsfeld zwischen Parlament und Regierung, ebenda, S. $33 \mathrm{ff}$.

164 Gesetz vom 11. 4. 1978, BGB1. I S. 453. - Die Verfassungsschutzgesetze der Länder sind zum größeren Teil in den letzten Jahren novelliert bzw. beschlossen worden. Vgl. die Nachweise bei C. Arndt, DVBl. 1978, S. 385 ff. (Fn. 6-8). Die Frage der parlamentarischen Kontrolle hat dabei insbesondere in den Beratungen des Nds. Landtags, die jedoch nicht zur Einrichtung einer besonderen parlamentarischen Kontrollinstanz führten, und der Hamburgischen Bürgerschaft - dort mit anderem Ergebnis - eine Rolle gespielt.

165 Insbesondere im Vergleich zur bisherigen Praxis des sog. Parlamentarischen Vertrauensmännergremiums (PVMG), dessen Beibehaltung die Enquete-Kommission Verfassungsreform, BT-Drucks. 7/5924, S. $60 \mathrm{ff}$., aus wohlerwogenen Gründen empfohlen hatte; vgl. allerdings die Sondervoten der Abg. Dr. Arndt und Dr. Lenz, a. a. O., S. $76 \mathrm{ff}$. 
regierung „über die allgemeine Tätigkeit" der Dienste und „über Vorgänge von besonderer Bedeutung" „umfassend“ unterrichtet zu werden. Aber nach $\S 3$ Abs. 2 des Gesetzes werden „Zeit, Art und Umfang der Unterrichtung der Kontrollkommission...unter Beachtung des notwendigen Schutzes des Nachrichtenzugangs durch die politische Verantwortung der Bundesregierung bestimmt". Die zwischen beiden Vorschriften offenkundig bestehende Spannung verdeutlicht das - unausweichliche! - Dilemma ${ }^{166}$ zwischen notwendiger parlamentarischer Kontrolle und nicht minder notwendiger Effektivität der Dienste, die zu gewährleisten gleichfalls von der Verfassung geboten wird ${ }^{107}$.

Auf das Prinzip der Gewaltenteilung gestützten Bedenken, wie sie gegen den Entwurf des Hamburgischen Gesetzes vom 13. Februar $1978^{168}$ bestanden ${ }^{169}$, begegnet das Bundesgesetz nicht. Ein anderer Einwand, daß nämlich die Einrichtung der PK als eines Hilfsorgans des Parlaments ${ }^{170}$ im Wege der Verfassungsänderung hätte erfolgen müssen ${ }^{171}$, ist bisher jedoch

166 Dazu bes. Hömig, a. a. O., S. 28 ff.

167 BVerfGE 30, 1 ff., 20. - Die parlamentarischen Kontrollbefugnisse kranken allgemein an dem weitgehenden Recht der Exekutive, der kontrollierenden Legislative Informationen vorzuenthalten; vgl. dazu $R$. Schmid, Zur demokratischen Kontrolle der Nachrichtendienste in: Merkur 1978, S. $306 \mathrm{ff}$, , sowie Vorschlag und Erwägungen der Enquete-Kommission Verfassungsreform, BTDrucks. 7/5924, S. 50 ff. S. auch Art. 32 Hamb. Verf.

168 Hamb. GVBl. S. 51.

189 Dazu Stern in Anlage 3 zur Drucks. 8/3280 der Bürgerschaft der Freien und Hansestadt Hamburg, S. 42, 55, 67; allgemein Hömig, a. a. O., S. $30 ;$ Borgs-Maciejewski, a. a. O., S. $33 \mathrm{ff}$.

${ }_{170}$ Wie das PVMG, anders aber als die auf die Bildung eines besonderen Ausschusses hinauslaufenden Vorschläge, ist die PK kein Ausschuß des Deutschen Bundestages; Rechtsfolge: Art. 43 II GG findet keine Anwendung. Ebenso C. Arndt, a. a. O., S. 387.

171 So auch H.U. Evers, Parlamentarische Kontrolle der Nachrichtendienste, NJW 1978, S. 1144 f.; s. ferner E. Friesenhahn, Anlage 2 zur Drucks. 8/3280, S. $17 \mathrm{f}$., und Anlage 3 zur Drucks. 8/3280, S. 59, der Bürgerschaft der Freien und Hansestadt Hamburg zu dem im Hamb. Gesetz vorgesehenen KontrollausschuB, dessen Befugnisse allerdings über die üblichen Instrumente parlamentarischer Kontrolle erheblich hinausgehen (vgl. §§ 9 II a (Pflicht zur Aktenvorlage), 9 II $b$ (Anhörung von Beamten als Auskunftspersonen), 10 (Entgegennahme von Petitionen und deren Untersuchung)). Auch der von einem Untersuchungsausschuß des 5. Deutschen Bundestages empfohlene Ausschuß für Angelegenheiten der Nachrichtendienste sollte die Rechte eines Untersuchungsausschusses - und zwar ausschließlich - wahrnehmen und seine verfassungsrechtliche Grundlage in einer Ergänzung des Art. 45 a GG finden; vgl. BT-Drucks. V/3442. Ähnlich der Vorschlag des Abg. Dr. Arndt, a. a. O. Diese Unterschiede zur Regelung des Bundesgesetzes werden nicht übersehen. 
nicht ausgeräumt. Zwar unternimmt das Gesetz den Versuch dazu, indem es in $\S 1$ Abs. 2 bestimmt, daß die Rechte des Bundestages und seiner Ausschüsse unberührt bleiben. Diese Vorschrift dürfte sich in der Praxis jedoch - von spektakulären Ausnahmefällen abgesehen - als falsa demonstratio erweisen. Denn nicht nur de facto, sondern nach der Intention des Gesetzes wird die Kontrolle der Regierung in bezug auf die Tätigkeit der Dienste mindestens schwerpunktmäßig in der PK erfolgen. Hinzu kommt, daß die Regierung gegenüber der Kommission Auskunftspflichten hat, die diejenigen nach Art. 43 Abs. $1 \mathrm{GG}^{172}$ deutlich überschreiten. Das Bundesgesetz vom 11. April 1978 hätte daher m. E. ähnlich wie das Gesetz über den Wehrbeauftragten ${ }^{173}$ und das Gesetz über den Petitionsausschuß $\beta^{174}$ einer verfassungsgesetzlichen Grundlage bedurf $t^{175}$.

\section{Rechtsgrundlagen}

Während dem durch Beschluß der Bundesregierung errichteten BND die Auslandsaufklärung obliegt ${ }^{176}$, Eingriffe dieses Dienstes in die Rechtssphäre von im Geltungsbereich des Grundgesetzes lebenden Personen also schon seiner Aufgabenstellung nach nicht vorgenommen werden dürfen und das Fehlen einer gesetzlichen Grundlage deshalb unbedenklich ist ${ }^{177}$, liegen die Dinge beim MAD anders. Rechtsgrundlage des MAD ist ein Organisationsakt des Bundesministers der Verteidigung; ein Gesetz über den MAD, das seine Aufgaben und Befugnisse umschreibt, existiert nicht. Der MAD als wesentlicher Bestandteil des "Militärischen Nachrichtenwesens" ${ }^{\text {"178 }}$ hat einerseits eine Informations-, andererseits eine Schutz- und Sicherungsfunktion ${ }^{179}$. Zur Erfüllung dieser Aufgaben muß der MAD wie der Verfassungsschutz im Inland systematisch Nachrichten sammeln und auswerten, eine Tätigkeit, die, soweit sie Personen be-

${ }^{172}$ Dazu J. von Einem, Die Auskunftspflicht der Regierung gegenüber dem Parlament, Göttinger Diss. 1977.

173 Vom 26. 6. 1957, BGBl. I S. 652.

174 Vom 19. 7. 1975, BGBl. I S. 1921.

175 Vgl. schon meine Rede in der 78. Sitzung des Deutschen Bundestages am 9. 3. 1978, Prot. S. 61101 B; zust. Evers, a. a. O. (Fn. 171); a. M. C. Arndt, DVBl. 1978 , S. 386.

176 Vgl. die Dienstanweisung vom 4. 12. 1968, abgedruckt in BTDrucks. 7/3246, S. 47.

177 So mit Recht Stern, Staatsrecht I, S. 186.

178 Vgl. zu diesem Stichwort Th. Walde in: Zoll/ Lippert/Rössler, Bundeswehr und Gesellschaft. Ein Wörterbuch, 1977, S. $187 \mathrm{ff}$.

${ }_{179}$ Walde, a. a. O., nennt als Ziel des Militärischen Nachrichtenwesens auf der Grundlage der bestehenden dienstlichen Verfügungen: „die Wehrlage fremder Staaten, die Gewährleistung der Sicherheit im militärischen Bereich, die Verteidigungsbereitschaft der eigenen Bevölkerung". 
trifft ${ }^{180}$, schon als solche nach einhelliger Meinung in deren Persönlichkeitsrecht eingreift und damit einer gesetzlichen Grundlage bedarf ${ }^{181}$. Gleiches gilt, soweit zu den genannten Zwecken "nachrichtendienstliche Mittel"182 eingesetzt werden. Es ist deshalb ein dringendes Gebot der Rechtsstaatlichkeit, den MAD endlich mit der bisher fehlenden gesetzlichen Grundlage auszustatten.

Im Hinblick auf die Ämter für Verfassungsschutz wird insbesondere seit dem Fall Traube ${ }^{183}$ die Frage diskutiert, ob der Einsatz von Lauschmitteln ein zulässiges „nachrichtendienstliches Mittel" ist bzw. ob, wenn nein, eine entsprechende Klarstellung im Gesetz geboten und ggf. verfassungsrechtlich zulässig wäre. $\mathrm{Da}$ in diesem Zusammenhang auch das Problem des Rückgriffs auf die allgemeinen Notrechtsbefugnisse, insbesondere auf den sog. rechtfertigenden Notstand ( 334 StGB), zum Zwecke der Rechtfertigung eines vom Gesetz „an sich“ nicht erlaubten Eingriffs in individuelle Rechte eine Rolle spielt ${ }^{184}$, sind ihm vorab einige Erwägungen zu widmen ${ }^{185}$.

Die Rede ist nicht von einem allgemeinen Staatsnotrecht -

180 Nach Walde, a. a. O., haben sich in den Karteikästen des MAD bisher Erkenntnisse über rund 4 Mio. Personen angesammelt, etwa unter den Kennworten „Risikopersonen“ oder „Merkmalperson im V-Fall“.

181 de Lazzer/Rohlf, Der „Lauschangriff“, JZ 1977, S. 207 ff., 209 m. w. Nachw. (Fn. 43); ebenso Borgs-Maciejewski, a.a. O. B 6/77, S. 17, ebenfalls m. Nachw.

${ }_{182} \S 3$ III BVerfSchG.

183 Dazu s. die Verhandlungen in der 17. Sitzung des 8. Deutschen Bundestages am 16. März 1977, Prot. S. $957 \mathrm{ff}$.

${ }^{184}$ Für die ältere Diskussion dieser Problematik vgl. die Nachw. in der Begründung des Musterentwurfs eines einheitlichen Polizeigesetzes des Bundes und der Länder i.d. F. des Beschlusses der Innenministerkonferenz vom 25. 11. 1977, S. $14 \mathrm{f}$. Neu aufgeflammt ist die Kontroverse insbes. seit dem sog. Fall Traube, gewissen Vorkommnissen in der Justizvollzugsanstalt Stuttgart-Stammheim und der von den Justizministern der Länder (mit Ausnahme Berlins) vor Inkrafttreten des entsprechenden Gesetzes - während der Schleyer-Entführung angeordneten „Kontaktsperre“. Dazu s. vor allem die Entscheidungen des $\mathrm{BGH}$ vom 23. 9. 1977, NJW 1977, S. 2173 , und des BVerfG v. 4. 10. 1977, BVerfGE 46, 1 ff., sowie: Amelung, Erweitern allgemeine Rechtfertigungsgründe, insbes. $\S 34$ StGB, hoheitliche Eingriffsbefugnisse des Staates? NJW 1977, S. 833 ff.; ders., Nochmals: $§ 34$ StGB als öffentlich-rechtliche Eingriffsnorm? NJW 1978, S. $623 \mathrm{f}$; Kirch hof, Polizeiliche Eingriffsbefugnisse und private Nothilfe, NJW 1978, S. 969 ff.; $R$. Lange, Terrorismus kein Notstandsfall? NJW 1978, S. 784 ff.; P. Lerche, Der gezielt tödlich wirkende SchuB nach künfigem einheitlichen Polizeirecht - zum Verhältnis hoheitlicher Eingriffsbefugnisse zu den allgemeinen Notrechten in: Um Recht und Freiheit, Festschr, für F.-A. v. d. Heydte, 1977, S. 103 ff.; Schwabe, Zur Geltung von Rechtfertigungsgründen des StGB für Hoheitshandeln, NJW 1977, 
obgleich die Berufung auf den rechtfertigenden Notstand ihm gefährlich nahekommt. Zumal nach der 17. Novelle zum Grundgesetz vom 24. Juni 1968 ist - für wie unzureichend man die verfassungsrechtlichen Vorkehrungen für die verschiedenen Fälle des Staatsnotstandes auch halten mag - für die undifferenzierte Anerkennung eines allgemeinen Notrechts des Staates kein Raum ${ }^{186}$. Der Rückgriff auf die Notrechtsbefugnisse des bürgerlichen und Strafrechts im öffentlichen Recht kommt nach den allgemein anerkannten Grundsätzen nur dann in Betracht, wenn die Vorschriften des öffentlichen Rechts lückenhaft sind ${ }^{187}$ und die Heranziehung der einem anderen Rechtsgebiet angehörenden Vorschriften nicht eine von den Wertungen des öffentlichen Rechts abweichende Konfliktlösung mit sich bringt ${ }^{188}$. Damit ist die Anwendung etwa des Nothilferechts ${ }^{189}$ ebenso vereinbar wie prinzipiell, obgleich gewiß nur in ganz außerordentlichen Lagen, auch die des Rechtsgedankens des übergesetzlichen Notstands ${ }^{190}$. Beide sind Bestandteile des sog. Allgemeinen Teils des Rechts ${ }^{191,}{ }^{192}$.

S. 1902 ff.; Sydow, Forum: § 34 StGB - kein neues Ermächtígungsgesetz! JuS 1978, S. 222 ff., jew. m. w. Nachw. Vgl. ferner: $E$. W. Böckenförde, Der verdrängte Ausnahmezustand, NJW 1978, S. 1881 ff.; M. Schröder, AöR 103 (1978), S. 135 ff.

185 Vgl. noch $F$. Schaffstein, Die strafrechtlichen Notrechte des Staates in: Gedächtnisschrift für $H$. Schröder, hgg. von W. Stree u. a., 1978, S. 97 ff.

${ }_{186}$ A. M. wohl Stern, Staatsrecht I, S. 564 Fn. 514, der anzunehmen scheint, eine abschließende Kodifikation für den inneren Notstand könne nicht angenommen werden. Die Differenz dürfte jedoch ohne sachliche Bedeutung sein, da sich die nachfolgenden Darlegungen Sterns mit meinen Erwägungen decken. Das gilt insb. für seine Auseinandersetzungen mit de Lazzer/Rohlf.

${ }_{187}$ Zutreffend weist Schwabe, a. a. O. (Fn. 184), S. 1907 Fn. 55, darauf hin, daß hier die eigentlichen Probleme liegen.

${ }_{188}$ So in den in $\S 82 \mathrm{Satz} 2,48$ II Satz 6 VVfG geregelten Fällen; anders zu beurteilen war der Fall BVerfGE 33, 1 ff., 16: kein Notwehrrecht der Gefängnisverwaltung gegen beleidigende Briefe eines Häftlings.

${ }^{189}$ Vgl. dazu D.-P. Steffan, Notwehr und Notstand als Rechtsgrundlagen für hoheitliche Eingriffe (demnächst in DOV).

$100 \mathrm{Zu}$ Recht erwähnen de Lazzer/Rohlf, a. a. O. (Fn. 181), S. 212, die „Schutzpflicht des Staates gegenüber der Menschenwürde der übrigen Bürger", die in extremen Ausnahmesituationen die Berufung auf den in $\S 34$ StGB ausgedrückten Rechtsgedanken rechtfertigen könne. Auf die in der Rechtsprechung des BVerfG Bedeutung gewinnende Tendenz, den Staat zum Schutz der Grundrechte für verpflichtet zu halten, weist $E$. Benda, Die verfassungsrechtliche Relevanz des Sozialrechts in: Verhandlungen des Deutschen Sozialgerichtsverbandes, 6. Bundestagung Essen, 1975, S. $32 \mathrm{ff}$., 35, hin. Nachw. aus der Rechtsprechung daselbst. Vgl. auch J. Isensee, Verfassungsgarantie ethischer Grundwerte und gesellschaftlicher Konsens, NJW 1977, S. 545 ff., 547 Fn. 17: „Staatspflicht zum Grund- 
Im Bereich des Verfassungsschutzes gilt grundsätzlich nichts anderes. Sein Aufgabenbereich ist jedoch die „Früherkennung (von Gefahren) durch Vorfeldbeobachtung.... im Vorfeld der polizeilichen Tätigkeit"193. Es geht ihm also mindestens regelmäßig nicht um die Abwehr konkreter, unmittelbar bevorstehender Gefahren oder bereits eingetretener Störungen, wie die

rechtsschutz gegen Übergriffe Dritter". Dieser Rechtsgedanke könnte auch zur verfassungskonformen Auslegung jener Vorschriften der StPO Anlaß geben, die die Uberwachung des Verkehrs zwischen Verteidiger und inhaftierten Mandanten regeln und, wie sich zumal aus der mehrfachen Ablehnung entsprechender Vorschläge durch den Gesetzgeber ergibt, die Überwachung des mündlichen Verkehrs ausschließen. Liegen nun sichere Anhaltspunkte dafür vor, daß bei einem Verteidigerbesuch ein Mordkomplott geschmiedet werden soll (so der von Schwabe, a. a. O. (Fn. 184), S. 1907 Fn. 55, konstruierte Fall), verbietet das Schutzprinzip möglicherweise die Beachtung des Überwachungsverbots. Der in diesem Fall mögliche Verteidigerausschluß ( $\$ 138$ a StPO) ist wie eine offene Überwachung nicht immer ein geeignetes Mittel, die Ausführung des Mordplans zu verhindern. Unter dieser Voraussetzung wird der Einsatz eines Lauschmittels unvermeidlich, will man nicht sehenden Auges der Durchführung des Mordplans ihren Lauf lassen. Auf diesen Standpunkt mag man sich stellen. Man wird aber kaum erwarten dürfen, daß der in der Verantwortung stehende Amtsinhaber sich ihn zu eigen macht. Das fiat iustitia, pereat mundus (hier: pereat homo) ist kein in der Praxis brauchbares Handlungsprinzip. Der Verfassungsjurist hat auch die Aufgabe, dem zu verantwortlichem Handeln Berufenen die Möglichkeit zu eröffnen, seiner Verantwortung gerecht zu werden. Dazu Böckenförde, a. a. O. (Fn. 184), S. 1895.

191 Forsthoff, Lehrbuch des Verwaltungsrechts, Bd. 1, 10. Aufl. 1973, S. $168 \mathrm{ff}$. Auch Salzwedel, Gedächtnisschrift für Peters, S. $768 \mathrm{ff}$., der sich besonders dezidiert gegen die Heranziehung des übergesetzlichen Notstands wendet, tut dies nicht ohne jede Einschränkung; vgl. einerseits S. 769: „Der übergesetzliche Notstand hat im öffentlichen Recht in dieser Form (sic!) keine Stätte“, andererseits S. 770: Ablehnung des übergesetzlichen Notstands nur, soweit die Rechtsordnung „eine genaue Stufenfolge von Gefahrenlagen und Eingriffsbefugnissen aufgestellt und die damit verbundenen Risiken für die innere Sicherheit der Bundesrepublik um der Sicherheit der Bürger vor der Exekutive willen bewußt (!) in Kauf genommen hat". Anderes ist auch hier nicht gemeint.

${ }_{192} \mathrm{Zu}$ den gewichtigsten Einwänden von Amelung, a.a.O. (Fn. 184), mit der Heranziehung der allgemeinen Notrechtsbefugnisse würden der Vorbehalt des Gesetzes umgangen, der Bestimmtheitsgrundsatz mißachtet und die rechtsstaatliche Sicherungsfunktion von Verfahrens- und Kompetenznormen preisgegeben, vgl. Schwabe, a. a. O. (Fn. 184), S. $1906 \mathrm{ff}$.

${ }^{103}$ So Bundesminister Prof. Dr. Maihofer, a. a. O. (Fn. 183), S. 985 f.; vgl. auch die Ausführungen des Abg. Dr. Wallmann, das. S. $962 \mathrm{D}$. Ähnlich, wenngleich zu weitgehend, de Lazzer/Rohlf, a. a. O. (Fn. 181), S. 209. - Im Hinblick auf diese spezifische Qualität der Aufgaben des Verfassungsschutzes ist Stern, Staatsrecht I, S. 188, zuzustimmen, wenn er seine Charakterisierung als Polizei für unzureichend hält; a. M. etwa Salzwedel, a. a. O., S. $772 \mathrm{f}$. 
Anwendung der Notrechtsbefugnisse sie voraussetzt ${ }^{194}$. Allerdings endet unbeschadet der in $\S 3$ Abs. 3 BVerfSchG niedergelegten institutionellen Trennung von Verfassungsschutz und Polizei die Zuständigkeit der Verfassungsschutzbehörden nicht notwendig dann, wenn sich die zu bekämpfende Gefahr in der beschriebenen Weise verdichtet hat; denn auch in dieser Lage mag das Sammeln und Auswerten von Nachrichten, beispielsweise zur Bestimmung der Dimension der Gefahr, noch nützlich und geboten sein.

Aus alledem folgt für den Einsatz von Lauschmitteln in Wohnungen ${ }^{195}$ ohne Wissen des Wohnungsinhabers durch Behörden des Verfassungsschutzes:

- Ein Rückgriff auf die Grundsätze des rechtfertigenden Notstandes ist nicht statthaft. Art. 13 GG regelt die Materie abschließend. Eine Rechtslücke besteht nicht ${ }^{196}$.

- Betrachtet man den Einsatz von Lauschmitteln als Eingriff oder Beschränkung i. S. von Art. 13 Abs. 3 GG $^{197}$, ist er nur unter den dort genannten Voraussetzungen - also aufgrund des verfassungsunmittelbaren Vorbehalts der ersten oder aufgrund Gesetzes nach der zweiten Alternative zulässig, es sei denn, man hielte heimliche Eingriffe in das

194 Weiteres kommt hinzu. Das für den Verfassungsschutz typische systematische Sammeln und Auswerten von Nachrichten wird immer ein geeignetes, zur Abwehr jener Gefahren, denen die Nachrichtendienste $\mathrm{zu}$ begegnen haben, auch fast immer ein erforderliches Mittel sein. Die auf dem Spiele stehenden und zu schützenden Rechtsgüter - freiheitliche demokratische Grundordnung, Bestand und Sicherheit von Bund und Ländern - sind zudem von so hohem Rang, daß der Ausgang der etwa im Rahmen des rechtfertigenden Notstandes anzustellenden Güterabwägung kaum je zweifelhaft sein wird. Das rät zu äußerster Vorsicht bei der Heranziehung der allgemeinen Notrechtsbefugnisse, die, wenn überhaupt, nur unter strengster Beachtung des Ubermaßverbots in Betracht gezogen werden kann.

${ }_{195}$ Mit Salzwedel, a. a. O., S. 781, ist entg. Evers, Privatsphäre, S. 202, anzunehmen, daß der Schutz des Art. 13 GG nicht an den Außenwänden der Wohnung endet. Mithin macht es keinen Unterschied, ob das in der Wohnung gesprochene Wort durch eine in der Wohnung angebrachte "Wanze" oder durch ein Richtmikrofon von außen aufgenommen wird. Auch kommt es nicht auf die Qualität des Wortes an, ob es also der privaten Sphäre zuzurechnen ist oder - wie beispielsweise bei einem Agententreff - nicht. Derartige Erwägungen sollen in einem 1969 von den damaligen Bundesministern des Innern und der Justiz angefertigten Gutachten enthalten sein; vgl. Die WELT vom 19. März 1977.

${ }_{196}$ Zutr. insoweit de Lazzer/Rohlf, a. a. O. (Fn. 181), S. 121, zu

Art. 13 III GG: „Kodifikation des Notstandsfalles“.

107 So die wohl überwiegende Meinung: de Lazzer/Rohlf, a. a. O., S. 208; ferner Hömig, a. a. O. (Fn. 163), S. 26. 
Grundrecht des Art. 13 GG für eine Verletzung seines Wesensgehalts (Art. 19 Abs. 2 GG) und damit für schlechthin unerlaubt ${ }^{188}$.

- Sind Abhörgeräte „nachrichtendienstliche Mittel“ i.S. von $\S 3$ Abs. 3 S. 2 BVerfSchG ${ }^{199}$, dürfen sie auch von Verfassungsschutzbehörden zum Einsatz gebracht werden, wenn es um die Abwehr einer gemeinen Gefahr ${ }^{200}$ oder einer Lebensgefahr für einzelne Personen geht; die Kompetenzschranke des $\S 3$ Abs. 3 S. 1 BVerfSchG wird damit nicht überschritten ${ }^{201}$. Soll hingegen nur erkundet werden, ob eine Gefahr besteht, ist der Tatbestand des Art. 13 Abs. 3 1. Alt. GG nicht gegeben ${ }^{202}$.

198 So Salzwedel, a.a.O., S. 781, und de Lazzer/Rohlf, a.a.O., S. $210 \mathrm{f}$, die mit der Erwägung, derartige Eingriffe beeinträchtigten den Menschenwürdegehalt des Grundrechts zugleich wohl einer gesetzlichen (einschließlich einer verfassungsgesetzlichen) Regelung des Problems entgegenzutreten versuchen. Die Autoren vermögen ihren Gedankengang freilich nicht bis zur letzten Konsequenz durchzuhalten; vgl. den S. 209 Fn. 37 geschilderten Fall und S. 212 Fn. 85. Evers, BK, Art. 73 Nr. 10, RN 53, nimmt einen Verstoß gegen Art. 19 II GG denn auch nur an, wenn ein solcher Eingriff "nicht in rechtsstaatlich befriedigender Weise eingeschränkt wird“.

${ }_{199}$ Das ist anzunehmen. Zur Problematik des (zu?) unbestimmten Rechtsbegriffs "nachrichtendienstliche Mittel" s. BT-Drucks. VI/ 5333, S. 5; Hömig, a. a. O., S. 27 f.; Borgs-Maciejewski, a. a. O. (Fn. 163), S. 22 ff., der die mangelnde rechtsstaatliche Bestimmtheit der Rechtsgrundlagen des Verfassungsschutzes durch eine Intensivierung seiner parlamentarischen Kontrolle kompensieren zu können glaubt; Stern, Staatsrecht I, S. 188 f.; ders., a. a. O. (Fn. 169), S. 73 f.; Schwagerl, das.; ders., $\mathrm{Zu}$ den Änderungen im Verfassungsschutzrecht, DOV 1974, S. 109 ff., 113 f.; de Lazzer/Rohlf, a. a. O., S. 209 f.

${ }^{200}$ Zum Begriff Drews/Wacke/Vogel/Martens, Gefahrenabwehr, 8. Aufl., 2. Bd. 1977, S. 94 m. Nachw. Eine Gefahrenlage dieser Art läge z. B. vor, wenn konkrete Anhaltspunkte dafür gegeben sind, daß in einer Wohnung über den terroristischen Einsatz etwa einer Rakete gegen ein Atomkraftwerk oder ein Flugzeug verhandelt werden soll.

201 A. M. Salzwedel, a. a. O., S. 781, und - soweit es sich um die "Zentralstelle“ (Art. 87 I 2 GG) handelt - Evers, BK, Art. 73 Nr. 10 RN 53; es ist jedoch nicht einzusehen, warum insoweit anders verfahren werden soll als bei Eingriffen in das Grundrecht des Art. 10 GG. Das Belauschen ist ein typisches nachrichtendienstliches Mittel; auf das dafür verwendete Instrument und die Art des damit bewirkten Grundrechtseingriffs kommt es unter dem Gesichtspunkt der föderalistischen Kompetenzverteilung nicht an. Vgl. auch Evers, Privatsphäre, S. 199.

${ }^{202}$ Zweifelhaft ist, ob die Tatbestandsmerkmale des Art. 13 III 1. Alt. GG auch bei bloßer Anscheinsgefahr als erfüllt angesehen werden können. Die Frage dürfte zu bejahen sein. Im Erg. ähnlich M. Schröder, AöR 103 (1978), S. 127. 
- Auf der Grundlage des Art. 13 Abs. 3 2. Alt. GG hingegen kann der Verfassungsschutz nach geltendem Recht nicht tätig werden, da es insoweit an einer gesetzlichen Grundlage fehlt. Die Verfassungsschutzgesetze des Bundes und der Länder können zu Einschränkungen des Grundrechts der Unverletzlichkeit der Wohnung schon deshalb nicht ermächtigen, weil sie Art. 13 GG als eingeschränktes Grundrecht nicht nennen ${ }^{203}$. Die Verfassungsschutzbehörden sind also insoweit auf die Amtshilfe der Polizei angewiesen, die diese Hilfe indessen nur im Rahmen ihres eigenen rechtlichen Könnens leisten darf ${ }^{204}$. Die einschlägigen Vorschriften gestatten jedoch im allgemeinen der Polizei nur ein offenes Eindringen in die Wohnung ${ }^{205}$. Damit erweist sich dieser Ausweg für den Verfassungsschutz als ungangbar. Dem ließe sich abhelfen durch eine Zitierung des Art. 13 GG in den Verfassungsschutzgesetzen ${ }^{206}$. Auch dann freilich dürfte der Verfassungsschutz nur ,zur Verhütung dringender Gefahren für die öffentliche Sicherheit und Ordnung “207 tätig werden. Um die Vereinbarkeit mit der Verfassung zu gewährleisten, wäre überdies eine derjenigen

${ }^{203}$ Wollte man annehmen, daß diese Gesetze gleichwohl zu Abhörmaßnahmen unter Verletzung des Art. 13 GG ermächtigen, bedürften sie im Blick auf Art. 19 I 2 GG insoweit einer verfassungskonformen restriktiven Interpretation.

204 \& 5 II Nr. 1 VVfG.

205 Vgl. de Lazzer/Rohlf, a. a. O. (Fn. 181), S. 210 m. Nachw,

206 So $E$. $v$. Loewenstern, Militär, Wanzen und Gesetz in: Die WELT vom 7. 2. 1978. Bedenkt man, daß nach BVerfGE 30,1 ff., 20, dem Verfassungsschutz die Mittel, deren er zur Erfüllung seines Verfassungsauftrags bedarf, nicht vorenthalten werden dürfen, dürfte es sogar geboten sein, eine entsprechende Novellierung des BVerfSchG vorzunehmen. Der Einwand, was einmal im Gesetz stehe, werde automatisch zur Regel, "Lauschangriffe" müßten aber die Ausnahme bleiben (so beispielsweise der Abg. Brandt (Grolsheim) in der 17. Sitzung des 8. Deutschen Bundestages, Prot. S. 969; anders dag. der Abg. Dr. Wendig, das., S. 972), ist - zumal auf dem Hintergrund der inzwischen bekannt gepordenen Abhörpraktiken des MAD - alles andere als überzeugend. Das Gegenteil vielmehr ist richtig: je klarer die gesetzliche Regelung, desto geringer die Gefahr ungesetzlicher Übergriffe, vorausgesetzt nur, die Regelung trägt den Bedürfnissen der Dienste in dem unabdingbar notwendigen Umfang Rechnung. Allgemein i.d.S. Böckenförde, a.a.O. (Fn. 184), S. 1885.

${ }_{207}$ BVerwGE 47, 31 ff. (Leitsatz 3). - Der Begriff der dringenden Gefahr ist nicht außer Streit; vgl. Drews/Wacke/Vogel/Martens, a. a. O., S. $94 \mathrm{~m}$. Nachw.; erstaunlich freilich ist, daß die Kontrahenten - s. einerseits Martens, a. a. O., andererseits Dagtoglou, BK, Art. 13 RN 115 - sich jeweils auf BVerfGE 17, 232 ff., 251 f., berufen! Das deutet darauf hin, daß die Unterschiede so groß nicht sein können. 
des G 10 entsprechende Verfahrensregelung ${ }^{208}$ unabdingbar $^{209}$.

- Hält man das nicht für ausreichend, wäre zu erwägen, die Anbringung akustischer oder auch optischer Beobachtungsgeräte als eine Form der Durchsuchung i.S. des Art. 13 Abs. 2 GG zu behandeln, womit sie - im Regelfall - dem Richtervorbehalt unterfiele, der engen Zweckbindung des Art. 13 Abs. 3 GG jedoch nicht mehr unterläge. Dieser Schritt kann freilich nur getan werden, wenn man - entgegen der wohl h. M..$^{210}$ mit Dagtoglou ${ }^{211}$ - die Begriffe „Durchsuchungen“ sowie „Eingriffe und Beschränkungen“ nicht als sich wechselseitig ausschließende Begriffe betrachtet. Ob der Verfassungsschutz auf diesem Wege zusätzlichen Spielraum gewönne, ist im Hinblick auf den übergreifenden Grundsatz der Verhältnismäßigkeit des Mittels allerdings füglich zu bezweifeln.

\section{Verfassungsschuiz und innerer Notstand}

Unter dem Eindruck des am 5. September 1977 in Köln an Hanns-Martin Schleyer und seinen Begleitern begangenen Verbrechens hat G. Mann in einem aufrüttelnden Artikel in der WELT ${ }^{212}$ ausgesprochen, was ist: Wir befinden uns, meist latent, je und je evident, in einem Ausnahmezustand, „in einer grausamen und durchaus neuen Art von Bürgerkrieg“"213. Die

208 Einschaltung eines (quasi-)richterlichen Organs vor Vollzug der Maßnahme; spätere Benachrichtigung des Betroffenen, dem dann der Rechtsweg offensteht.

200 Wie das BVerfG entscheiden würde, ist schwer vorherzusagen. Auf die warnende Passage der dissenters, BVerfGE $30,1 \mathrm{ff}$., $46 \mathrm{f}$., ist hinzuweisen. Auf der anderen Seite wird man sich der durch die Stadtguerillataktik, die absolute moralische Hemmungslosigkeit der Terroristen, die ins Unvorstellbare gesteigerten waffentechnischen Möglichkeiten und schließlich die überaus hohe Verletzlichkeit der modernen Industriegesellschaft veränderten Gefahrenlage bewußt sein müssen, die es u. U. erfordert, "bis an die Grenzen dessen zu gehen, was vom Rechtsstaat erlaubt und geboten ist", wie es Bundeskanzler $H$. Schmidt nach dem Anschlag auf die Deutsche Botschaft in Stockholm formuliert hat, 168. Sitzung des 7. Deutschen Bundestages vom 25. 4. 1975, Prot. S. 11784 B.

210 Z. B. BVerwG a. a. O.

211 A. a. O., RN 71.

212 Quousque tandem?, Die WELT vom 7. 9. 1977, S. 1.

${ }^{213}$ Die Ausnahmesituation ist, gemessen an der Normallage der ersten 25 Jahre der Bundesrepublik Deutschland, eine wirkliche und nicht nur eine eingebildete, wie Denninger, Verfassung und Gesetz (Fn. 39), S. 31, zu meinen scheint. Schon gar keine Rede kann davon sein, daß irgendjemand, der in diesem Staat eine höhere Verantwortung trägt, angesichts der Entwicklung des Terrorismus die "Sensibilität für die Zerbrechlichkeit rechtsstaatlicher Strukturen" verloren hätte. 
Frage ist damit gestellt, ob unsere Verfassungsordnung ausreicht, der neuartigen Bedrohung Herr zu werden, die ihr aus dem Terrorismus erwachsen ist $t^{214,215}$.

Das Grundgesetz hat im Prinzip auf den Ausnahmezustand als Mittel der inneren Befriedigung verzichtet ${ }^{216}$, dafür jedoch den Staat im Normalzustand mit einem weitgefächerten Instrumentarium ausgestattet, das ihn in den Stand setzen soll, die Entstehung einer Lage zu verhindern, zu deren Bewältigung er des verfassungsrechtlichen Ausnahmezustandes bedürfte ${ }^{217}$. Die generelle Tauglichkeit dieses Konzepts einer Verdrängung des Ausnahmezustandes ${ }^{218}$ zu bezweifeln, besteht Anlaß. Die mangelhaften Erfolge in der Bekämpfung des Terrorismus scheinen mir indessen weniger auf diesen elementaren Fehlern unseres Verfassungsrechtes als (von anderem abgesehen) auf der unzureichenden Anwendung und Ausschöpfung seiner Möglichkeiten wie auch derjenigen des einfachen Rechts zu beruhen ${ }^{219}$. Schon deshalb will es zweifelhaft erscheinen, ob mit grundlegenden Änderungen des Verfassungsrechts die Abwehrkraft des Staates gegen diese Art der Bedrohung gestärkt werden kann. Anders gewendet: die Normalität der Verhältnisse ist nicht so tiefgreifend gestört, daß die Normativität des geltenden Verfassungsrechts die bestehende Wirklichkeit grundsätzlich verfehlen müßte ${ }^{220}$.

Im einzelnen: Mit einer Rückkehr zum Recht des Belagerungszustandes im Sinne des preußischen Gesetzes vom 4. Juni

214 Aus der umfangreichen Literatur über den Terrorismus sei hier nur der zusammenfassende Ưberblick erwähnt, den G. Boeden, der Leiter der Abteilung Terrorismusbekämpfung im Bundeskriminalamt, auf der von der CDU am 29. und 30.11. 1977 in Bonn veranstalteten Fachtagung gegeben hat: Entwicklung und Erscheinungsformen des Terrorismus in: H. Geißler (Hrsg.), Der Weg in die Gewalt, 1978, S. 22 ff.

215 Von notwendigen Veränderungen auf dem Gebiet des einfachen Rechts kann hier nicht die Rede sein.

${ }^{210}$ R. Wassermann, a. a. O. (Fn. 56), S. 125 ff. Zur Problematik dieser Entscheidung E.-W. Böckenförde, NJW 1978, S. 1885 ff.

217 Dazu oben I 3.

218 Böckenförde, a. a. O.

219 Die Beispiele dafür sind zahllos. Um nur einige zu nennen: organisatorische Insuffizienzen im Bereich der Fahndung; Mängel im Strafvollzug; die Schwerfälligkeit des Strafverfahrens; die Duldung rechtsfreier Räume (Hochschulen); die Nichtanwendung der Art. 9 II, 18, 21 II GG.

${ }^{220}$ Zum Verhältnis von Normativität und Normalität grundlegend H. Heller, Staatslehre, 2. Aufl. 1961, S. 249 ff.; s. a. C. Schmitt, Legalität und Legitimität in: Verfassungsrechtliche Aufsätze, 1958, S. $263 \mathrm{ff}, 321$. 
1851 und des Art. 68 RV ${ }^{221}$ wäre nichts gewonnen. Sein rechtsstaatlicher Vorzug, die Eindeutigkeit von Beginn und Ende und die Vorhersehbarkeit der im Falle seiner Erklärung eintretenden Rechtsfolgen, macht ihn untauglich zur Bekämpfung der modernen Stadtguerilla, deren Charakteristikum eine mit langem Atem operierende, sich in unregelmäßigen und unberechenbaren Aktionen manifestierende Zermürbungsstrategie ist, die sich dem entschlossenen Gegenschlag nicht stellt. Daraus darf andererseits nicht der Schluß gezogen werden, es empfehle sich eine Rezeption des Art. 48 Abs. 2 WRV, dessen wesentlicher rechtsstaatlicher Mangel, die Verwischung der Grenzen von Verfassungsstörung, Ausnahmezustand und Normallage, eine unveränderte Utbernahme in das geltende Verfassungsrecht ohne weiteres verbietet. Das freilich darf nicht hindern, sich des Art. 48 WRV „mit seiner breiten Erfahrungspraxis als Modell zu bedienen, um eine allein auf den Terrorismus beschränkte besondere Regelung zu treffen".

Diese Erwägung Th. Eschenburgs ${ }^{222}$ trifft sich mit dem Vorschlag $A$. von Winterfelds ${ }^{223}$, „die regelungsbedürftige Gesamt-

${ }^{221}$ Dazu E. R. Huber, Deutsche Verfassungsgeschichte seit 1789, 3. Bd., 1963, S. $1042 \mathrm{ff}$.

${ }_{222}$ Lehren für die Terrorbekämpfung aus Art. 48 der Weimarer Verfassung, ZParlR 1977, S. 457 ff., 459.

223 Terrorismus - "Reform" ohne Ende? ZRP 1977, S. 265 ff., 267. - Gegen $v$. Winterfeld wendet sich J. Lameyer, Streitbare Demokratie contra Terrorismus? ZRP 1978, S. 49 ff. Lameyers Standpunkt: der Rechtsstaat werde derzeit nicht von Terroristen gefährdet, sie seien nicht in der Lage, ihn in seiner Substanz zu treffen; er lebe durch seine Institutionen, und diese funktionierten; auch der Bestand des Staates sei nicht gefährdet; mithin sei die Lösung des Terrorismusproblems zunächt (?) ein kriminaltechnisches Unterfangen, nicht ein Problem der Staatsverteidigung, beruht auf einer naiven und gefährlichen Fehleinschätzung der Lage. Er verkennt, daß die subtile Strategie des Terrorismus (einschließlich seines Umfelds im Bereich des mindestens potentiell gewalttätigen politischen Extremismus) auf die Zerstörung des Staates als „Friedenseinheit“ ( $E$. W. Böckenförde, Der Staat als sittlicher Staat [Fn. 22], S. 12), seiner Friedensabwehrfunktion, zielt und damit im Bewußtsein der Rechtsgemeinschaft" völlig zu Recht „als schwerste Beeinträchtigung des Gemeinschaftsfriedens" (so v. Winterfeld, a. a. O.) erscheint. In diesem - zentralen - Bereich kann eben gerade nicht mehr von einem auch nur annähernd befriedigenden Funktionieren der staatlichen Institutionen die Rede sein — von den, wie der Blick auf die italienische Szene zeigt, durchaus vorhandenen Steigerungsmöglichkeiten des Terrorismus zu schweigen! Die Geschichte nicht nur südamerikanischer Staaten zeigt, welche Konsequenzen drohen, wenn der demokratische Staat seine Aufgabe, die Sicherheit von Leib und Leben seiner Bürger zu garantieren, nicht mehr zu erfüllen vermag. Zur Charakterisierung des Terrorismus vgl. auch $H .-J$. Vogel, Strafverfahrensrecht und Terrorismus - eine Bilanz, NJW 1978, S. 1217 ff., 1218. 
materie in einem Gesetz zur Bekämpfung des Terrorismus zu kodifizieren“, statt auf dessen Schläge mit immer neuen Veränderungen der allgemeinen Rechtsordnung zu reagieren ${ }^{224}$. Das gegen Uberlegungen dieser Art mitunter vorgebrachte $\mathrm{Be}-$ denken, man dürfe den Terroristen nicht die Genugtuung verschaffen, den Staat zu Ausnahmemaßnahmen gezwungen zu haben $^{225}$, an sich gewichtig, büßt an Überzeugungskraft in dem Maße ein, in dem der Staat bei ihrer Bekämpfung versagt und sich von Fall zu Fall zu mehr oder weniger verhüllten Maßnahmegesetzen ( $v$. Winterfeld) oder gar zum Rückgriff auf den rechtfertigenden Notstand gezwungen sieht.

Folgt man dem Vorschlag von Winterfelds, dann wäre im Rahmen der Konzeption eines solchen Sondergesetzes gegen den Terrorismus punktuell die Notwendigkeit von Verfassungsänderungen zu prüfen. Das Erfahrungsfeld des Art. 48 Abs. 2 WRV umfaßt insonderheit die Verlagerung der Rechtsetzungsbefugnisse auf die Exekutive, die Suspendierung von Grundrechten, Durchbrechungen der bundesstaatlichen Kompetenzordnung, den Einsatz der Streitkräfte zur Wiederherstellung der öffentlichen Sicherheit und Ordnung, die Entsendung von Kommissaren der staatlichen Zentralgewalt und die Einsetzung von Ausnahmegerichten ${ }^{226}$.

Eines über das schon jetzt zulässige $\mathrm{Maß}$ hinausgehenden Verordnungsrechts der Regierung bedarf es nicht ${ }^{227}$. Die Entsendung von Beauftragten ist ein typisches Mittel der Bundesexekution ${ }^{228}$ - das ist nicht das Thema! Eine Erweiterung von

224 Ahnlich zum prinzipiellen Problem der Regelung des Ausnahmezustandes Böckenförde, NJW 1978, S. 1886.

${ }^{225}$ H.-J. Vogel, a. a. O., befürchtet, eine Sondergesetzgebung enthielte das implizite Eingeständnis, Terrorismus sei ein von gewöhnlicher Kriminalität so außerordentlich abweichendes Phänomen, daß seine verfahrensrechtliche Bewältigung mit den geltenden Vorschriften nicht möglich sei. Genau dieses wird jedoch durch die in Vogels Aufsatz für das Gebiet des Strafverfahrensrechts dargestellten Rechtsänderungen während der letzten Jahre, denen Änderungen auf anderen Rechtsgebieten entsprechen, bezeugt. Die kriminelle Energie der Terroristen ist tatsächlich singulär und mit der Wirtschaftskriminalität (Vogel zieht diese Parallele) - bei aller Verabscheuungswürdigkeit derselben - schlechterdings nicht vergleichbar.

${ }_{226}$ Eschenburg, a. a. O., S. $458 \mathrm{f}$.

227 Hier ist natürlich nicht an die Diskussion um das sog. selbständige Verordnungsrecht der Exekutive gedacht; dazu der Schlußbericht der Enquete-Kommission Verfassungsreform, BT-Drucks. 7/5924, S. 91 f.; H. H. Klein, Erwägungen der Enquete-Kommission Verfassungsreform des Deutschen Bundestages $\mathrm{zu}$ einer Neufassung des Art. 80 GG, DOV 1975, S. 523 ff.

${ }_{228}$ Vgl. Art. 37, 84 III GG. 
Bundeszuständigkeiten auf dem Gebiet der gegen mutmaßliche Straftäter einer bestimmten Qualität gerichteten Maßnahmen der Ermittlung, der Fahndung und Strafverfolgung muß, wenn sie sich als notwendig erweisen sollte ${ }^{229}$, möglich sein; dazu ist im übrigen eine Verfassungsänderung nicht immer nötig ${ }^{230}$. $\mathrm{Zu}$ prüfen ist ferner, ob es zur Eröffnung der Möglichkeit im Zusammenhang der Terrorismusbekämpfung notwendiger Grundrechtseingriffe hier oder da der Erweiterung von Gesetzesvorbehalten bedarf - in aller Regel freilich wird mit den vorhandenen, vom Verfassungsgeber mit bemerkenswerter Weitsicht formulierten Vorschriften auszukommen sein ${ }^{231}$.

228 Vgl. das Gesetz über die Einrichtung eines Bundeskriminalpolizeiamtes (Bundeskriminalamtes) i. d. F. vom 29. 6. 1973, BGBl. I S. 704, mit späteren Änderungen. Die Möglichkeiten der Einflußnahme dieser Stellen auf die zuständigen Behörden der Länder sind schon jetzt, gerade auch in dem hier in Rede stehenden Bereich, erheblich. Pannen, wie sie etwa bei der Fahndung nach den Entführern H.-M. Schleyers auftraten, sind nicht o. w. auf einen Kompetenzmangel von Bundesbehörden zurückzuführen.

${ }^{230}$ Dazu $v$. Winterfeld, a. a. O., S. 268.

231 So ist die systematische Durchsuchung von Wohnungen nach einem Entführungsfall auf der Grundlage des Art. 13 II GG gesetzlich regelbar. In diesem Zusammenhang erscheinen die Skrupel, die die Mehrheit im Deutschen Bundestag bei der Verabschiedung des Gesetzes zur Änderung der Strafprozeßordnung vom 14. 4. 1978, BGBl. I S. 497, speziell seines Art. 1 Nr. 1 (§ 103 StPO), plagten, einigermaßen merkwürdig auf dem Hintergrund einer Vorschrift, die sich im Entwurf der SPD-Fraktion des Nds. Landtags für ein Denkmalschutzgesetz vom 17. 12. 1976, LT-Drucks. 8/2154, findet. Dort heißt es: „Die Besichtigung einer Wohnung ... gegen den Willen der Betroffenen darf nur durch das Amtsgericht, bei Gefahr im Verzuge auch durch die ... Behörden angeordnet werden“. Auch die notwendige Beschleunigung des Strafverfahrens in Terroristenprozessen (vgl. die Entwürfe eines Gesetzes zur Beschleunigung strafrechtlicher Verfahren der CDU/CSU-Fraktion des Deutschen Bundestages, BT-Drucks. 8/323, und eines Strafverfahrensänderungsgesetzes $19 \ldots$, BT-Drucks. 8/976 sowie den Bericht des Rechtsausschusses des Deutschen Bundestages vom 1.6.1978, BTDrucks. 8/1844 und das Gesetz vom 5.10.1978, BGBl. I, S. 1645) ist ohne Verfassungsänderung erreichbar; der Einrichtung von Ausnahmegerichten, die eine Änderung von Art. $101 \mathrm{GG}$ voraussetzen würde, wäre $\mathrm{zu}$ widerraten. - Gleiches - keine Verfassungsänderung erforderlich - gilt für eine Vielzahl weiterer erwägenswerter Maß3nahmen (vgl. v. Winterfeld, a. a. O., S. 268 f.). So wäre z. B. an eine Erweiterung des in Art. 5 II GG enthaltenen Gesetzesvorbehaltes nur dann zu denken, wenn Presse und Rundfunk sich in künftigen Fällen weniger verantwortungsbewußt verhalten sollten als während der Entführung Schleyers. Die damals von den Behörden praktizierte restriktive Nachrichtenpolitik war nicht etwa verfassungswidrig. Nicht unbedenklich ist es daher, wenn, wie einer Pressemitteilung des Deutschen Presserates $z u$ entnehmen ist, auf dessen Sitzung am 25. und 26. 4. 1978 mit Staatssekretär Bölling vom Presse- und Informationsamt der Bundesregierung Einvernehmen 
Schließlich könnte es sich erweisen, daß in bestimmten Situationen die Polizeikräfte des Bundes und der Länder nicht ausreichen, alle ihnen zufallenden Aufgaben zufriedenstellend zu erfüllen. Eine behutsame Erweiterung der Einsatzmöglichkeiten der Bundeswehr in inneren Krisenlagen (Art. 87 a Abs. 4 GG), etwa in Richtung auf den Personenschutz oder die Durchführung von Straßenkontrollen, muß erwogen werden.

Eine diesen Problemkreis abschließende verfassungspolitische Bemerkung sei angefügt:

Bei allem Verständnis für rechtsstaatlich motivierte Zweifel an der Richtigkeit des hier in Erwägung gezogenen und etwaiger ähnlicher Vorschläge wird $\mathrm{zu}$ bedenken sein, daß die Dynamik des politischen Prozesses, wenn es nicht gelingt, einer werdenden Krise rechtzeitig Herr zu werden, zu überschießenden, dann jedoch nicht mehr zu verhindernden Reaktionen führen könnte ${ }^{232}$. „Der kluge Mann baut vor“233.

\section{Verfassungsschutz und Verfassungspflege}

Der Schutz der Verfassung ist nicht nur eine Sache speziell diesem Zweck gewidmeter Normen und ihres Vollzugs. Der demokratische Rechtsstaat hat nur Bestand, solange seine Bürger freiheitlich gesonnene Demokraten sind ${ }^{234}$. Der die Identität des Staates prägende Kanon von Verfassungsnormen und Verfassungsgrundsätzen ist deshalb notwendiger Gegenstand staatlicher Verfassungspflege. Die Verfassung muß Staat machen, wenn sie von Dauer sein soll ${ }^{235}$. Die unter dem Titel "Grundwerte und Staat" geführte Diskussion"236 hat überdies,

darüber erzielt wurde, daß es eine "Nachrichtensperre" wie damals nicht wieder geben werde.

${ }^{232}$ Im gleichen Sinne H.-J. Vogel, a. a. O. (Fn. 223), S. 1218. Er verweist in Fn. 13 beispielhaft - ob zu Recht, mag hier dahinstehen auf das nach der Entführung Aldo Moros erlassene italienische Gesetzesdekret vom 21. 3. 1978 .

${ }^{233} \mathrm{Fr}$. Schiller, Wilhelm Tell.

${ }^{234}$ Vgl. Isensee, NJW 1977, S. 550; ders., Demokratischer Rechtsstaat (Fn. 30), S. 105, 106 f.: "Bürgerfreiheit ermöglicht und fordert die Bürgertugend".

${ }^{235}$ R. Altmann, Macht die Verfassung noch den Staat? Carl Schmitt wird neunzig, FAZ vom 8. 7. 1978, Beilage „Bilder und Zeiten".

${ }^{236} H$. Schmidt, Grundwerte heute in Staat und Gesellschaft, Bulletin des Presse- und Informationsamtes der Bundesregierung vom 27. 5. 1976, S. 581 ff.; W. Maihofer, Grundwerte in Staat und Gesellschaft, Bulletin vom 24. 6. 1976, S. 711 ff.; $H$. Kohl, Freiheit, Solidarität, Gerechtigkeit in: Die Frau in der offenen Gesellschaft 3/1977, S. $8 \mathrm{ff}$; J. Isensee, NJW 1977, S. $545 \mathrm{ff}$; O. Kimminich, Die Grundwerte im demokratischen Rechtsstaat, ZPol. 1977, S. 1 ff.; H. Kuhn, Der Streit um die Grundwerte, ZPol 1977, S. $18 \mathrm{ff}$; E. W. Böckenförde, Der Staat als sittlicher Staat (Fn. 22). 
so kontrovers sie verläuft, die Erkenntnis unterstrichen, „daß der Staat... abhängig ist von Prinzipien" - nicht rechtsnormativer Qualität! —, „die er nicht geschaffen hat und über die er nicht verfügt, sondern die er vorfindet“"237. Auch diesem moralischen Fundament ${ }^{238}$ seiner Verfassungsordnung und ihrer Geltung kann der Staat nicht gleichgültig gegenüberstehen. Er registriert sein Vorhandensein nicht nur ${ }^{239}$, er lebt aus $\mathrm{ihm}^{240}$.

Dabei geht es nicht um die amtliche Verordnung einer Staatsideologie ${ }^{241}$. Wohl aber ist es eine der vornehmsten, allerdings auch schwierigsten ${ }^{242}$, Aufgaben des Staates, vor allem durch sein Beispiel ${ }^{243}$, jedoch auch durch gezieltes Handeln, die

\footnotetext{
${ }^{237}$ H. Kuhn, a. a. O., S. 25.
}

238 J. Isensee, Demokratischer Rechtsstaat, S. 95, spricht von den „staatsfreien ethischen Elementen der gesellschaftlichen Homogenität". Wie schwierig es ist, sie zu fassen, haben Isensees Vortrag und die anchließende Diskussion (a. a. O., S. $119 \mathrm{ff}$.) einmal mehr gezeigt. ${ }^{239}$ In deutlicher Wendung gegen die Gedankengänge $H$. Schmidts betont i.d.S. H. Kohl, a. a. O., S. 10: „Der Staat ist aber nicht nur der Notar von Mehrheitsmeinungen ... Der Politiker ... hat dio Pflicht, für die Grundwerte der Verfassung aktiv einzutreten". Ebenso Isensee, NJW 1977, S. 551: Staatsorgane haben „die rechtliche Verpflichtung, dafür zu sorgen, daß dieses Fundament der realen Verfassungsgeltung (scil. der soziale Konsens) unversehrt bleibt". Auch H. Schmidt, der die "Zuständigkeit für die Grundwerte" in die Gesellschaft verweist, weiB - nicht ohne Widerspruch dazu - den Staat verpflichtet, „den vorhandenen Bestand an Grundwerten, an ethischen Grundüberzeugungen und Werthaltungen zu schützen“ (a. a. O., S. 584).

${ }^{240}$ Vgl. H. Kuhn, Der Staat, 1967, S. 419: „Lebt doch der Staat von einem Leben, das seinem Machtbereich entzogen ist". Ebenso Isensee, Demokratischer Rechtsstaat (Fn. 30), S. 103.

${ }^{241}$ Mißverständlich in diesem Sinne $H$. Schelskys Klage über den "Staat, an den niemand glaubt", Deutsche Zeitung vom 23. 12. 1977, kritisch dazu Böckenförde, Der Staat als sittlicher Staat (Fn. 22), S. 24 f.; s. a. H. Hattenhauer, Uber Auftrag und Vollmacht des Staates, Schriften der H. Ehlers-Akademie, 1975, S. 13. Als „idealistischreaktionäres Gegenstück“ zum ,antagonistischen Dissensmodell des Klassenkampfes" betrachtet $E$. Denninger, Verfassung und Gesetz (Fn. 39), S. 34, das „fiktive Konsensmodell eines ,Grundkonsenses aller Demokraten““. Es werde, so Denninger, „gegen die legitimen Reformversuche des demokratischen Gesetzgebers" mobilisiert und, während für die Klassenkampftheorie der status quo indiskutabel und inakzeptabel sei, gelte gleiches für die Konsenstheorie bezüglich jedes anderen Zustandes als des status quo. So wird durch einen dialektischen Trick (und die Behauptung einer Unwahrheit) das Bemühen um die Erhaltung der Verfassungsgrundlagen - mit den Worten $H$. Kohls, a. a. O., S. 10: "das Vertrauen in den Bestand und die Wirksamkeit gewisser Grundregeln der politischen Ordnung" dem Bestreben, sie zu beseitigen, moralisch und verfassungsrechtlich gleichgestellt!

242 Isensee, a. a. O., S. 118.

243 Böckenförde, a. a. O., S. $31 \mathrm{ff}$. 
zutiefst humane, aus leidvoller geschichtlicher Erfahrung mit anderen politischen Ordnungssystemen erwachsene Idee demokratischer Rechtsstaatlichkeit zu fördern und für sie zu werben. Daß er ihre dauernde Uberzeugungskraft nicht zu garantieren, gemeint ist: zwangsweise durchzusetzen vermage44, liegt in der Natur der Sache sowohl als auch daran, daß der Gesinnungszwang dem Rechtsstaat versagt bleiben muß. Das selbstverständliche Postulat weltanschaulicher Neutralität des Rechtsstaates $^{245}$ dahin zu überspitzen, daß dieser Staat auch gegenüber seinen eigenen ideellen und verfassungsrechtlichen Grundlagen eine neutrale, wenn nicht gar kritische Haltung einzunehmen habe, ist jedoch nicht mehr als die absurde Ausgeburt einer sinnentleerten Emanzipationspädagogik ${ }^{246}$.

Was ich mit staatlicher Verfassungspflege meine, sei abschlieBend an drei Beispielen gezeigt.

Erstens. Das Grundgesetz untersagt den Mißbrauch der Legalität zur Zerstörung der Legitimität. Gegen dieses verfassungsrechtliche Verbot wird verstoßen, „wenn der Gesetzgeber" - nicht nur im Einzelfall und gewissermaßen zufällig, sondern im bewußten Eingehen des Risikos - „nach Lösungen sucht, die verfassungswidrig sind oder gerade noch am Rande der Verfassungsmäßigkeit balancieren "247. Die notwendige Autorität der Verfassung wird zusätzlich geschädigt, wenn der solche Lösungen verwerfende Spruch des BVerfG - mitunter schon, bevor er ergangen ist - Reaktionen hervorruft, die an der Bereitschaft zweifeln lassen, sich ihm zu beugen. Kritik am BVerfG ist nicht nur erlaubt, sondern auch notwendigis.

${ }^{244}$ Vgl. E. W. Böckenförde, Die Entstehung des Staates als Vorgang der Säkularisation in: ders., Staat, Gesellschaft, Freiheit, 1976, S. 42 ff., 60: „Der freiheitliche, säkularisierte Staat lebt von Voraussetzungen, die er selbst nicht garantieren kann"; Isensee, Demokratischer Rechtsstaat, S. 108.

${ }^{245}$ H. Kuhns, ZPol. 1977, S. 28 f., Stellungnahme gegen die "blasse und unrealistische Lehre vom weltanschaulich neutralen "Staat" scheint mir auf der mangelnden Unterscheidung zwischen der marxistisch-kommunistischen Doktrin und der in ihrem Namen betriebenen "geistigen und territorialen Expansionspolitik" zu beruhen. Diese gilt es von Verfassungs wegen zu bekämpfen, jene ist zu tolerieren. Daß Weltanschauungen - mit unterschiedlicher Energie - auf ihre Umsetzung in gesellschaftliche Praxis ausgehen, ist dabei nicht übersehen. IMit diesem Risiko muß der Rechtsstaat leben.

246 Vgl. die Frage $H$. Webers, Diskussionsbeitrag in: Essener Gespräche zum Thema Staat und Kirche 11 (1977), S. 140, ob es denn wirklich richtig sei, daß dem demokratischen Staat kein eigenes Staatsethos innewohnt und innewohnen darf.

247 Isensee, NJW 1977, S. 551.

${ }_{248}$ Die Entscheidung des BVerfG beansprucht Maßgeblichkeit, nicht Stiftung von Konsens, wie schon die Einrichtung des Sonder- 
$\mathrm{Zu}$ den Grundlagen unserer Verfassung gehört jedoch neben der Bindung aller politischen Entscheidungen an die Verfassung die Kompetenz des BVerfG zu letztverbindlicher Interpretation des Verfassungsrechts. Sie heischt Anerkennung auch dort, wo das Gericht nach dieser oder jener Meinung irrt. Solchem Irrtum ist mit der Uberzeugungskraft des Arguments, nicht mit der Versagung des Gehorsams oder disqualifizierender Polemik zu begegnen. Staats- und Verfassungsorgane, einschließlich der politischen Parteien, die diese Regel mißachten, verletzen ihre Rechtspflicht zu Schutz und Pflege der Verfassung.

Zweitens. Staatliches Schulmonopol und verfassungsrechtliche Gleichordnung von elterlichem Erziehungsrecht und staatlichem Auftrag zur Bildung und Erziehung der Kinder ${ }^{249}$ verleihen der inhaltlichen Bestimmung des staatlichen Erziehungsauftrags außerordentliche Bedeutung. Auch wenn das Grundgesetz im Gegensatz zur Weimarer Reichsverfassung (Art. 148 Abs. 1) und zu den Verfassungen der Länder ${ }^{250}$ sich dazu nicht ausdrücklich äußert, geht es doch erkennbar davon aus, daß schulische Erziehung nicht nur die Vermittlung von Können und Wissen umfaßt, sondern auch von Wertvorstellungen und Handlungsprinzipien, soweit es sich um jenen „Wertfundus und Prinzipienkanon" handelt, „über den ein allgemeiner und

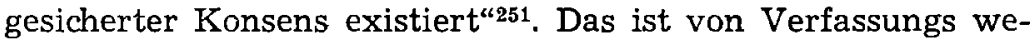
gen mindestens insoweit der Fall, als die unabänderlichen Grundlagen des Verfassungsrechts in Rede stehen ${ }^{252}$. Auch die Einsicht, daß, weil anders kein Staat zu bestehen vermag, "Gesetzesgehorsam nicht lediglich als heteronome Rechtsplicht" geschuldet wird, ,sondern auch als autonome ethische Leistung (zu) erbringen" ist ${ }^{253}$, bildet einen notwendigen Gegenstand der staatsbürgerlichen Erziehung in der staatlichen Schule. Nicht kritische Distanz, sondern eine positive Einstellung zum eigenen Staat und seiner Verfassung ist das vorgegebene Ziel staatlicher Jugenderziehung 254 .

votums zeigt; s. D. Göldner, Integration und Pluralismus im demokratischen Rechtsstaat, 1978 , S. $45 \mathrm{f}$.

${ }^{249}$ BVerfGE 34, 165 ff., 181 f.; 47, 46 ff., 71 f., Kritisch und einschränkend zur Gleichrangigkeitsthese $F$. Ossenbühl, Schule im Rechtsstaat, DOV 1977, S. $801 \mathrm{ff} ., 807 \mathrm{f}$.

${ }_{250}$ Vgl. z. B. Art. 12 I LVBW und dazu J. Isensee, Demokratischer Rechtsstaat (Fn. 30), S. 114.

251 Ossenbühl, a. a. O., S. 808.

252 Dazu BAG NJW 1978, S. 69, und ZBR 1976, S. 306 ff., 308.

253 Isensee, a. a. O., S. 103.

254 Wissenschaft und Rechtsprechung mußten sich in den letzten Jahren bedauerlicherweise mehr mit der Abwehr von Mißbräuchen des staatlichen Erziehungsauftrags beschäftigen als mit der Defini- 
Drittens. In seinem Beschluß vom 20. Oktober 1977 bemerkt das BVerfG: „Der Rechtsstaat kann sich nur verwirklichen, wenn sichergestellt ist, daß Straftäter im Rahmen der geltenden Gesetze verfolgt, abgeurteilt und einer gerechten Strafe zugeführt werden" "255. Auf die Gefahr hin, daß Denninger diese elementare Feststellung zu jenen „Einfach-Sätzen“ rechnet, „die stets mit der Sicherheit unanfechtbarer Plausibilität auftreten können" ${ }^{256}$, die er aber in Wahrheit für nichts weniger als plausibel zu halten scheint, erachte ich die Aufgabe des Staates, die Unverbrüchlichkeit der Rechtsordnung zu wahren, dennoch für fundamental. Denn: „das Gesetz nur kann uns Freiheit geben" ${ }^{257}$. Der in den letzten Jahren eingetretene Verfall der Autorität des Rechts ${ }^{258}$, die falsche Duldsamkeit des Staates gegenüber wie immer begründeter Anwendung von

tion seiner positiven Inhalte. Es liegt auf der Hand, daß die Situation von Schule und Schüler, die Bildsamkeit des letzteren und seine noch nicht entwickelte Fähigkeit, sich gegen selektive und emotionalisierte Stoffvermittlung und dadurch ermöglichte Ideologisierung (s. die Warnungen Th. Oppermanns, Nach welchen rechtlichen Grundsätzen sind das öffentliche Schulwesen und die Stellung der an ihm Beteiligten zu ordnen? Gutachten für den 51. Deutschen Juristentag, S. C. 93, vor einer „politischen Konfessionsschule“) zur Wehr zu setzen, eine ständige Verlockung darstellt, den politischen Willensbildungsproze $\beta$ auf diesem Wege zu steuern; dazu erheblich BVerfGE 44, $125 \mathrm{ff}$., $140 \mathrm{ff}$,, wo festgestellt wird, daß es dem Staat grundsätzlich nicht gestattet ist, auf den Willensbildungsprozē $B$ des Volkes mit dem Ziel einzuwirken, "Herrschaftsmacht in Staatsorganen zu erhalten oder zu verändern". Ebenso gilt es die Begehrlichkeit von Interessenverbänden abzuwehren, die sich der Schule zur Durchsetzung ihrer partikularen Interessen über sog. „engagierte curricula“ (vgl. etwa Dietze, RdJB 1976, S. $349 \mathrm{ff.}, 355 \mathrm{f}$.) bedienen möchten. (In diesen Zusammenhang gehört auch die Diskussion über die Tendenzuniversität: s. einerseits etwa Kirchhof, Kooperationsvereinbarung zwischen Hochschulen und Verbänden, ZRP 1976, S. 239 ff., andererseits - die Berechtigung seiner Einwände ungewollt bestätigend - Holländer/Schmidt, Kooperation aus Gegenstrategie in: Gewerkschaftliche Monatshefte 1977, S. $75 \mathrm{ff}$, 80, und Bamberg/Kröger/Kuhlmann, Arbeitswelt, Gewerkschaften und Hochschulen - Zusammenarbeit von Gewerkschaften und Hochschulen als Instrument gewerkschaftlicher Interessenvertretung in: Gewerkschaftliche Monatshefte 1977, S. 82 ff.). Wo Mißbräuche dieser Art vom Staat selbst ausgehen, verspricht nur die Stärkung individualrechtlicher Positionen Erfolg. Außer Oppermann und Ossenbühl, a. a. O., s. zum Thema noch G. Püttner, Toleranz und Lehrpläne für Schulen, DOVV 1974, S. $656 \mathrm{ff}$.

${ }^{255}$ BVerfGE 46, 214 ff., 222.

${ }^{256}$ Gewalt, innere Sicherheit und demokratischer Rechtsstaat, ZRP 1973, S. 268 ff., 268.

257 J. W. von Goethe, Natur und Kunst. - Wie hier nachdrücklich Böckenförde, Der Staat als sittlicher Staat, S. $14 \mathrm{f}$.

${ }^{253} \mathrm{~K}$. Doehring, Der Autoritätsverlust des Rechts in: Festschrift für E. Forsthoff, 1972, S. 103 ff. 
Gewalt, hat nicht etwa zu einer Festigung der Grundlagen unserer Verfassungsordnung beigetragen, sondern vielmehr Zweifel und Verdruß an Demokratie und Rechtsstaatlichkeit genährt ${ }^{259}$. Private Gewalt, ob „symbolisch“260 oder nicht, darf im Rechtsstaat - abgesehen vom Ausnahmefall der individuellen Notwehr und Nothilfe - nicht geduldet werden ${ }^{261,262}$.

259 Vgl. D. Merten, Rechtsstaat und Gewaltmonopol, 1975, S. $45 \mathrm{ff}$; H. Schwarz, Unser Staatswesen - Leitbild für den Bürger? Schriften der H. Ehlers-Akademie, 1978, S. 10, bemerkt zutreffend den Widerspruch, daß der Bürger in seinem privaten Leben eine Fülle von Vorschriften $\mathrm{zu}$ beachten hat und, tut er dies nicht, mit Bußgeldern und Strafen überzogen wird, andererseits aber erlebt, daß der Staat militanten Hausbesetzern und kommunistischen Kadern mit Langmut und Nachsicht begegnet.

260 Denninger, a. a. O., S. 269.

261 Denninger, a. a. O., ist zuzustimmen, wenn er darauf hinweist, daß Gewalt, die tatsächlich vorhandene Konflikte indiziert, durch den präventiven oder repressiven Einsatz staatlicher Gewalt nicht wirksam dauerhaft bekämpft werden kann. Richtig ist auch, daß die Unterdrückung privater Gewalt bei gleichzeitigem Verzicht auf die Lösung jener Konflikte eine „entlegitimierende Wirkung“ hat (vgl. auch Denninger, Verfassung und Gesetz [Fn. 39], S. 38). Jedoch sind diese Feststellungen unvollständig; denn es bleibt unberücksichtigt, a) daB, wo Gewalt geübt wird, solche Konflikte oft nur in der Einbildung der Akteure existieren oder, wo sie wirklich vorhanden sind, von ihnen nur zum Vorwand für die Verfolgung ganz anderer Ziele genommen werden (zur Rolle der Gewalt in der "Strategie der Systemüberwindung“ s. Schelsky in: Systemüberwindung, Demokratisierung und Gewaltenteilung, 2. Aufl. 1973, S. 30 ); b) daß die Anwendung von Gewalt zur Nachahmung verführt, wenn sie ungestraft bleibt, etwa vorhandene Mißstände also keineswegs eine verbesserte Chance erhalten, beseitigt $\mathrm{zu}$ werden; c) daB schließlich die Demonstration staatlicher Entschlossenheit oft auch eine legitimierende Wirkung hat - so muß Dennirger, a. a. O., selbst widerwillig anerkennen, daß die „Helden von Mogadischu (der Autor setzt sie in Gänsefüßchen, was wohl seine Verachtung für die ihnen zuteilgewordene „wohlstand-bourgeoise“ Bewunderung ausdrücken soll) der Popularitätskurve des Bundeskanzlers wieder nach oben" verholfen haben.

${ }^{262} \mathrm{Im} \mathrm{Maße}$, in dem der Staat den Bürger gegenüber privater Gewalt ohne Schutz läßt, ist dieser gezwungen, zur (organisierten) Selbsthilfe zu greifen. Zur Aktualität dieses Problems s. W. Hoffmann-Riem, Ubergang der Polizeigewalt auf Private? Schriftenreihe der Polizei-Führungsakademie 3/77, S. 6 ff. Seinen Bedenken ist zuzustimmen. Die Rechtsordnung würde jedoch auf den Kopf gestellt, wollte man seinem Vorschlag (a. a. O., S. $17 \mathrm{f}$.) folgen, in Analogie zu der Figur des Zweckveranlassers die des Risikoveranlassers zu bilden und diesem, also dem Inhaber besonders gefährdeten Eigentums (Kernkraftwerk!) oder dem Veranstalter risikoreicher Ereignisse (öffentliche Versammlungen!) die Kosten des gegebenenfalls erforderlichen polizeilichen Einsatzes aufzubürden. Hier wird verkannt, daß nicht der Eigentümer oder Veranstalter darüber entscheidet, ob er ein "Risiko veranlaßt", sondern daß es im Belieben Dritter steht, eine Sache oder ein Verhalten zur „Provokation“ zu 
Gleiches gilt für jede Aufweichung des aus gutem Grund formalen Rechtsbegriffs der Gewalt ${ }^{269}$, die, wie die Erfahrung lehrt, zunächst zur Verharmlosung bestimmter Formen der Gewalt, dann zu deren Steigerung führt. Die Expansion der Gewalt ist nicht eine Folge verschärfter Repressivität, sondern immer stärker um sich greifender Permissivität in Staat und Gesellschaft. Im demokratischen Rechtsstaat, in dem hinreichend gesichert ist, „daß Veränderungen, die von relevanten Gruppen der Gesellschaft für nötig gehalten werden, die Chance der Realisierung erhalten", in dem "die Menschenrechte nicht prinzipiell verletzt", sondern im Gegenteil prinzipiell geschützt werden, ist das staatliche Monopol legitimer Gewaltanwendung ,schon um des inneren Friedens willen“ unaufgebbar ${ }^{264}$. Der Schutz der Verfassung fordert, daß der Staat alles daransetzt, dieses Monopol zu behaupten.

erklären. Die Folge wäre, daß nur noch kapitalkräftige Kreise sich bestimmte Arten rechtmäßigen Verhaltens leisten können. Ob der Autor das bedacht hat?

${ }^{263}$ Dazu Merten, a. a. O. (Fn. 259), S. 51 ff. Er warnt zu Recht vor der Übertragung der im Völkerrecht überwundenen Lehre vom bellum iustum auf das innerstaatliche Recht, also vor der Annahme, das wirkliche oder vermeintliche Vorliegen einer iusta causa rechtfertige die Anwendung von Gewalt. S. a. H. Weichmann, Von der Verwirrung unserer Zeit in: Gefährdete Freiheit, 1974, S. 9 ff., 13 f. ${ }_{264}$ Gewalt und Gewaltanwendung in der Gesellschaft. Eine theologische Thesenreihe zu sozialen Konflikten. Erarbeitet von der Kammer der Evangelischen Kirche in Deutschland für öffentliche Verantwortung, 1973, S. 18 f. (These 5). 
Leitsätze des Mitberichterstatters über:

\section{Verfassungstreue und Schutz der Verfassung}

I. 1. Gegenstand des Verfassungsschutzes sind die freiheitliche demokratische Grundordnung sowie der Bestand und die Sicherheit des Bundes und der Länder.

2. Der Inhalt des Begriffs der freiheitlichen demokratischen Grundordnung ist identisch mit dem Gegenstand der Unantastbarkeitsgarantie des Art. 79 III GG. Daraus folgt: die Verfassung gewährleistet die Unangreifbarkeit bestimmter mit normativer Kraft ausgestatteter Rechtsgrundsätze, nicht einer wie immer definierten "religion civile“.

3. Auch die Staatlichkeit der Bundesrepublik Deutschland ist durch die Verfassung geschützt.

4. Das Grundgesetz hat die ihm zugrundeliegende Staatsidee in die Form bestimmter Rechtsgrundsätze gegossen und diese der politischen Disposition entzogen. Es hat aus geschichtlichen Erfahrungen die Folgerung gezogen, da $\beta$ die Verwirklichung auf die Beseitigung der freiheitlichen demokratischen Grundordnung gerichteter Ziele zu verhindern ist, mit welchen Mitteln auch immer sie verfolgt werden.

5. Die vom Grundgesetz zum Schutz der Verfassung getroffenen Vorkehrungen sind $z u$ einem wesentlichen Teil Bestandteil des Normal- und nicht des Ausnahmezustandes. Sie beschreiben Schranken sowohl staatlichen als auch individuellen Handelns.

6. Die Streitbarkeit der Verfassung ist eine das Grundgesetz insgesamt prägende Grundentscheidung, die die Auslegung der einzelnen Verfassungsnormen, einschließlich der Grundrechte, nicht unbeeinflußt läßt.

7. Der Verfassungsfeind ist weder rechtlos noch unfrei. Er hat jedoch wie jeder Bürger, der die seinen Rechten gezogenen Schranken übertritt, mit den an Gesetz und Recht gebundenen Reaktionen der staatlichen Gewalt zu rechnen.

II. 8. Der Schutz der Verfassung ist Pficht aller staatlichen Einrichtungen und Amtsträger.

9. Die Befugnis der in $\S 43$ I BVerfGG genannten Verfassungsorgane, ein Parteiverbotsverfahren einzuleiten, ist eine 
nach pflichtgemäßem Ermessen auszuübende Zuständigkeit. Je nach den Umständen reduziert sich das Ermessen auf Null.

10. Aus dem Bemühen, den Verkümmerungsproze $\beta$ aufzuhalten, dem das Staatsschutzkonzept des Grundgesetzes seit geraumer Zeit unterworfen ist, erwachsene Vorschläge, das Parteiverbotsverfahren zu ändern, begegnen verfassungsrechtlichen und verfassungspolitischen Bedenken.

11. Verfassungswidrige Vereinigungen sowie Ersatzorganisationen verbotener Parteien und Vereinigungen sind zu verbieten. Ein Ermessensspielraum besteht nicht.

III. 12. Es gibt keine allgemeine Pficht des Bürgers zur Verteidigung der freiheitlichen Demokratie. Jedoch nimmt das Grundgesetz einen Mißbrauch der Grundrechte zum Kampf gegen die freiheitliche demokratische Grundordnung nicht hin (BVerfG).

13. Die Beamtengesetze konkretisieren zutreffend die schon kraft Verfassungsrechts bestehende Treupficht der Beamten. Sie verlangt mehr als distanzierte Indifferenz, nämlich das Bekenntnis zum Staat der Bundesrepublik Deutschland und seiner verfassungsmäßigen Ordnung. Die beamtenrechtliche Treupficht gilt ohne Einschränkung auch für beamtete Wissenschaftler.

IV. 14. Die parlamentarische Kontrolle des administrativen Schutzes von Staat und Verfassung ist durch das Gesetz vom 11. April 1978 auf eine neue Grundlage gestellt worden. Ob damit die rechte Mitte zwischen Wirksamkeit der Kontrolle und Effektivität des Verfassungsschutzes gefunden wurde, wird die Zukunft erweisen. Zur Verabschiedung des Gesetzes vom 11. April 1978 hätte es einer Verfassungsänderung bedurft.

15. Die bestehenden Rechtsgrundlagen des administrativen Verfassungsschutzes sind nicht ausreichend. Die Tätigkeit des MAD entbehrt einer wirksamen Rechtsgrundlage.

16. Ein Rückgriff des Staates auf die allgemeinen Notrechte des bürgerlichen und Strafrechtes ist nur zulässig, wenn die Vorschriften des öffentlichen Rechts lückenhaft sind und die Heranziehung der Notrechte nicht eine von den Wertungen des öffentlichen Rechts abweichende Konfliktlösung bedeutet.

17. Im Bereich des Verfassungsschutzes ist diese Frage jedoch aus Gründen, die in der Natur seiner Tätigkeit liegen, von geringer Aktualität. Einen sog. Lauschangriff unter Beeinträchtigung des Grundrechts der Unverletzlichkeit der Wohnung darf der Verfassungsschutz nach geltendem Recht nur unter den Voraussetzungen des Art. 13 I 1. Alt. GG führen. 
Denkbare gesetzliche Erweiterungen der Befugnisse des Verfassungsschutzes zur Durchführung von Lauschaktionen sind nicht frei von verfassungsrechtlichen Bedenken.

V. 18. Für eine wirksame Bekämpfung des Terrorismus bedarf es der Mittel eines - ggf. einzuführenden - verfassungsrechtlichen Ausnahmezustandes nicht. Es empfiehlt sich jedoch, statt die bisherige Übung schrittweiser Veränderung der allgemeinen Gesetze fortzusetzen, die notwendigen Regelungen in einem besonderen Gesetz zusammenzufassen. Punktuelle Änderungen des geltenden Verfassungsrechts könnten sich als notwendig erweisen.

V1. 19. Ein wirksamer Schutz setzt eine intensive Pflege der Verfassung und der moralisch-ethischen Grundlagen ihrer Geltung voraus. Sie wird in erster Linie durch das Beispiel der im Staat Verantwortlichen, insbesondere durch die Vorbildlichkeit ihres Rechtsgehorsams, geleistet. 


\section{Aussprache und Schlußworte}

\section{Verfassungstreue und Schutz der Verfassung}

Vorsitzender (Oppermann): Sehr verehrte Herren Kollegen! Der Beifall nach den beiden Referaten heute morgen hat wohl bereits gezeigt, daß das Unternehmen geglückt ist, hier in der Staatsrechtslehrervereinigung im verfassungsrechtlichen Sinne ein gleichzeitig hochpolitisches Thema anzusprechen, welches derzeit wie kaum ein anderes unser Staats- und Demokratieverständnis prägt. Ich lade Sie ein, unsere Diskussion in gleichem Geiste zu führen, damit weitere Erträgnisse herausschauen.

Zunächst haben sich dankenswerterweise die Herren Kollegen Walter Haller und Siegbert Morscher bereiterklärt, uns über Verfassungstreue und Schutz der Verfassung in der Schweiz und in Österreich etwas zu berichten.

Haller: Den Ausdruck „Verfassungsschutz" sucht man in der schweizerischen Verfassung und Gesetzgebung vergeblich. Wenn ein schweizerischer Staatsrechtslehrer vom „Schutz der Verfassung" spricht, meint er damit im allgemeinen institutionelle Vorkehrungen, die - wie die Verfassungsgerichtsbarkeit - dazu dienen, die Korrektur verfassungswidriger Akte zu ermöglichen oder das Zustandekommen solcher Akte zu verhindern. Die Bundesverfassung sieht auch nicht die Möglichkeit einer Verwirkung von Grundrechten vor. An einer einzigen Stelle deutet sie die Problematik an, die uns heute beschäftigt: In Art. 56 wird die Vereinsfreiheit nur unter dem Vorbehalt gewährleistet, daß ein Verein weder in seinem Zweck noch in den dafür bestimmten Mitteln rechtswidrig oder staatsgefährlich sei, wobei die Kantonalgesetzgebung die erforderlichen Bestimmungen über den Mißbrauch der Vereinsfreiheit aufzustellen hat.

Der Umstand, daß die Verfassung die Möglichkeit des Mißbrauchs von Grundrechten zum Zwecke der Beseitigung der freiheitlichen Ordnung nur am Rand erwähnt und daß sich Wissenschaft sowie Gerichtspraxis kaum je in grundsätzlicher Weise damit auseinandergesetzt haben, bedeutet nicht, daß das Problem bei uns überhaupt nicht existiert. Angesichts der verschiedenen geschichtlichen Erfahrungen, der geringeren aktuel- 
len Bedrohung und des Fehlens besonders normierter Schutzvorkehrungen gegen „Verfassungsfeinde“ in der Bundesverfassung ist jedoch bei uns die Fragestellung wenig aktuell, wann Schutzvorkehrungen gegen diejenigen, welche die freiheitliche Ordnung umwälzen wollen, ihrerseits das Fundament der Freiheit untergraben.

Sämtliche Grundrechte - die geschriebenen und die vom Bundesgericht aus der Verfassung abgeleiteten ungeschriebenen - stehen unter dem Vorbehalt der Zulässigkeit von Beschränkungen zum Schutz polizeilicher Güter, auch wenn die Verfassung nur bezüglich einzelner Freiheitsrechte solche Schranken ausdrücklich vorbehält. Als polizeiliche Güter, zu deren Schutz der Staat verpflichtet ist, werden auch die staatliche Sicherheit und die verfassungsmäßige Ordnung angesehen. Durch das Erfordernis einer gesetzlichen Grundlage sowie die Beachtung allgemeiner Grundsätze von Verfassungsrang wie Rechtsgleichheit und Verhältnismäßigkeit werden freiheitsbeschränkende Maßnahmen in die Armatur des Rechtsstaates eingefügt. Insbesondere erlaubt eine differenzierte Anwendung des Verhältnismäßigkeitsgrundsatzes, dem besonderen ideellen Gehalt des jeweils in Frage stehenden Freiheitsrechts Rechnung zu tragen, wobei der schweizerische Richter erhebliche nicht-justiziable Beurteilungsspielräume der für die staatliche Sicherheit primär verantwortlichen politischen Organe anerkennt.

Unter dem Gesichtspunkt der Verhältnismäßigkeit dürfte das völlige Verbot einer politischen Partei nur in Zeiten, in denen die Schweiz in ihrer Existenz bedroht ist, mit der Verfassung in Einklang zu bringen sein. Im Jahre 1940 ordnete die Bundesregierung die Auflösung der kommunistischen Partei und der rechtsextremen Nationalen Bewegung der Schweiz an. Unmittelbar nach Kriegsende wurden die Verbote wieder aufgehoben. Bereits kurz vor dem Ausbruch des Zweiten Weltkrieges hatte das Bundesgericht ein kantonales Verbot der kommunistischen Partei geschützt.

Die nicht zahlreichen Entscheidungen, in denen sich das Bundesgericht mit dem Verhältnis des Staatsschutzes zu den Grundrechten zu befassen hatte, datieren fast alle aus den dreißiger Jahren, als Links- und Rechtsextremisten unter Berufung auf Freiheitsrechte die verfassungsmäßige Ordnung umzustürzen versuchten und bedrohliche Entwicklungen im Ausland zum Aufsehen mahnten. In Urteilen, die weder durch methodologische Argumentation noch durch begriffliche Schärfe hervorstechen, zeigte das Gericht eine - unter Berücksichtigung der abzuwehrenden schweren Bedrohungen verständliche - zu- 
nehmende Neigung, von Kantonen ergriffene Maßnahmen gegen verfassungsfeindliche Kräfte zu schützen, wobei es wiederholt den Ausnahmecharakter solcher Maßnahmen hervorhob.

Während des Zweiten Weltkrieges nahm sich der Bund in verstärktem Maße der Bekämpfung staatsfeindlicher Umtriebe an, womit diese $\mathrm{Maßnahmen}$ weitgehend gerichtlicher Utberprüfung entzogen wurden, was mit unserer zaghaften Ausgestaltung der Verfassungsgerichtsbarkeit zusammenhängt (keine Verfassungsbeschwerde gegen Bundesakte; keine vorfrageweise richterliche Kontrolle der Verfassungsmäßigkeit von Bundesnormen der Gesetzesstufe).

Verschiedene notrechtliche Strafnormen wurden 1950 in das ordentliche Gesetzesrecht übergeführt. Diese Bestimmungen des Strafgesetzbuches stellen heute das wichtigste rechtliche Instrumentarium des Staatsschutzes im engeren Sinne dar, auch wenn sie nicht häufig zur Anwendung gelangen. Art. 257 StGB, der den Tatbestand des Angriffs auf die verfassungsmäßige Ordnung normiert, enthält eine Formulierung, die wahrscheinlich nicht die von Herrn Denninger aufgestellten Kriterien der Meßbarkeit erfüllt. Danach wird mit Gefängnis bis zu fünf Jahren bestraft, ,wer eine Handlung vornimmt, die darauf gerichtet ist, die verfassungsmäßige Ordnung der Eidgenossenschaft oder der Kantone rechtswidrig zu stören oder zu ändern". Auch wenn hier kein "clear and present danger" verlangt wird, muß doch hervorgehoben werden, daß strafrechtliche Interventionsmöglichkeiten nicht bestehen, solange Strategen der Systemüberwindung keine rechtswidrigen Mittel einsetzen oder Straftaten vorbereiten (vgl. BGE 98 IV 127 f.).

Besondere Zurückhaltung gebietet die Ausgestaltung des Verfahrens der Verfassungsrevision: Die Bundesverfassung darf jederzeit ganz oder teilweise geändert werden, wobei 100000 stimmberechtigte Schweizerbürger eine solche Revision verlangen können und demzufolge die Möglichkeit haben müssen, durch Propagierung entsprechender Anliegen die für eine Volksinitiative auf Verfassungsrevision notwendigen Unterschriften zusammenzubringen. Die Bundesverfassung enthält keine Bestimmung analog Art. 79 Abs. 3 GG, und ob überhaupt aus der Verfassung materielle Schranken der Verfassungsrevision abgeleitet werden können, ist in der Lehre äußerst umstritten. Unter diesen Umständen fällt es schwer, Bestrebungen auf Abschaffung der bundesstaatlichen Gliederung, demokratischer Institutionen oder sogar einzelner Grundrechte als „verfassungsfeindlich" $\mathrm{zu}$ apostrophieren und ihre Unterdrükkung dogmatisch zu rechtfertigen. Daß die Idee der Freiheit die Beseitigung eines sich aus der Würde der menschlichen Per- 
son ergebenden Kernbereichs der Freiheit niemals rechtfertigen kann, auch wenn dabei die Spielregeln des demokratischen Entscheidungsprozesses beachtet werden, ist zwar eine These, der sich wahrscheinlich die meisten meiner Kollegen anschließen könnten. Solche Uberlegungen spielen jedoch im pragmatischen Rechtsdenken des Schweizers eine untergeordnete Rolle, ist man doch zuversichtlich, daß Volksinitiativen der erwähnten Art nicht die geringste Erfolgsaussicht haben.

Wir haben keine Bundesstelle, die mit dem deutschen Bundesamt für Verfassungsschutz verglichen werden kann. Zwar ist der Bundesanwaltschaft eine gerichtliche Polizei unterstellt, die laut Gesetz in Zusammenarbeit mit den Staatsanwaltschaften und Polizeien der Kantone einen Informationsdienst im Interesse der Wahrung der inneren und äußeren Sicherheit der Schweiz zu betreiben hat (Art. 17 Bundesgesetz über die Bundesstrafrechtspflege). Soweit sich dieser personell bescheiden dotierte Bundespolizeidienst - es gehören ihm gegenwärtig insgesamt 66 Bedienstete an - überhaupt mit vorbeugenden Staatsschutzaufgaben zu befassen hat, beschränken sich diese auf die Beobachtung von Aktionen extremistischer Einzelpersonen und Gruppen im Vorfeld der Strafbarkeit. Das bei einigen Leuten verbreitete Gefühl, der Staat verhalte sich bei der Úberwachung verfassungsfeindlicher Bestrebungen zu passiv, hat die bedenkliche Folge, daß sich Private manchmal als Staatsschützler aufspielen und ihre Informationen weitergeben, was besondere Probleme aufwirft, da wir kein Datenschutzgesetz haben und - was ein vor zwei Jahren bekannt gewordener Fall zeigte - noch kein genügender Persönlichkeitsschutz derjenigen besteht, die in den Kartotheken solcher selbsternannter Hüter der Verfassung verzeichnet sind. Der Entwurf einer neuen Bundesverfassung will sicherstellen, daß jedermann die ihn betreffenden amtlichen und privaten Akten einsehen darf, wenn nicht überwiegende öffentliche oder private Interessen eine Geheimhaltung erfordern (Art. 10 Abs. 4 Verfassungsentwurf).

Auch in der Schweiz ist anerkannt, daß der Beamte in einem besonderen Rechtsverhältnis zum Staat steht und daß sich daraus Treuepflichten ergeben, die ihm zusätzliche Beschränkungen von Grundrechten auferlegen. In den heute geltenden Personalvorschriften für die allgemeine Bundesverwaltung findet sich eine Normen des Beamtengesetzes konkretisierende Dienstanweisung der Bundesregierung von 1950, wonach Arbeitnehmer des Bundes zu entlassen sind, „denen nach ihrer politischen Tätigkeit das für ihre Stellung erforderliche Vertrauen nicht mehr entgegengebracht werden kann... Dieses Vertrauen fehlt, 
wenn die Gewißheit nicht mehr besteht, daß ein Dienstpflichtiger dem Lande die Treue unbedingt wahrt, alles tut, was die Interessen des Bundes fördert, und alles unterläßt, was sie beeinträchtigt“. Diese Verwaltungsverordnung wird sehr selten angerufen. Bei deren Auslegung betonte das Bundesgericht, daß die politische Aktivität nur dann berechtigte Zweifel an der für den öffentlichen Dienst notwendigen Vertrauenswürdigkeit begründe, wenn die oppositionelle politische Haltung die Gefahr mit sich bringe, daß der Dienstnehmer seine konkrete dienstliche Position aus politischen Gründen mißbrauchchen oder wesentliche Dienstpflichten verletzen könne (BGE 99 Ib 138/39).

Das Problem der "Radikalen im öffentlichen Dienst" wird bei uns am häufigsten im Zusammenhang mit Lehrerwahlen erörtert. Die Kantone, in deren Zuständigkeit das Schulwesen fällt, sehen etwa vor, daß das Wählbarkeitszeugnis verweigert oder entzogen werden dürfe, wenn die Vertrauenswürdigkeit fehlt oder Treuepflichten in schwerer Weise verletzt wurden. Wenn die Volksschullehrer - wie in einigen Kantonen durch das Volk gewählt werden, kann es leicht vorkommen, daß ein als Extremist in Verruf geratener Lehrer trotz Wählbarkeitszeugnis nicht wiedergewählt wird.

Zusammenfassend darf festgestellt werden, daß sich der Schweizer bei der Verteidigung der freiheitlichen Ordnung in sehr starkem Maße auf das Funktionieren demokratischer Mechanismen, vor allem direkt-demokratischer Institutionen, verläßt. Hingegen kommt der Rechtsschutz desjenigen, der sich in einen diametralen Gegensatz zu den herrschenden politischen Anschauungen stellt, bisweilen zu kurz. In der Einschaltung des Richters dürfte ja gerade die wesentliche Bedeutung der Art. 19 und 21 GG liegen.

Vorsitzender: Vielen Dank, Herr Kollege Haller. Ich glaube, wir haben aus Ihrer ebenso ruhigen wie klaren Darstellung des Schutzes der Verfassung in der Schweiz zu unserer Freude entnehmen können, daß die Verfassung bei Ihnen genau so fest steht wie der Kurs Ihrer Währung! Herr Kollege Morscher, ich darf Sie bitten, über Österreich zu uns zu dieser Thematik zu sprechen.

Morscher: In Österreich ist weder der Begriff der „Verfassungstreue" noch jener des "Schutzes der Verfassung" eine sozusagen ausdrückliche Kategorie der geltenden Verfassungsordnung und der Verfassungsdogmatik. Dennoch können 
selbstredend auch hier bestimmte Institutionen und Regelungen darunter subsumiert werden.

Trotz des einen oder anderen Ansatzes in der Theorie, Osterreichs Verfassungsordnung nicht als relativ wertneutral, sondern als "wehrhafte", "streitbare“, als "wehrbereite“ oder "militante" Demokratie zu erweisen, hat sich diese Auffassung nicht durchgesetzt. Auch kennen wir in Österreich keine unabänderlichen Verfassungsbestimmungen im Sinne des Art. 79 Abs. 3 des Bonner Grundgesetzes. Dennoch ist selbstverständlich auch für das Funktionieren des österreichischen Gemeinwesens der Konsens über bestimmte Grundsätze und Werte Voraussetzung - wie gerade auch die leidvollen Erfahrungen in der Ersten Republik bewiesen haben. Darüber hinaus aber wird Pluralität und natürlich auch all das andere, was die Herren Denninger und Klein angeführt haben, vorausgesetzt; diese vorausgesetzte Pluralität wird nunmehr besonders deutlich in Art. I $\S 1$ Abs. 1 des neuen österreichischen Parteiengesetzes (BGBl. 1975/404) zum Ausdruck gebracht: „Die Existenz und Vielfalt politischer Parteien sind wesentlicher Bestandteil der demokratischen Ordnung der Republik Österreich“.

Wenn also auch keine unabänderlichen Verfassungsbestimmungen, so kennt die österreichische Bundesverfassung dennoch Verfassungsvorschriften mit erhöhter Bestandsgarantie; gemäß Art. 44 Abs. 2 B-VG bedarf nämlich jede "Gesamtänderung der Bundesverfassung " nach Durchführung des parlamentarischen Bundesverfassungsgesetzgebungsverfahrens zu ihrem verfassungsmäßigen Zustandekommen der Zustimmung über eine Volksabstimmung. Hinzu treten die auf Verfassungsstufe stehenden Bestimmungen des Art. $17 \mathrm{MRK}$ und des Art. 8 des Ósterreichischen Staatsvertrages, wobei nach letzterer Bestimmung Österreich „eine demokratische, auf geheimen Wahlen gegründete Regierung hat". Ferner ist auf Art. 9 des genannten Staatsvertrages betreffend Auflösung nazistischer Organisationen und Art. $10 \mathrm{zu}$ verweisen, der Österreich verpflichtet, die antinationalsozialistische Verfassungsgesetzgebung aufrechtzuerhalten ebenso wie die Habsburger Verfassungsgesetzgebung. Auch damit ist aber das demokratische Prinzip innerstaatlich letztlich nicht unabänderlich, eine hoffentlich nur rein theoretisch bedeutsame Einsicht. Sollte es sich bei der Aussage Otto Mayers, „Verfassungsrecht vergeht, Verwaltungsrecht besteht", um eine sozusagen „ewige Wahrheit" handeln, scheint der Verzicht der österreichischen Bundesverfassung auf die Statuierung unabänderlicher Verfassungsbestimmungen jedenfalls nicht unvernünftig. 
Im übrigen gelten als wichtigste Indikatoren für die Bejahung einer wehrhaften Demokratie gleichermaßen aber als bedeutende Institutionen des Schutzes der Verfassung die Möglichkeit der Grundrechtsverwirkung, des Verbotes politischer Parteien, ein politisches Strafrecht, Treueklauseln, besondere Behörden zum Schutz der Verfassung und eine Notstandsverfassung. Dazu in Kürze aus österreichischer Sicht:

Eine Grundrechtsverwirkung in der heute üblichen spezifischen Bedeutung des Wortes kennen wir in Osterreich im wesentlichen nicht. Das ergibt sich insbesondere daraus, daß Art. 20 des kraft Art. 149 Abs. 1 B-VG als Bundesverfassungsgesetz geltenden Staatsgrundgesetzes über die allgemeinen Rechte der Staatsbürger aus dem Jahre 1867 durch Art. 149 Abs. 2 B-VG außer Kraft gesetzt wurde; diese aufgehobene Bestimmung hatte die Suspension einzelner Grundrechte ausdrücklich vorgesehen. Sehen wir von jenen Problemen ab, die sich aus den Artikeln 15 bis 17 und 60 der MRK allgemein und damit auch für Österreich für den gegebenen Zusammenhang ergeben, sind noch zwei Gesichtspunkte zu erwähnen:

1. Art. 142 Abs. 4 und Art. 143 B-VG sehen vor, daß im Zusammenhang mit einem verurteilenden Erkenntnis des VfGH über eine Anklage gegen bestimmte oberste Organe (Staatsgerichtsbarkeit, rechtliche Ministerverantwortlichkeit) unter besonders erschwerenden Umständen auch auf zeitlichen Verlust der politischen Rechte erkannt werden kann.

2. Die Grundrechte stehen überwiegend unter einem „Gesetzesvorbehalt", manche Grundrechte wie jene der Vereins- und Versammlungsfreiheit gelten nach der Rechtsprechung des VfGH nur nach Maßgabe der einschlägigen Ausführungsgesetze. Im Hinblick auf die Zersplitterung und das Alter der geltenden österreichischen Grundrechtsbestimmungen - ihr Kern, das Staatsgrundgesetz über die allgemeinen Rechte der Staatsbürger stammt ursprünglich aus dem Jahre 1867 — kommt der Judikatur des VfGH besondere Bedeutung zu. Diese Rechtsprechung des VfGH ist relativ zurückhaltend und geht im Zweifelsfall eher von der Dispositionsfreiheit des einfachen Gesetzgebers aus. Dieser judicial self-restraint zeigt sich besonders deutlich in den Erkenntnissen des VfGH in Sachen Drittelparität an Universitäten und Fristenlösung, in welchen der österreichische VfGH keine Bedenken gegen die einfachgesetzlichen Regelungen hatte und damit $\mathrm{zu}$ Ergebnissen gelangt ist, die jenen des deutschen Bundesverfassungsgerichtes geradezu konträr gegenüberstehen. Die Möglichkeit des Verbotes politischer Parteien in der spezifischen Bedeutung des Wortes besteht in Osterreich nicht. Doch ist auf jene Verfassungsbestim- 
mung des Parteiengesetzes (Art. I $\S 1$ Abs. 3 BGBl. 1975/404) zu verweisen, wonach die Gründung politischer Parteien frei ist, sofern bundesverfassungsgesetzlich nichts anderes bestimmt ist.

Etwas problematisch halte ich es, aus dem Bestand eines „politischen Strafrechts" eine wehrhafte Demokratie abzuleiten, da dieser Begriff immer umstritten war und heute in ganz besonderer Weise ist, da gerade auch Nichtdemokratien ein solches kennen und da ferner kein Staat bekannt ist, der kein solches Strafrecht hätte. Auch Osterreich hatte und hat selbstverständlich derartige Bestimmungen. Das neue österreichische Strafgesetzbuch (BGBl. 1974/60) kennt in den $\S \S 242$ ff. eine Fülle einschlägiger Tatbestände, die durchaus auch auf die neueste Entwicklung eine Antwort zu geben versuchen. Vor kurzem wurde auch das vom Nationalrat genehmigte Europäische UUbereinkommen zur Bekämpfung des Terrorismus im Bundesgesetzblatt kundgemacht, das immerhin unter anderem vorsieht, daß bestimmte Straftaten gerade nicht als politische Straftat angesehen werden, und zwar offenkundig im Sinne einer wehrhaften Demokratie.

Zum Aspekt der Verfassungstreue ist hervorzuheben, daß dabei in hohem Maße affektive Beziehungen zwischen Staat und Bürger im Spiele sind, die letztlich durch Rechtsvorschriften jedenfalls allgemein nicht „angeordnet“, aber auch nicht umfassend vorausgesetzt werden können. Dementsprechend kennen die österreichischen Verfassungsvorschriften auch keine ausdrücklichen Treuevorschriften und auch keine politischen Treuegelöbnisse zu Republik und Verfassung für alle Staatsbürger. Auch auf einfachgesetzlicher Stufe wird in Osterreich kein allgemeines politisches Treuegelöbnis gefordert.

Besondere Regelungen bestehen aber für bestimmte Gruppen von Organen bzw. Organwaltern, und zwar sowohl auf Verfassungs- als insbesondere auf einfachgesetzlicher Ebene. In der Verfassung selbst sind verankert die staatsrechtliche Verantwortlichkeit und die Gelöbnisleistung bei Amtsantritt der obersten politischen Organe. Eine ausdrückliche Verfassungsvorschrift wie jene des Art. 5 Abs. 3 des Bonner GG kennen wir in Osterreich nicht. Zahlreich sind die einfachgesetzlichen Regelungen für bestimmte Gruppen öffentlicher Funktionäre wie Beamte, Lehrer, Richter, Mitglieder des VwGH und VfGH, aber auch für Soldaten u. ä. Zwei Gruppen seien herausgegriffen:

Rechtsanwälte:

Derzeit bestehen in Österreich schon mangels einer entsprechenden Zahl einschlägiger Prozesse keinerlei aktuelle Pro- 
bleme. Sonderregelungen im Bereich der Strafprozeßordnung kennen wir in Österreich nicht.

Beamte, am Beispiel der Bundesbeamten:

Hier bestehen in Österreich auf Verfassungsebene keine ausdrücklichen Anordnungen betreffend Verfassungstreue der Beamten, und es werden solche auch nicht aus der Verfassung abgeleitet. Auf einfachgesetzlicher Ebene können solche Gesichtspunkte einfließen über das Ernennungserfordernis der persönlichen (selbstverständlich auch fachlichen) Eignung.

$\mathrm{Zu}$ den Schlüssel-, gleichzeitig aber auch Reizbegriffen Radikalen-Erlaß bzw. Berufsverbot ist für Österreich festzuhalten, daß normativ zwar schon die geltende Rechtslage allenfalls zumindest eine gewisse Handhabe zur Erlassung solcher Anordnungen bieten könnte, daß sie aber tatsächlich diesbezüglich nicht strapaziert wurde.

Bei der Ernennung von Beamten besteht in Österreich allerdings eine Besonderheit. Zwar gewährt Art. 3 des Staatsgrundgesetzes über die allgemeinen Rechte der Staatsbürger allen Staatsbürgern die gleiche Zugänglichkeit zu öffentlichen Ämtern und Art. 66 Abs. 2 des Staatsvertrages von St. Germain sowie Art. 8 des Staatsvertrages von Wien enthalten diesbezüglich Sondervorschriften. Nach der Judikatur des VfGH gewährt aber Art. 3 des Staatsgrundgesetzes keinen Rechtsanspruch auf Verleihung eines bestimmten Postens, sondern nur das Recht, sich um einen solchen Posten zu bewerben (VfSlg. $415,779,1709,2602$, 2982). Damit wird diesem Grundrecht nicht nur jede Wirksamkeit genommen, sondern es besteht keine Möglichkeit des nichtangestellten bzw. übergangenen Bewerbers, diese Entscheidung durch VwGH und/oder VfGH überprüfen zu lassen.

Zum Bestand von besonderen Verfassungsschutzämtern ist aus der Sicht Österreichs zu bemerken, daß der staatspolizeiliche Dienst kompetenzrechtlich zur "Allgemeinen Sicherheitspolizei" zählt und Bundessache in Gesetzgebung und Vollziehung ist (Art. 10 Abs. $1 \mathrm{Z} 7 \mathrm{~B}-\mathrm{VG}$ ). Wie Herr Pernthaler 1966 in seinem Beitrag im Sammelband Verfassungsschutz nachgewiesen hat, geht die Organisation des staatspolizeilichen Dienstes in Österreich auf eine Verordnung des Jahres 1850 zurück und seit dem Jahre 1966 hat sich diesbezüglich nichts geändert. Wenn deshalb Peter Fleischmann und Martin Walser in offenkundiger Abwandlung der eingangs zitierten Formel Otto Mayers meinen, Regierungen bestehen, die Staatspolizei bleibt, kann ich dem aus österreichischer Sicht nicht entgegentreten. Zur Skizzierung der aktuellen Lage darf ich noch hinzufügen, $\mathrm{da} \beta$ das aus konkreten Mißständen heraus vom Nationalrat mit 
einstimmiger Entschließung geforderte Staatspolizeigesetz bzw. Polizeibefugnisgesetz nicht nur nicht zum Gesetz gediehen ist, sondern daß nach parlamentarischer Anfragungsbeantwortung des zuständigen Bundesministers im Jahre 1976 trotz Vorliegens einer Regierungsvorlage eines Polizeibefugnisgesetzes aus dem Jahre 1969 (1268 BlgNR 12. GP) solche Bemühungen nicht einmal mehr weiterverfolgt werden (II-245 BlgNR 14. GP).

Seit dem Jahre 1974 (BGBl. 1974/8) haben wir im Staatsgrundgesetz über die allgemeinen Rechte der Staatsbürger einen neuen Art. $10 \mathrm{a}$, wonach verfassungsgesetzlich gewährleistet ist, daß das Fernmeldegeheimnis nicht verletzt werden darf und Ausnahmen davon nur aufgrund eines richterlichen Befehles in Gemäßheit bestehender Gesetze zulässig sind.

Besondere Einrichtungen der politischen Kontrolle bezüglich der staatspolizeilichen Tätigkeit bestehen in Österreich nicht und sind auch nicht in Diskussion. Parlamentarische Untersuchungsausschüsse sind es, die in den gelegentlichen Fällen von Mißbrauchsvermutungen größeren Ausmaßes eingesetzt werden; von den seit 1945 eingesetzten 10 Untersuchungsausschüssen haben sich bisher zwei mit einschlägigen Fragen befaßt.

Ein ausgebautes Notstandsverfassungsrecht besteht in Österreich nicht, obwohl und gleichermaßen weil es historische Anlaßfälle gibt (insbesondere auch 1933 und 1938). Ansätze dazu zeigen sich jedoch in der Möglichkeit der Einberufung des Nationalrates $\mathrm{zu}$ außerordentlichen Tagungen (Art. $28 \mathrm{Abs} .2 \mathrm{~B}-\mathrm{VG}$ ) und einzelner Bestimmungen des Bundesgesetzes über die Geschäftsordnung des Nationalrates (BGBI. 1975/410). Die wichtigste Regelung der Bundesverfassung ist jene über das „Notverordnungsrecht des Bundespräsidenten" im Sinne des Art. 18 Abs. 3-5 B-VG. Nach Art. 79 Abs. 2 B-VG ist das Bundesheer über die militärische Landesverteidigung hinaus auch bestimmt, soweit die gesetzmäßige zivile Gewalt seine Mitwirkung in Anspruch nimmt, zum Schutz der verfassungsmäßigen Einrichtungen und ihrer Handlungsfähigkeit sowie der demokratischen Freiheiten der Bewohner sowie zur Aufrechterhaltung der Ordnung und Sicherheit im Inneren überhaupt. Schließlich sind die Ermächtigungen zur Erlassung gesetzesvertretender Verordnungen aufgrund des Art. II $\S 4$ des V-ÜG 1929 (Allgemeine Sicherheitspolizei) und Art. 118 Abs. 6 B-VG (Ortspolizeiliche Verordnungen) anzuführen.

$\mathrm{Zu}$ einem allfälligen überverfassungsgesetzlichen Notstand darf ich berichten, daß dieser Fragenkreis im wesentlichen in Österreich nicht von der Sparte Verfassungsrecht bzw. öffentliches Recht abgedeckt wird. 
Wie Stern, der gegenwärtige Vorsitzende unserer Vereinigung, in dieser Beziehung jedenfalls völlig unbestritten dargelegt hat, beruht der Schutz der Verfassung im weiteren Sinn auf einer Vielzahl von Vorkehrungen, und er hat hierfür auch einen konkreten Katalog angeboten (Stern, Das Staatsrecht der Bundesrepublik Deutschland I, München 1977, 150 ff.). Im wesentlichen kennen wir in Österreich Gleiches, insbesondere eine Verfassungsgerichtsbarkeit mit umfassender Zuständigkeit, das Prinzip der Gewaltenteilung mit Kontrollen und Inkompatibilitäten, das - allerdings recht schwach ausgebildete - bundesstaatliche Prinzip, ein Maß an Offentlichkeit, das Mindestanforderungen entspricht, die Presse- und Informationsfreiheit und Grund- und Freiheitsrechte insgesamt. Österreich hat darüber hinaus im Bund und zum Teil in Ländern und Gemeinden plebiszitäre Einrichtungen, die selbstverständlich weit über jene der Bundesrepublik Deutschland hinausgehen, andererseits aber lange nicht jene Bedeutung wie in der Schweiz besitzen.

Die abschließende Frage, ob sich der Staatsrechtslehrer in optimaler und liberaler Weise für die Verfassung stark gemacht hat, und was er in Zukunft in dieser Richtung tun kann, darf ich hier laut - selbstverständlich aber nur mir - stellen!

Vorsitzender: Herzlichen Dank, Herr Kollege Morscher, für Ihr außerordentlich konzentriertes Referat, in dem wir die Mehrzahl der Probleme, die uns in der Bundesrepublik bewegen, wiedergefunden haben, wenngleich - soweit man dies in der Kürze der Darstellung sehen konnte - in einer durchaus andersartigen Sicht im Verhältnis zwischen Österreich und der Bundesrepublik.

Wir gehen damit zunächst in den ersten großen Diskussionsteil hinein, also in die Grundfragen. Ich darf hierzu Herrn Zacher bitten, zu uns zu sprechen.

Zacher: Zunächst eine Bemerkung zu dem Problemkreis der Sicherheitsempfindlichkeit. Herr Denninger hat ihn angesprochen und hat eine Konzentration der Verfassungsprüfung auf die sicherheitsempfindlichen Bereiche vorgeschlagen. Ich würde meinen, daß wir hier sehr viel stärker $z u$ einer Differenzierung und zu einer Differenzierung der Anforderungen kommen müßten, daß uns dabei die Vokabel „sicherheitsempfindlich" nicht genügen darf, und daß wir auch nicht sagen dürfen, nur dort, wo Sicherheitsempfindlichkeit ist, nur dort dürften Kontrollvoraussetzungen angestellt und verlangt werden. Ich 
denke an einen Ausspruch, der mich stark beunruhigt hat, und den - wenn ich recht unterrichtet bin - der rheinländischpfälzische Ministerpräsident Vogel getan hat: nichts sei ,sicherheitsempfindlicher" als die Seele eines Schulkindes. Ich glaube, wir geraten auf Abwege, wenn wir die Verfassungskontrolle in dieser Weise über die Vokabel "Sicherheitsempfindlichkeit" ausdehnen. Ich würde meinen, daß wir hier etwas anderes brauchen. Hier müssen wir darüber nachdenken, daß ein Lehrer einen großen pädagogischen Spielraum braucht und deshalb müssen wir hier etwa unterscheiden zwischen Exekutivbereichen, in denen tatsächlich Sicherheitsempfindlichkeit herrscht - hoheitlichen Exekutivbereichen und solchen der Daseinsvorsorge - und Bereichen, in denen die Tätigkeit ohne diese "Sicherheitsempfindlichkeit" ein besonders großes personales Vertrauen in den zu Berufenden voraussetzt. Die Verfassungskontrolle hat diesen Aspekten spezifisch Rechnung zu tragen, nicht aber unter dem Gesichtspunkt der Sicherheitsempfindlichkeit.

Ich komme von hier, von diesem rollenspezifischen Zusammenhang, zu einer Grenzfrage dessen, was heute berührt worden ist, nämlich zu den Rollen in Gesellschaft und Staat, die die Brücke schlagen zwischen Staat und Gesellschaft, wo gewisse Spielregeln von gesellschaftlichen Grenzen eingehalten werden müssen, weil diese Rollen in irgendeiner Weise am Funktionieren des Rechtsstaates teilhaben. Hauptbeispiel solcher „Brückenschläger“ sind Rechtsanwälte. Das Versagen einzelner von ihnen, ihr Nichtmehr-Mitspielen bei unserer verfassungsmäßigen Ordnung hat uns ja in einer ganz einzigartigen Weise überfallen. Eine andere Gruppe, die nicht so spektakulär ist, die aber alle Tage spektakulär werden kann, sind etwa die Sozialarbeiter. Sehr nahe liegen die Verbände, die ebenfalls diese Brückenposition haben. Daran, daß wir hier rollenspezifische Kriterien der Verfassungstreue und rollenspezifische Anforderungen an die Verfassungstreue brauchen, wollte ich nur erinnern.

Das zweite - und hier fällt es mir sehr schwer, mich kurz zu fassen; ich werde es trotzdem versuchen - wäre das, was ich zur Grundrechtsinterpretation und -politik im engeren Sinne sagen möchte, nämlich daß wir sehr viel mehr, als es in den Referaten zum Ausdruck gekommen ist, eine verfassungspolitische Vorwärtslösung suchen müssen. Grundrechte sind in einer stetigen dynamischen Entwicklung. Immer neue Entfaltungsbereiche des Menschen treffen mit immer neuen Gefährdungen vom Staat her zusammen. Grundrechte sind die Schwielen der menschlichen Würde. Wo die Staatsgewalt sich an der 
Menschenwürde reibt, entstehen neue Grundrechte, und ich glaube, wir sind in einer solchen Situation, daß die Menschenwürde hier neue, neu angelegte und adäquat strukturierte Schwielen braucht. Das neue Ziel der Grundrechtskontrolle ist ausdiskutiert, nämlich, daß diesmal die Freiheit um der Freiheit willen beschränkt werden soll. Die neuen Techniken des Eingriffes, nämlich, daß man die Privatsphäre zersetzen kann, etwa mit akustischen Mitteln usw., sind noch nicht hinreichend ausdiskutiert. Ich glaube nicht, daß man hier mit dem Grundrecht auf Wohnung etwas ausrichten kann. Ich glaube vielmehr, daß man hier die Privatheit als solche etwa zur Substanz machen muß, vielleicht auch die Frage eines Rechtes auf Nichtbeobachtet-Werden aufwerfen muß. Auch die neuen Schutztechniken des Staates für die Grundrechte sind, glaube ich, noch nicht grundlegend genug ins Auge gefaßt. Man hat zunächst geglaubt, man könnte mit Art. 18 und Art. 21 GG neue Abwehrmechanismen einführen. Sie sind uns entglitten. Herr Klein hat das durchaus in Rechnung gestellt. Wir haben damit aber noch nicht wirklich Tritt gefaßt, weil wir uns noch nicht entschlossen haben, diesen Art. 18 und den Art. 21 eindeutig zu abandonnieren. In dieser Halbheit stecken wir. Und darum glaube ich, daß wir eine positive Vision von einer zukünftigen Grundrechtsordnung brauchen: Welche Grundrechtssubstanzen sollen mit welchen Techniken gegen welche typischen Angriffe wirklich geschützt werden? Ich glaube, daß wir hier wahrscheinlich die Schwelle dessen, was durch Interpretation allein möglich ist, schon überschritten haben, also den Verfassungsgeber brauchen. Ihre Freiheit von Angst, Herr Denninger, scheint mir da ein wichtiger Impuls zu sein, solche Erfindungen, wie wir sie brauchen, $z u$ tun; aber sie ist nicht die Erfindung, die wir brauchen, selbst.

Häberle: Herr Vorsitzender, verehrte Kollegen. Beide Referenten haben an den verschiedensten Stellen drei Begriffe verwendet, die uns in verfassungstheoretische "Höhen" oder ,Tiefen" führen und denen wegen ihrer grundsätzlichen Bedeutung jetzt systematisch nachzugehen ist: dem "Verfassungsschutz" (Herr Klein, Leitsatz 1, Herr Denninger, Leitsätze 16, 17, 22), der "Verfassungstreue“ (Herr Klein, 13, Herr Denninger, 12) und der Figur des „Verfassungsfeindes“ (Herr Klein, 7, Herr Denninger, 18).

Erstens zum Verfassungsschutz. Meines Erachtens ist zu unterscheiden zwischen Verfassungsschutz im engeren Sinne wie er den Landesämtern und dem Bundesamt für Verfassungsschutz letztlich grundrechtsförderlich aufgetragen ist. Ich möch- 
te wegen der allgemeinen politisch-klimatischen Verkrampfung heute aber auch gerade den Verfassungsschutz im weiteren Sinne herausstellen, der allen obliegt. In seiner Mitte steht Art. 1 Abs. 1 GG, Herr Zacher, Ihre ja auch sprachlichpolitisch wichtige „Vorwärtsverteidigung“ der Grundrechte; hierher gehören der Verfassungsschutz durch Art. 79 Abs. 3 und 19 Abs. 2 GG, als Institution das Bundesverfassungsgericht. Dieser Verfassungsschutz im weiteren Sinne ist ja im Sondervotum zum Abhörurteil des Bundesverfassungsgerichts im 30. Band erarbeitet worden, in Passagen, die wesentlich auf das Gutachten von Herrn Dürig aus dem Jahre 1969 zurückgehen. Und, Herr Denninger, ich begrüße ausdrücklich Ihren Begriff der „Freiheit von Angst" als anthropologische, Art. 1 Abs. 1 GG zugehörige Prämisse.

Zweitens ein Wort zur "Verfassungstreue". Diesen Begriff möchte ich nur für einen einzigen speziellen Bereich anerkennen, für den Sonderstatus des Beamten, ihn aber sonst, auch für Schüler, entschieden ablehnen. Eine freiheitliche Verfassung kann sich dies leisten. So darf man entgegen einigen jüngsten Äußerungen im Schrifttum die Grundrechte des Bürgers nicht etwa unter einen allgemeinen juristischen Verfassungsvorbehalt der Verfassungstreue stellen, auch nicht die Rechtsanwälte; die "freie Advokatur" hat ihre eigenen spezifisch zu ermittelnden Grenzen. Freilich sind über die „Geeignetheitskriterien" und dienstrechtlich beim Berufsbeamten spezielle und strenge Anforderungen im Sinne der Verfassungstreue zu stellen. Dabei ist eine Unterscheidung nach mehr oder weniger "sicherheitsempfindlichen" Bereichen abzulehnen; denn es hängt langfristig von der Schule $a b$, welche Verfassungstheorie wir uns leisten können. Im allgemeinen Staatsbürgerverhältnis gibt es dagegen kein rechtliches Verfassungstreuepostulat. Erinnern wir uns des $\S 113$ der Frankfurter Paulskirchenverfassung von 1849. Danach hatten die Mitglieder der beiden Häuser den Eid zu leisten, „die deutsche Reichsverfassung getreulich zu beobachten und aufrechtzuerhalten". Für das GG kennen wir aus guten Gründen so etwas nicht. Es paßt als juristisches Institut nicht in eine parlamentarische Republik: weder für ihre Abgeordneten, noch für ihre Bürger. - Den dritten Begriff, den „Verfassungsfeind“, möchte ich streichen: weil er sich nicht im Grundgesetztext findet, weil er nicht dem gestuften Abwehrsystem der Art. 5 Abs. 3 S. 2, 9 Abs. 2, 18 und 21 entspricht, mit dem sich das GG differenziert gegen seine Gegner wehrt, und schließlich weil er an ein schematisches Freund/Feind-Denken erinnert. 
Erlauben Sie mir zum Schluß zwei Fragen an die Referenten: Zum einen. Sie haben Beide vom "Grundkonsens" gesprochen; dem stimme ich zu. Nur, welches ist Ihre verfassungstheoretische Begründung dieser Kategorie? Ich möchte dafür die Wiederaktualisierung der klassischen Lehre vom Gesellschaftsvertrag als „Verfassungsvertrag" vorschlagen, so wie wir sie - seit kurzem - etwa im Rentenbereich als „Generationenvertrag" wieder brauchen. - Zum anderen: Sie haben beide auf Moralisch-Ethisches Bezug genommen (Herr Klein, Leitsatz 19, auch Herr Denninger). Wir sollten die Verfassungen auf allgemeine und besondere Erziehungsziele ,abklopfen“, nach Verfassungsbestimmungen "als" Erziehungszielen suchen. $\mathrm{Zu}$ denken ist an den Respekt vor der Menschenwürde, an die Toleranz, andere Elemente der freiheitlich demokratischen Grundordnung. Wir brauchen aber auch das Verfassungs- bzw. Bürgerethische, nicht Staatsethische, in einem Sinne, auf den schon Rudolf Smend hingewiesen hat. Wir sollten angesichts unserer Utberjuridifizierung in verfassungsvergleichender Arbeit an angloamerikanische Erkenntnisse zur "civic culture", "political culture“ anknüpfen, um zu wissen, daß wir an eine Grenze des Rechtlichen zum Rechtskulturellen hin angelangt sind.

Sie, lieber Herr Denninger, haben sich über Spinner auf Popper berufen, sehr mit Recht; nur hat Popper mit besonderem Nachdruck auch die Toleranzgrenzen betont! Im übrigen teile ich in vielem den verfassungstheoretischen Ansatz von Herrn Denninger, etwa den gemeinwohlpluralistischen und verfahrensorientierten, nur: Sie haben eingangs spektakuläre, schlimme Einzelfälle mit einem Effekt wie beim Haydn'schen „Paukenschlag“ gebracht - um auf eine Würdigung unseres Herrn Vorsitzenden anzuspielen. Ich habe aber Zweifel, ob Sie damit der ganzen politischen Wirklichkeit unserer bundesdeutschen freiheitlichen Ordnung gerecht geworden sind. Zusammenfassend: Zustimmung zu vielen Ihrer verfassungstheoretischen Aussagen, Herr Denninger; Bedenken, ob Sie in der Bestandsaufnahme das ganze Spektrum unserer freiheitlichen Wirklichkeit eingefangen haben. Vielen Dank.

Klein: Ich will es nur klarstellen, Herr Häberle, damit kein Mißverständnis entsteht. Ich habe an einer Stelle, im Zusammenhang mit der schulischen Erziehung, von den Wertvorstellungen und Handlungsprinzipien gesprochen, von jenem jetzt kommt ein Zitat von Herrn Ossenbühl — ,Wertfundus und Prinzipienkanon', über den ein allgemeiner und gesicherter Konsens existiert und habe hinzugefügt: Das ist von Verfassung wegen mindestens insoweit der Fall, als die unabänder- 
lichen Grundlagen des Verfassungsrechts in Rede stehen, wobei ich mich eindeutig einmal mehr auf Art. 79 Abs. 3 beziehe.

Denninger: Ich möchte gerne auch zu dieser Grundfrage, die Herr Häberle hier aufgeworfen hat, Stellung nehmen. Der Begriff Verfassungskonsens, Grundkonsens, ich spreche auch manchmal von Basiskonsens, ist in der Tat - meine ich - der Klärung bedürftig. Hier wird nämlich sehr viel an Wertvorstellungen und Wert-Theorien sozusagen mit leichter Hand untergeschoben, eingeschmuggelt. Ich verstehe den Begriff zunächst in einem juristischen Sinne und denke dann auch an Art. 79 Abs. 3 und denke vor allen Dingen an die im weitesten Sinne prozeduralen Regelungen, die wir haben. Ich glaube, da $B$ ich mich da mit Ihnen weitgehend einigen kann. Ich möchte sogar sagen, es ist ein Kennzeichen unserer Demokratie, daß wir die Erhaltung dieser Prozeduren anstreben müssen, denn nur wenn wir diese offenen pluralen Prozeduren erhalten, dann kann im Verfahren das entstehen - sozusagen ungewollt, gewissermaßen von selbst -, was wir intendieren. Also: Ein indirektes Verfahren zur Herstellung von Grundwerten durch Anerkennung von Grundrechten und entsprechenden demokratischen Verfahrensweisen. Das würde ich zunächst einmal unter Grundkonsens verstehen. Daß ich die Realanalyse sicher nicht exakt und nicht erschöpfend vorgeführt habe, dürfte klar sein. Ich habe einfach, um die Problematik zu veranschaulichen, drei Beispielfälle, die ich aber ohne Mühe und mit Belegen in fast beliebiger Anzahl auch vervielfachen könnte, vorgeführt. Es war nicht meine Absicht, damit die gesamte Wirklichkeit der Bundesrepublik exemplarisch vorzuführen, sondern es war meine Absicht, auf einen Aspekt, der ja auch die Bedeutung dieser Thematik hier und heute unterstreicht, hinzuweisen.

H. P. Ipsen: Herr Denninger hat in These 22 am Schluß davon gesprochen, der beste Verfassungsschutz werde durch die Verfassungstreue des Bürgers geliefert. Was er vom Bürger hält, hat er in den Thesen 8 und 10 gekennzeichnet; er hat vom Willen zur Verfassung gesprochen und von den vorinstitutionellen Elementen Freiheit von Angst, Vertrauen, demokratisches Engagement, worin ich auch Kennzeichnungen des Bürgers - der Referent hat immer „Bürger" gesagt - sehe, der in der Pluralität das Volk unserer Bundesrepublik bildet. Er hat daraus auch Konsequenzen gezogen, er hat vom favor civis gesprochen, im Sinne einer Vermutung etwa dahin, daß man ihm Verfassungsfeindlichkeit oder ähnliches Verhalten nachzuweisen habe im geordneten Verfahren. 
Herr Klein hat gewisse Charakterisierungen bezogen auf die Oberen, also nicht auf die Regierten, sondern auf die Regierenden, und zum Schluß hat er in der These 19 davon gesprochen, am schönsten wäre es, wenn sie Vorbilder in der Wahrnehmung der Verfassungstreue und der Rechtmäßigkeit des Handelns wären. Herr Denninger hat zu seinem Thema Montesquieu zitiert, wobei ich offen lasse, wie weit dieser nur seinem König vorführen wollte, welch' gute Bürger er beherrsche.

Insgesamt gesehen haben beide Referenten von den Menschen, um die es geht, von denen da oben und von denen da unten, ein recht positives Bild. Sie sind sympathische, vermutungsweise staatsbejahende Figuren, von denen eigentlich garnichts zu befürchten ist, und das mit rechtlichen Konsequenzen zur Methode der Verfassungsauslegung, zur Handhabung der rechtsstaatlichen Prozeduren, zu Beweislastfragen usw. Ich habe indes das dunkle Gefühl, daß wir mit solchen anthropologischen Methoden an die Auslegung und Anwendung unserer Verfassung nicht herangehen können. Dies ist kein Maßstab, der Dinge Herr zu werden, dies ist keine adäquate Methode. Ich will schließen mit der Frage, ob nicht erst nach diesen optimistischen Feststellungen, die man unterschreiben mag ich wollte, es wäre so -, unsere Wissenschaft zur Auslegung des Grundgesetzes und der Rechtsordnung anfängt.

Isensee: Die ,Freiheit von Angst' hat es mir angetan. Herr Denninger schlägt vor, die Roosevelt-Formel aus der politischen Rhetorik in die Jurisprudenz zu übernehmen. Dieser Vorschlag verblüfft. Denn der Rechtsstaat stellt auf objektive Grenz- und Zielkriterien ab. Herr Denninger hebt zu Recht hervor, daß der freiheitliche Staat auf das objektive Fundament der Gesetzmäßigkeit, nicht dagegen auf das subjektive von Moralität und Gesinnung gegründet ist. Aber gerade die Subjektivität schleicht sich mit der Rezeption der ,Freiheit von Angst' wieder ein. Bestimmungsgrund des staatlichen Handelns soll ein Gefühl oder - was dasselbe ist - die Abwesenheit eines Gefühles sein. Ein Freiheitsrecht, also ein Maßstab staatlichen Handelns, kann nicht von unberechenbaren und willkürlichen Emotionen des Einzelnen abhängen. Im übrigen zeigt das Beispiel des Extremistenproblems, daß Angst sich auch inszenieren läßt.

Wenn die ,Freiheit von Angst' aber nicht die aktuell vorhandene Angst, die begründete Angst - objektive Ursachen, die das Vertrauen in die Rechtlichkeit des Staates zerstören können - meint, so deckt sich die rhetorische Formel mit dem uralten juristischen Staatszweck der ,Sicherheit". Sicherheit 
aber ist ein klarer, auf objektive Sachverhalte ausgerichteter Begriff, der im übrigen eine liberale Tradition seit Kant und Humboldt aufweist.

Unterstellt, die ,Freiheit von Angst' lasse sich in die juristische Begriffswelt verpflanzen, so bliebe hier die Radikalenfrage immer noch ein unglückliches Beispiel. Es mag auch dahinstehen, wieweit die ,Angst' der Bewerber echt, wieweit sie inszeniert ist. Wenn aber die ,Freiheit von Angst' verböte, die ,angst'-geschüttelten Bewerber vor der Einstellung auf ihre Verfassungstreue zu prüfen und diese Prüfung in die Zeit nach der Einstellung, in den Vorbereitungs- und Probedienst, verschoben würde, so verschöbe sich die ,Angst' nur und griffe auf ein Rechtsverhältnis über, in dem der Widerrufs- und Probebeamte nach heutiger Rechtsprechung bereits einen hohen Grad an Statussicherheit, also ,Freiheit von (rechtlich begründeter) Angst', genießt. Der Widerrufs- oder Probebeamte, der vor seiner Ubernahme als Lebenszeitbeamter trotzdem unter der gegebenen Rechtslage einen Entlassungsgrund wegen verfassungsfeindlicher Betätigung liefert, verdient allerdings die Entlassung - wegen seiner Torheit.

Das Merkwürdigste am Exempel der Radikalenfrage liegt darin, daß ein Freiheitspostulat auf die Vergabe von öffentlicher Gewalt angewendet wird, daß Freiheit den staatlichen Amtsträgern, nicht aber den amts- und gewaltunterworfenen Bürgern zugute kommen soll: dem Steuerpflichtigen, den Subventionsempfängern, den Eltern schulpflichtiger Kinder. Gerade diese aber können das Fürchten lernen, wenn der Staat nicht mehr sicherstellt, daß seine Amtsträger auf dem Boden der Verfassung stehen.

Herr Denninger sieht immerhin einige Kautelen für ,sicherheitsempfindliche' Bereiche vor. Was aber ist, sicherheitsempfindlich"? Der Verfassungsschutz doch wohl nicht: Denn dieser hat kaum Funktionen; er darf nur wenig wissen, und das wenige, was er weiß, - dem Verfassungsgebot der Amtshilfe zum Trotz - auch nicht weitersagen. Der Dienst im Verfassungsschutz kann, wenn die Prämissen stimmen, unbedenklich Verfassungsfeinden geöffnet werden. - Dagegen mache ich mir eine Prämisse des Referats uneingeschränkt zu eigen: daß die Sicherheit einer Verfassung abhängt von der freien $\mathrm{Zu}$ stimmung der Bürger. Daraus folgt, daß sicherheitsempfindlich die Staatsfunktionen sind, die machtvoll auf den Verfassungskonsens der Bürger einwirken. Der eigentlich sicherheitsempfindliche Bereich, empfindlicher als Polizei, Militär und Verfassungsschutz, ist: die Schule! 
Denninger: Herr Ipsen und Herr Isensee, ich wartete fast auf den Einwand methodologischer Art, daß ich hier eine Kategorie einführen würde, die sozusagen rechtlich nicht tragbar, nicht faßbar, nicht qualifizierbar sei; ich habe deshalb, wenn Sie das bitte nachlesen wollen, ausdrücklich von den vorinstitutionellen Elementen und von diesen nicht auf der gleichen Stufe mit den eigentlich verfassungsrechtlich-institutionellen Elementen der freiheitlich-demokratischen Grundordnung in diesem $\mathrm{Zu}$ sammenhang gesprochen. In der Tat bin ich der Meinung, daß es sich bei der Freiheit von Angst um eine teils anthropologische, teils aber eben auch - und darauf wollte ich heute nur den Akzent legen - um eine demokratietheoretische Kategorie handelt. Herr Böckenförde hat mehrfach und - wie ich meine - sehr zu Recht darauf hingewiesen, daß der säkulare Staat von Voraussetzungen lebt, - so ähnlich formulierte er es wohl -, die er selbst nicht garantieren kann; und das Gleiche gilt eben auch für die freiheitliche Demokratie. Das wollte ich mit diesem Hinweis zum Ausdruck bringen. Ich würde mir allerdings erlauben, die Kritik noch einen Millimeter weiterzutreiben und die Gegenfrage zu stellen: Ist denn die Kategorie der Streitbarkeit, mit der heute so viel operiert wird, ist sie denn justiziabler, ist sie denn etwas Präziseres, Habhafteres? Die rechtsvergleichenden Ausführungen der beiden Kollegen aus der Schweiz und Osterreich waren mir hier sehr wertvoll. Dieses ganze Verfahren um wehrhafte und streitbare Demokratie ist doch offenbar ein deutsches Philosophicum, letzten Endes ein deutsches Unikat, das in dieser Form jedenfalls im Ausland kaum etwas Vergleichbares hat.

Auf das Problem der Sicherheitsempfindlichkeit, das Sie, Herr Zacher, zu Anfang anschnitten, erlauben Sie mir, später im Schlußwort noch einmal zurückzukommen.

Grabitz: Ich will die Diskussion etwas weiter lenken, und die Bemerkung von Herrn Denninger gibt mir Anlaß, das vielleicht besser zu tun, als ich es vorhin vermocht hätte.

Ich wurde nicht - wie Herr Isensee - so sehr aufgeschreckt durch das Wort „Freiheit von Angst" oder "vor Angst", sondern eher durch jenes Etikett, was Sie diesem Theorem - für Sie ist es ja ein Theorem - aufsetzen, nämlich das eines vorinstitutionellen Grundsatzes. Ich habe das die ganze Zeit in Gedanken immer anders übersetzt, nämlich mit: „vorkonstitutionell“, oder wir können auch sagen: „außerkonstitutionell“. Das meinen Sie doch offensichtlich auch; denn mit Ihrem Hinweis, daß es etwas Demokratietheoretisches ist, haben Sie ja im Grunde gesagt, daß es sich um einen Grundsatz handelt, der 
oberhalb oder außerhalb des positiven Rechtes steht. Und hier frage ich mich nun, ob Sie, Herr Denninger, nicht genau das tun, was Sie eigentlich nicht wollen. Sie haben sich mit Recht gegen Versuche gewandt, über die verfassungspositive Legalität auch der freiheitlich-demokratischen Grundordnung, wie sie in Art. 79 Abs. 3 GG gesichert ist, sozusagen noch einen Himmel der Legitimität aufzuspannen, so eine Art ideologische Verkleidung eines "Verfassungs-Christo", in die dann irgendetwas hineingepackt werden kann, sei es ein parteipolitisches Programm von rechts oder von links, eine konfessionelle Grundanschauung oder was auch immer. Ich frage mich nur, wer so etwas unternimmt. Darüber haben sie nicht gesprochen. Nach meiner Lektüre der Literatur ist das etwas, was man der Judikatur des Bundesverfassungsgerichts aus einer ganz bestimmten verfassungspolitischen, ja, ich meine sogar: politisch eindeutigen Richtung unterstellt. Denn ich habe nicht feststellen können, daß in irgendeiner Entscheidung des Bundesverfassungsgerichts - auch nicht in der Radikalenentscheidung ein Unterschied gemacht worden wäre zwischen einer überhöhten Legitimität der freiheitlich-demokratischen Grundordnung und der knochenharten Legalität, die das Grundgesetz hier aufstellt in Form des Satzes von der freiheitlich-demokratischen Grundordnung. Ich glaube, Sie kämpfen hier, wenn Sie das Bundesverfassungsgericht meinen, gegen ein Phantom.

Aber, und das ist das Letzte, was ich bemerken möchte, gegen das, was Sie sagen, ist ein methodologischer Einwand vorzubringen. Sie tun im Grunde dasselbe, was man dem Bundesverfassungsgericht - wie ich meine zu Unrecht - vorwirft. Sie ersetzen den Wertehimmel einer Verfassungsethik - ich möchte es einmal so formulieren - sozusagen durch die Libido einer Verfassungspsychologie. In ein Recht auf Freiheit von Angst (gibt es vielleicht auch ein Recht auf Lust?) können Sie ja alles hineinpacken. Sie verschieben hier einen extrakonstitutionellen Maßstab für die Grundrechtsauslegung nur aus der Ethik in die Psychologie oder in die Psychoanalyse mit ganz konkreten Konsequenzen, wie etwa Thre Auslegung von Art. 2 Abs. 1 GG, des Rechtes auf die Persönlichkeit und die Privatsphäre, zeigt. $\mathrm{Ob}$ man in dieser Angst haben muß oder nicht, ist doch nicht eine Voraussetzung, sondern allenfalls das Ergebnis der Grundrechtsinterpretation und -anwendung. Ich muß mir doch gefallen lassen, daß bei Vorliegen der gesetzlichen Voraussetzungen die Kriminalpolizei bei mir eine Durchsuchung macht; und selbstverständlich habe ich dann Angst. Dagegen existiert kein Grundrechtsschutz. 
Vorsitzender: Vielen Dank, Herr Grabitz. Ich bemerke mit Interesse, daß in sehr verschiedenartigen Diskussionsbeiträgen gegenseitige Kritiken gleichermaßen dahin gehen, ich überspitze es jetzt einmal, nicht hinreichend die Position von Forsthoff in der ersten Carl Schmitt-Festschrift zur Verfassungsauslegung einzunehmen. Herr Roellecke wollte sich noch zu den Grundwerten insgesamt äußern. Damit schließen wir diesen Komplex dann ab und kommen zur streitbaren Demokratie.

Roellecke: Herr Isensee und Herr Grabitz haben viel von dem vorweggenommen, was ich sagen wollte. Auch ich wollte Herrn Denninger fragen, wie er zu seinen anthropologischen, vorkonstitutionellen Kategorien kommt. Auch ich meine, daß "Freiheit von Angst" kein Element ist, das juristisch sinnvoll verwendet werden kann. Ich erinnere daran, daß Heidegger die Angst als Grundbefindlichkeit des Menschen beschrieben hat. Für Anhänger der Existenzphilosophie wäre eine „Freiheit von Angst" deshalb etwas Unmenschliches. Vor allem aber habe ich den Eindruck, als ob die anthropologischen Voraussetzungen Herrn Denningers in genau der gleichen Weise den Verfassungsfeind konstituierten wie die von ihm bekämpften Grundwerte.

Der Feindbegriff ist bei Herrn Denninger negativ besetzt. Als Feind gilt ihm offenbar der ganz andere, der schon als solcher zu vernichten ist. Wer ist nun der ganz andere? Nach Herrn Denninger der, der aus dem Basiskonsens über Grundwerte herausfällt. Die Grundwerte konstituieren also insofern den Verfassungsfeind, als sie ihn als Negation ihrer selbst zum Unwerten, zum Zuvernichtenden stempeln.

Diese Konsequenz ergibt sich jedoch nicht aus den Inhalten der Grundwerte - darauf geht Herr Denninger gar nicht ein -, sondern aus dem formalen Argument, daß jede Position ihre Negation negiert, daß Werte also das Unwerte vernichten wollen. Wenn man aber den Feind nur als Negation eines Positiven versteht, dann sind die anthropologischen Elemente Herrn Denningers Positionen, die ihre Gegner schlimmer denn als Feinde - die sie als Un- und Untermenschen negieren müssen. Denn was ist eigentlich mit dem, der sich von seiner Angst nicht befreien lassen will, der mißtrauisch bleiben will, der zum demokratischen Engagement partout nicht bereit ist? Ist er von der „vorausgesetzten Grundverfassung des Bürgers" aus nicht böser als der, der die Meinungsfreiheit nicht als Wert fühlt? Ermöglicht also die von Herrn Denninger vorausgesetzte Grundverfassung nicht eine schrecklichere Vernichtung ihrer Gegner als die Grundwerte? 
Tomuschat: Ich habe mich zu Wort gemeldet, weil ich Herrn Grabitz widersprechen wollte. Ich meine, man kann ein Wort der Verteidigung zugunsten der Formel der Freiheit von Angst sagen. Es handelt sich doch ganz offensichtlich um eine heuristische Formulierung. Sie spielt an auf die freiheitlich-demokratische Grundordnung. Diese Grundordnung soll freiheitlich, soll demokratisch sein, und das trifft eben nur dann zu, wenn jedermann, auch als politischer Mensch, sich frei äußern, sich so geben kann, wie er es für richtig hält. Das ist demokratische individuelle Bestimmungsmacht. Niemandem soll eine Schablone von Staats wegen aufgepreßt werden. Ich erinnere im übrigen an die Gemeinwohldiskussion. Dort ist es heute gängige Erkenntnis, da $\beta$ das Gemeinwohl nur aus dem Konzert der divergierenden Meinungen hervorgehen kann, die sich gewiß, Herr Grabitz - in den Grenzen der allgemeinen Gesetze halten müssen; hier aber ist es gerade das Problem, daß man Elemente eingeführt hat, die gesetzlich mit dem Strafverbot gar nicht erfaßt sind. Das Strafgesetz ist der Musterfall des allgemeinen Gesetzes. Uber das Strafrecht hinausgehend haben wir aber - wie Herr Klein es gesagt hat - die Verteidigungslinie nach vorn verlegt. In der Tat: der kluge Mann baut vor, bloß bis zu welchem Punkt? Baut er eine oligarchische Verteidigungsstruktur auf, deren Gewicht dann demokratische Freiheit erstickt? Das ist das Problem, über das es zu diskutieren gilt. Auf der anderen Seite liegt auf der Hand, daß Beamter zu sein heißt, ein öffentliches Amt zu haben, Verantwortung zu tragen der Allgemeinheit gegenüber. Beides war gegeneinander abzugrenzen. Ich finde, daß beide Referate zu thesenhaft gewesen sind, daß sie nicht genug abgewogen haben zwischen der Freiheitlichkeit, die ja gewiß ein Element unserer freiheitlich-demokratischen Grundordnung bildet und bleibt, bleiben muß, und dem Vertrauens- oder Verantwortungsgesichtspunkt. Und, meine Herren, je stärker wir den Bereich der feststehenden, unverbrüchlichen Verfassungswerte ausdehnen, um so mehr geraten wir in ganz evidente Gefahren hinein. Wir sollten gewiß uns klar darüber sein, welchem Bilde wir nicht ähnlich sein wollen, dem Bilde nämlich eines deutschen Staates, der DDR heißt und wo man weiß, wie die unumstößliche staatliche Wahrheit lautet. Das Bewußtsein darf nicht verlorengehen, daß die Bundesrepublik sich prinzipiell von der DDR abheben muß, daß wir in einem freiheitlichen Staat leben, der nicht unter einer Masse von ewigen Wahrheiten die Freiheit erdrückt. 
Denninger: Ich bin dankbar, daß dieses Problem hier ausführlich besprochen wurde; ich bin andererseits der Meinung, daß der methodische Standort der Kategorie Freiheit von Angst weder von mir noch von Ihnen jetzt hier ausreichend präzisiert worden ist und auch nicht präzisiert werden kann. Ich lasse mir vielleicht den Vorwurf gefallen, Herr Grabitz, daß auch ich eine Art neuen Wertkodex akzeptiere; ich würde das nicht mit dem Wort Libido einer Verfassungspsychologie abtun; da würde ich erwidern, daß psychologische Sachverhalte auch objektiviert und zu Systemkategorien werden können. Wenn ich von Freiheit von Angst spreche, so ist das eine Art Systemkategorie und eine Verfassungserwartung. Ich darf darauf hinweisen, daß ich im gleichen Atemzug auch von der Bereitschaft zum demokratischen Engagement gesprochen habe. Das läßt sich sehr viel leichter exemplifizieren. Wir haben keine Wahlpflicht, erwarten aber, daß die Bürger zur Wahlurne gehen. Wenn die Bürger das nicht täten, würde die Demokratie nicht funktionieren. Den gleichen Stellenwert hat, meine ich, wenn auch etwas grundsätzlicher, die Freiheit von Angst, d. h. sie ist eine Kategorie, die einerseits außerhalb der Konstitution des Staates in der Konstitution des Menschen angelegt ist, andererseits aber in die Konstitution, in die Verfassung, hineinreicht, weshalb ich so frech war vorzuschlagen, den Katalog der freiheitlich-demokratischen Grundordnung, der ja nicht abschließend definiert ist, um diese Momente zu ergänzen. Das war alles, was ich wollte.

H. P. Schneider: Gestatten Sie mir vorab noch einen kurzen Nachtrag zu den Äußerungen von Herrn Isensee und Herrn Grabitz. Ich habe mich gewundert, daß sich ihr Diskussionsbeitrag nicht sofort einen gestrengen Blick des Herrn Vorsitzenden Völkerrechtlers zugezogen hat, als Sie die Kategorie „Freiheit von Furcht" auf die Ebene der Ethik oder gar der Psychologie entrücken wollten. Immerhin handelt es sich hier um eine Formel, die als positiver Rechtsbegriff in diesem Herbst 30 Jahre alt wird. Sie findet sich nämlich in der Menschenrechts-Erklärung der Vereinten Nationen von 1948 sowie im Bürgerrechtspakt von 1966 (jeweils in der Präambel). Dort wird ein menschliches Leben "frei von Furcht und Not" gefordert. Ich denke, gerade in diesem Zusammenhang tritt der unmittelbare Menschenrechtsbezug dieser Formel besonders deutlich hervor, und würde deshalb glauben, daß, wenn man sie methodisch noch weiter aufbereiten könnte, mit ihr sehr wohl auch juristisch $\mathrm{zu}$ argumentieren wäre, zumal doch letztlich 
niemand die Positivität jener völkerrechtlichen Erklärungen wird in Zweifel ziehen können.

Ich möchte aber die Diskussion noch auf einen anderen Gesichtspunkt lenken, und zwar auf das Problem der freiheitlichen demokratischen Grundordnung. Ich habe mich sehr darüber gefreut, daß trotz der Verschiedenheit ihrer Standpunkte beide Referenten - und wir alle wohl - darin einig sind, daß es uns bei der Frage nach dem Schutz der Verfassung darum geht, den Fortbestand der Verfassung in die Zukunft zu sichern. Schutz der Verfassung ist also im wesentlichen Fortbestandsschutz eines Kernbestands der Verfassung. Diese Erkenntnis zwingt uns, die Debatte um eine historische Dimension zu erweitern, dergestalt, daß wir uns fragen, ob denn die Begriffe, Herr Klein, auf die Sie sich beziehen, also die Verfassungsgrundsätze im Sinne von Art. 79 Abs. 3 GG, historisch einen so festen, bestimmten Inhalt haben, wie Sie in These 2 annehmen, d. h. so bestimmte, juristisch eindeutig fixierbare Strukturprinzipien sind, daß wir uns darüber heute und in alle Zukunft einig sein können. Ich darf daran erinnern, daß Begriffe wie „Rechtsstaat" und „Demokratie“ immer zugleich politische Kampfbegriffe gewesen sind, die bereits im Zeitpunkt ihrer Entstehung umstritten waren - wenn Sie nur an das Rechtsstaatsverständnis von Mohls auf der einen Seite (in der Polizeiwissenschaft nach den Grundsätzen des Rechtsstaats von 1844) und Stahls auf der anderen Seite (in seiner Rechts- und Staatslehre von 1856) denken; zwischen diesen beiden Rechtsstaatsvorstellungen liegen zweifellos Welten.

Man kann natürlich einwenden, daß beide Positionen sich auch heute noch im Rahmen jenes Grundkonsenses halten, der schon mehrfach angesprochen worden ist. Dann aber reduziert sich unser Problem auf die Frage, wo die Grenzen eines solchen Grundkonsenses verlaufen, der sozusagen durch fließende Geltungsfortbildung in die Zukunft hinein bewahrt werden soll. Es scheint, daß dieses Problem mit juristischen Mitteln nur sehr beschränkt lösbar ist und daß jeder Versuch, es allein mit Hilfe der herkömmlichen Interpretationsmethoden $\mathrm{zu}$ lösen, zum Scheitern verurteilt sein dürfte, weil er Dinge zu verfestigen versucht, die sich ihrer Natur nach einer begrifflichen Zementierung entziehen und folglich der politischen Auseinandersetzung überlassen bleiben müssen. Deshalb würde ich meinen, wir sollten insgesamt etwas mehr Vertrauen in die Offenheit und Fortbestandsfähigkeit unserer Verfassung haben und zugleich etwas mehr Vertrauen in die Selbstheilungskräfte des politischen Prozesses - ähnlich übrigens, wie wir es oft recht fraglos in das Wirtschaftsleben zu investieren geneigt 
sind. Ich sage dies im Bewußtsein der Tatsache, daß die Gegenwart zu solchen, etwas optimistischen Erwartungen wenig Anlaß bietet. Aber ich meine doch, daß hier vor allem im Vertrauen auf die demokratischen Organisationsstrukturen und Verfahrensnormen unserer Verfassung das eigentliche Desiderat eines konstruktiven Schutzes der Verfassung liegt und in deren wissenschaftlicher Durchdringung die wichtigste Aufgabe einer künftigen Verfassungsrechtslehre. Ich würde also dem "favor civis" von Herrn Denninger gern einen „favor constitutionis" zur Seite stellen wollen.

Böckenförde: Eine Bemerkung in dem Referat von Herrn Denninger hat mich sehr nachdenklich gemacht, die sich darauf bezog, daß die gegenwärtige Praxis und theoretische Anwendung des Begriffs der streitbaren Demokratie zu einem Auseinanderfall von Legalität und Legitimation führe. Mir scheint das in der Tat eines der Kernprobleme zu sein. Ich bin mit Herrn Klein der Auffassung, daß der Begriff der abwehrbereiten Demokratie seinen Sitz zunächst in Art. 79 Abs. 3 hat: das Grundgesetz hat sich entschlossen, bestimmte Grundentscheidungen legal unantastbar zu machen, sie nicht dem demokratischen Prozeß anzuvertrauen, sondern als ihm vorausliegend festzuhalten. (Dazu nur eine kleine Zwischenfrage: Ich weiß nicht, ob Sie, Herr Klein, auch das bundesstaatliche Prinzip in den Begriff mit hereinnehmen wollen; im Begriff der freiheitlich-demokratischen Grundordnung ist es seit der Entscheidung des BVerfG im 2. Band ausdrücklich nicht enthalten, wie ich glaube, aus guten Gründen.)

Das Grundgesetz selbst hat, so meine ich, den Hiatus, der sich heute zwischen Legalität und Legitimität auftut, noch geschlossen gehalten, und zwar dadurch, daß es legale Verfahren und Verbotsmöglichkeiten zur Verfügung gestellt hat, um die abwehrbereite Demokratie zu realisieren. Die hat es im Art. 9 Abs. 2, im Art. 18, im Art. 21 Abs. 2 zur Verfügung gestellt. Es ist dabei nicht ohne Interesse, daß der Art. 9 Abs. 2 ausdrücklich davon spricht, daß Vereinigungen, deren Zweck oder Tätigkeit sich gegen die verfassungsmäßige Ordnung richten, verboten sind. Ebenso heißt es im Art. 18: Wer die näher genannten Grundrechte zum Kampf gegen die freiheitlich-demokratische Ordnung mißbraucht, verwirkt sie. Im Art. 21 Abs. 2 heißt es, daß die entsprechenden politischen Parteien verfassungswidrig sind, über die Frage der Verfassungswidrigkeit allerdings das Bundesverfassungsgericht und nicht die Exekutive entscheidet. Nun gehört es zu unserer heutigen Wirklichkeit, daß quer durch alle politischen Gruppierungen immer der 
Grundsatz der Opportunität in Anspruch genommen wird; es sei eine Frage der Opportunität, ob ein Verbot ausgesprochen, $\mathrm{ob}$ ein Verbotsantrag beim Bundesverfassungsgericht gestellt werde. Das ist meines Erachtens der Kernpunkt, von dem aus es zum Auseinanderfall von Legalität und Legitimität kommt. Wenn zumindest der eindeutige Wortlaut noch eine Grenze möglicher Verfassungsinterpretation ist, wir uns darüber noch einig sind, ist ja nicht einzusehen, wie aus dem Satz ,sind verboten' in Art. 9 Abs. 2 GG gefolgert werden kann ,können verboten werden'.

Das Vereinsgesetz hat ein Verfahren zur Verfügung gestellt, die zuständigen Behörden bestimmt, aber was heute praktiziert wird, ist, daß dieses Verbotsverfahren gar nicht angewandt wird, man aber gleichwohl Vereinigungen, die man für verfassungswidrig hält, so behandelt, als ob das Verfahren bereits durchgeführt sei. Zumindest also im Hinblick auf Art. 9 Abs. 2 ist jede Inanspruchnahme von Opportunität erschlichen, sie findet in der Verfassung keine Grundlage. Was dadurch in der Praxis geschieht, ist, daß der Bürger des Schutzes rechtsstaatlicher Verfahren beraubt wird. Er soll sich an den Meinungen in Verfassungsschutzberichten über Verfassungsfeindlichkeit von Aktivitäten orientieren, das Beurteilungsrisiko übernehmen, ohne daß eine Feststellung in einem gesicherten Verfahren erfolgt, dessen Ergebnis Verbindlichkeit beanspruchen kann.

Im Hinblick auf Art. 21 Abs. 2 ist ebenfalls zu beachten, daß es dort nicht heißt: Uber das Verbot entscheidet das Bundesverfassungsgericht, sondern über die Verfassungswidrigkeit entscheidet das Bundesverfassungsgericht. Auch das ist als Schutzbestimmung normiert worden, um der Exekutive eine rechtserhebliche Feststellung darüber zu entziehen, ob eine politische Partei verfassungswidrig ist oder nicht. Auch hier ist der Begriff Verfassungsfeindlichkeit in dem Moment, wo er Rechtserheblichkeit beansprucht, ein erschlichener Begriff. Die Exekutive kann eine Meinung und Ansicht haben über die Zielsetzung und Tätigkeit von politischen Parteien, aber es ist ihr nicht zugestanden, mit rechtserheblicher Wirkung selbst festzustellen, daß politische Parteien verfassungswidrig sind. Soll dies geschehen, muß der Antrag beim Bundesverfassungsgericht gestellt werden. Wird für diesen Verbotsantrag Opportunität in Anspruch genommen, dann muß nach meiner Auffassung auch die Konsequenz mit in Erwägung gezogen werden - und insofern stimme ich dem Sondervotum Rupp in dem Radikalenbeschluß des BVerfG $\mathrm{zu}$-, daß dann an die Mitgliedschaft in einer solchen Partei kein rechtlicher Nachteil 
oder eine Vermutung im Hinblick auf verfassungswidrige Einstellung angeknüpft werden kann. Entweder sagt man: Wir sind stark und selbstgewiß genug, das stört uns gar nicht, eine so geringe Minderheit von Extremisten können wir integrieren oder verdauen. Oder aber, wenn man dieses Risiko für zu groß hält, dann muß man die Konsequenzen ziehen und den Verbotsantrag stellen, an den sich wieder ein Verfahren mit entsprechenden Garantien anschließt.

Ich bin auch im Hinblick auf die Frage der Ersatzorganisation weitgehend Ihrer Meinung, Herr Klein. Die Zuständigkeit für die Frage, ob die DKP eine Ersatzorganisation der KPD und deshalb zu verbieten sei, lag seinerzeit - 1968 - beim Bundesinnenminister, nicht bei der Bundesregierung; der seinerzeitige Bundesinnenminister, jetzt Präsident des Bundesverfassungsgerichts, hat davon abgesehen, diese Verbotskompetenz auszuüben, wiewohl hier ein Opportunitätsprinzip gewiß nicht ersichtlich ist.

Wir haben nach alledem heute die Situation, daß der Bürger, der sich legal verhält, noch nicht der loyale oder der gute Bürger ist. Der einzelne beteiligt sich an Vereinigungen, die nicht verboten sind, wiewohl sie für verfassungsfeindlich gehalten werden; er tut nichts Illegales, weil ja das Verbotsverfahren nicht angestrengt wird, hält sich also im Rahmen der Legalität, gleichwohl begründet dies Zweifel an seiner Verfassungstreue. Es gehört jedoch zum Rechtsstaat und zum Verfassungsstaat, zumal zu einem Verfassungsstaat, der die eigene Legitimitätsverteidigung zur Aufgabe seiner gesetzgebenden und gesetzanwenden Organe macht, daß Legalität und Legitimität beieinander gehalten werden, daß gerade nicht gesagt werden kann: Wenn Du Dich im Rahmen der Gesetze hältst, dann bist Du noch nicht der loyale und vertrauenswürdige Bürger. Da, meine ich, hat der Bürger doch — frei nach Otto Mayer - das Recht darauf, zu wissen, wessen er sich vom Staate zu versehen hat. Und $\mathrm{m}$. E. führt das auch gleich in die Problematik beim Zugang zum öffentlichen Dienst hinein. Es gehört auch zu der Deckung von Legalität und Legitimität, daß von dem Bürger, der in den öffentlichen Dienst treten will, Verhaltensforderungen erwartet werden, da $\beta$ er in seinem Verhalten der Verfassung und den Gesetzen entspricht, daß er in seinem Verhalten - in seinem amtlichen und in Grenzen auch seinem außerdienstlichen Verhalten - eintritt für die freiheitlich-demokratische Grundordnung, aber es gehört nicht dazu, daß man sich seiner Gesinnung zu versichern sucht - ich möchte dazu hier nicht weiter vorgreifen, weil das ja ein eigener Punkt ist. 
Starck: Nachdem schon so viel über den Begriff Freiheit von Angst gesagt worden ist, muß ich mir leider versagen - auch mit Rücksicht auf die Zeit - eigene Bedenken dagegen hier anzumelden. Ich sehe, ähnlich wie Herr Isensee und Herr Grabitz die Gefahr, daß man diesen Begriff, der sich gewissermaßen auf Rädern befindet, jeweils dort hinstellen kann, wo man ihn gerade braucht; das tut im Verfassungsrecht nicht gut. Nur eine kurze zweite Bemerkung: Herr Klein hat sehr einsichtig zu unterscheiden versucht zwischen dem Staatsrecht und der Staatsbürgerethik. Wenn man einmal die Erziehungsziele aus den Landesverfassungen heranzieht und sie von einigen Arabesken befreit, dann findet man, daß in diesen Erziehungszielen genau das, was wir als Staatsbürgerethik bezeichnen, enthalten ist. Nun sind diese Erziehungsziele für die Schulen und damit für die Lehrer verpflichtend, damit wohl auch verpflichtend für diejenigen, die die Lehrerausbildung betreiben, also wird die Staatsbürgerethik über die verfassungsrechtlichen Erziehungsziele doch zu einer Rechtskategorie. Ich hätte darüber gerne noch eine Auskunft von Herrn Klein wie auch von Herrn Denninger, der sich mit dieser Frage, obwohl sie nahegelegen hätte, nicht beschäftigt hat.

Quaritsch: Herr Denninger hat den Aufsatz von Karl Loewenstein aus dem Jahre 1937 erwähnt, in dem unter dem Titel, Militant Democracy and Fundamental Rights' wohl zum ersten Male das Prinzip der streitbaren Demokratie entwickelt wurde. Das Datum ist nicht belanglos. Der Aufsatz erschien im August 1937, nachdem Roosevelt einige Monate zuvor in seiner bekannten Quarantäne-Rede den außenpolitischen Gegenangriff gegen die autoritären Regimes in Europa und in Japan angekündigt hatte. Die Abhandlung Loewensteins in der verbreiteten wie einflußreichen "American Political Science Review" bildete dazu das innenpolitische Pendant. Loewenstein sprach dem demokratischen Verfassungsstaat das Recht, aber auch die Pflicht zu, unter bestimmten Bedingungen zeitlich und inhaltlich begrenzt Grundrechte zu suspendieren und nicht-demokratische Parteien und paramilitärische Verbände zu verbieten. Er hat sich damals ausführlich - und das vermisse ich bei Herrn Denninger - mit dem von ihm sog. ,Fundamentalismus' auseinandergesetzt, dem Hans Kelsen zuzurechnen war, der die Meinung vertrat, die Demokratie müsse ihre Feinde genauso behandeln wie ihre Freunde und lieber mit wehender Flagge untergehen, als sich selbst untreu zu werden. Loewenstein hat den Fundamentalismus als empirisch widerlegt und praktisch diskreditiert angesehen; ich sehe nicht, wes- 
halb dieses Urteil revidiert werden müßte. Es ist kein Selbstwiderspruch und keine Selbstaufhebung der freiheitlich-pluralistischen Demokratie, wenn dieses Verfassungssystem gegen ihre Feinde mit rechtsstaatlichen Mitteln verteidigt wird. Wer die Bundesrepublik deshalb auf die Ebene der DDR gerückt sieht, ist blind für die himmelweit verschiedenen Mittel, die diese beiden Staaten gegen Systemfeinde einzusetzen pflegen.

Auch die rechtssystematischen Einwendungen gegen den Begriff der streitbaren Demokratie gehen fehl. Mit ihm werden abkürzend die auf System-Verteidigung gerichteten Einzelvorschriften des Grundgesetzes und des öffentlichen Dienstrechts zusammengefaßt; zugleich benennt der Begriff die den Vorschriften gemeinsame Tendenz. Nicht einmal altmodische Positivisten würden sich scheuen, diese Tendenz bei der Rechtsanwendung zu berücksichtigen.

Die von Herrn Denninger als "vorkonstitutionelles Element" unserer Verfassungsordnung bezeichnete „Freiheit von Angst“ hat ihre Geschichte, die gleichfalls nicht vergessen werden darf. Sie ist eine der „Vier Freiheiten“, die Roosevelt 1943 der Welt verkündete - sinnigerweise auf einem Schlachtschiff im Atlantik. Es war eine politische Parole, die sich gegen die illiberalen Systeme der Achsenmächte richtete. Herausgelöst aus diesem politisch-historischen Zusammenhang und hineingestellt in die gegenwärtige Situation der Bundesrepublik kann die Anwendung dieses Grundsatzes nur diese Folge haben: Freiheit von Angst genießen insbesondere die Verfechter der Unfreiheit.

Als Auftakt hat uns Herr Denninger drei Fälle erzählt. Ich hatte deshalb erwartet, nun würden wir über die Realien des Verfassungsschutzes unterrichtet werden. Diese Erwartung blieb unerfüllt. Denn nach der unmaßgeblichen Äußerung eines unmaßgeblichen Stadtrates über eine neunzehnjährige Schülerin (ist ihr deshalb der Studienplatz verweigert worden?) war schon Schluß. Das ist bedauerlich. Um das vom Referenten gezeichnete Bild der Praxis abzurunden, hier ein weiterer Fall: Ein Diplom-Psychologe namens Geuter wurde am 1. 4. 1978 im Psychologischen Institut des Fachbereichs 11 der Freien Universität Berlin als beamteter Wissenschaftlicher Assistent eingestellt. G. ist ein wegen Nötigung, Hausfriedensbruch, Beleidigung und Verstoßes gegen das Versammlungsgesetz mehrfach vorbestrafter gewalttätiger Sympathisant des Kommunistischen Studentenverbandes (KSV). Das letzte gegen ihn ergangene strafgerichtliche Urteil war erst am 3. 3. 1977 rechtskräftig geworden. Die Einstellung wurde in Kenntnis dieser Tatsachen unter bewußter Ausschaltung der für die Uberprü. 
fung der Verfassungstreue zuständigen Landeskommission vom FU-Präsidenten befürwortet und vom Senator vollzogen. Dabei wurde auch noch die Personalkommission der FU rechtswidrig übergangen. Zwei Vizepräsidenten der FU hatten vorher mehrfach gegen diese rechtswidrige Einstellung protestiert. Als sie einen öffentlichen Protest ankündigten, drohten die Senatsverwaltung und das FU-Präsidialamt mit Disziplinarmaßnahmen. So, Herr Denninger, kann "Verfassungsschutz" auch aussehen.

Denninger: Herr Quaritsch, ich fühle mich entweder gar nicht oder nur höchst partiell betroffen und getroffen. Ich habe ausdrücklich gesagt, daß ich die Kelsensche Position in dieser Form nicht akzeptiere, sondern eine Weiterentwicklung. In meinem Text steht: Die freiheitliche Demokratie muß streitbar sein, gerade um der Erhaltung der pluralistischen Offenheit willen. Gerade diese Offenheit ist es, die sie mit absoluten Vorsätzen verteidigen muß. Das habe ich heute morgen gesagt - und mehr nicht. Insofern ist Ihre Wiederholung der Kritik am Fundamentalismus völlig berechtigt, aber von mir geteilt; und was der Berliner Verfassungsschutz macht, das interessiert mich hier theoretisch überhaupt nicht, nicht wahr.

Stein: Mir scheint, daß ein Aspekt in beiden Referaten zu kurz gekommen ist, nämlich das Verhältnis von Verfassung und sozialem Wandel. Nach meiner Utberzeugung spielt dieses Verhältnis für die Probleme, die heute von uns hier diskutiert werden, eine zentrale Rolle. Ich will das zu verdeutlichen versuchen.

Wenn eine Verfassung in Kraft tritt, werden in dieser Verfassung regelmäßig Probleme zu lösen versucht, die mindestens einige Jahre vorher schon bestanden haben. Denn es dauert einige Zeit, bis ein soziales Problem eine genügende Schärfe erreicht hat, um perzipiert zu werden. Und es dauert weitere Jahre oder Jahrzehnte, bis dieses perzipierte soziale Problem sich im politischen Willensbildungsproze $\beta$ niederschlägt und bis es noch später verfassungsrechtlich geregelt wird. Deswegen muß jede Verfassung notwendig hinter der Entwicklung der sozialen Wirklichkeit etwas zurückbleiben. Angesichts der ständig zunehmenden Geschwindigkeit des sozialen Wandels wird damit die Frage der Anpassung jeder Verfassung an den sozialen Wandel zu einem Problem von ständig größerer Bedeutung. Wer sich daher für die Erhaltung unserer freiheitlichdemokratischen Grundordnung einsetzt, muß sich dafür einsetzen, daß unsere gegenwärtige Verfassung - im Gegensatz 
zur freiheitlich-demokratischen Grundordnung - nicht zementiert wird, sondern flexibel bleibt, um diese Anpassung zu ermöglichen. Es gibt wohl kaum eine wirksamere Methode, um zu erreichen, daß eine Verfassung revolutionär beseitigt wird, als die Zementierung dieser Verfassung. Sie muß dazu führen, daß sich im Laufe der Zeit infolge des Spannungsverhältnisses zwischen der jetzt gewandelten sozialen Wirklichkeit und der zementierten Verfassungsordnung so viel Zündstoff ansammelt, daß es zu einer Verfassungsdurchbrechung kommt.

Die Problematik, die wir heute diskutieren, bezieht sich ja nicht auf die Abwehr von unmittelbaren Verletzungen der Verfassung, sondern bezieht sich auf die Abwehr von unmittelbaren Versuchen zur Änderung oder Ersetzung unserer Verfassungsordnung, soweit sie nämlich gleichzeitig als Beeinträchtigung der freiheitlich-demokratischen Grundordnung gesehen werden. Deshalb sind alle Maßnahmen zum Schutz der Verfassung (im Sinne eines Schutzes der freiheitlich-demokratischen Grundordnung) notwendig mit einer Erschwerung von Verfassungsänderungen verbunden. Daraus folgere ich natürlich nicht, daß derartige Maßnahmen stets zu unterbleiben hätten. Mir geht es nur darum, daß bei allen derartigen Maßnahmen, insbesondere bei den Maßnahmen zur Abwehr „verfassungsfeindlicher" Bewerber um Beamtenstellen, dieser Aspekt stärker, als das bisher geschehen ist, berücksichtigt wird. Ich messe der Frage, ob solche Maßnahmen freiheitsmindernd wirken, geringere Bedeutung bei als der Frage, ob sie die Flexibilität unserer Verfassung beeinträchtigen. Ich erinnere nur daran, daß in der öffentlichen Diskussion jeder, der sich - in seiner eigenen Terminologie - für eine „Systemveränderung“ einsetzt, allein deshalb als "Verfassungsfeind" i. S. eines Gegners unserer freiheitlich-demokratischen Grundordnung angesehen und bekämpft wird. Deshalb gilt es zu verhindern, daß durch Maßnahmen zum „Schutz der Verfassung" die öffentliche Meinungsbildung und die politische Willensbildung über tiefergreifende Änderungen der Verfassung erschwert wird.

Klein: Herr Stein, ich meine, das, was Sie hier gesagt haben über den Wandel in der sozialen Wirklichkeit und die notwendig retardierende Reaktion der Rechtsordnung einschließlich der Verfassungsordnung, ist eine allgemeine Wahrheit, die jeder von uns akzeptiert. Ich sehe insofern gar keine Meinungsverschiedenheit zwischen uns, es sei denn, Sie bezögen das, was Sie gesagt haben, auch auf das, was nach meinen Darlegungen der eigentliche und ausschließliche Gegenstand des Verfassungsschutzes ist. Insofern allerdings würde ich Ihnen nicht 
folgen, wenn Sie gemeint haben sollten, daß das, was in Art. 79 Abs. 3 - ich lasse vor der Klammer die Frage der Bundesstaatlichkeit - gewährleistet ist, durch die soziale Wirklichkeit überholbar sei. In diesem Sinne, wenn ich da zurückkommen darf auf die Ausführungen von Herrn Hans-Peter Schneider, würde ich auch meinen, daß es unzulässig ist, die naturgemäß in der Theorie vielfach ausfüllbaren Begriffe der Demokratie oder der Rechtsstaatlichkeit, also der Grundsätze, auf die Art. 79 Abs. 3 Bezug nimmt, unter einem verfassungsrechtlichen Aspekt beliebig zu variieren. Denn was das Grundgesetz unter Demokratie und Rechtsstaatlichkeit versteht, das allerdings ist, wie ich meine, innerhalb gewisser Toleranzgrenzen sicher zu einem hohen Grade durch die Verfassung selbst bsetimmt, und darauf nimmt Art. 79 Abs. 3 Bezug und nicht auf das, was in der Literatur mit dem Etikett "demokratisch“, seltener „rechtsstaatlich“, versehen wird.

Doehring: Zunächst ein Wort zu dem, was Herr Ekkehart Stein gesagt hat: Die Unabänderbarkeiten der Verfassung, wenn sie wirklich die Revolution provozieren würden, legen die Frage nahe, woher es kommt, daß die Ostblockverfassungen noch bestehen, denn diese bezeichnen sich in ihrer Grundtendenz sämtlich als unabänderbar, und trotzdem halten sie stand. Diese Theorie erscheint mir fraglich.

Aber nun zur streitbaren Demokratie. Ich habe etwas den Eindruck gehabt, insbesondere bei dem Referat von Herrn Denninger, als wenn man von einer Insel spricht. Ich möchte darauf hinweisen, daß die Unterwanderungen bzw. die Gefahren unserer Demokratie nur zum Teil von innen kommen, zu einem sehr großen Teil aber von außen gesteuert sind. Das gibt dann ein etwas anderes Bild. Wenn man fragt, wie weit denn die Streitbarkeit der Demokratie gehen darf, um nicht selbst wieder etwas zu zerstören, was wir schützen sollten, dann kommt es wesentlich darauf an, wie intensiv der Angriff auf unsere Freiheit ist. Von daher muß man die Sache beleuchten. Ich habe in dem Referat von Herrn Denninger nichts darüber gehört, wie stark nun eigentlich diese Gefährdung ist, immer nur etwas darüber, wie stark die Gefährdung derjenigen sei, die in den Geruch kommen könnten, diesem System nicht anzuhängen. Aber über die objektive Gefährdung des Staates - die mir eine ganz wesentliche Frage zu sein scheint - habe ich nichts gehört. Ich muß jetzt auch noch einen Augenblick eine Verbindung herstellen zum öffentlichen Dienst, zum Staatsbediensteten, und wende mich noch einmal der internationalen Sicht und der Rechtsvergleichung zu. Wir haben eine 
größere Arbeitsgruppe gebildet, die nun vor dem Ende ihrer Arbeit steht, um zu untersuchen, wie man in anderen Staaten mit den verfassungszerstörenden Bestrebungen fertig zu werden versucht. Ich will und kann hier meinen Kollegen ihre Ergebnisse nicht vorwegnehmen, aber eines ist sicher: der Gerichtsschutz, auf den wir so stolz sind, und der Begründungszwang, sie existieren in den meisten auch rechtsstaatlichen Demokratien der Welt auf dem Gebiet der Beamteneinstellungen überhaupt nicht, sondern das geht dort sehr viel einfacher vor sich. Dazu stellt sich die Frage auch für Europa; ich weiß nicht, ob wir nicht über ein Scheinproblem reden. Wenn in Brüssel bei den Gemeinschaften Bedienstete angestellt werden sollen, und es würde sich jemand bewerben, der das Statut einer Partei oder eines Vereins unterschrieben hätte, die den Europagedanken komplett ablehnen, käme man doch ganz bestimmt nie und nimmer auf den Gedanken, daß die Verwaltung der Europäischen Wirtschaftsgemeinschaft einen solchen Bewerber einstellen würde; das aber ist genau die Lage unseres Verfassungsrechts, es ist dasselbe Bild. Die Loyalitätserklärung für Europa des europäischen Beamten endet zwar nicht mit einem Eid, aber die Loyalität wird sehr ernst genommen, und das hat auch der Europäische Gerichtshof in Luxemburg klar gesagt. In den Vereinten Nationen haben wir die gleiche Loyalitätsverpflichtung. Soll denn der Generalsekretär Waldheim jemanden einstellen, der die Grundgedanken der Friedenssicherung, Völkerverständigung und Menschenrechte ablehnt? Er wird das hoffentlich nicht tun. Die Parallelen hier sind wohl evident und völlig klar; aber bei uns spricht man von Gesinnungsschnüffelei, wenn wir nur versuchen, das festzustellen, was selbstverständlich die Brüsseler Behörden auch feststellen müssen. Im übrigen werden die Akten dort gar nicht offengelegt, das Verfahren ist nicht öffentlich, und der Abgelehnte hat keinen Zugang zu den Akten, was in den meisten westlichen Demokratien ebenso gehandhabt wird.

Jetzt komme ich zu einer Frage, die Herrn Böckenförde beschäftigt hat, aber auch und insbesondere Herrn Denninger, nämlich zu dem Verhältnis von Verhalten und Gesinnung. Es wird gesagt, Gesinnung werde geprüft, solle aber nicht geprüft werden, denn nur das Verhalten dürfe geprüft werden. Die entsprechende Frage ist doch aber gar nicht, ob Gesinnung schlechthin geprüft wird, sondern um welche Gesinnung es sich handelt, denn die eine Gesinnung könnte den Ausschließlichkeitsanspruch einer Ideologie zum Inhalt haben und keine Debatte über die politische Prämisse zulassen, die andere Gesinnung aber kann gerade die Toleranz, die wir wollen, zum 
Gegenstand haben. Sollen wir insoweit nicht prüfen dürfen? Wie können wir denn eigentlich ein Verhalten werten, das letztlich auf Gesinnung beruht? Gesinnung und Verhalten sind sich ergänzende Faktoren. Ich habe in Hitlers „Mein Kampf" gefunden, daß dort ein hohes Lied auf das politisch neutrale Berufsbeamtentum zu lesen ist. Nach 1933 war es dann anders. Was aber war denn Hitlers Gesinnung, und was war sein Verhalten? War sein Buch Verhalten oder war es die Offenbarung seiner Gesinnung, oder war alles gelogen? Man hätte sicherlich auch den Regierungsrat Hitler früher in bezug auf seine Gesinnung prüfen sollen, und man hätte sich manches erspart. Wenn Sie sagen, Sie seien in einem „braunen Strudel“ zur Welt gekommen, Herr Denninger, hoffe ich doch, daß Sie nicht in einem roten Strudel untergehen. Beide Strudel mag ich nicht, und ich war schon vor Ihnen auf der Welt und vor dem braunen Strudel, dessen Kommen ich bewußt erlebt habe. Ich möchte auch eine Wiederholung verhindern und darin sind wir uns wohl völlig einig.

Wenn nun aber jemand das DKP-Statut, die Grundsatzerklärung von 1969, unterschreibt, in der steht, daß der Leninismus-Marxismus revolutionär durchgesetzt werden soll und in dem auch die Verpflichtung zum Handeln im Sinne des Kommunistischen Manifests zu lesen ist, in dem gesagt ist, daß gegebenenfalls mit Gewalt gehandelt werden muß - wenn jemand so etwas unterschreibt, und er will dann als Lehrer angestellt werden oder in den öffentlichen Dienst eintreten, dann wäre die richtige Lösung wohl, ihm zu sagen, er solle doch austreten aus dieser Vereinigung und dann könne man weiter sprechen. Aber der Bewerber kann nicht diese Unterschrift aufrechterhalten und diejenige zur Verfassungstreue leisten. Welche Gesinnung der Bewerber hat, kann ich auch nur wiederum an seinem Verhalten - nämlich seiner Unterschrift prüfen. Der Austritt aus der Partei wäre eine Gesinnungsfrage und eine solche des Verhaltens; belogen werden kann man natürlich immer.

Damit wollte ich sagen: Die Trennung zwischen Verhalten und Gesinnung, zwischen Verhaltens- und Gesinnungsprüfung, ist auf diesem Gebiet nicht durchführbar, ebensowenig wie die Differenzierung zwischen sicherheitsempfindlichen und anderen Beamtenposten; ich kann sie nicht vollziehen. Ich bin z. B. mehrfach von der Kriminalpolizei gewarnt worden, aber ich weiß nicht immer, wer mich nun anruft, und man hat mir auch gesagt, ich solle am Telefon keine Antwort geben, auch dann nicht, wenn angeblich die Polizei anruft. Sehen Sie, das sind reale Unsicherheiten. Ich weiß auch nicht - um ein anderes 
Beispiel zu nennen - ob jede Postsendung mich erreicht, und es ist schon einiges an Post verloren gegangen; es gibt Hilfspostboten, z. B. Studenten in Urlaubszeiten, die ich nicht kenne, die aber mich kennen. Auch auf diesen Gebieten möchte ich keine Sicherheitseinbrüche haben, sondern das volle Vertrauen, daß diese Funktionen des Staates überwacht werden, „überwacht", nicht wie in einem übermächtigen Polizeistaat, aber doch so, daß ich diese Angst - das ist übrigens meine Angst, im Gegensatz zu der angeblichen Angst des tberwachten nicht haben muß. Wenn wir die Gesinnung prüfen, geht es um die Gesinnung zur Freiheit im positiven Sinne, denn wir wollen den besten Beamten haben und nicht nur den schlechten vermeiden. Wenn wir das beachten, dann, glaube ich, sind wir durchaus auf dem richtigen Wege, und ich frage mich, warum wir uns eigentlich so sehr um diese Dinge streiten müssen.

Vorsitzender: Vielen Dank, Herr Doehring. Wir kommen jetzt schon indirekt vom Allgemeineren ins Konkrete und sind so materiell bereits im Teil B, also in den Einzelfragen, insbesondere Zugang zum Öffentlichen Dienst. Herr Denninger, Sie waren sehr angesprochen: eine kurze Zwischenbemerkung?

Denninger: Ja, Herr Doehring, ich bin Ihnen wirklich sehr dankbar, daß Sie sozusagen hier den Finger ins Schlimme gelegt haben, aber die Fragen, die Sie stellen, möchte ich eigentlich an Sie zurückgeben. Die Tatsache, da stimme ich Ihnen zu, daß Verhalten und Gesinnung sehr eng zusammenhängen und daß Gesinnung sehr schwer feststellbar ist, ist für mich geradezu ein indirekter Beweis dafür, daß wir die Wahl haben, entweder so etwas wie einen favor civis anzuerkennen und mit ihm auch praktisch zu arbeiten - ich habe versucht, ein paar Folgerungen zu skizzieren - oder, daß wir eben von einem grundsätzlichen Mißtrauenssystem aus denken müssen; dann allerdings müssen wir noch ganz andere, polizeistaatlichere Methoden einführen, d. h. wenn wir Ihre Forderung des in jedem Fall sicheren, gesinnungstreuen Briefträgers usw. ernstnehmen und Konsequenzen auf der Mißtrauensbasis daraus ziehen wollen, dann wird sich dieser Staat hier ganz erheblich verändern müssen. Und vor dieser Option würde ich eben dazu neigen, vielleicht mit ein bißchen, von Herrn Ipsen ja jedenfalls kritisiertem Optimismus, doch eben nicht das Hobbes'sche Menschenbild zugrundezulegen, sondern ich würde auf einer Vertrauensbasis - aber das ist auch wieder eine Art objektivierten Vertrauens - operieren wollen, mindestens einmal den Versuch hierzu machen. Das beginnt bei der Frage 
nach dem Maßstab, an dem Sie den Grad der Gefährdetheit dieser Republik messen wollen; Sie stellten ja die Frage, nicht wahr. Da könnten wir nun stundenlang Voten gegeneinander austauschen. Ich würde mich hier etwa auf den ehemaligen Generalbundesanwalt Max Güde beziehen, der ja nun ein Kenner der Materie aus dem Staatsschutzbereich sein dürfte. Er hat neuerdings ganz dezidiert festgestellt, da $\beta$ die Bundesrepublik zu keinem Zeitpunkt ihres Bestehens in irgendeiner Weise durch einen inneren Feind gefährdet war. Sie können natürlich auch Gegenmeinungen auftischen, etwa die von Herrn Willms, nicht wahr, der bedauert, daß der Staatsschutz allmählich verkümmert, oder unter dem Titel ,Rückzug in die Zitadelle' einen ständigen Rückgang des an sich dringend notwendigen Staatsschutzes beklagt. Ich glaube, daß es sehr schwierig ist, sich hier überhaupt über objektive Maßstäbe zu einigen. Wollen Sie das Verhältnis von abgelehnten Bewerbern zu angehörten oder überprüften nehmen, dann kommen Sie auf minimale Promille-Sätze bzw. Null-Komma-Promille-Sätze; ist das ein Indiz für Gefährlichkeit? Ich würde Ihnen ohne weiteres zustimmen, wenn Sie sagten: Das ist kein Indiz. Man weiß ja gar nicht, wie gefährlich die im einzelnen sind, usw.

Ich glaube, Sie sehen alle diese Schwierigkeiten. Ich glaube wir können in dieser Situation nicht anders, als auf bestimmte Vermutungslagen zurückzugreifen.

Doehring: Ich wollte nur von dem statischen Denken weg. Ich wollte sagen, die Abwehrbereitschaft und Abwehrkraft und auch die Freiheitseinbuße müssen sich danach richten, wie intensiv der Angriff ist.

Denninger: Da stimme ich Ihnen völlig zu, Herr Doehring.

Delbriick: Ich hatte eigentlich an Herrn Klein, aber vor allem an Herrn Denninger noch Fragen. Ich möchte zum Ausdruck bringen, daß ich in den Referaten eine gewisse Operationalisierung der Prinzipien vermißt habe, denen man im einzelnen zustimmen mag oder nicht. Es läßt sich über das Radikalenproblem kräftig streiten in der Ebene der Prinzipien. Ob optimistisches oder pessimistisches Menschenbild usw., das alles sind treffliche Gegenstände einer ausführlichen Diskussion. Denn, Herr Denninger, auch bei Ihnen wird Verfassungstreue - in Ihren Thesen ab VI - im Einzelfall geprüft. Das ist sicher auch meiner Ansicht nach richtig, aber die ganzen Probleme, mit denen wir als Juristen uns quälen, fangen an diesem Punkt eben erst an. Dann nämlich geht es um die Frage der Krite- 
rien, die Maßstäbe, die den Verdacht für eine Überprüfung hinreichend erscheinen lassen, so daß ich anfange zu prüfen, usw. usw. Hier bleibt für mich Entscheidendes offen. Ich möchte dies verdeutlichen: Herr Klein hat bei mir den Eindruck erweckt, daß er die streitbare Demokratie sozusagen als einen umgreifenden Verfassungsvorbehalt versteht, der dann - mehr oder minder von der Gefahrenlage abhängig - einseitig zu Lasten der Freiheitsverbürgungen realisiert wird.

Herr Denninger hat im Gegensatz dazu die Toleranz als ein Kriterium eingeführt, aber für mich eben auch noch nicht operationalisiert genug, nicht scharf genug in dem Sinne, daß man den Eindruck gewinnen könnte, hier würde jetzt eine echte Güterabwägung o. ä. juristisch-methodisch in die Prüfung eingebracht. Ich glaube, wir müssen - und das wäre etwas, wo ich um weitere Konkretisierung bitten würde - uns bemühen, dieses ganze Problem methodisch einzuordnen in die Denkkategorien und -figuren, die wir als Juristen zur Hand haben, etwa z. B., daß man die Entscheidungen, die anfallen, trifft in der Spannung zwischen einerseits Toleranz als Verfassungsschutz - denn auch die Realisierung der Verfassung im Sinne der Freiheitsverbürgung ist ja Verfassungspflege oder auch Verfassungsschutz - und Verfassungsschutz im engeren Sinne als Abwehr von feindlichen Eingriffen. Wenn man in dieser Dichotomie, in dieser Spannung, die Güterabwägung von vornherein einführt, so glaube ich, dann wird auch die Blickrichtung des Administrators von vornherein mehr eingeengt und konzentriert darauf, daß er hier zwischen zwei mindestens gleichwertigen Rechtsgütern abzuwägen hat. Die einseitige so habe ich es verstanden - die einseitige Einordnung der streitbaren Demokratie als Verfassungsvorbehalt - oder wie immer - scheint mir zu Lasten des freiheitlichen Denkens zu gehen. Ich stimme da völlig mit dem überein, was Herr Tomuschat gesagt hat. Wir haben etwas aus dem Blick verloren, daß eben auch die Toleranz als die andere Komponente unserer Verfassung der Pflege bedarf, wenn wir uns nicht an Modelle annähern wollen, die wir alle für verwerflich halten.

Klein: Herr Delbrück, ich habe in der Tat gesagt, - jedenfalls gemeint - daß das Prinzip der streitbaren Demokratie bzw. das Postulat eines wirksamen Schutzes der freiheitlichen demokratischen Grundordnung ein Prinzip der Verfassung ist, das, wie manches andere, die Interpretation jeder einzelnen Verfassungsnorm beeinflußt. Aber ich habe auch gesagt, Bestandteil der freiheitlichen demokratischen Grundordnung sind auch und gerade die Grundrechte, so daß wir hier doch einem 
Phänomen begegnen, das uns aus der allgemeinen Verfassungstheorie und Methodologie durchaus geläufig ist, daß wir nämlich - ich habe den Begriff von Herrn Hesse ausdrücklich gebraucht - hier unter Umständen widerstreitende Verfassungsprinzipien zu praktischer Konkordanz, d. h. jeweils optimal zur Wirkung bringen. Wie Sie darin eine einseitige Abwägung zu Lasten der Freiheit sehen können, ist mir nicht ganz verständlich.

Bull: Ich spreche über Verfassungsschutz (im weiteren Sinne) als Massenproblem und über positiven Verfassungsschutz. Wenn wir heute Zahlen der Einstellungsüberprüfungen für den Offentlichen Dienst haben, die in die Hunderttausende gehen; wenn wir uns vergegenwärtigen, da $\beta$ der Öfentliche Dienst, der ja insgesamt - jedenfalls potentiell - einer weiteren Utberprüfung unterliegen könnte, rund 3,6 Millionen Personen umfaßt; wenn man weiter wahrnimmt, daß in der Offentlichkeit der Eindruck besteht, als gebe es generell Uberprüfungen etwa des Reiseverkehrs oder des Leseverhaltens von Bürgern, dann ist das keine bloß quantitative Frage mehr, sondern eine qualitative Frage - und ein Aspekt, den wir hier berücksichtigen müssen. Dies zu berücksichtigen, ist auch ein Stück richtige Methodik zur Bewältigung des Themas, das wir uns heute gestellt haben. Wir müssen dabei selbstverständlich unterscheiden zwischen dem, was objektiv vorliegt, und dem, was subjektiv wahrgenommen wird.

In meiner Tätigkeit als Bundesbeauftragter für den Datenschutz erhalte ich viel Echo aus der Bevölkerung, bekomme viele Briefe und erfahre bei Diskussionen und in anderen Veranstaltungen viel über die Stimmung im Lande in bezug auf den Verfassungsschutz - im engeren und im weiteren Sinne. Ich kann Ihnen versichern, daß die Folgen des Eindrucks, daß eine große Anzahl von Mitbürgern einer Utberprüfung bis hin zur Gesinnungsprüfung ausgesetzt werde - wie gesagt, als subjektive Wahrnehmung - daß dieser Eindruck katastrophale Folgen hat für die Einstellung der Menschen zum Staat. Wenn wir hier um Vertrauen werben und Vertrauen in die demokratische Grundordnung als eine Voraussetzung des Fortbestandes der Verfassung postulieren, dann müssen wir sehen, daß der Vertrauensschaden aus der gegenwärtigen Entwicklung enorm ist. Ich klammere auch die Verschuldensfrage aus; ich klammere aus die Richtigstellung falscher Meldungen in den Medien.

Nur ein Punkt sei am Rande erwähnt: eine systematische Utberprüfung des Leseverhaltens in den Bibliotheken gibt es 
gegenwärtig nach meinen Untersuchungen nicht. Ich stelle das richtig, wo ich kann, aber der Eindruck bei vielen bleibt, daß allein durch die Hunderttausende von therprüfungen die Bundesrepublik auf einem gefährlichen und vertrauensschädlichen Wege sei.

Deshalb ist ein gezielteres Vorgehen, ein Abgehen von dem Streben nach umfassender Untersuchung der Verfassungstreue der Bürger, dringend geboten. Das von Denninger angeführte Postulat wechselseitigen Vertrauens, der favor civis, gehört in diesen Zusammenhang. Aber dieses Vertrauen ist gerade bei den jungen Bürgern nicht leicht zu schaffen, und damit komme ich zur "Verfassungspflege" - um das Stichwort der Diskussionsgliederung aufzunehmen - oder besser: zum positiven Verfassungsschutz im Gegensatz zu dem abwehrenden, rein negativen Verfassungsschutz.

Wie kann man es anfangen, dabei wirklich überzeugend $z u$ sein? Ich meine, eine Forderung muß hier unbedingt miterwähnt werden: die überzeugende Korrektur rechtswidriger $\mathrm{Zu}$ stände. Dies sollte in keiner Liste fehlen, die Postulate zum Aufbau von Vertrauen in die Gemeinschaft enthält. Es gehört dazu das Ernstnehmen der Grundrechte - Herr Klein hat hier einen bemerkenswerten Beitrag zu Art. 13 geleistet, andere Ausführungen in den Referaten brauche ich vielleicht nicht besonders zu zitieren - Es geht ferner darum, zum Beispiel auch in Anknüpfung an Traditionen der deutschen Staatsrechtslehre - ich nenne die Namen Evers und Salzwedel klarere rechtliche Regelungen, Rechtsmeinungen, Vorschläge zur Verbesserung der Rechtslage aus unserem eigenen Kreise heraus zu produzieren. Das wäre immerhin ein Stück „erste Hilfe" (im doppelten Sinne) für das Gemeinwesen, das in Gefahr ist abzurutschen.

$\mathrm{Zu}$ dem positiven Verfassungsschutz in diesem Sinne gehören sodann auch die Kontrollinstanzen. Ich meine, wir sollten das Gesetz über die parlamentarische Kontrolle der Nachrichtendienste nicht von vornherein abwerten, sondern einmal sehen, ob nicht auch ein Stück Kontrolle wirksam werden kann. Anderes ist erwähnt worden, ich will mich kurz fassen, ich will an Sie alle appellieren mitzuwirken bei der Klarstellung von Fragen, die dann unter „Einzelfragen“ zu behandeln wären, z. B. der Frage der Weitergabe ungesicherter Erkenntnisse des Verfassungsschutzamtes (nicht schlüssiger, nicht relevanter Erkenntnisse) - Stichwort Narr-Urteil - und eines Verwertungsverbotes für rechtswidrig erlangte Informationen. Wenn ich einige Gedanken von heute vormittag weiterdenke, müßten ja angesichts der prekären Rechtssituation von BND und MAD 
die von diesen Institutionen erlangten Erkenntnisse daraufhin überprüft werden, ob sie überhaupt verwertet werden dürfen. Ich stelle nur die Frage. Das Sozialgeheimnis und seine Grenzen, insbesondere gegenüber Justiz und Kriminalpolizei, wären ebenfalls $\mathrm{zu}$ bedenken - und so weiter. Ich bedanke mich für Ihre Geduld.

Vorsitzender: Vielen Dank, Herr Bull. Da Sie die Staatspflege bzw. Verfassungspflege ausdrücklich angesprochen haben, möchte ich als Schüler von Herbert Krüger nicht unerwähnt lassen, daß dieser von ihm in die Staatslehre so nachhaltig eingeführte Terminus im Zusammenhang dieser Referate bereits von mehreren Seiten in der Sache gebührende Beachtung gefunden hat.

Klein: Es ist nicht so sehr die millionenfache Uberprüfung, die ich kritisch sehe, als die Art, wie mit ihr in der Diskussion umgegangen wird. Ich meine, man muß sich doch einmal vor Augen halten, worum es sich bei diesen Hunderttausenden oder Millionen handelte. Es handelt sich schlicht um die Zahl derjenigen, die sich seit dem Jahre 1972 um Eintritt in den Offentlichen Dienst beworben haben. Und bezüglich dieser Bewerber erging eine routinemäßige Anfrage an die Verfassungsschutzämter, die - ich bitte, mich jetzt nicht auf den Prozentpunkt festzulegen - in 95 bis $98 \%$ der Fälle mit dem Vermerk: „Keine Erkenntnisse“ zurückkamen. Damit war der Fall erledigt. Und in den restlichen $2-5 \%$ der Fälle lagen gewisse Erkenntnisse vor, die sich wiederum in dem weit überwiegenden Teil dieser Fälle als nicht relevant erwiesen für die zu prüfende Frage. Die Zahl derjenigen Fälle, wo sich wirklich Erkenntnisse ergaben, die dann zur Ablehnung des Bewerbers aus diesem Grunde führten, beläuft sich auf weniger als 3000 , wenn ich das richtig weiß. Wenn Herr Bull, nicht nur natürlich in bezug auf diesen Punkt, die anderen übersehe ich weit weniger gut als er, so daß ich mich dazu nicht äußern kann, von katastrophalen Folgen für die Einstellung zum Staat sprach, die sich daraus ergäben, dann meine ich, daß diese katastrophalen Folgen sich vielmehr daraus ergeben, daß geflissentlich unkommentiert mit diesen Zahlen in der öffentlichen Diskussion operiert wird.

Meyer: Bevor ich zur Verfassungspflege komme, möchte ich noch kurz auf einige Äußerungen, die vorher gefallen sind, eingehen. Erstens: Ich verstehe nicht, warum man den Begriff Freiheit von Angst nicht als juristischen Begriff auffassen will, 
obwohl wir in Art. $1 \mathrm{GG}$ die Menschenwürde als juristischen Begriff haben und es offensichtlich keine Schwierigkeiten macht, mit ihm umzugehen. Zweitens: Es ist richtig, Herr Isensee, daß die Extremisten die Angst schüren und als Propagandamittel nutzen, - sie sind ja schließlich auch politische Menschen -, aber es ist nicht richtig, daß es nur geschürte Angst gibt, und es ist leider nicht so einfach, wie Sie, Herr Quaritsch, sagen, daß nur die Angst zu haben brauchen, die Verfassungsfeinde sind. Wenn es so wäre, könnten wir uns ja beruhigen. Es geht um diejenigen, die, ohne Verfassungsfeinde zu sein, Angst haben müssen, und solche Leute gibt es. Der Verfassungsschutz wäre töricht, mit den Recherchen erst zu beginnen, wenn jemand schon ein Verfassungsfeind ist. Also recherchiert er in einer Art Grauzone, in der sich notwendig auch Leute bewegen, die weder Verfassungsfeinde sind noch es werden wollen. Auch diese Leute unterliegen unter Umständen der Oberservierung und in ihrem Gefolge durchaus beruflichen Nachteilen, wie einige Urteile gezeigt haben. Die Frage ist, ob uns das ohne jedes Interesse lassen kann. Ich meine: nein. Wenn Sie, Herr Klein, sagen, nur bei $5 \%$ lägen so etwas wie Erkenntnisse vor, so wird man doch berücksichtigen müssen, daß $5 \%$ von einer sechsstelligen Zahl immerhin eine ganze Menge von Personen sind.

Nun aber zur Verfassungspflege. In dem Lichte, das - nach einer Äußerung von Herrn Stern heute morgen - ex oriente kommen soll, wobei allerdings nach der Sternschen Geographie Göttingen schon im Osten liegt, fühle ich mich eher als Verfassungsschänder denn als Verfassungspfleger, jedenfalls soweit Herr Klein diesen Begriff gebraucht hat. Vielleicht bin ich aber auch nur ein Radikaler im Öffentlichen Dienst. Herr Klein hat nämlich behauptet, es sei ein Mißbrauch der Legalität zur Zerstörung der Legitimität, wenn sich die parlamentarische Mehrheit bei ihrer Gesetzgebung vorsätzlich am Rande der Verfassungsmäßigkeit bewege. Nun kenne ich kaum ein einigermaßen wichtiges Gesetz in letzter Zeit, bei dem nicht von allen oder einigen Gegnern der Vorwurf der Verfassungswidrigkeit erhoben worden ist, und man kann nur mit Fug annehmen, daß sich alle am Rande der Verfassungsmäßigkeit bewegen. Wir leben also in einem Staat, in dem die Verfassungsorgane, insbesondere Parlament und Regierung, sich der von Herrn Klein verlangten Verfassungspflege nicht annehmen. Aber auch der Bundesrat verweigert sich, denn er hat ein Antragsrecht nach Art. 21 GG, und es gibt extremistische Kleinstparteien, die durchaus zum Verbot anstünden, wenn der Bundesrat den Antrag stellen würde. Wir finden hier sozusa- 
gen eine andere Art der Solidarität aller Demokraten. Nun habe ich allerdings die Vermutung, daß Herr Klein in diesem Punkt nicht Verfassungs-, sondern Grabpflege meint, nämlich Pflege am Grabe der Politik. Es ist ja nicht verwunderlich, daß in der ganzen Debatte der Begriff Politik - wenn ich recht zugehört habe - nicht gefallen ist. Wenn aber der Mehrheitsgesetzgeber sich nicht mehr frei im Rahmen der Verfassung bewegen darf, wird der status quo zum höchsten Verfassungsgut und das Bundesverfassungsgericht zur Gouvernante des unmündigen Gesetzgebers. Das ist das Ende der Politik. Die Verfassung lebt aber eher von der Politik als vom Recht. Naturwissenschaftlich mag der Satz ,Ex oriente lux nicht zu bestreiten sein, aber es stimmt wohl auch, daß es im Osten zuerst dunkel wird.

Vorsitzender: Vielen Dank, Herr Meyer. - Wir sollten nunmehr ganz zu den Einzelfragen übergehen. Hier liegt nach den Wortmeldungen der Schwerpunkt ganz eindeutig auf den Komplexen Zugang zum Öffentlichen Dienst und Verfassungsschutz. Zunächst möchte ich an dieser Stelle Sie, Herr Kollege Fromont bitten, uns etwas über die diesbezügliche Rechtslage in Frankreich aufzuklären. Es tut unserer folgenden Diskussion sicher gut, wenn wir einen Augenblick von den bundesrepublikanischen Verhältnissen abstrahieren und uns einem Lande wie Frankreich zuwenden, das eine große Tradition des Schutzes der Verfassung hat, nicht zuletzt über die Regelungen des Ausnahmezustandes.

Fromont: Darf ich mir nur ein paar Bemerkungen erlauben. Erstens: die Problematik hat in Frankreich mit der Verfassungsauslegung wenig zu tun. Dafür gibt es mehrere Gründe: Vor allem bilden die verfassungsrechtlichen Normen in Frankreich kein abgeschlossenes System. Sie wissen ja, daß wir eigentlich keine einheitliche Verfassung, sondern drei verfassungsrechtliche Texte nebeneinander haben, und zwar erstens die Menschenrechtserklärung von 1789, dann die Präambel der Verfassung von 1946 und drittens die Verfassung von 1958 - und noch dazu die sog. verfassungsergänzenden Gesetze. Deshalb spielen die Verfassungsauslegung, die Probleme der Verfassungsauslegung, keine große Rolle. Dazu kommt selbstverständlich, daß der Conseil Constitutionnel erst anfängt, seine Kontrolle über die Gesetzgebung zu vertiefen. Man kann grob sagen, daß die Zahl der als verfassungswidrig erklärten Gesetze noch gering ist. Zweitens: Frankreich ist hauptsächlich ein Nationalstaat, d. h. es ist kein Staat, der ausschließlich oder 
hauptsächlich auf einer Ideologie aufgebaut wird, wie es $\mathrm{m}$. E. die Bundesrepublik ist. Frankreich ist hauptsächlich ein Nationalstaat, ein Staat, der auf nationalem Konsens beruht. Deshalb werden alle Franzosen grundsätzlich zuerst und hauptsächlich als Franzosen behandelt, und wahrscheinlich deshalb verhält sich der französische Staat viel strenger gegenüber Separatisten aus Korsika oder aus der Bretagne oder auch gegenüber Kriegsdienstverweigerern. Sie wissen, daß die Rechtsstellung der Kriegsdienstverweigerer in Frankreich gar nicht liberal ist, aber umgekehrt verhält sich der französische Staat ziemlich großzügig gegenüber den verschiedenen politischen Minderheiten, die radikale Meinungen haben. Noch dazu kommt wahrscheinlich, daß die Kommunistische Partei in Frankreich nicht als verfassungswidrige Partei betrachtet wird, weil Frankreich, wie Sie wissen, schon kommunistische Minister seit dem Ende des letzten Krieges gehabt hat; wir haben heute noch viele Kommunisten, die entweder hohe Beamte oder Bürgermeister von großen Städten sind. Nun zu den Einzelfragen: Ich glaube, ich werde mich auf die Frage des Zugangs zum Öfentlichen Dienst beschränken. Bei diesem Zugang herrschen zwei Grundprinzipien. Einerseits das Prinzip der Gleichheit; dieses Prinzip der Gleichheit steht in der Menschenrechtserkälrung von 1789, und deshalb darf die Regierung die Ernennung von Kandidaten nur wegen Meinungsäußerungen nicht ablehnen. Aber es gibt auch einen gegensätzlichen Grundsatz und zwar das Neutralitätsprinzip. Dieses Prinzip betrifft hauptsächlich die Ausübung der Funktion, des Amtes, aber auch daneben der Aktivitäten der Beamten außerhalb der Dienstzeit. Das ist die berühmte ,Obligation de réserve', - ich glaube, man kann dies mit Zurückhaltungspflicht übersetzen; dies bedeutet, ein Beamter darf keine scharfen oder kämpferischen Aktivitäten gegenüber der Regierung betreiben, und nicht nur während der Zeit, wo er schon Beamter ist, sondern auch schon vorher. Das bedeutet also, daß der Zugang zum Offentlichen Dienst doch etwas beschränkt ist, d. h. jemand, der offensichtlich Mitglied der Kommunistischen Partei ist und sogar Verantwortung in dieser Partei hat, kann zwar Beamter werden, aber wenn in diesem Zusammenhang sehr scharfe oder kämpferische Aktivitäten von ihm betrieben werden, dann darf er nicht Beamter werden.

Schlaich: Herr Klein sprach von einem „permanenten Skandalon", das der Pflege der Verfassung abträglich sei. Ich will im Zusammenhang mit der Frage des Zugangs zum öffentlichen Dienst ein weiteres nennen - die parteipolitische Äm- 
terpatronage. Die Referenten haben dieses Thema beide ausgelassen. Mit diesem Skandalon haben wir uns ja seltsamerweise weithin abgefunden, obwohl hier permanent die Verfassung verletzt wird, permanent ein Verfassungszerfall, ein Verfall an Verfassungstreue stattfindet; in den Kategorien von Herrn Denninger: diese parteipolitische Ämterpatronage schafft durchaus Angst und Verdruß um Einstellung und Beförderung, und zwar wohl in größerem Ausmaß als bei der gegenwärtigen Behandlung wirklicher oder vermeintlicher Extremisten anläßlich ihrer Einstellung, hier wird auch durchaus Vertrauen auf die Verfassung kaputt gemacht, denn das Grundgesetz formuliert ja bezüglich des Zugangs zu öffentlichen Ämtern das Leistungsprinzip, und hier wird zwar Bereitschaft zu Engagement geweckt, zum Engagement nämlich in den Parteien, aber nur allzu oft $\mathrm{zu}$ einem verlogenen Engagement. Warum haben wir Staatsrechtslehrer uns an diesen Verstoß gegen Art. 33 Abs. 2 und 3 und gegen Art. 3 Abs. 3 GG eigentlich derart gewöhnt, daß er nur selten angemerkt wird? Um nur eines zu nennen: weil wir uns das Verfassungsprinzip „Parteienstaatlichkeit" mit viel zu weitgehenden Konsequenzen haben aufschwätzen lassen. In der Verfassung steht von einem solchen materiellen Verfügungsrecht der politischen Parteien nichts. Art. 21 GG spricht von der Mitwirkung der Parteien ,bei der politischen Willensbildung des Volkes", nicht aber der Willensbildung des Staates. Sicherlich paßt sich die Vorstellung von der Parteienstaatlichkeit ein in unser Bild vom Pluralismus und von der Gemeinwohlverwirklichung durch eine Vielzahl von Gruppen. Aber ich kann nicht sehen, daß das Grundgesetz nun Staatskirchen und Staatskirchentum abschafft, auch den Verbändestaat nicht kennt, diesen Parteienstaat aber gestattet. Zugespitzt gesprochen: Haben wir dem Grundgesetz hierin nicht partiell ein Neues Modell der Verfassung zugrundegelegt und verletzen mit Hilfe dieses Modells die formulierte Verfassung in Art. 3 und 33? Noch einmal bewußt zugespitzt gesprochen: wie erfolgreich, mit welcher Aussicht auf Utberzeugung können wir dann eigentlich die Verfassung vor Leuten schützen, die nun auch ein anderes Modell von der Verfassung haben? - Zur Vermeidung von Mißverständnissen: ich spreche von der verfassungsrechtlichen Reichweite der Parteienstaatlichkeit, nicht von der unbestrittenen politischen Rolle der Parteien und ich weiß, daß es politische Beamte gibt und geben muß. Und ich halte die Fernhaltung von Verfassungsfeinden aus dem öffentlichen Dienst für notwendig. Nur: mit diesem Ernstfall des Schutzes der Verfassung anläßlich der Einstellung in den öffentlichen Dienst wird man sich schwer tun, solange 
man im Normalfall der Einstellung nicht ohne Verfassungswidrigkeit auskommt. - Das war ein Statement, nicht eine Frage, ich bitte also nicht um eine Antwort, sondern um Zustimmung.

Bei den Folgerungen aus ihrer Analyse haben beide Referenten meines Erachtens wiederum zu einseitig auf den Ernstfall gesehen und den Normalfall vernachlässigt. Fast habe ich den Eindruck, wir sind mit mehr Eifer dabei, den Verfassungsfeinden, die sich um eine Einstellung in den öffentlichen Dienst bewerben, zu erklären, worin ihre Verfassungsfeindlichkeit liege, als daß wir den Verfassungsfreunden sagen, wo sie ihre Verfassungsfreundschaft gepflegt und aufgehoben wissen können. Auch dazu nur ein Hinweis, der sich für ein Mitglied in der Fakultät von Herrn Friesenhahn nahegelegt: Was ist eigentlich mit dem Eid des Beamten? Im Diensteid wird Treue zur Verfassung versprochen; der Eid dient dem Schutz der Verfassung im Normalfall, im Täglichen. Aber wir verstecken ihn eher (sofern es sich nicht um die Amtsübernahme durch Regierungsmitglieder handelt), nehmen jedenfalls diesen Normalfall des Schutzes der Verfassung häufig nicht sehr ernst. Sicherlich wird man sich für dieses Versprechen des Beamten eine neue Form und einen neuen Inhalt ausdenken können. Aber man müßte doch dabei deutlicher die Flagge eines demokratischen Selbstbewußtseins zeigen.

Zuleeg: Ich möchte zu Anfang unterstützen und begrüßen, was Herr Denninger hier gesagt hat. Ich muß das deswegen vorausschicken, weil ich eine Kritik an seinem Leitsatz 20 anbringen möchte, der im Ansatz von meiner Zustimmung umfaßt wird. Und zwar heißt es im Leitsatz 20, daß eine Anfrage an das Amt für Verfassungsschutz nur noch erfolgen soll, wenn im Einzelfall Verdachtsmomente auftauchen. Ich meine, daß bei einem solchen Satz das Vertrauen in die Behörde viel zu groß ist. Wenn Verdachtsmomente genügen, dann wird sich die Praxis m. E. kaum ändern. Deshalb meine These, daß die Úberprüfung durch den Verfassungsschutz im nicht sicherheitsempfindlichen Bereich, - ich betone, daß diese Einschränkung mir wichtig erscheint -, unzulässig ist. Dabei ziehe ich die Grenzen des nicht sicherheitsempfindlichen Bereichs bewußt so, daß die Schule dazu gehört, daß die Schule also nicht sicherheitsempfindlich ist. Angesichts der Möglichkeit von Disziplinarmaßnahmen, angesichts der Möglichkeit der Einwirkung auf die Lehrer, vor allem durch die Lehrprogramme, angesichts der Kontrollmöglichkeiten steht in der Schule der Bestand des Staates nicht ernsthaft auf dem Spiele. 
Zur juristischen Begründung für meine These, daß im nicht sicherheitsempfindlichen Bereich keine Überprüfung durch den Verfassungsschutz stattfindet, dient der Grundsatz der Verhältnismäßigkeit. Ich habe den Referaten entnommen, daß über die Anwendbarkeit des Grundsatzes der Verhältnismäßigkeit Einigkeit besteht. Dabei sind die Zahlen, die schon genannt worden sind, von ganz ausschlaggebender Bedeutung. Wir haben unzählige Utberprüfungen, und wir haben eine verschwindend geringe Zahl von Fällen, in denen die Überprüfung zu dem Erfolg führt, daß jemand nicht eingestellt wird. Dieses Verhältnis muß gerechtfertigt werden, und dabei muß - ich knüpfe an das an, was Herr Delbrück gesagt hat - eine Güter- und Interessenabwägung stattfinden. Wir müssen uns also fragen: Was geschieht hier zu dem Zweck, wenige Bewerber vom Offentlichen Dienst fernzuhalten? Hier muß man einmal den Bereich des Einzelnen ins Auge fassen: Durch den Verfassungsschutz wird die Privatsphäre, die durch Art. 1 Abs. 1 GG geschützt ist, beleuchtet und durchdrungen. Hier wird eine Angst erzeugt, daß - wie immer man sich verhält - man vielleicht dem Verfassungsschutz auffallen könnte, und dementsprechend wird die Einstellung verschleiert, wird die Betätigung zurückgeschraubt. Der zweite Punkt betrifft die Allgemeinheit: Durch die intensive Nachprüfung wird ein Geist erzeugt, den man bei einer großen $\mathrm{Zahl}$ von jungen Leuten feststellen kann, die nicht glauben, im besten Falle nicht glauben, $\mathrm{da} B$ es eine freiheitlich-demokratische Grundordnung gibt, die es zu verteidigen gilt. Man muß noch hinzufügen, daß diese fehlende Überzeugung sehr häufig bei Lehrern festzustellen ist, also bei denjenigen, die doch gerade das - um ein Wort von Herrn Klein aufzugreifen - in die Hände gelegt bekommen, was Verfassungspflege bedeutet, was das staatsbürgerliche Bewußtsein bildet. Aber ich finde, wir können noch weitere Gesichtspunkte aufführen. Wir gehen immer davon aus, daß der Verfassungsfeind nicht in den Öffentlichen Dienst aufgenommen werden soll. Selbstverständlich! Nur darüber, was ein Verfassungsfeind ist, was die freiheitlich-demokratische Grundordnung besagt, kann man sich endlos streiten, und daher muß m. E. bei der Abwägung die Ungewißheit über die Auslegung dieser Begriffe berücksichtigt werden. Ein weiterer Gesichtspunkt: die Mangelhaftigkeit der Prognose, was ein Bewerber, der in den Offentlichen Dienst gelangt, später anstellt. Zum Schluß noch der Hinweis auf die Strafgesetze und der Hinweis auf die Einwirkung in der Probezeit. Alle Gesichtspunkte zusammengenommen, - ich könnte das noch weiter ausmalen -, sprechen dafür: keine Überprüfung durch den Verfas- 
sungsschutz bei der Einstellung von Bewerbern in den Offentlichen Dienst mit Ausnahme des sicherheitsempfindlichen Bereichs!

Kriele: Ich wollte ein Wort sagen zu der neueren Tendenz, totalitäre Verfassungsfeinde, zum Beispiel Mitglieder der DKP, zunächst einmal in den Öffentlichen Dienst einzustellen, dann abzuwarten, ob sie sich legal verhalten und falls nicht, sie im Wege des Disziplinarrechts wieder zu entfernen. Ein Vorschlag, den ja auch Herr Böckenförde in seiner jüngsten Schrift gemacht hat.

Abgesehen von allerlei grundsätzlichen Erwägungen, die schon hier zur Sprache gekommen sind, möchte ich vier Thesen zu bedenken geben. Die erste betrifft die Begründung, Gesinnung sei rechtlich unbeachtlich, wir müßten auf Verhalten abstellen. Das ist zwar richtig; wir haben aber bisher unterschieden zwischen Gesinnung und der totalitären Bereitschaft zur Gesinnungsdurchsetzung, die sich organisiert. Man kann z. B. für eine auch radikale Änderung der Wirtschaftsordnung im Rahmen der Verfassung sein, das ist die Gesinnung. Das Akzidens, das hinzukommt, die Bereitschaft, diese Gesinnung durchzusetzen gegen die Gesinnung, gegen das Gewissen, gegen die Meinungen der Mitbürger, das allein macht die Verfassungsfeindschaft aus. Wenn dies jetzt auch eine Gesinnung ist und der Staat sich Gesinnungen gegenüber neutral verhalten muß, dann muß er sich auch demgegenüber neutral verhalten, - Verfassungstreue und Verfassungsfeindschaft werden relativ. Wir sind wieder bei Weimar, bei der Identität von Legalität und Legitimität, die uns Herr Böckenförde ausdrücklich empfiehlt, bei der ich nur in Erinnerung rufen möchte, daß sie sich in der Geschichte nicht so ausgezeichnet bewährt hat, wie es uns jetzt vorgehalten wird.

Zweite These: Die Nichteinstellung in den Offentlichen Dienst ist keine Strafe. Eine Strafe knüpft an ein Verhalten an. Hier geht es um den Rechtsgrundsatz, daß niemand verpflichtet ist, jemanden einzustellen, von dem er weiß, daß er nicht für, sondern gegen ihn ist, arbeiten will, selbstverständlich auch der Staat. Dem geht ein Urteil über die Eignung voraus, die selbstverständlich die persönliche Verläßlichkeit betrifft. Der Gedanke, die Nichteinstellung sei anzusehen wie eine Strafe, wird suggeriert durch das Wort "Berufsverbote". Das ist der polemische Sinn dieser Sprachstrategie. Wir sind bisher davon ausgegangen, daß jedenfalls der intelligentere Teil unseres Volkes das durchschaut. Drittens: Die Gesetzesgeltung wird ausgehöhlt. Mitglieder der DKP bieten die Gewähr dafür, daß sie im Ernst- 
fall, also am Tage X, nicht für, sondern gegen die freiheitlichdemokratische Grundordnung eintreten wollen. In den Beamtengesetzen steht: In den Öfentlichen Dienst darf nur - ich betone: „darf nur" - eingestellt werden, wer die gegenteilige Gewähr bietet. Nun haben wir eine Reihe von rabulistischen Tricks erfunden, um das genaue Gegenteil zu subsumieren. Der Staat macht den Bürgern die Kunst der Rechtsverdrehung vor, das Prinzip der Gesetzesgeltung wird lächerlich gemacht.

Viertens, und das ist mein ernstester Punkt: Der Diensteid wird entwertet. Wenn ein Mitglied der DKP den Diensteid leistet, obwohl er weiß, er hat Instruktionen von seiner Parteiführung, sich zunächst legal zu verhalten, aber nur bis zum Ernstfall am Tage X, dann wird der Staat gewissenlos hintergangen. Wenn jetzt aber der Dienstherr, der den Eid abnimmt, weiß, mit wem er es zu tun hat, dann wird er nicht hintergangen, sondern er ist Anstifter und augenzwinkernder Komplize. Er macht sich damit die Umdeutung des Verfassungseides im kommunistischen Sinne zu eigen: Also aus Menschenwürdeund Demokratieprinzip ergibt sich ein Verfassungsauftrag zum Verfassungsumsturz. Damit werden aber alle, die den Eid im ernsthaften Sinne geleistet haben, sowohl desavouiert als auch diskriminiert. Ihnen wird eine Bindung auferlegt, die anderen in gleicher Weise keineswegs zugemutet wird. Aus dem Grundsatz der Gleichberechtigung folgt, daß sie sich dann auch an den so zu interpretierenden Eidesinhalt halten dürfen. Die Verfassungsloyalität erodiert, die sittlichen Grundlagen unseres Staates werden lächerlich gemacht, das Bewußtsein von Ehre und Gewissen wird destruiert.

Mußgnug: Herr Denninger hat sein Referat mit einer Blütenlese von Einzelfällen eingeleitet, die auch die einschlägigen Meinungsmacher immer wieder abfeiern, wenn sie gegen das zu Felde ziehen, was sie irreführend als das „Berufsverbot" bezeichnen. Ich kann diese Blütenlese um ein weiteres Beispiel ergänzen. Denn ich war an der FU Berlin verschiedentlich Zeuge von Anhörungsverfahren, in denen Bewerber um Hilfskraft-, Assistenten- und auch Professorenstellen mehr oder weniger plump auf ihre politische Gesinnung überprüft worden sind. Vor allem erinnere ich mich lebhaft an eine öffentliche Fachbereichsratssitzung, bei der ein gestandener Wissenschaftler von Studenten aus dem Lager der Chaoten lautstark befragt wurde, was ihn dazu getrieben habe, neben seiner hauptamtlichen Lehrtätigkeit als ordentlicher Professor einer westdeutschen Universität an einer Polizeischule als Lehrbeauftragter an der Ausbildung zukünftiger Kriminalpolizisten mitzu- 
wirken. Die Studenten schöpften daraus den Argwohn, er könne möglicherweise allzufest auf dem Boden des Grundgesetzes stehen und daher für eine Berufung an die FU nicht in Frage kommen. In der Presse liest man zwar über derartige Gesinnungsprüfungen so gut wie nichts. Aber das schließt nicht aus, daß sie an einigen unserer Universitäten unter der Hand gleichwohl zur Routine geworden sind. Sie zeigen, daß manche von denen, die sich so lebhaft über die Routineprüfungen der Einstellungsbehörden beklagen, als Studenten selbst mit auftrumpfendem Imponiergehabe Bewerber überprüft und eingeschüchtert haben.

Was sich hinter der vielgescholtenen Routineanfrage in Wahrheit verbirgt, hat Herr Klein bereits klargestellt. Seine Ausführungen machen deutlich, daß es ganz abwegig ist, hinter ihr "Gesinnungsschnüffelei" und ähnliche Unzuträglichkeiten zu vermuten. Denn die Frage, ob Tatsachen vorliegen, die begründeten Anlaß zu Zweifeln an der Verfassungstreue des betreffenden Bewerbers geben, werden die Einstellungsbehörden doch wohl stellen dürfen. Ist es nämlich ihre Pflicht, diesen Zweifeln nachzugehen, so wirkt es doppelzüngig, ihnen zu erklären: Ihr dürft zwar begründete Zweifel überprüfen; aber ihr überschreitet eure Befugnisse, wenn ihr versucht herauszubekommen, ob Grund für solche Utberprüfungen besteht. Würde man die Routineanfrage abschaffen, so würde das die Einstellungsbehörden ohnehin nur dazu zwingen, ihre Ermittlungen in die Grauzone der privaten Warnungen und Empfehlungen zu verlegen. Das aber würde weit mehr Unheil anrichten als das Verfahren der Routineanfrage bei der zuständigen und daher zuverlässigeren Stelle.

Mich verwundert im übrigen, warum man sich so sehr gegen die politische Routineüberprüfung auflehnt. Dies steht im merkwürdigen Gegensatz zu der Bereitwilligkeit, mit der die vielen sonstigen Routineüberprüfungen akzeptiert werden, die vor jeder Einstellung in den öffentlichen Dienst stattfinden. Keiner von uns hat z. B. dagegen aufbegehrt, daß er sich vor seiner Ernennung zum Professor amtsärztlich untersuchen lassen mußte. Wir sind vielmehr alle murrend, aber folgsam zum Gesundheitsamt gegangen und haben dort unseren Kreislauf kontrollieren, unsere Reflexe abklopfen und unsere Lungen durchleuchten lassen.

Niemand ist auf die Idee verfallen, daß dies gesunde Bürger dem durch nichts Konkretes begründeten Pauschalverdacht aussetzt, sie verheimlichten verborgene Leiden, die ihre Dienstfähigkeit in Frage stellen. Was die Gesundheit seiner Beamten anbelangt, so darf der Staat also ,intolerant" sein. Bei der 
Verfassungstreue indessen soll es die Toleranz gebieten, gar nicht erst nach ihr zu fragen? Das reimt sich nicht. Es reimt sich schon deshalb nicht, weil wir vor allem an die denken sollten, die unverschuldet in den Geruch mangelnder Verfassungstreue geraten. Durch die Routineüberprüfung werden sie nicht belastet, weil sich ihr jedermann zu stellen hat. Uberprüfungen dagegen, die nur ausnahmsweise durchgeführt werden, stigmatisieren diejenigen, die sie auf sich nehmen müssen.

Deckt die Routineanfrage Tatsachen auf, die der Überprüfung bedürfen, so bin ich allerdings mit Herrn Klein und Herrn Denninger dafür, großzügig zu verfahren und außer acht zu lassen, was einer längst abgeschlossenen Vergangenheit angehört. Für verfehlt halte ich nur das Ignorieren um des Ignorierens willen. Denn es führt allzu leicht dazu, daß auch ignoriert wird, was ein Staat, der auf die Aufrechterhaltung seiner Verfassung bedacht ist, nicht ignorieren darf.

Was die Frage der „bloßen“ Mitgliedschaft in einer radikalen Partei angeht, so bewegt mich die Frage, was ein KBW-Mitglied, das einen wesentlichen Teil seines Einkommens an diese Partei abführt, denn noch tun soll, um seine verfassungsfeindliche Gesinnung unter Beweis zu stellen. Denn Verfassungen werden nicht nur durch brutale Gewalt gefährdet. Auch die Scheckbücher der Mäzene des Umsturzes sind im Kampf gegen die Demokratie und den Rechtsstaat eine höchst wirksame Waffe. DKP und KBW wissen es zu schätzen, daß ihre Gönner und Beitragszahler sie zu gebrauchen verstehen. Für die Verfassung eintreten, heißt daher, aus diesen Parteien austreten und vor allem die Zahlungen an sie einstellen.

Gestatten Sie mir noch eine letzte Bemerkung zu Herrn Denningers Leitsatz Nr. 8. Er sagt mit Recht, daß es unmöglich ist, den Willen zur Verfassung herbeizukommandieren. Er übersieht jedoch, daß sich der Wille zur Verfassung dafür um so leichter durch organisierte Exorzismen austreiben läßt. Aus diesem Grunde gehören politische Exorzisten nicht in den öffentlichen Dienst, schon gar nicht in den Schuldienst.

Küchenhoff: Ich möchte zunächst doch das zurückweisen, was Herr Mußgnug am Anfang als angeblich zum Thema gehörend als Beispiel angeführt hat. Wir haben ja das sehr ernste Problem der Anhörungsverfahren. In Ablehnungsbescheiden, auch in Ablehnungsbescheiden von Gerichten gibt es Hunderte von Fällen, in denen das Schutzobjekt der Verfassungstreue: die freiheitlich-demokratische Grundordnung in dem auch von mir akzeptierten Sinne - wie Herr Klein hier definiert hat - 
nämlich gleich Art. 79 Abs. 3, weit, weit ausgedehnt wird, auf jeden einzelnen Verfassungssatz, auf jeden einzelnen Rechtssatz, auf Verordnungen, auf Verwaltungsvorschriften, ja auch auf die Verfassungswirklichkeit. Das ist nicht bloß in der politischen Auseinandersetzung passiert - was schon bedauerlich genug ist - sondern passiert in solchen formalisierten Ablehnungsentscheidungen von Einstellungsbehörden und Gerichten, und dann kommt Herr Mußgnug und erzählt uns hier von etwas ganz anderem, nämlich nicht von einem Verfassungstreueverfahren, sondern von einem Berufungsverfahren. Das möchte ich doch zurückweisen, das hat doch mit unserer Sache nichts zu tun, so schlimm das alles ist, was in diesen Verfahren dann auch passiert - und genau sein Beispiel - das lehne ich natürlich als Frage mit Entschiedenheit ab.

Nun zu dem, wozu ich mich eigentlich gemeldet hatte: Herr Delbrück hatte schon kritisiert, daß die Referenten die eigentlichen Probleme nicht hinreichend konkret erörtert haben, für mich galt das vor allen Dingen für Herrn Klein, der ja mit der Begründung, daß alles schon so viel beschrieben und diskutiert worden sei, er sich ja nur auf Thesen beschränken könnte. Er hatte bei diesen Thesen auch das akzeptiert, was dann durch die Interventionen von Herrn Doehring hier noch einmal diskutiert worden ist, auch von Herrn Böckenförde angeschnitten worden ist, nämlich, daß diese Gewährbieteklausel für die Bewerbungen ja doch auf Gesinnungsprüfung hinausläuft. Herr Doehring hat zu meinem großen Erstaunen eine Möglichkeit, Gesinnung und Verhalten rechtserheblich abzugrenzen, in Frage gestellt. Damit hat er aber die Rechtsstaatlichkeit überhaupt in Frage gestellt, denn die ganze Verfassungstheorie, Verfassungsgeschichte des Rechtsstaates und damit auch alles das, was zur Rechtsstaatlichkeit im Sinne des geltenden Rechtes gehört, setzt ja doch voraus, daß man an Verhalten anknüpft, und - Herr Kriele - nicht nur im Strafrecht, sondern auch in allen anderen Bereichen des Eingriffsrechts! Das dürfte doch eigentlich gar keiner Erörterung mehr bedürfen. Vielleicht kann Herr Klein dazu doch in seinem Schlußwort Stellung nehmen. Ich möchte ihn eigentlich - um das auch etwas aufzulockern - noch mit einem Begriff konfrontieren, der mir dabei eingefallen ist: $\mathrm{Ob}$ Sie vielleicht dem Begriff der streitbaren Demokratie dann noch den Begriff der streitbaren Rechtsstaatlichkeit zur Seite stellen, der dann eine Auflockerung der Rechtsstaatlichkeit bedeuten könnte, bis hin zu dem was dann mit § 34 StGB gemacht worden ist oder auch mit Freiheitsgarantien wie derjenigen des Art. 2 Abs. 2, Satz 1, die man nämlich von Eingriffsgrenzen zu Eingriffsgrundlagen umfunk- 
tioniert hat, was sich doch mit allen herkömmlichen Rechtsstaatsbegriffen, wie wir sie geschrieben haben und wie wir sie unseren Studenten lehren, nicht vereinbaren läßt. Dann, Herr Klein, wie vereinbaren Sie die These, daß die Utberprüfungen oder - ich möchte es auch präzise sagen - die systematische Routinenachfrage alle Beamtenkategorien und alle Beamtenaufgaben formal gleich erfassen solle. Wie vereinbart sich das mit der Tatsache, daß hier doch die faktischen Möglichkeiten, unmittelbar oder mittelbar Verfassung zu gefährden, in einem Beruf als Beamter, auch als Berufssoldat, auch als Richter, doch ganz, ganz unterschiedlich sind. Diese Differenzierungselemente, die auch schon ein Vorredner hier in die Debatte gebracht hat, möchte ich Sie doch bitten, zu erörtern. Dazu gehört auch ein Spezialgesichtspunkt, den noch niemand hier eingeführt hat. Wie ist es denn - wieder das berühmte Schulbeispiel wenn der Lehrer im Unterricht agitiert, indoktriniert, propagiert - wie man das nun nennen möge - dann begeht er doch ein ganz einfaches Dienstvergehen, da brauche ich doch die ganze Problematik der Verfassungstreue und von einschlägigen Begriffsbestimmungen und Abgrenzungen überhaupt nicht zu bemühen, da macht er was, wenn er statt zu unterrichten agitiert, indoktriniert etc., macht er etwas, wozu er gar nicht angestellt ist, ein einfaches Dienstvergehen. Dann kann man ein Verfahren gegen ihn einführen, und wenn - aus welchen Gründen auch immer - die Verfahren nach der Gerichtspraxis nicht so laufen, wie ich das hier möchte, dann muß man eben die Gesetze einmal präzisieren; ich halte das für eine Schutzbehauptung, wenn immer gesagt wird, wir müssen bei den Bewerbern so rigoros sein, so umfassend sein, weil wir sie später nicht mehr rauskriegen. In dem Zusammenhang - und das ist eine sehr wichtige Frage, ob denn das Prinzip der Verhältnismäßigkeit diesen ganzen Anfrage-, Sammel-, Weitergabe und Anhörungsaufwand rechtfertigt, wenn man bedenkt, daß es ja bei den Erkenntnissen, die da gesammelt und weitergegeben werden, doch um Momentaufnahmen in jugendlichen Prägephasen mit allen ihren Unbedingtheiten und Rigorismen handelt, bei Leuten, die sich ja dann ganz anders entwickeln. Wir wissen doch alle, wie die Entwicklung junger Menschen weitergeht in weiteren Sozialisationsstufen des Berufs- und Familienlebens, vor allem beim Eintritt in ein solches. Damit hat sich hier niemand auseinandergesetzt bisher, und ich möchte auch schon den Einwand vorwegnehmen, daß sich das um nichtrechtserhebliche Anthropologismen handelte. Es handelt sich um Gesichtspunkte, die ganz eindeutig im Wege der teleologischen Interpretation zu berücksichtigen sind. Und ein Letztes: 
Wie steht es mit der Verhältnismäßigkeit bezüglich der vielfältig belegten und von einigen auch schon erwähnten Verunsicherung bei inzwischen zigtausenden von jungen Leuten und gerade bei solchen, die durch die Anhörung positiv durchgekommen sind - ich habe zahlreiche Belege dafür, daß die dann anschließend aus jedem Engagement, in dem sie vorher waren, auch in Jugendgruppen der etablierten Parteien, der Bundestagsparteien und in anderen Jugendgruppen, die mit Verfassungsfeindlichkeit nichts $\mathrm{zu}$ tun haben, die dann hineingeraten waren in die Mühle, weil sie mal auf einer studentischen Mischliste kandidiert hatten, daß diese dann nachher aus jeglichem Engagement ausgestiegen sind. Ich habe hier das kann ich nun jetzt wegen der Winke des Herrn Diskussionsleiters nicht vorlesen, obwohl ich möchte - weil es nämlich der Brief eines Berliner Rechtsanwaltes ist, um Herrn Quaritsch zu sagen, was es in Berlin sonst noch alles gibt, z. B. außer dem, was er vorgetragen hat.

Vorsitzender: Nach diesen verschiedenen Beiträgen zur Bedeutung der Verfassungstreue beim Zugang zum öffentlichen Dienst sowie zu den Fragen der Einschaltung des Verfassungsschutzes in diesen Zusammenhängen sollten wir nunmehr allmählich abschließen. Ich bitte die beiden Herren Referenten, zunächst Herrn Klein, ihr Schlußwort zu uns zu sprechen, nachdem sich eine Fülle von Anfragen und Stellungnahmen bei ihnen angesammelt hat.

Klein: Herr Vorsitzender, verehrte Kollegen! Am Beginn meines Schlußwortes steht, nicht nur aus Gründen der Höflichkeit, ein ausdrückliches und nachdrückliches Wort des Dankes an den Herrn Berichterstatter, Herrn Denninger. Die pointierte Form seiner Darstellung hat es mir möglich gemacht, nicht weniger pointiert $\mathrm{zu}$ referieren. Ohne seinen Vorgang - und das war das Risiko, aber auch das Privileg der Zweitberichterstattung, die mir zufiel - wäre möglicherweise manches von dem, was ich gesagt habe, so wie ich es gesagt habe, deplaziert erschienen.

Zweitens danke ich auch nicht nur aus Gründen der Höflichkeit für die vielfachen Belehrungen, die ich in der Diskussion erfahren habe, wobei ich besonders erfreut war durch die Tatsache, daß Herr Ipsen meine Einschätzung der Regierenden als zu freundlich empfand. Ich fürchtete eigentlich eher, nach der zwar vorsichtig formulierten, so doch deutlichen Kritik, die ich in meinem Schlußabschnitt hier angebracht habe, häufiger auf Beiträge zu stoßen, wie denjenigen des Herrn Meyer, den 
ich mir im übrigen des näheren zu qualifizieren versage. Drittens: Ich hätte es begrüßt, wenn in der Diskussion etwas mehr, als dies tatsächlich geschehen ist, die ja doch auch vorhandenen Gemeinsamkeiten, die zwischen den beiden Referaten bestanden, hervorgetreten wären, aber es liegt wohl in der Natur einer solchen Diskussion, sich an den Gegensätzen zu reiben, während doch das Ubereinstimmende vielleicht das Wesentlichere ist. Einer Reihe von Beiträgen kann ich uneingeschränkt zustimmen; ich betone das mit besonderer Freude und mit besonderem Nachdruck im Hinblick auf das, was Herr Kriele hier gesagt hat, ich stimme aber auch - und natürlich - Herrn Schlaich zu, wenngleich ich an ihn die Frage richten muß, wie er sich als praktisch Handelnder verhielte, wenn - gesetzt den Fall - nach 30jähriger Herrschaft einer Partei die andere die Regierung übernimmt und den Umstand vorfindet, da 3 in den obersten Verwaltungsbehörden des Landes oder des Bundes - wenn es dahin einmal kommen sollte eben die parteipolitische Einfärbung der führenden Beamten völlig einseitig ist. Wie wollen Sie dann reagieren, anders reagieren als dadurch, daß Sie einen Verfassungsbruch durch einen anderen zu korrigieren versuchen, wenn ich das in dieser sicherlich nicht ganz korrekten Form so einmal ausdrücken darf. Viertens: Herr Zacher, die Differenzierung der Anforderungen an die Verfassungstreue je nach der wahrgenommenen Funktion ist sicherlich bedenkenswert, unbeschadet der Tatsache, Herr Küchenhoff, daß das Bundesverfassungsgericht auf das Bundesverfassungsgericht habe ich mich in diesem $\mathrm{Zu}-$ sammenhang bezogen - diese Differenzierung für unzulässig erklärt hat. Ich wage allerdings zu bezweifeln, ob solche Utberlegungen zu einem praktikablen und überzeugenden Ergebnis führen werden. Wir haben ja auf einem anderen, aber verwandten Felde derartige Utberlegungen in der Vergangenheit schon vielfach angestellt, wenn es nämlich um die Frage des Streikrechts der Beamten ging, - auch da gibt es Meinungen, die eben besagen, in bestimmten Bereichen sei das bestehende Verbot des Streikrechts nicht so wesentlich wie in anderen und könne deshalb fallengelassen werden - , die Frage ist, kann man hier Grenzen überzeugend ziehen?

Herr Häberle hat die Anregung gegeben, den Begriff des Verfassungsfeindes aus unserem Sprachgebrauch zu streichen; hier stoßen Sie bei mir nicht auf prinzipiellen Widerstand. Bismarck hat, als es um das Indemnitätsgesetz ging, einmal gesagt: in verbis simus faciles; ich fürchte nur, daß es sich um einen so eingebürgerten Begriff handelt, da $\beta$ er sich 1 . rein faktisch nicht mehr aus unserem Sprachgebrauch eliminieren 
läßt und daß 2. seine Eliminierung auch unversehens einen Erfolg haben könnte, den Sie so wenig wollen wie ich, nämlich eine Verharmlosung der Erscheinung, die damit bezeichnet wird. In diesem Zusammenhang kann ich Herrn Böckenförde nur zustimmen, insoweit er zum Opportunitätsprinzip und Legalitätsprinzip gesprochen hat. In der Tat, die Ausdehnung des Opportunitätsprinzips hat zur notwendigen Folge die Ausdehnung jener Grauzone der noch bestehenden Legalität, aber gleichwohl zulässigerweise so bezeichneten Verfassungsfeindlichkeit; und daß es sich hier um eine alles in allem nicht erfreuliche Erscheinung handelt, die möglicherweise durch eine striktere Beachtung des Legalitätsprinzips vermieden werden könnte, ist sicherlich nicht zu bestreiten. Ich darf in diesem Zusammenhang daran erinnern, daß Ernst Forsthoff in einem seiner letzten Beiträge in der Festschrift für Gehlen dieses Problem angesprochen hat. Herrn Tomuschat hat Herr Quaritsch bereits weitgehend die Antwort gegeben, die auch ich mir vorgenommen hatte ihm zu geben; sicherlich, Herr Tomuschat, akzeptiere ich den Vorwurf, in der Frage der Abwägung zwischen notwendigem Schutz der Freiheit einerseits und den Notwendigkeiten des Verfassungsschutzes andererseits nicht allzu konkret geworden zu sein. Das lag vielleicht an der Abstraktionshöhe, auf der wir notgedrungen dieses Problem zu diskutieren hatten, und wohl auch daran, daß jene Herstellung praktischer Konkordanz, von der ich mehrfach gesprochen habe, eben immer nur im konkreten Fall am konkreten Beispiel befriedigend erörtert werden kann. Die Gefahr - Herr Quaritsch hat es bereits gesagt - daß die Bundesrepublik, sei es auch nur scheinbar, in ein Licht gerät, in das Licht gerät, in dem zu Recht die DDR steht, sehe ich nicht, solange wir mit Eindeutigkeit daran festhalten, daß Gegenstand des Verfassungsschutzes eben einzig und allein das ist, was in Art. 79 Abs. 3 steht und was sich - ich wiederhole das, und ich glaube Herr Denninger hat es - nicht heute in seinem Referat, aber einmal bei anderer Gelegenheit - einmal ähnlich ausgedrückt, wobei es sich im wesentlichen ja doch um Verfahrensregelungen handelt und allerdings auch um einige elementare Grundsätze, die auf dem Prinzip der Menschenwürde basieren. Es geht also nicht um die staatliche Verordnung einer Wahrheit, sondern um den - freilich, wie ich meine - unbedingten Respekt vor diesen Grundsätzen. Herr Küchenhoff, um dies als Vorletztes zu sagen, Sie haben mich auf den $\S 34$ StGB angesprochen. Ich kann nun auf die Details nicht mehr eingehen; ich verweise Sie im wesentlichen auf das, was ich in meinem Referat ausgeführt habe, möchte Sie nur konkret daraufhin 
befragen, ob Sie in der Situation nach der Entführung von Hanns-Martin Schleyer vor Erlaß des Kontaktsperregesetzes in Kenntnis der Bedeutung der Kontakte zwischen den inhaftierten und den in Freiheit befindlichen Terroristen und der Gefährlichkeit dieser Kontakte tatsächlich als verantwortlich handelnder Politiker auf die Anordnung dieser Kontaktsperre verzichtet hätten und wenn ja, ob Sie im Ernst glauben, diesen, wie ich meinen möchte, respektablen Standpunkt, den ja auch der damalige Justizsenator von Berlin eingenommen hat, Ihrerseits für allgemeinverbindlich erklären zu können. Ich meine, unsere Verfassungsordnung und wir als Verfassungsrechtler haben auch die Aufgabe, bei aller Wahrung rechtsstaatlicher Prinzipien die in die Verantwortung gestellten, zu politischem Handeln Berufenen mit den Instrumenten auszustatten, die sie in die Lage setzen, ihrer Verantwortung gerecht zu werden, wenn anders wir sie nicht auf zweifelhafte - verfassungsrechtlich zweifelhafte - Irrwege verweisen wollen.

Eine letzte Bemerkung: Ich komme noch einmal zurück auf das, was Herr Hans-Peter Schneider angesprochen hat, als er über die Unklarheit der von Art. 79 Abs. 3 in Bezug genommenen Grundsätze in Art. 1 und 20 sprach. Ich habe darauf bis zu einem gewissen Grade in der Diskussion schon erwidern können, ich möchte das noch um einen Punkt ergänzen: Herr Böckenförde hat vor einiger Zeit einmal in einem Aufsatz die Frage nach der verfassungsmäßigen Grundrechtstheorie, und allgemeiner nach der verfassungsmäßigen Verfassungsinterpretation gestellt, und wenn ich recht verstehe, ich hoffe, ich tue ihm nicht Unrecht, hat er damit eine Heidelberger Tradition aufgegriffen, der wir uns - wenn ich so sagen darf - gemeinsam verbunden fühlen. Sie alle erinnern sich ja der Kritik, die Ernst Forsthoff an der von ihm so genannten geisteswissenschaftlichen Methode der Verfassungsauslegung geübt hat. Nun, nicht so sehr die von Forsthoff seinerzeit empfohlene Therapie scheint mir heute aktuell zu sein, als vielmehr das von ihm erkannte Problem. Dieses Problem bestand darin, an der Tatsache festzuhalten, daß die Verfassungsnorm eine Entscheidung enthält; daß Verfassungsinterpretation die Aufgabe hat, diese Entscheidung zu verdeutlichen. In seiner Schrift über die Problematik der Verfassungsauslegung lauten die beiden nach meinem Dafürhalten wichtigsten Sätze: „Die Verfassung ist ein Gesetz, das durch bestimmte Entscheidungen einen bestimmten Zustand politischer Gesamtordnungen festlegt". Und wenig später dann: „Wer das Entscheidungselement aus der Verfassung eliminiert, spielt es unvermeidlich dem Verfassungsinterpreten in die Hände“. Herr Böckenförde hat daran 
anschließend darauf hingewiesen, daß, wo die Verfassungsauslegung zur Inhaltsbestimmung statt zur Inhaltsermittlung wird, die Frage nach der Demokratisierung der Verfassungsinterpretation notwendigerweise aufgeworfen wird. Eine verfassungsgemäße Verfassungsinterpretation also muß diesen Umstand, den Forsthoff deutlich zu machen versuchte, beachten. Vielen Dank.

Denninger: Nachdem, meine Herren, die Zeit nun schon sehr fortgeschritten ist und Herr Klein auch ein verhältnismäßig ausführliches Schlußwort gesprochen hat, werden Sie es mir vielleicht nicht verübeln, wenn ich mich jetzt recht knapp fasse.

Zunächst möchte auch ich meiner Freude darüber Ausdruck geben, daß ich meinerseits feststellen konnte, Herr Klein, daß in unseren Darlegungen doch in einigen wichtigen Partien Übereinstimmung bestand, zuletzt etwa in den Fragen der Grundrechtsberührung durch Maßnahmen des Verfassungsschutzes. Was Sie heute morgen zu Art. 13 und den damit zusammenhängenden Fragen gesagt haben, das findet völlig meine Zustimmung. Auch ich habe - und dafür möchte ich an dieser Stelle meinen Dank abstatten - in der Diskussion eine ganze Menge gelernt, ich bin aber nicht in der Lage, dieses nun als gewissermaßen fertiges Ergebnis hier zu reproduzieren. Sie haben mit Recht bemerkt - es ist mehrfach bemerkt worden -, daß in dem Referat Vieles gefehlt hat. Ich war und bin mir dessen bewußt. Ich gebe zu, daß ich von den grundsätzlichen Fragen vielleicht stärker fasziniert war, als das von der Gesamt-Thematik her nahegelegt worden wäre, obwohl ich der Meinung bin, daß gerade dieses Thema seinen Reiz dadurch bekommt, daß man gezwungen wird, über ganz grundsätzliche Probleme des Verhältnisses von Recht und Macht, Recht und Politik, etwa Freiheit des Bürgers und Staatsgewalt, einmal nachzudenken. Unter diesem Aspekt bedauere ich es, daß es die Zeit heute nachmittag nicht mehr erlaubt hat, etwa den letzten Punkt: Überverfassungsgesetzlicher Notstand noch einmal als Reprise dessen, was zu Beginn diskutiert worden ist, aufzunehmen.

Ich möchte nun nur ein paar Punkte herausgreifen und bitte um Nachsicht, wenn in der Liste wiederum einiges fehlt. Ich beginne bei dem Buchstaben $Z$, also bei den Beiträgen von Herrn Zacher, der ganz zu Beginn gesprochen hat, und von Herrn Zuleeg. Da stand im Mittelpunkt die Frage nach den Anforderungen, die man an die Überprüfungspraxis und vielleicht auch sogar an die Beamtentreue oder die Treue anderer 
Staatsdiener oder -bürger zu stellen habe. Ich möchte hier vor voreiligen Entwicklungen warnen. Man kann jetzt bereits feststellen, daß die Rechtsprechung, so geschehen, Herr Zacher, in einem Vorlagebeschluß des BGH, daß die Rechtsprechung dazu neigt, die Rechtsanwälte ganz generell den Beamten gleichzustellen und zu sagen, da sie eine Aufgabe des Schutzes des Rechtes haben, genau wie Richter oder andere Beamte, seien an sie auch beamtengleiche Treueanforderungen zu stellen. Ich glaube, daß diese Entwicklung - wenn sie so weiter getrieben wird - gerade das nicht erreicht, was ich mit meiner Kritik zu erreichen versuchte. In diesem Zusammenhang - Herr Mußgnug ist leider nicht mehr da - zur Frage: Warum vertragen wir es ohne weiteres, physisch durchleuchtet zu werden, aber warum sind wir empfindlich, wenn es darum geht, etwa politische Gesinnungen zu überprüfen? Hier mag Vieles eine Rolle spielen. Ein wichtiger Gesichtspunkt ist sicherlich der, daß der Begriff der - verzeihen Sie das Wort! - der ,politischen' Gesundheit im Gegensatz zur ,physischen' Gesundheit eben sehr viel weniger genau umrissen ist, und gerade darüber ja der Streit geht. Das würde ich auch, ohne das nun im einzelnen ausführen zu können, den Bemerkungen von Herrn Kriele entgegenhalten wollen.

Für mich waren heute nachmittag besonders diejenigen Beiträge interessant, in denen mir deutlich wurde, daß es beim Problem des Schutzes der Verfassung zentral um das Problem der Erhaltung der Identität des politischen Systems geht. Das waren Äußerungen, die von Herrn Stein etwa, von Herrn Meyer, von Herrn Hans-Peter Schneider und anderen - unter ganz unterschiedlichen Aspekten - gemacht wurden. Mir scheint hier tatsächlich das zentrale Problem zu liegen, wobei die Rolle der Legalität doch noch einmal überdacht werden sollte. Sie zeigt nämlich geradezu, was in dem herkömmlichen Verständnis von Rechtsstaatlichkeit als Wort nicht immer ohne weiteres mitschwingt, daß Legalität gesehen werden muß als ein Mittel der Innovation. Herr Stein hat bemängelt, daß dies in den Referaten vielleicht nicht genügend hervorgehoben worden sei. Ich möchte meinen, daß das in meinem Referat an einer Stelle doch ganz deutlich zum Ausdruck gekommen ist. Die Legalität ist in der Tat eine hervorragende Errungenschaft, um die Revolution unnötig zu machen, um es einmal so pointiert $\mathrm{zu}$ formulieren, und das bedeutet verfassungstheoretisch, daß wir die Verfassung für solchen innovatorischen Wandel offenhalten müssen; und von daher kommen dann die ganzen Bedenken gegen voreilige Fixierung von Wertordnungen. Nun hat Herr Grabitz mir, in gewisser Weise zu Recht, vorgehalten, 
ich würde meinerseits wieder eine Art anthropologischen Unterbau oder U'berbau — vielleicht sogar psychologischen, libidinösen Unterbau - propagieren. Herr Grabitz, ich möchte darauf nur noch einmal erwidern: Das ist nicht Neues, das machen wir Juristen seit eh und je, und das Bundesverfassungsgericht tut es auch, nämlich immer dann, wenn es vom Menschenbild des Grundgesetzes spricht, nicht wahr. Also, hier ist ein Punkt erreicht, der heute zum Thema wurde, der die Grenze des wechselseitigen Ineinanderhineinragens von Konstitutionellem und Außerkonstitutionellem bezeichnet. Ich glaube, daß wir bei einer Theorie der freiheitlichen Demokratie, wenn wir sie ansatzweise vom Grenzfall her, vom Ausnahmezustand her in diesem Fall - oder wie immer - zeigen wollen, darauf gar nicht verzichten können.

Es wären noch eine Menge Bemerkungen zu machen, die Zeit ist sehr knapp geworden; ich möchte noch einen Punkt erwähnen: Die Frage nach konkreten Maßstäben, die von Herrn Delbrück gestellt wurde, ist nur zu berechtigt. Ich würde aber kontern wollen, indem ich sage, hier liegt eine genuine Aufgabe der Rechtsprechung, und die Rechtsprechung hat - meine ich - hier manche Lösungsmöglichkeit verbaut, so etwa auch das Bundesverfassungsgericht, wenn es das Streitbarkeitsprinzip in der Weise einsetzt, daß es sagt, dieses habe die Güterabwägung, die ja nun erst im Einzelfall zu beginnen hätte, bereits vorgezeichnet. Wenn das tatsächlich der Fall ist, dann erübrigt sich jede eigentliche Güterabwägung unter Berücksichtigung der individuellen Momente. Dann prävaliert eben immer das Streitbarkeitsprinzip. Wir müßten in diesem Zusammenhang auch darauf sehen, daß man in der Rechtsprechung sich von Pauschalurteilen löst, etwa von dem Satz, daß Verfassungsschutzakten grundsätzlich ihrem Wesen nach immer geheim seien. Das sind solche Verallgemeinerungen, die einer differenzierteren Betrachtung der Problematik nicht gerecht werden können.

Ich darf damit schließen und noch einmal betonen, daß ich mich sehr bedanke bei dieser Vereinigung, daß Sie mir Gelegenheit gegeben haben, meine Ansichten, die - wie nicht anders zu erwarten war - auf erheblichen Widerspruch, aber auch - wie ich erfreut feststellen kann - auf manche partielle Zustimmung gestoßen sind, hier vorzutragen. Ich danke sehr.

Vorsitzender: Meine Herren Berichterstatter, meine verehrten Herren Kollegen! Ich glaube, sowohl die Referate heute morgen als auch die jetzige Diskussion - nicht zuletzt die Länge dieser Diskussion - haben gezeigt, daß es richtig und wich- 
tig war, daß die Vereinigung sich dieses besonders wesentlichen Themas in unserer Staatsordnung angenommen hat und daß ihm trotz vielfältiger Erörterung noch neue Seiten abgewonnen werden könnten. Dafür haben wir sowohl den Referenten als auch den Diskussionsteilnehmern vom heutigen Tage zu danken! Ich schließe hiermit die Aussprache über den ersten Beratungsgegenstand. 
